\title{
PROPOSTA DE UM MODELO DE PLANEJAMENTO AGREGADO DA PRODUÇÃO NUMA USINA DE AÇÚCAR E ÁLCOOL VINCULADO À FLUTUAÇÃO DE PREÇOS EM MERCADOS À VISTA E NO MERCADO FUTURO
}

Orientador: Prof. ${ }^{\circ}$ Doutor Miguel Cezar Santoro

Dissertação apresentada à Escola Politécnica da Universidade de São Paulo como parte dos requisitos exigidos para obtenção do título de mestre em Engenharia de Produção.

São Paulo 2009 
Este exemplar foi revisado e alterado em relação à versão original, sob responsabilidade única do autor e com a anuência de seu orientador.

São Paulo, de novembro de 2009.

Assinatura do autor

Assinatura do orientador

\section{FICHA CATALOGRÁFICA}

\section{Carvalho, Marcelo Dias}

Proposta de um modelo de planejamento agregado da produção numa usina de açúcar e álcool vinculado à flutuação de preços em mercados à vista e no mercado futuro / M.D.Carvalho. -- ed.rev. -- São Paulo, 2009. 201 p.

Dissertação (Mestrado) - Escola Politécnica da Universidade de São Paulo. Departamento de Engenharia de Produção.

1. Pesquisa operacional 2. Planejamento da produção 3. Programação da produção 4. Controle da produção I. Universidade de São Paulo. Escola Politécnica. Departamento de Engenharia de Produção II. t. 


\section{AGRADECIMENTOS}

Agradeço primeiramente à minha esposa Michele, à minha filha Júlia e a meu filho Vinícius pela compreensão diante dos vários momentos em que não pude estar presente fazendo-os companhia.

À minha mãe, meu pai e meus irmãos, que sempre me apoiaram de forma incondicional em minha longa jornada estudantil desde pequeno.

Ao José Luiz da Silveira Barros, da usina USALPA, pelo inestimável apoio na fase de coleta de dados da pesquisa e disponibilização de vários contatos importantes de outras usinas sem os quais a elaboração desta obra seria muito mais difícil.

Ao aluno e amigo Thales pelas valiosas leituras e sugestões críticas durante a elaboração da dissertação.

Ao meu orientador Miguel Cezar Santoro pelo apoio e confiança em mim depositados e pelo seu lidar sempre acolhedor.

Aos membros da banca examinadora pelas valiosas sugestões e críticas que se tornaram peças chaves para o enriquecimento desta obra.

Obrigado a todos que por ventura tenham sido esquecidos por mais esta fase importante no desenrolar de minha vida. 


\section{RESUMO}

O objetivo de estudo desta dissertação é o desenvolvimento de um modelo de planejamento agregado da produção que apóie as decisões de nível gerencial e de diretoria das usinas de açúcar e álcool no que tange às variedades de cana colhidas em cada semana, às compras de cana-de-açúcar de terceiros, ao tipo de transporte (próprio ou terceirizado) a se utilizar em cada semana, ao total de cana moída por semana para atendimento da demanda e aos processos (industrial e comercial) que se devem escolher para produzir e comercializar açúcar e álcool. As decisões devem ocorrer em função de preços nos mercados interno, externo e mercado futuro, do fluxo de caixa da empresa, da capacidade da usina para armazenar açúcar e álcool e da possibilidade de uso de estoque de terceiros.

As decisões por compra de cana, escolha de processos e venda de produtos são tomadas semanalmente num horizonte móvel de planejamento de 52 semanas, que inclui o tempo de safra no centro-sul do Brasil (meados de março a meados de dezembro, aproximadamente 36 semanas) mais o período de entressafra (aproximadamente 16 semanas, de meados de dezembro a meados de março).

A procura por melhores estratégias de comercialização de tal forma a auxiliar a tomada de decisões é uma necessidade constante dos empresários do setor, que muitas vezes são surpreendidos pelas variações de preços de açúcar e álcool no mercado interno, externo e mercado futuro.

$\mathrm{Na}$ parte comercial, este trabalho utiliza o método Delphi de previsão de preços de açúcar e álcool que balizam as tomadas de decisão no planejamento e controle da produção das usinas de açúcar e álcool. Define-se Hedge como a operação financeira de proteger determinado ativo de uma empresa contra variações inesperadas de preços. Neste trabalho, utiliza-se um modelo de escolha de mix de produto para Hedge vinculado à lucratividade e minimização de risco denominado "Modelo de SemiVariância com análise de cenários de Markowitz”.

Nas decisões relacionadas com as partes agrícola, industrial e comercial, faz-se uso de um modelo de programação linear inteira mista e para resolvê-lo utiliza-se o software de programação matemática LINGO e suas interfaces com a planilha eletrônica Excel. Nas decisões vinculadas ao mix ótimo para o Hedge em cada semana, faz-se uso de um modelo de programação quadrática resolvido pelo LINGO e suas interfaces com a 
planilha eletrônica Excel. Um estudo de caso foi realizado numa usina de açúcar e álcool no município de Junqueirópolis (SP) para validar o modelo proposto.

Palavras-chave: Usinas de açúcar e álcool; planejamento agregado da produção; programação linear inteira mista; seleção de processos; seleção de produtos; previsão de preços; mercado futuro (hedge); modelos de portfólios de Markowitz. 


\section{ABSTRACT}

The objective of study this dissertation is to develop a model of aggregate production planning to support the decisions of management and board level of sugar and alcohol plants in regard to varieties of cane harvested each week, purchasing cane of nonsugar, the type of transport (own or outsourced) to use each week, the total cane

processed per week for taking care of the demand and processes (industrial and commercial) and that must be chosen to produce and sell sugar and alcohol. Decisions must occur in terms of domestic, foreign and future market prices, the company's cash flow and the capacity to store sugar and alcohol and the possibility of using stock to third parties.

Decisions about buying cane, choice of processes and products for sale are made in a weekly mobile planning horizon of 52 weeks, which includes the time of harvest in central-southern Brazil (mid-March to mid-December, approximately 36 weeks ) plus the off-season (approximately 16 weeks, from mid-December to mid March). The demand for better marketing strategies to help such decision making is a constant need for entrepreneurs in the sector, which are often surprised by the changes in prices of sugar and alcohol in the internal, external and future market.

In the commercial part, this study uses the Delphi method of forecasting the price of sugar and alcohol that guides the decision-making in planning and controlling the production of sugar and alcohol plants. Hedging is defined as a financial transaction to protect certain assets of a business against unexpected changes in prices. In this work, it is used a model of choice of product mix for Hedge linked to profitability and minimizing risk named "Model of Semi-Variance analysis with scenarios of Markowitz." In decisions related to the agricultural, industrial and commercial parts it is used a type of mixed integer linear programming and to solve it is used the mathematical programming software LINGO and its interface with Excel spreadsheets. In decisions related to the optimal mix for Hedge in each week, is used a quadratic programming model solved by LINGO and its interface with Excel spreadsheets. A case study was conducted in a sugar mill and alcohol in the city of Junqueirópolis (SP) to validate the proposed model.

Keywords: Plants of sugar and alcohol, aggregated production planning, mixed integer 
linear programming, selection of processes, selection of products, price forecasting, futures market (hedge), models of portfolios of Markowitz. 


\section{SUMÁRIO}

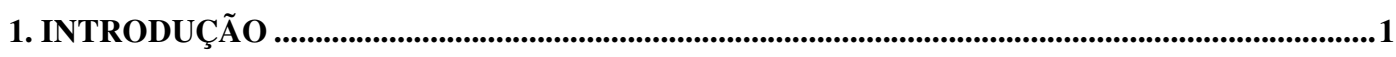

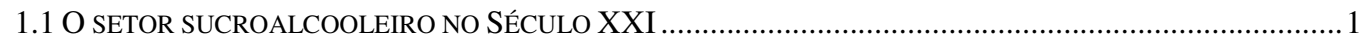

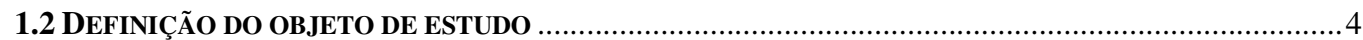

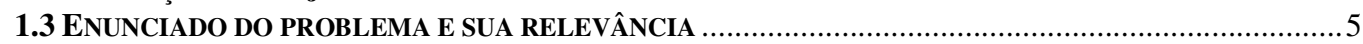

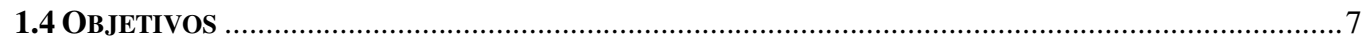

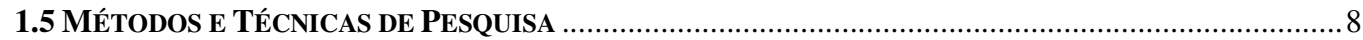

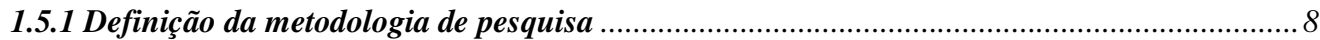

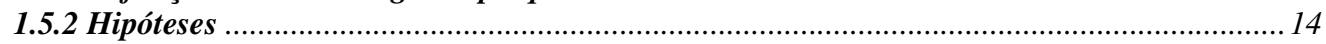

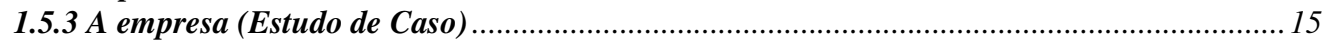

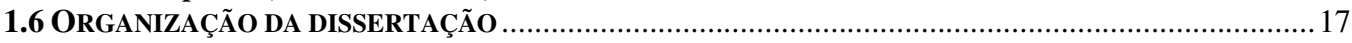

2. O SISTEMA AGROINDUSTRIAL DA CANA E OS PROCESSOS DE PRODUÇÃO E

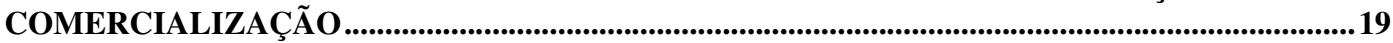

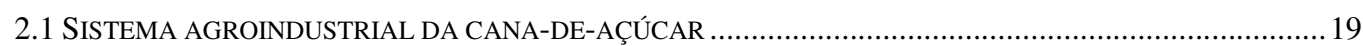

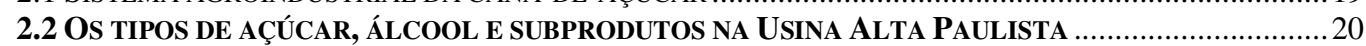

2.3 PROCESSOS DE PRODUÇÃo DA ETAPA AGRÍCOLA ................................................................. 21

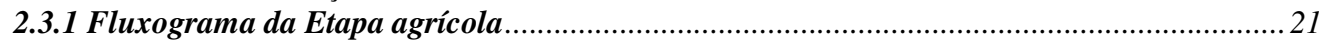

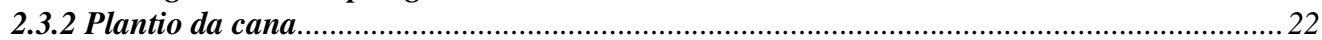

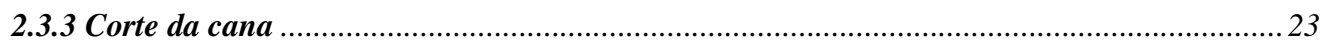

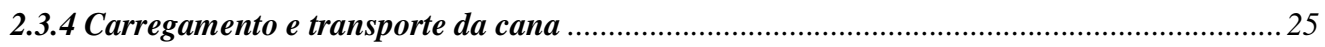

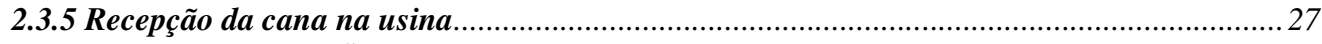

2.4 PROCESSOS DE PRODUÇÃO DA ETAPA INDUSTRIAL ..................................................................29

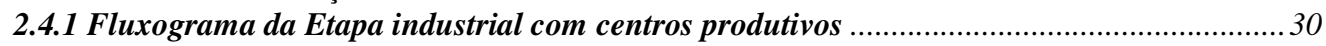

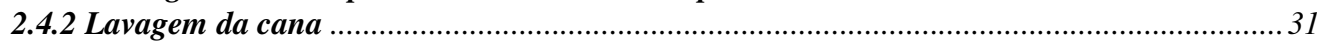

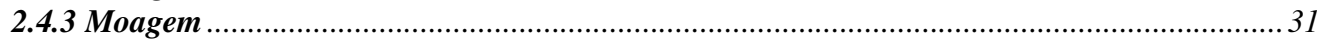

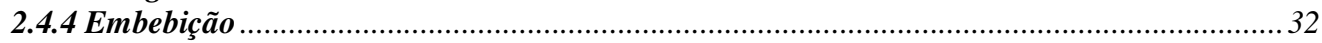

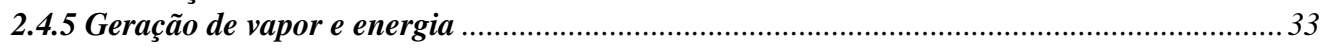

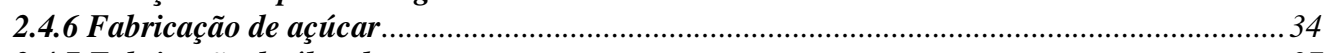

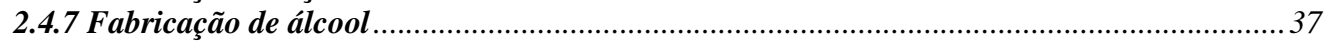

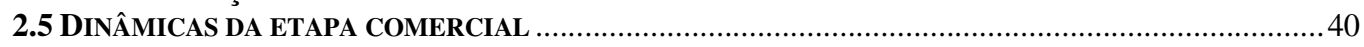

2.5.1 O departamento comercial das usinas ..................................................................................... 40

2.5.2 Negociação de açúcar e álcool em mercados futuros ........................................................ 43

2.5.3 A operação dos contratos futuros de álcool anidro (hedge da venda de álcool) .................. 44

2.5.4 A operação dos contratos futuros de açúcar (hedge de venda de açúcar) .......................... 45

2.5.5 A operação de comercialização de álcool hidratado .......................................................... 46

3. REVISÃO BIBLIOGRÁFICA E REFERENCIAL TEÓRICO.......................................................47

3.1 REFERENCIAL TEÓRICO RELATIVO ÀS ETAPAS CCT (CARREGAMENTO, CORTE E TRANSPORTE) E

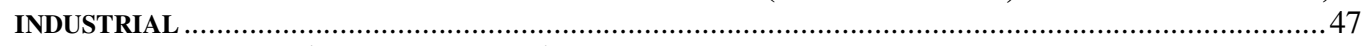

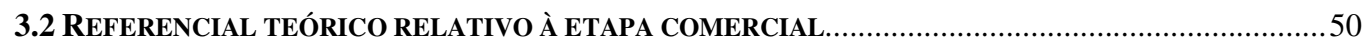

3.3 MODELOS DE OTIMIZAÇÃO DE PORTFÓLIOS E A ETAPA COMERCIAL..........................................5

4. CUSTOS E RECEITAS ASSOCIADOS AOS PROCESSOS DE PRODUÇÃO E

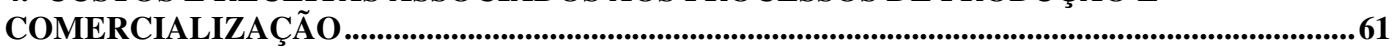

4.1 CUSTOS ASSOCIADOS À ETAPA AGRÍCOLA ………………………………………………….....61

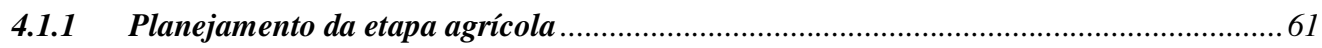

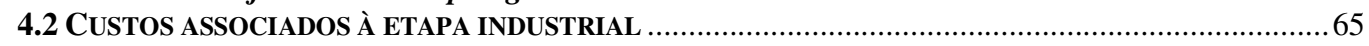

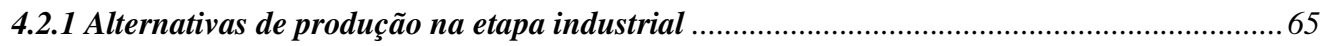

4.3 CUSTOS E RECEITAS ASSOCIADOS ÀS ETAPAS COMERCIAL E DE ESTOCAGEM .............................6

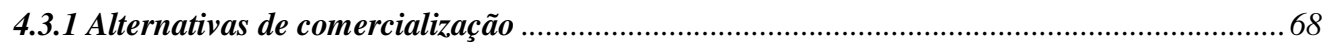

5. O MODELO GLOBAL DO PROBLEMA..............................................................................................72

5.1 FLUXO DE INFORMAÇÕES E PRODUÇÃO DO MODELO GLOBAL DE OTIMIZAÇÃO ............................. 72 5.2 O PROBLEMA DO MIX DE PRODUÇÃO NO PPCP DAS USINAS E A ETAPA COMERCIAL ....................75 5.3 O MODELO SEMI-VARIÂNCIA COM ANÁLISE DE CENÁRIOS DE MARKOWITZ PARA A DECISÃo DE MIX DE PRODUÇÃO NO HEDGE DE USINAS DE AÇÚCAR E ÁLCOOL .............................................. 75

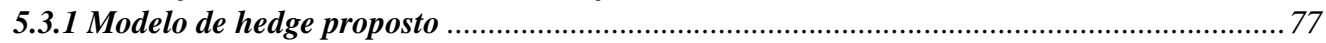


5.4 O MODELO MATEMÁTICO DE OTIMIZAÇÃo PARA A ETAPA DE PRODUÇÃO/COMERCIALIZAÇÃo. 81

6. RESULTADOS COMPUTACIONAIS COM OS MODELOS..................................................90

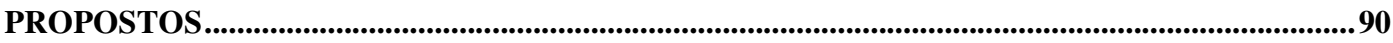

6.1 EXEMPLO ILUSTRATIVO DO MODELO DE ANÁLISE DE CENÁRIOS A PARTIR DE SEMI-VARIÂNCIA DE MARKOWITZ NUMA USINA DE AÇÚCAR E ÁLCOOL ................................................................. 90 6.2 EXEMPLO ILUSTRATIVO DO MINIMODELO DE PRODUÇÃO INDUSTRIAL/COMERCIALIZAÇÃO E

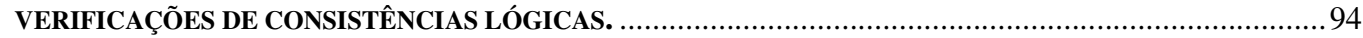

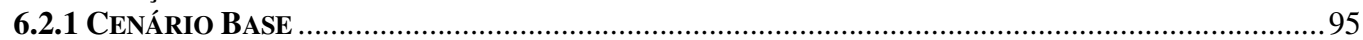

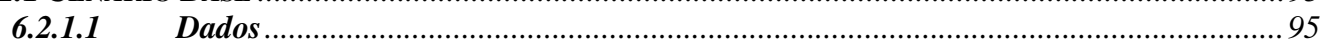

6.2.2 Cenário1- Mudança na composição da frota de transporte da cana ................................ 104

6.2.3 Cenário 2- Valorização do preço para mercado interno................................................... 104

6.2.4 Cenário 3- Valorização do preço para mercado externo ................................................... 106

6.2.5 Cenário 4- Aumento na demanda hedge dos produtos acabados ..................................... 107

6.2.6 Cenário 5- Mudança no custo de estocagem ................................................................. 107

6.2.7 Cenário 6- Produção nula em determinada semana....................................................... 108

6.2.8 Cenário 7 - Assumindo maior risco ................................................................................ 109

6.3 O MODELO COMPLETO E A ANÁLISE DE RESULTADOS .................................................... 110

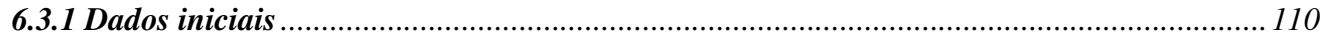

6.3.2 Resultados com o modelo completo SOVTICE .............................................................. 111

6.3.3 Comparação entre os resultados da aplicação do modelo SOVTICE e resultados da USALPA.

6.3.4 Validação do modelo através de pesquisa de opinião junto a um grupo de usinas

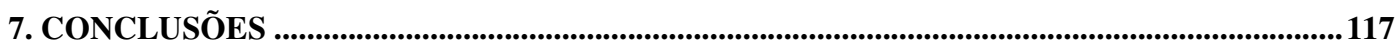

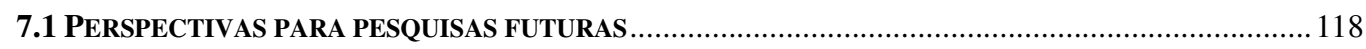

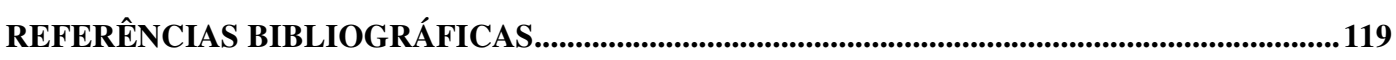

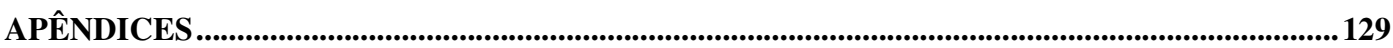

APÊNDICE A- PANORAMA HISTÓRICO DA CANA-DE-AÇÚCAR ................................................. 129 APÊNDICE B- CUSTOS AGRÍCOLAS, RENDIMENTOS AGROINDUSTRIAIS, CUSTOS COMERCIAIS E DE

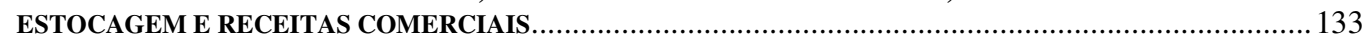

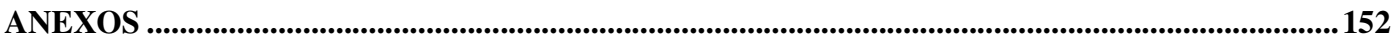

ANEXO A - A LINGUAGEM DE MODELAGEM LINGO ..................................................152

ANEXO B- CÓDIGO NO LINGO PARA O EXEMPLO ILUSTRATIVO DO MODELO SEMIVARIÂNCIA COM ANÁLISE DE CENÁRIOS DE MARKOWITZ ..............................................154

ANEXO C- CÓDIGO NO LINGO PARA O MODELO SEMI-VARIÂNCIA COM ANÁLISE DE

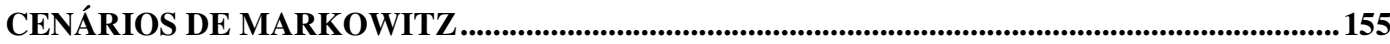

ANEXO D -CÓDIGO NO LINGO PARA O EXEMPLO ILUSTRATIVO DO MODELO SOVTICE (SELEÇÃO DE ORIGEM, VARIEDADE, TRANSPORTE, PROCESSO

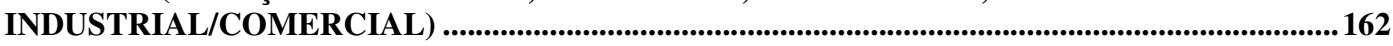

ANEXO E- DADOS DE ENTRADA PARA O MODELO SOVTICE.............................................164

ANEXO F- DADOS DE SAÍdA PARA O MODELO SOVTICE ........................................................179

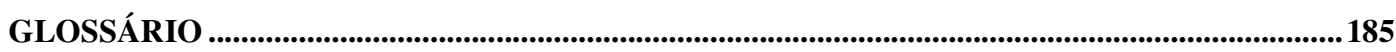




\section{LISTA DE FIGURAS}

Figura 1. Custo total de produção de combustivel em diferentes países ................................................ 1

Figura 2. Níveis de planejamento e integração das várias etapas .......................................................... 7

Figura 3. Questões que são contempladas nesta dissertação ................................................................. 8

Figura 4. Fluxograma simplificado de produção de açúcar e álcool numa usina.................................... 10

Figura 5. Fluxograma simplificado da produção de açúcar e álcool numa usina com descrição de perdas

no processo e diferentes possibilidades de produção............................................................................ 11

Figura 6. Caracterização da usina Alta Paulista (USALPA)................................................................ 16

Figura 7. Sistema agroindustrial da cana-de-açúcar ....................................................................... 19

Figura 8. Fluxograma simplificado da etapa agrícola de produção de cana-de-açúcar..........................221

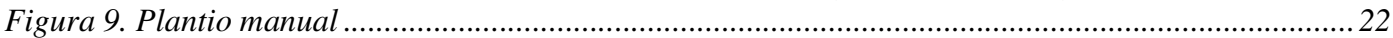

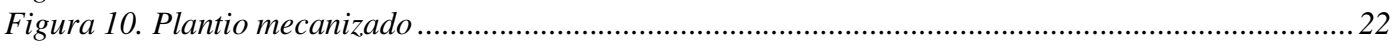

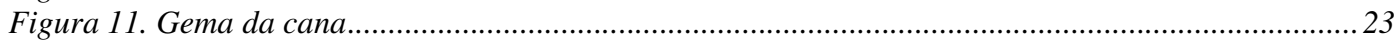

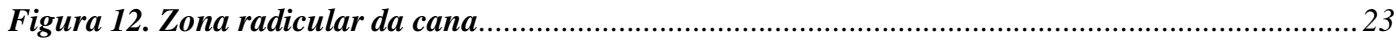

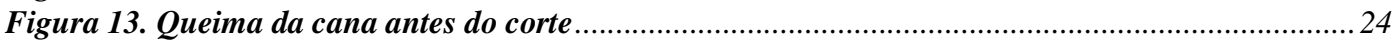

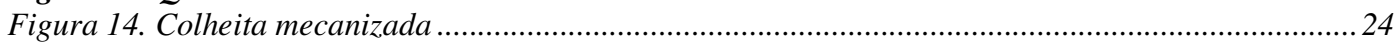

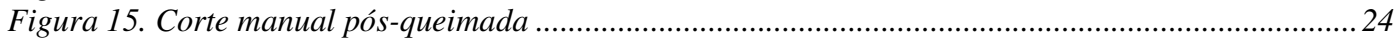

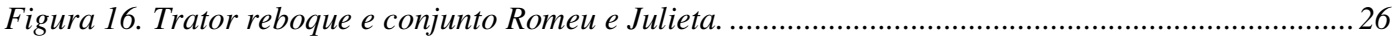

Figura 17. Carregamento do caminhão .............................................................................................. 26

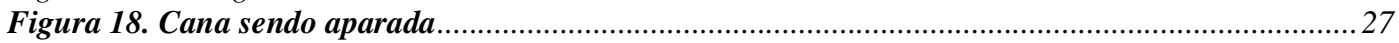

Figura 19. Estoque de cana no pátio da usina ...............................................................................28

Figura 20. Topografia da área a ser plantada ............................................................................................2 29

Figura 21. Caminhão voltando para o campo, o que encerra a etapa agrícola. ......................................2 29

Figura 22. Fluxograma da etapa industrial com centros produtivos.................................................... 30

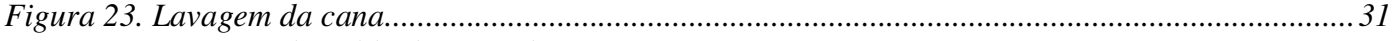

Figura 24. Extração do caldo da cana-de-açúcar ................................................................................ 31

Figura 25. Fertilização da lavoura de cana com torta de filtro proveniente da usina, um

aproveitamento de subproduto do processo de fabricação de açúcar e álcool. ....................................35

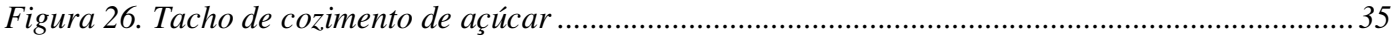

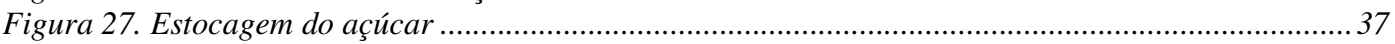

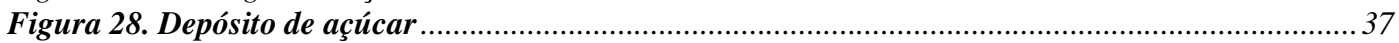

Figura 29. O funcionamento do departamento comercial das usinas de açúcar e álcool ..................... 41

Figura 30. Operações de compra e venda no pregão da BM\&F Fonte: Marques et al (2006) .............. 42

Figura 31. Fluxograma de planejamento da Etapa agrícola .....................................................................64

Figura 32. Fluxograma dos caminhos de produção de açúcar, álcool e melaço..................................... 67

Figura 33. Administração do estoque e comercialização dos produtos nas usinas ..................................6 69

Figura 34. O modelo global do problema com suas três etapas ............................................................. 72

Figura 35. Quantidades de cada produto em estoque em cada semana .............................................. 101

Figura 36. Quantidade de cana colhida de cada variedade em cada semana ...................................... 102

Figura 37. Quantidade transportada de cana por frota própria ou terceirizada ................................. 102

Figura 38. Transporte (t) por frota própria e terceirizada ............................................................. 104

Figura 39. Quantidade estocada de cada produto ............................................................................... 105

Figura 40. Quantidade estocada de cada produto ............................................................................ 108

Figura 41. Quantidade estocada de cada produto em cada semana .................................................. 112

Figura 42. Quantidade comercializada de cada produto em cada semana no mercado interno............. 113

Figura 43. Quantidade comercializada de cada produto em cada semana no mercado externo ............ 113

Figura 44. Produção de combustiveis ao longo dos ano no Brasil................................................... 131

Figura 45. Onde se produz açúcar e álcool no Brasil....................................................................... 132 


\section{LISTA DE TABELAS}

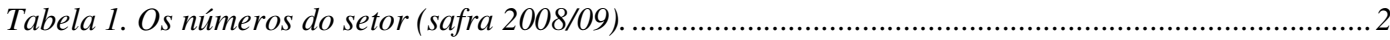

Tabela 2. Referencial teórico relativo às etapas $\mathbf{C C T}$ e industrial .....................................................4

Tabela 3. Disponibilidade de cada variedade de cana própria .............................................................62

Tabela 4. Disponibilidade de cada variedade de cana de terceiros ......................................................62

Tabela 5. Composição tecnológica média de 5 variedades de cana ....................................................6 63

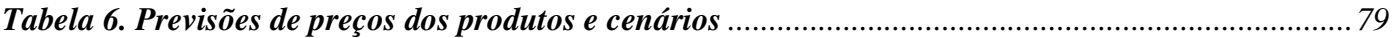

Tabela 7. Preços futuros de açúcar, álcool anidro e álcool hidratado segundo indicadores CEPEA/ESALQ/BMF

Tabela 8. Rentabilidades futuras de açúcar, álcool anidro e álcool hidratado segundo indicadores

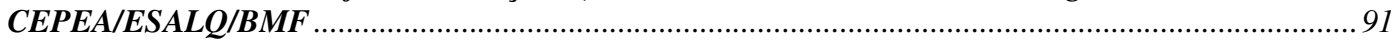

Tabela 10. Porcentagem de utilização de cana de terceiros .................................................................. 95

Tabela 11. Capacidade de transporte $(t)$ da frota própria ......................................................................95

Tabela 12. Moagem mínima $(t)$ de cana por semana ........................................................................95

Tabela 13. Moagem máxima $(t)$ de cana por semana.........................................................................95

Tabela 14. Capacidade de estocagem dos produtos acabados $\left(\right.$ em $t$ ou $\left.\mathrm{m}^{3}\right)$........................................... 96

Tabela 15. Custos semanais de duas variedades de cana hipotéticas ..................................................... 96

Tabela 16. Custos em estoque próprio e terceirizado dos produtos acabados ......................................... 96

Tabela 17. Custos semanais que se pretende proteger com o mecanismo do hedge ................................. 96

Tabela 18. Preços (em $R \$ / t$ ou $\left.R \$ / \mathrm{m}^{3}\right)$ dos produtos que a usina irá travar no hedge ............................ 97

Tabela 19. Saída do Minimodelo Markowitz......................................................................................... 97

Tabela 20. Valores monetários obtidos com os hedges dos produtos ...................................................... 97

Tabela 21. Quantidade de cada produto para atender o hedge em cada semana.....................................97

Tabela 22. Valores dos produtos $\left(R \$ / t\right.$ ou $\left.R \$ / m^{3}\right)$ no mercado interno em cada semana .......................... 97

Tabela 23. Valores dos produtos $\left(R \$ / t\right.$ ou $\left.R \$ / m^{3}\right)$ no mercado externo em cada semana......................... 98

Tabela 24. Demandas dos produtos no mercado interno ................................................................ 98

Tabela 25. Demandas dos produtos no mercado externo ................................................................... 98

Tabela 26. Estoque inicial $\left(\mathrm{t}\right.$ ou $\mathrm{m}^{3}$ ) de cada produto acabado ........................................................... 98

Tabela 27. Previsão de safra $(t)$ de cada variedade de cana ....................................................................98

Tabela 28. Taxas de corretagem para os produtos acabados nos mercados spot .........................................99

Tabela 29. Taxas de corretagem para os produtos acabados na operação de hedge ...............................99

Tabela 30. Características técnicas de cada processo industrial no Minimodelo .................................... 99

Tabela 31. Características técnicas de cada processo comercial no Minimodelo.................................. 100

Tabela 32. Estoque $\left(\right.$ ou $\mathrm{m}^{3}$ ) dos produtos acabados em cada semana no minimodelo .......................... 100

Tabela 33. Disponibilidade ( $t$ ) de cana no campo no início de cada semana no minimoddelo ............... 101

Tabela 34. Quantidade $(t)$ de cada variedade de cana moída em cada semana ................................... 102

Tabela 35. Quantidade $(t)$ de cana transportada por frota própria e terceirizada em cada semana ...... 102

Tabela 36. Escolha de processos industriais/comerciais em cada semana........................................... 103

Tabela 37. Vendas $\left(t\right.$ ou $\mathrm{m}^{3}$ ) para mercado interno de cada produto acabado...................................... 103

Tabela 38. Vendas $\left(\mathrm{t} \mathrm{ou}^{3}\right.$ ) para mercado externo de cada produto acabado ...................................... 103

Tabela 39. Quantidade de cana transportada $(t)$ sob o cenário 1.......................................................... 104

Tabela 40. Vendas ( $t$ ou $\mathrm{m}^{3}$ ) dos produtos para mercado interno em cada semana sob o cenário 2 ........ 105

Tabela 41. Vendas ( $t$ ou $\mathrm{m}^{3}$ ) dos produtos para mercado externo em cada semana sob o cenário 2 ... 105

Tabela 42. Lista de processos referentes ao cenário 2....................................................................... 106

Tabela 43. Vendas ( $t$ ou $\mathrm{m}^{3}$ ) dos produtos para mercado interno em cada semana sob o cenário 3 ........ 106

Tabela 44. Vendas ( $t$ ou $\mathrm{m}^{3}$ ) dos produtos para mercado externo em cada semana sob o cenário 3 ....... 106

Tabela 45. Custo semanal $(\boldsymbol{R} \$)$ coberto pelo hedge em cada semana ............................................. 107

Tabela 46. Demanda hedge $\left(\mathrm{t}\right.$ ou $\left.\mathrm{m}^{3}\right)$ de cada produto em cada semana ............................................ 107

Tabela 47. Quantidade de cana em toneladas destinada para hedge no cenário base e cenário 4....... 107

Tabela 48. Estoque ( $\mathrm{ou}^{3} \mathrm{~m}^{\mathbf{3}}$ ) no fim de cada semana de cada produto sob o cenário 5 ..................... 108

Tabela 49. Tempo útil de moagem sob o cenário 6............................................................................ 109

Tabela 50. Preços dos produtos no mercado spot interno sob o cenário 6 ............................................ 109

Tabela 51. Quantidade de cana transportada $(t)$ sob o cenário 6.......................................................... 109

Tabela 52. Estoque de cana $(t)$ no fim de cada semana sob o cenário 6 .......................................... 109

Tabela 53. Saída do minimodelo Markowitz para o cenário 7........................................................... 109

Tabela 54. Saída do minimodelo Markowitz para o cenário base ....................................................... 110

Tabela 55. Capacidade de estocagem dos produtos acabados em $\mathrm{t}$ ou $\mathrm{m}^{3}$.......................................... 110

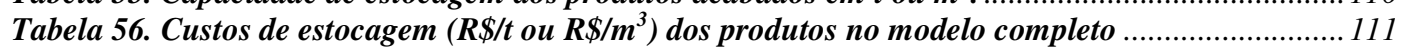


Tabela 57. Processos utilizados em cada semana no modelo SOVTICE …............................................ 112

Tabela 58. Comparação de resultados USALPA x SOVTICE ................................................................... 115

Tabela 59. Alguns softwares utilizados em Programação linear e suas capacidades .............................. 152

Tabela 60. Dados de entrada sem variação em cada semana ............................................................ 164

Tabela 61. Dados de entrada com variação em cada semana ...................... Erro! Indicador não definido.

Tabela 62. Disponibilidade de cada variedade de cana por fonte de fornecimento .............................. 165

Tabela 63. Características técnicas de cada processo industrial ..................................................... 166

Tabela 64. Características técnicas de cada processo comercial ........................................................ 166

Tabela 65. Custo agrícola $(R \$ / t)$ de cada variedade de cana própria por semana ................................. 167

Tabela 66. Custo agrícola $(R \$ / t)$ de cada variedade de cana de terceiros por semana.......................... 168

Tabela 67. Custos dos processos industriais/comerciais para as primeiras 12 semanas ....................... 169

Tabela 68. Rendimentos ( $t$ ou $\mathrm{m}^{3}$ ) por tonelada de cana processada/comercializada para os processos

industriais 1 e 2 e comerciais de 1 a 8 para as primeiras 12 semanas ................................................... 175

Tabela 69. Preços dos produtos comercializados no mercado spot interno......................................... 176

Tabela 70. Preços dos produtos comercializados no mercado spot externo .......................................... 177

Tabela 71. Demanda hedge dos produtos comercializados .......................................................... 178

Tabela 72. . Demanda spot para mercado interno dos produtos comercializados................................ 178

Tabela 73. Demanda spot para mercado externo dos produtos comercializados ................................ 178

Tabela 74. Estoque dos produtos acabados (em t ou $\mathrm{m}^{3}$ ) no final de cada semana............................... 179

Tabela 75. Disponibilidade de cada variedade de cana (t) no campo no início de cada semana.......... 180

Tabela 76. Quantidade (t) de cada variedade de cana colhida em cada semana ................................. 181

Tabela 77. Vendas $\left(t\right.$ ou $\mathrm{m}^{3}$ ) no mercado interno .................................................................................... 183

Tabela 78. Vendas $\left(\mathrm{t}\right.$ ou $\left.\mathrm{m}^{3}\right)$ no mercado externo........................................................................... 183

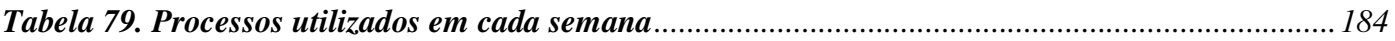




\section{LISTA DE SIGLAS, SÍMBOLOS E ABREVIATURAS}

AEAC

AEHC

APP

ART

ATR

$\mathrm{BM} \& \mathrm{~F}$

CCT

CEPEA

CONSECANA-SP

CTC

ESALQ

IAA

$\mathrm{M}$

MSE

MSI

OCDE

PTU

$\mathrm{SC}$

SCP

SCS

SOVTICE

estocagem

UDOP

UNICA

USALPA

VHP
Álcool Etílico Anidro Carburante

Álcool Etílico Hidratado Carburante

Área de preservação permanente

Açúcares Redutores Totais

Açúcar Total Recuperável

Bolsa de mercadorias e futuros

Carregamento, corte e transporte

Centro de Pesquisa e Estudos de Açúcar e Álcool

Conselho dos produtores de cana-de-açúcar do estado de SP

Centro de tecnologia canavieira

Escola Superior de Agricultura Luiz de Queiroz

Instituto de açúcar e álcool

Melaço

Mercado spot externo

Mercado spot interno

Organização para cooperação e desenvolvimento econômico

Porcentagem de tempo útil de moagem

Separação comercial

Separação do caldo primário

Separação do caldo secundário

Seleção de origem, variedade, transporte, industrial, comercial e

União das destilarias do oeste paulista

União dos produtores de cana-de-açúcar

Usina Alta Paulista

Very High Polarization 


\section{INTRODUÇÃO}

\subsection{O setor sucroalcooleiro no Século XXI}

Para melhor caracterizar a cadeia produtiva da cana-de-açúcar, esta pesquisa iniciou-se por uma revisão bibliográfica sobre o setor sucroalcooleiro, e buscou, a seguir, outras informações, secundárias e primárias, por meio de amplo levantamento de dados teóricos e de campo.

A primeira década do século 21 tem-se mostrado altamente favorável para o setor, com a diferença de que agora existe um mercado estabelecido para o álcool e grandes demandas do exterior, principalmente dos EUA e possivelmente num futuro próximo da Europa, Japão e China (UNICA, 2009). Isso confere às usinas de produção de açúcar e álcool importante papel na economia nacional, pois além de fornecerem um combustível renovável, com o menor custo de produção em todo o mundo (ver Figura 1), representa também uma nova fonte de geração de energia elétrica, a chamada co-geração de energia elétrica pela queima do bagaço da cana, fortalecendo a matriz energética nacional com uma fonte de energia limpa e renovável.

A conclusão é de um estudo divulgado em julho de 2008 pela Organização para Cooperação e Desenvolvimento Econômico (OCDE), que destaca o álcool do Brasil como o biocombustível que mais reduz a emissão de gases poluentes.

A diferença é significativa: enquanto os combustíveis de trigo, beterraba e óleos vegetais reduzem a emissão entre $30 \%$ e $60 \%$, e o de milho, 30\%, o álcool de cana permite redução de até $90 \%$ de gases poluentes.

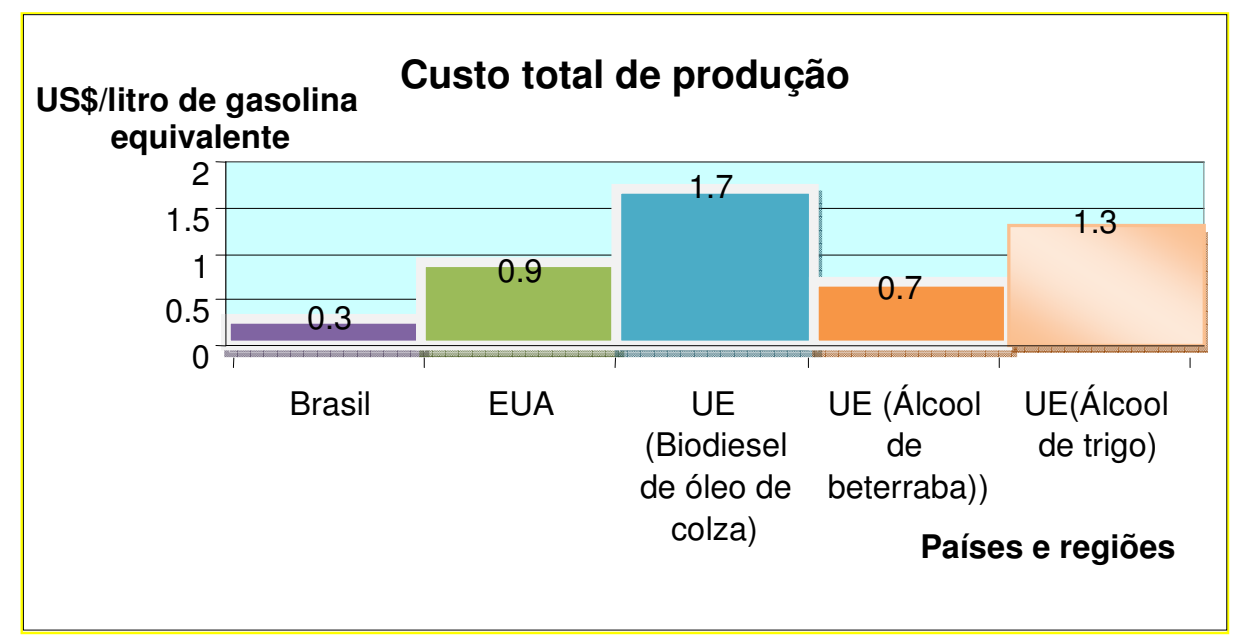

Figura 1. Custo total de produção de combustível em diferentes países Adaptado de OCDE, Relatório técnico, julho de 2008 
A atividade sucroalcooleira no Brasil envolve números muito expressivos (Tabela 1), pois se trata de uma das atividades de maior importância no âmbito econômico e social do país. O Brasil é considerado o maior produtor de cana-de-açúcar do mundo - 470 milhões de toneladas por ano, sendo 70,5 milhões da região Norte/Nordeste e 399,5 milhões da região Centro-Sul (UNICA, dezembro de 2008, referente à safra 2008/2009).

A produção brasileira aumentou em aproximadamente $65 \%$ nas últimas décadas e as exportações praticamente triplicaram, sendo importadores do açúcar brasileiro mais de 35 países na atualidade, tendo volumes de importação relevantes países como a Rússia, o Egito, a Nigéria, os Emirados Árabes, o Marrocos, o Yemen, os Estados Unidos e o Irã.

Tabela 1. Os números do setor (safra 2008/09). Fonte: UNICA, dezembro de 2008

\begin{tabular}{|l|l|}
\hline Movimenta: & $\mathrm{R} \$ 43$ bilhões por ano \\
\hline \hline Representa: & $3,65 \%$ do PIB \\
\hline \hline Gera: & 4 milhões de empregos diretos e indiretos \\
\hline \hline Envolve: & 72.000 agricultores \\
\hline \hline Mói: & 470 milhões de toneladas de cana \\
\hline \hline Produz: & 31 milhões de toneladas de Açúcar \\
\hline \hline Eroduz: & 22,5 bilhões de litros de Álcool \\
\hline \hline Exporta: & 19 milhões de toneladas de açúcar / US\$ 7 bilhões \\
\hline \hline Recolhe: & 3 bilhões de litros de Álcool / US $\$ 1,5$ bilhão \\
\hline \hline Investe: & $\mathrm{R} \$ 12$ bilhões em impostos e taxas \\
\hline \hline Compõem-se de: & $\mathrm{R} \$ 5$ bilhões/ano \\
\hline
\end{tabular}

Apesar do bom momento vivido pelo setor, há necessidade por parte de muitas usinas de adequação à crescente competitividade, sendo que muitas delas ainda operam como na década de 70, ou ainda pior, usinas que passam de pai para filho e que não se modernizam há várias décadas (principalmente aquelas localizadas no Nordeste). Fatores como produtividade, inovação, eficiência, flexibilidade e velocidade de reação às exigências do mercado são vitais para as usinas que pretendem continuar operando e buscam se expandir.

Os principais produtos gerados pelo setor sucroalcooleiro são o açúcar e o álcool. Destacam-se também os subprodutos como o bagaço da cana e a geração de energia elétrica, conforme listado a seguir. 


\section{Produtos:}

Açúcar - extraído através do caldo proveniente do esmagamento da cana-de-açúcar, com posterior branqueamento, decantação, evaporação, flotagem e cristalização. Existem diversos tipos de açúcar para diversos destinos, seja para refinarias ou para os diversos segmentos do mercado industrial de alimentos e bebidas, cada qual com seu valor no mercado, além das tradings, principal canal de exportação.

$\mathrm{Na}$ indústria sucroquímica, do açúcar podem-se extrair glicose, frutose, glicerina, ácidos, sorbitol e sucralose, entre outros. De outras fermentações, podem-se obter acetonas, antibióticos (penicilina, tetraciclinas), enzimas industriais (amilases, proteases), vitaminas (C, B2, B12), aminoácidos (lisina, fenilalanina) e insumos biológicos para a agricultura (bioinseticidas e fertilizantes).

Dentro dos vários tipos e classificações existentes no mercado, o açúcar como produto de consumo de massa é o produto que mais participa da alimentação diária dos brasileiros. Apresentando um consumo individual de $45 \mathrm{Kg} /$ habitante/ ano, um dos maiores do mundo, esse produto detém um portfólio de aplicações dos mais variados. Sua presença se faz obrigatória na produção industrial de diferentes gêneros alimentícios. As indústrias de refrigerantes, panificação, sucos artificiais e achocolatados são as que mais utilizam essa substância na fabricação de seus produtos (WAACK et al., 1998).

Álcool - proveniente da fermentação do caldo de cana, submetido a posterior destilação. Basicamente são de três tipos: o álcool neutro, usado na elaboração de bebidas em geral, cosméticos e produtos farmacêuticos; o hidratado carburante (96GL - 96\% de álcool e 4\% de água), usado para consumo direto nos automóveis e na indústria química; e, finalmente, o anidro $\left(99,5^{\circ} \mathrm{GL}\right)$, que é adicionado à gasolina na proporção de $20 \%$ de álcool na mistura. Como derivados do álcool existem os produtos da alcoolquímica, notadamente de dois grupos: os desidratados (etilenos) e os desidrogenados (acetaldeídos).

Melaço - Produto resultante do processo de fabricação de açúcar. Ou é destinado à fabricação de álcool ou vendido a outras usinas. 


\section{Subprodutos:}

Bagaço de Cana: resíduo fibroso da moagem. É utilizado como combustível nas unidades geradoras de vapor (caldeiras) para movimentar turbinas e gerar energia utilizada na moagem e com eventual retorno à rede pública de distribuição. Também é usado nas caldeiras de indústrias citrícolas, de papel e celulose e outras, também para geração de energia. Gera também a Pasta de Celulose para produção de papel e pode ser usado na alimentação animal. As folhas e pontas da cana-de-açúcar também têm o mesmo destino do bagaço.

Vinhaça: resíduo proveniente da destilação, usado como fertilizante na irrigação da lavoura.

Levedura: utilizada como insumo na indústria de alimentos e na indústria de ração animal. É o suplemento protéico para fins de alimentação animal mais barato até hoje encontrado.

Água de Lavagem: uso para biogás e fertirrigação.

Energia elétrica: energia gerada a partir da queima do bagaço nas caldeiras. $\mathrm{O}$ excedente pode ser vendido às concessionárias da rede pública de energia e tem se tornado um subproduto cada vez mais valorizado ultimamente.

\subsection{Definição do objeto de estudo}

Diante do alto crescimento das atividades do setor sucroalcooleiro no Brasil e sua crescente importância nos cenários econômicos nacional e internacional, as usinas de produção de açúcar e álcool brasileiras têm buscado cada vez mais melhorias em suas produtividades industrial e de campo e proteções na área comercial. Principalmente no estado de São Paulo, com sua alta competitividade industrial, as usinas buscam se modernizar para reduzir custos em todas as áreas de produção, do campo à etapa de comercialização. Muitas usinas buscam também essa modernização para que possam atrair investimentos de grandes grupos nacionais e internacionais e com isso se expandir através de parcerias. Para tanto, se reúnem cada vez mais em torno de associações e entidades que visam à pesquisa e à modernização do setor, como UNICA, UDOP, CTC dentre outras.

Através de um modelo de planejamento, programação e controle da produção, o presente trabalho pretende auxiliar no aumento da margem de contribuição de processos da cadeia produtiva das usinas de açúcar e álcool desde suas atividades no setor agrícola até suas operações no setor comercial, ou seja, abrangendo boa parte da cadeia 
produtiva. O trabalho poderá contribuir para diminuir a dificuldade que os profissionais de planejamento e controle da produção têm para programar os processos de produção nas usinas de uma forma mais agregada com as outras etapas do processo, desde a etapa agrícola até a comercial. Dessa maneira, o objeto de estudo desta dissertação será a integração das variáveis da parte agrícola, industrial e de comercialização a fim de maximizar a margem de contribuição agroindustrial da usina.

A Usina Alta Paulista (Usalpa), uma usina de médio porte, situada em Junqueirópolis (nos arredores de Presidente Prudente), com capacidade de moagem de cana de 200 ton/h e que atualmente passa por um processo de expansão de sua capacidade produtiva, servirá como usina representativa do setor sucroalcooleiro para testes e coleta de dados para validação do modelo proposto. A escolha da usina se deve à sua representatividade do setor quanto a tamanho e processos utilizados e facilidade de acesso a dados concedida pelos gestores.

\subsection{Enunciado do problema e sua relevância}

Diferentemente das fábricas de produção de açúcar e álcool dos EUA, que usam milho como matéria-prima, que pode ser estocado em grandes silos por um ano ou mais sem perdas significativas no teor de açúcar, no Brasil é muito grande o número de variáveis na produção sucroalcooleira. A começar pela matéria-prima, a cana-de-açúcar (não pode ser estocada por grandes períodos devido às perdas no teor de açúcar), que representa em torno de $60 \%$ do custo de produção do açúcar e do álcool (FERNANDES, A., 2003). Para compensar o alto custo na matéria-prima, o processo precisa ter alta eficiência e eficácia na retirada de açúcar e álcool. Para tanto, no caso da produção de açúcar e álcool, o processo deve ser bem controlado tanto no setor agrícola quanto nos setores industrial e comercial. Existe forte correlação entre a qualidade da cana que vem do campo e o rendimento da fermentação alcoólica e quantidade de açúcar produzido na usina. Assim, estudos permanentes devem ser feitos para determinar qual o melhor mix de variedade de cana que deve ser plantado para conseguir o máximo teor de açúcar. Quanto ao setor industrial, reduções de estoque de cana-de-açúcar, de perdas no processo de moagem e de fermentação e controle dos caminhos de produção a se adotar relacionados com as exigências e oportunidades do mercado são exemplos de fatores a serem estudados para o aumento de eficiência.

$\mathrm{Na}$ área comercial, o grande problema está nas constantes oscilações, nos mercados interno e externo, dos preços do açúcar e do álcool e a integração com a parte industrial para se produzir no tempo certo e na quantidade certa aqueles produtos que maximizem 
a margem de contribuição da empresa respeitando-se os contratos futuros já estabelecidos. Outro problema a ser explorado é o controle dos níveis de estoque de açúcar e álcool para maximizar os ganhos.

Os principais produtos oriundos da cana-de-açúcar, o álcool anidro, o álcool hidratado e o açúcar têm dinâmicas de preços e demandas diferentes no mercado interno, mercado externo e futuro. Atender estes três principais mercados, sem perdas significativas de margem de contribuição, exige muito planejamento e previsão e isso interfere diretamente no planejamento, programação e controle da produção das usinas, tanto na etapa agrícola/industrial quanto na etapa comercial. Durante séculos todo esse planejamento foi feito pelo governo, mas num processo que durou toda a década de 90 esta responsabilidade foi repassada integralmente ao setor privado. Hoje prevalece o regime de livre mercado, sem subsídios, e definem-se os preços de açúcar e álcool de acordo com as variações de oferta e demanda, numa relação direta com os mercados consumidores.

Esta dissertação parte do princípio de que não é suficiente apenas ter o melhor estudo genético de variedades de cana, o melhor manejo no cultivo, a melhor produtividade agrícola e industrial se o preço de venda dos produtos escolhidos para compor o mix não maximizar a margem de contribuição da empresa. Portanto, neste trabalho a etapa comercial toma um papel importante na modelagem do processo interferindo diretamente no planejamento, programação e controle da produção nas usinas de açúcar e álcool. A gestão de produção/estoques está vinculada ao modelo de previsão de preços de açúcar e álcool, de atendimento a contratos futuros estabelecidos pelas usinas e gerenciamento de seu fluxo de caixa.

Define-se a operação de hedge no caso das usinas de açúcar e álcool como o mecanismo pelo qual uma usina assume um preço de venda de seus produtos no futuro visando diminuir variações de preços. A palavra "hedge" pode ser entendida como "proteção" dos preços.

Dessa maneira, nesta dissertação procura-se proteger o caixa da usina com o estabelecimento em cada período de análise de um mix ótimo para o hedge de açúcar, álcool anidro e hidratado visando à minimização de riscos objetivando uma rentabilidade alvo e a cobertura de alguns custos importantes na usina.

Atentos a toda essa problemática, os profissionais ligados ao setor consideram de extrema importância o controle integrado do processo de maneira a melhorar as tomadas de decisão frente a tantas variáveis em jogo, incluindo aí a parte comercial. 
Dessa maneira, um estudo global das variáveis que interferem em todo o processo da cadeia produtiva do setor sucroalcooleiro ajudará a minimizar perdas, maximizar ganhos e contribuir para a melhoria da eficiência e eficácia do setor como um todo.

\subsection{Objetivos}

O objetivo deste trabalho é propor um modelo de planejamento agregado que contribua para maximizar a margem das usinas de açúcar e álcool considerando-se os custos referentes às etapas agrícola, industrial e comercial.

Para atingir esse objetivo, será necessária a minimização dos custos de produção da cadeia produtiva e integração das etapas agrícola, industrial e comercial na usina. Será utilizado o modelo econômico descritivo de sistemas agroindustriais segundo Brunstein (2005), conforme figura 2, em que se observa um destaque para a parte comercial, lacuna importante observada na literatura estudada. O nível tático descrito na figura está diretamente relacionado com o objetivo desta dissertação.

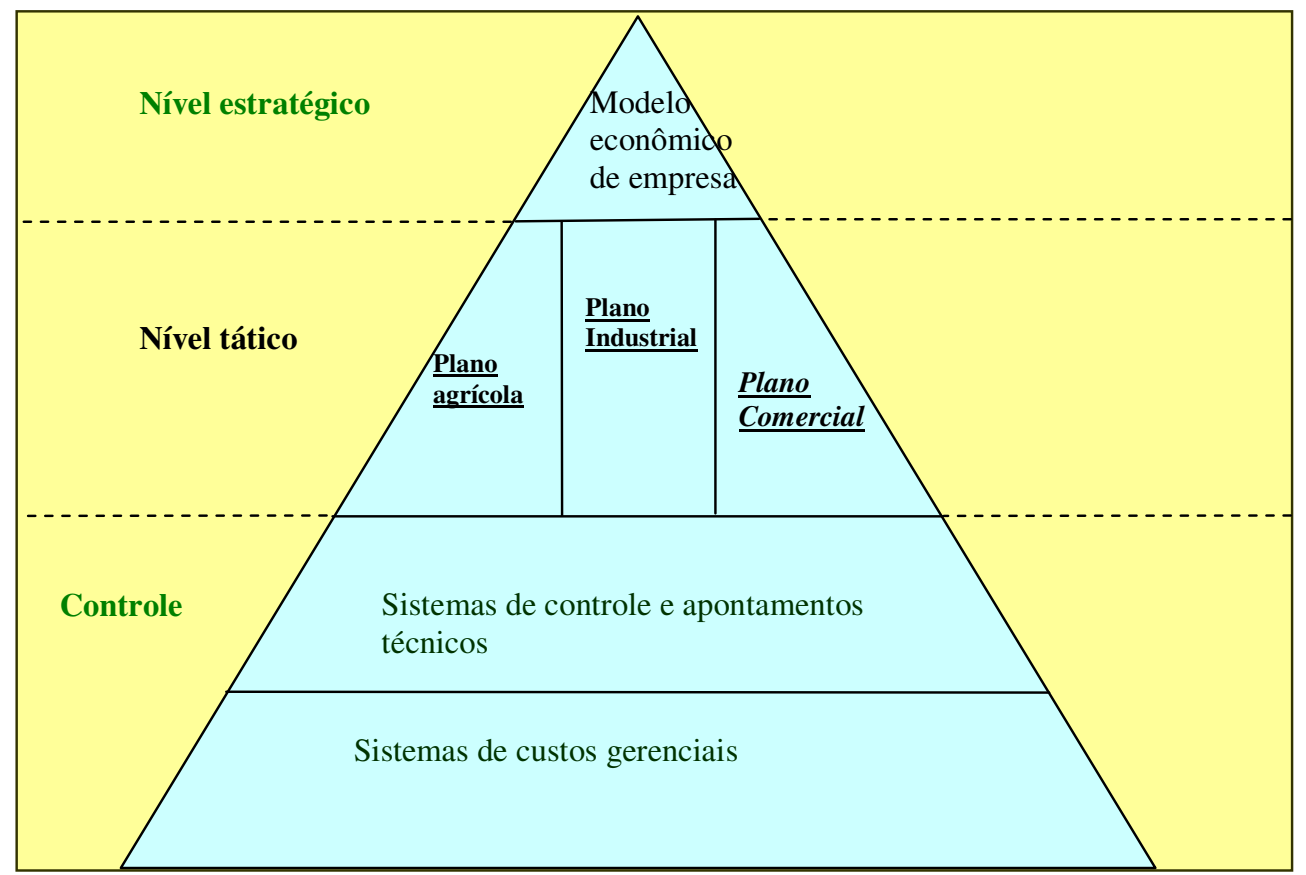

Figura 2. Níveis de planejamento e integração das várias etapas Fonte: Adaptação de Brunstein (2005) e Paiva (2006). 


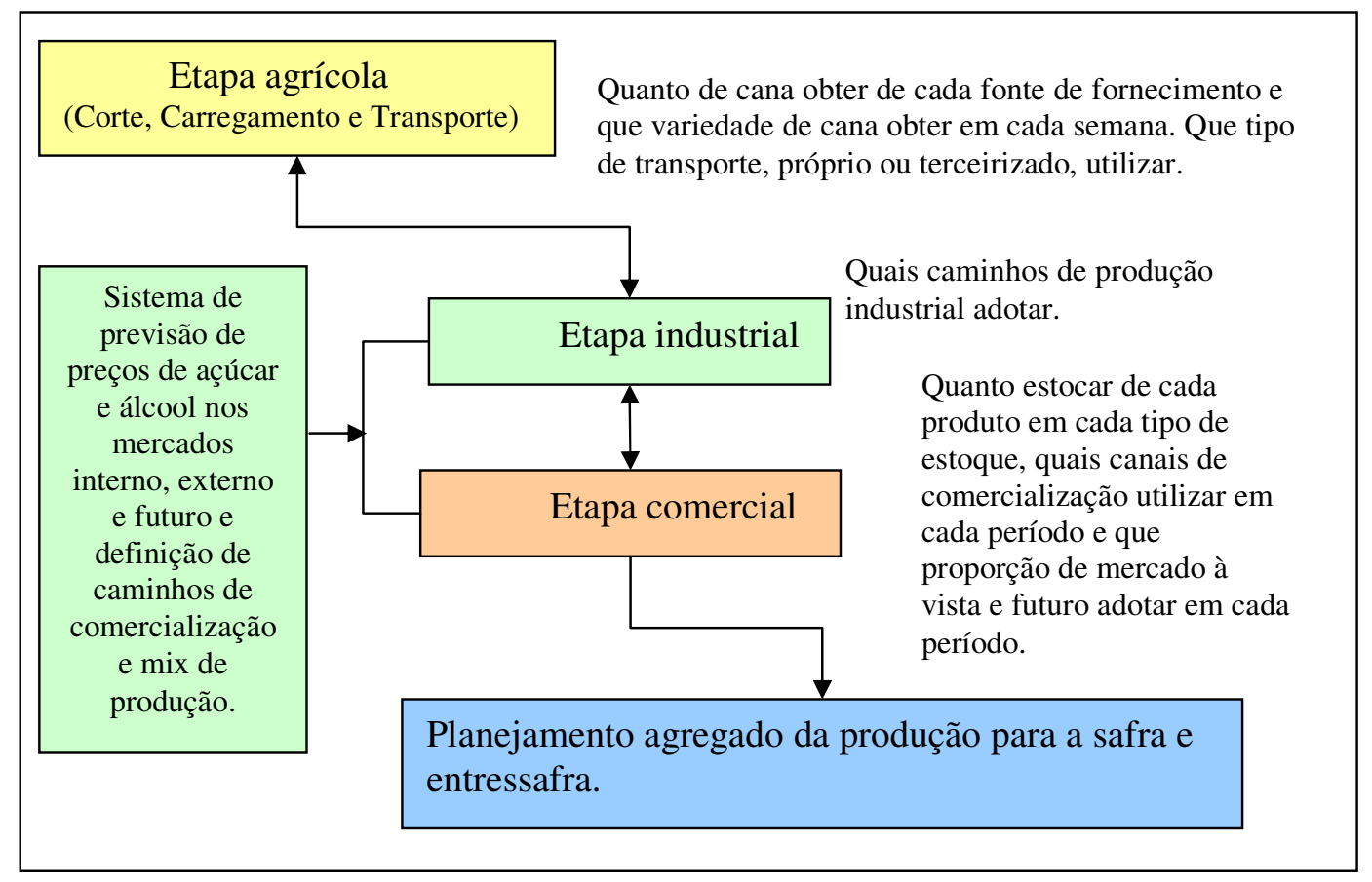

Figura 3. Questões que são contempladas nesta dissertação

Contemplando a etapa comercial, esta dissertação tem ainda por objetivo suprir uma importante lacuna verificada na literatura quanto à formulação de métodos e modelos quantitativos nesta etapa no setor sucroalcooleiro, fundamental para a maximização da margem de contribuição agroindustrial da empresa. Observa-se na figura 3 que há relações recíprocas entre as etapas agrícola, industrial e comercial, característica essencial para a boa aplicação deste modelo de planejamento agregado.

\subsection{Métodos e Técnicas de Pesquisa}

\subsubsection{Definição do método de pesquisa}

Os processos de produção de açúcar e de álcool podem ser resumidos nas seguintes etapas: recepção da cana-de-açúcar, extração do caldo nas moendas e tratamento do caldo. Esses processos ocorrem tanto na produção de açúcar como na de álcool. Para a produção de açúcar, o caldo decantado vai para os evaporadores, depois para os cozedores, cristalizadores, centrifugadores e, finalmente, para os secadores, que liberam o produto final em condição de consumo. Para a produção de álcool, o caldo é encaminhado para as dornas de fermentação, onde ocorre a transformação dos açúcares em álcool por meio de um processo biológico. Em seguida ocorre a destilação propriamente dita e a produção de álcool. 
Aparentemente, o processo de produção de açúcar e álcool parece ser simples na figura 4 e na descrição acima. No entanto, quando se busca melhorar sua eficiência é que se percebe que o número de variáveis que afetam direta e indiretamente o processo é demasiado grande. As perdas ocorrem em cada fase do processo produtivo e se estendem até a comercialização, como se observa no novo fluxograma da figura 5. Podem-se observar também várias opções de fabricação de açúcar e álcool através das separações dos caldos mistos e primários.

Por esse motivo, devido ao grande número de variáveis interagindo em todo o processo, neste projeto decidiu-se pela metodologia de pesquisa utilizando modelagem matemática para o auxílio nas tomadas de decisão. Como o objetivo principal do trabalho é a maximização da margem de contribuição da empresa, a metodologia de técnicas de Pesquisa Operacional utilizando modelagem por programação matemática permite uma comparação entre vários cenários e a escolha de um cenário ótimo dadas as várias restrições e opções inerentes aos processos agrícolas, industriais e comerciais estudados. 


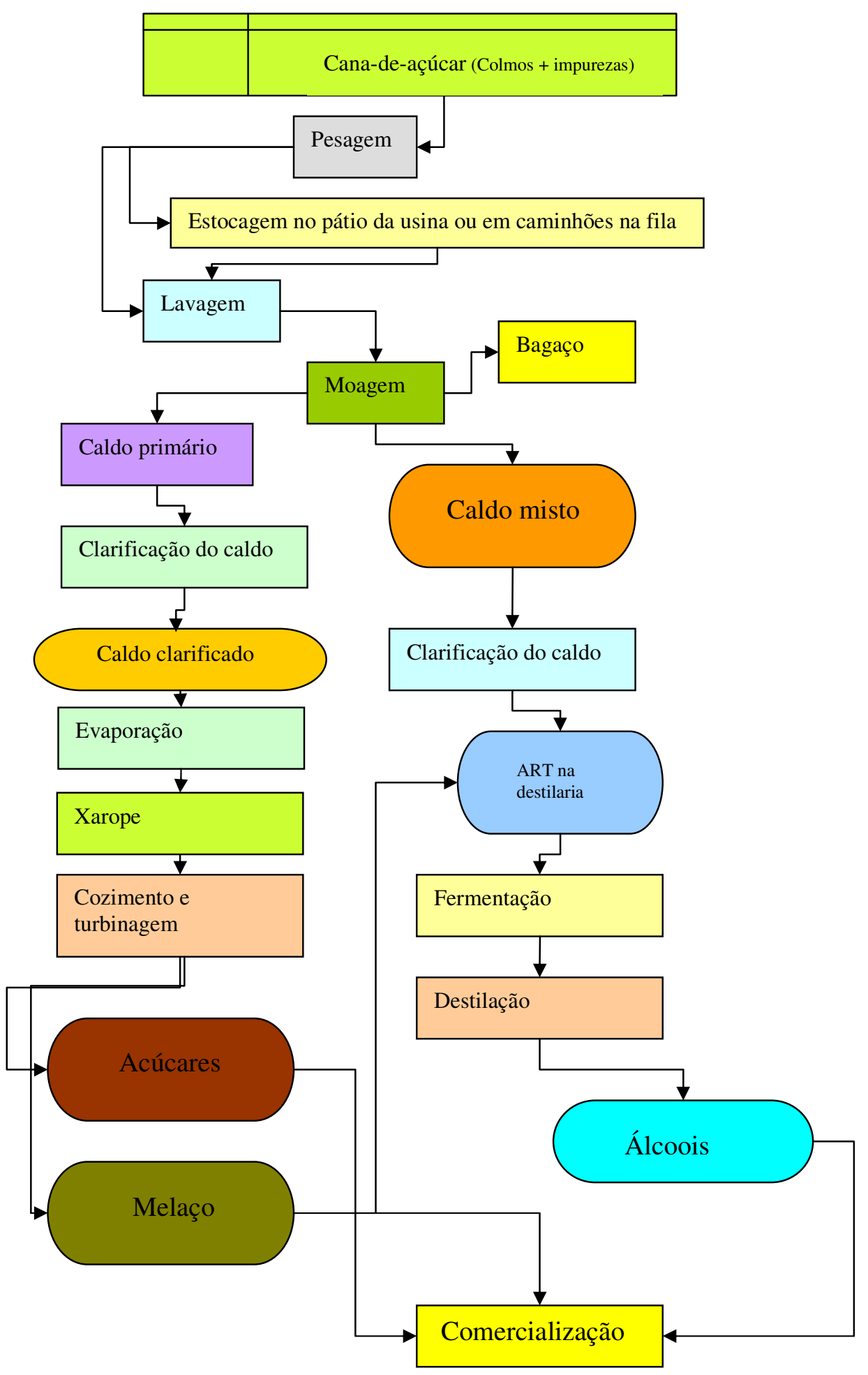

Figura 4. Fluxograma simplificado de produção de açúcar e álcool numa usina 


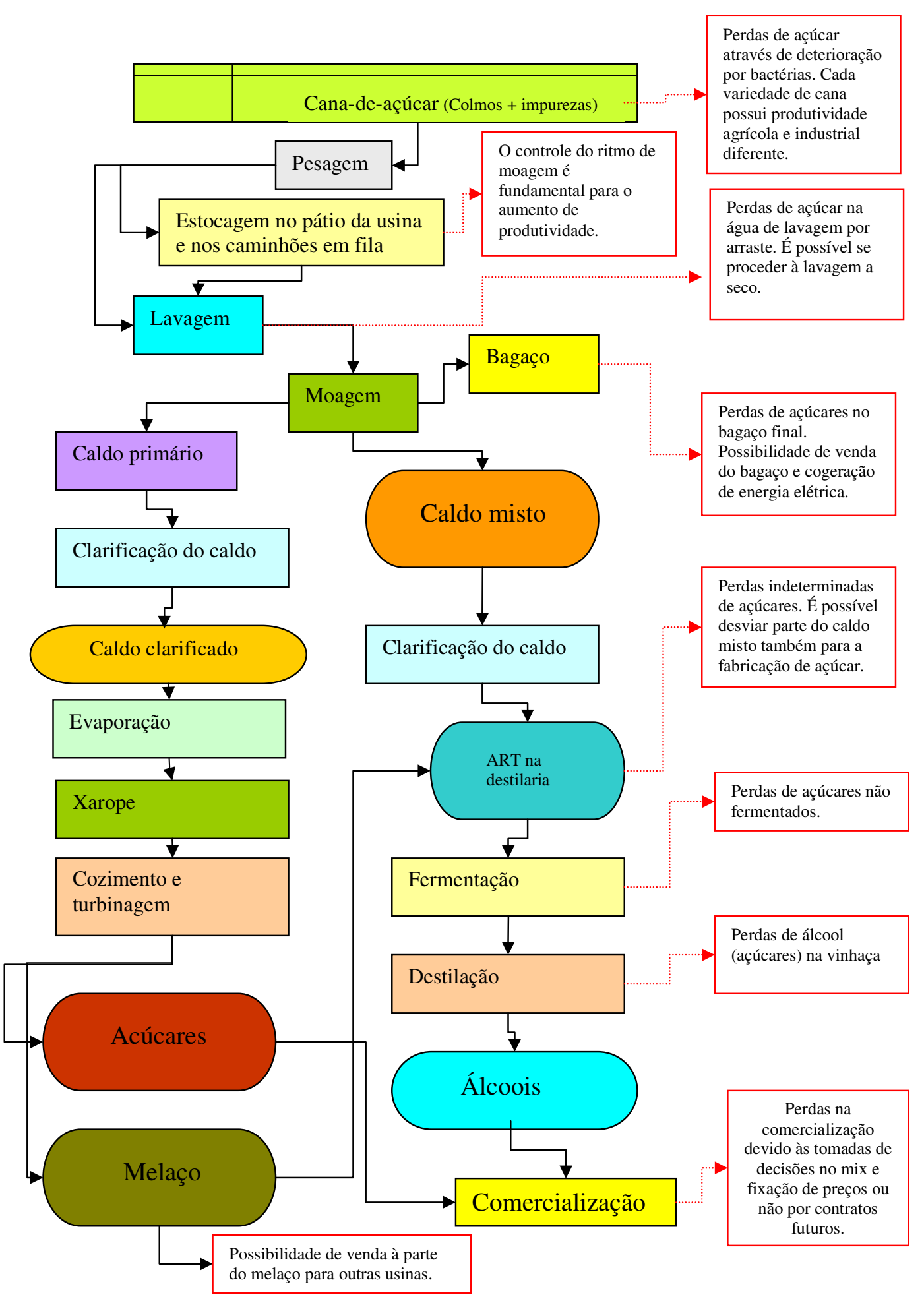

Figura 5. Fluxograma simplificado da produção de açúcar e álcool numa usina com descrição de perdas no processo e diferentes possibilidades de produção. 
Neste trabalho, segue-se o modelo de Bertrand e Fransoo em seu artigo "Operations management research methodologies using quantitative modeling" para o seu desenvolvimento e também o trabalho de Mirtroff et al. (1974), estabelecendo-se assim cinco fases para o projeto:

1. Conceituação do problema;

2. Fundamentação teórica;

3. Modelagem;

4. Implementação;

5. Discussão dos resultados.

No artigo de Bertrand e Fransoo, ocorre um direcionamento do foco para a metodologia de pesquisa em Administração de Operações baseada em modelos quantitativos, base para este trabalho.

Desenvolvendo as técnicas e passos necessários para a execução de trabalhos acadêmicos de qualidade em Operations Management (OM) e Operations Research (OR), o artigo também sublinha os pontos fortes e fracos das pesquisas que se baseiam em OM e OR e faz uma revisão da literatura divulgada sobre o assunto.

Destaca-se que para a aplicação dos métodos e técnicas de OM e OR, há a necessidade de simplificação dos problemas encontrados na vida real. Dentre as simplificações, encontram-se a inclusão para análise nos estudos apenas dos aspectos considerados de relevância para o problema e que seja bastante abrangente, independentemente de suas origens e aplicações particulares na indústria e nos segmentos de serviços. Dessa forma, para generalizar e tornar científico o estudo idealizam-se os problemas reais, como no caso de administração de estoques, controle estatístico do processo e problemas de manutenção, por exemplo, tradicionalmente estudados. Consegue-se assim com algumas abstrações da realidade tornar mais explícitos alguns trade-offs essenciais e algumas importantes interações entre funções, tornando viável a análise matemática dos problemas reais e auxiliando nas tomadas de decisão.

Entendendo por modelo científico nesta área do conhecimento aqueles que podem ser utilizados para predizer o comportamento ou desempenho de processos operacionais e que podem ser validados empiricamente de uma forma objetiva, o presente trabalho faz uso de dados de uma usina em particular para os testes de validação da pesquisa, podendo também generalizar seus estudos para um grupo maior de usinas.

Apesar das barreiras naturais para o estudo rigoroso científico em OM e OR, este trabalho pretende utilizar os estudos em Pesquisa Operacional para que ele possa se 
tornar uma ferramenta efetiva no auxílio às tomadas de decisão. Os estudos aqui presentes estão direcionados mais para os processos operacionais e comerciais da usina, combinando a pesquisa quantitativa teórica com a pesquisa quantitativa empírica e com o auxílio dos colaboradores das usinas estudadas. Trata-se de um trabalho nos moldes da pesquisa operacional do passado. Conforme escreveu Ackoff em um artigo: "O futuro das pesquisas em OR é o passado".

$\mathrm{O}$ artigo de Bertrand e Fransoo classifica as metodologias de pesquisa baseadas nos modelos de estudo de OM e OR em duas classes: a primeira é a axiomática, que estuda um mundo idealizado, formulando teorias a partir dele e fazendo muito uso de métodos e técnicas matemáticas, estatísticas e de ciência da computação, como otimização combinatória e teoria das filas. A segunda classe é a empírica, que está principalmente interessada em criar modelos que se adequem bem às relações causais que podem existir no mundo real. Nas duas classes encontram-se tanto a abordagem normativa quanto a abordagem descritiva. Dessa maneira, o artigo classifica os estudos em OM e OR em quatro tipos de pesquisa: Axiomática descritiva, Axiomática normativa, Empírica descritiva e Empírica normativa.

A metodologia desenvolvida neste trabalho enquadra-se no tipo de pesquisa Axiomática Normativa, já que serão utilizados modelos conceituais de modelagem já existentes na literatura, mas serão estabelecidos caminhos para as tomadas de decisão. Este trabalho inicia com uma ampla descrição das características das fases produtivas na cadeia produtiva do açúcar e do álcool, conceituando-se o problema, o que confere um caráter inicialmente descritivo para o estudo. 


\subsubsection{Hipóteses}

Para o desenvolvimento do trabalho e consequente modelagem, nesta dissertação assumem-se as seguintes hipóteses:

$>\quad$ Coletas de dados semanais durante todo o tempo de produção e comercialização (36 semanas nesta dissertação) dos produtos se constituem em dados representativos para a identificação de perdas de eficiência no processo de produção/comercialização e suas consequentes melhorias.

Quanto maior o número de variáveis que possam ser monitoradas, maior pode ser a margem de contribuição das empresas estudadas.

As medidas de quantidade de estoque de cana no campo para cada variedade de cana (previsão de safra da usina), que servem como base de entrada de dados para o modelo, são dados confiáveis para que o modelo possa rodar.

$>\quad$ A inclusão dos processos comerciais de negociação de açúcar e álcool conjuntamente com os processos industriais integra a abordagem de programação matemática do modelo proposto.

$>$ Medidas de tempos de resposta dos gerentes/diretores diante de mudanças no âmbito comercial (preços de açúcar e álcool) se constituem em bons dados de comparação com o estudo proposto.

Benchmarking com outras usinas melhora as coletas de dados, tornando essas coletas mais abrangentes para possíveis usos num número maior de empresas.

$>\quad$ As variedades de cana interferem no rendimento industrial/comercial.

> Uma política de mix de produção vinculada a métodos de previsão de preços dos produtos comercializados nos mercados interno e externo e no mercado futuro com a possibilidade de reter mais ou menos produção para cada um deles maximiza a margem de contribuição agroindustrial/comercial da usina.

O Método Delphi de previsão de preços se constitui num bom modelo de previsão para preços de açúcar e álcool visando replanejamentos semanais. 


\subsubsection{A empresa (Estudo de Caso)}

A Usina Alta Paulista, localizada no município de Junqueirópolis (nos arredores de Presidente Prudente, São Paulo), surgiu do incentivo do governo federal, pelo Proálcool, em 1977.

Fatores adversos da economia afetaram diretamente a estrutura patrimonial dessa organização e, em 1998, com um Passivo a descoberto (dívidas superiores ao Ativo), já em concordata, a Vale Verde (sua antiga razão social) entrou num processo de falência, o que resultou em seu fechamento.

No ano de 2001, a Usina Vale Verde passa a ser denominada Usina Alta Paulista, quando suas atividades foram retomadas após ser adquirida por um grupo de empreendedores de Pernambuco.

Hoje a indústria é responsável pela produção de Açúcar $\boldsymbol{V H P}$ (açúcar bruto destinado à exportação sem passar pelo processo de refinamento), Álcool Anidro (usado como aditivo para gasolina), Álcool Hidratado (para uso do consumidor final) e Melaço (para venda a outras usinas). Sua moagem anual chega a 1.200.000 toneladas de cana e esta é proveniente de plantios próprios $(90 \%)$ e de terceiros (10 \%), em terras próprias (5\%) e de terceiros $(95 \%)$ (dados da diretoria agrícola e industrial).

Toda sua área agriculturável está sob a gestão de Responsabilidade Social da empresa para a garantia de sustentabilidade do meio ambiente, ou seja, a organização tem por objetivo preservar as matas ciliares e implantar projetos de melhorias nas propriedades que ainda se encontram devastadas pelo cultivo da cana. Essa preocupação estende-se ao plantio de árvores na proporção de 15/1, ou seja, para cada árvore que é removida, plantam-se quinze. Existe ainda a preocupação em recuperar os córregos da região, evitando dessa maneira os assoreamentos e extinção dos mesmos.

Em relação à parte social e econômica, a Usina Alta Paulista gera em torno de 3500 empregos entre efetivos e safristas durante a safra e entressafra.

A Usina Alta Paulista pode ser considerada como representativa do universo sucroalcooleiro. Trata-se de uma usina de médio porte que deseja ganhar capacidade produtiva e melhoria de eficiência agrícola e industrial, fatores de sucesso buscados pela maioria das usinas. A região em que está instalada tem grande potencial para o desenvolvimento do cultivo da cana. Comparada com a região de Ribeirão Preto, sua grande vantagem é a larga disponibilidade de terras livres para o cultivo. Uma desvantagem é que a terra deve ser tratada mais vezes e com mais cuidado com 
implementos agrícolas. Trata-se de uma usina que pode fornecer dados representativos de maneira a serem generalizados para um conjunto maior de usinas brasileiras, funcionando dessa maneira como um bom lugar para a elaboração teórica e testes do presente estudo.

\section{Caracterização da usina Alta Paulista}

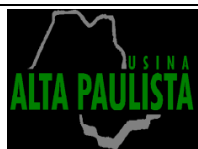

Moagem total na safra 2008/2009: 1.200 .000 toneladas

Cana própria : 12.123 ha.

Cana comprada de terceiros: 1.303 ha.

Moagem na safra 2006/2007: 920.000toneladas

Moagem na safra 2007/2008: 1.084.000 toneladas

Matéria-prima:

Produtividade agrícola de cana própria: 87 ton / ha. (safra 2008/2009).

ATR: $149.17 \mathrm{Kg}$ de cana

PC: $15,15 \%$ cana

Mix de Fabricação:

Cana destinada à fabricação de álcoois: $55 \%$

Cana destinada à fabricação de açúcares: $45 \%$

Pode-se chegar a uma proporção de $70 \%$ de álcool para $30 \%$ de açúcar, produção bastante alcooleira, ou a 50\% de álcool e 50\% de açúcar, o máximo de açucareira.

Atuais Capacidades industriais instaladas:

Moagem de cana: 5300 ton / dia

Fabricação de álcool anidro: 180.000 litros / dia

Fabricação de álcool hidratado: 220.000 litros / dia

Fabricação de açúcares: 7.000 sacas/ dia

Armazenagem de álcoois: 16.000.000 litros

Armazenagem de açúcares: 100.000 sacas

Média diária de recebimento de cana: 150 caminhões

Atuais Rendimentos e eficiência Industriais:

Eficiência de extração: $96.0 \%$

Eficiência de fermentação: 90,0 \%

Eficiência de destilação: $99.5 \%$

Rendimento de Destilação: 88,45 litros Ton / cana

Eficiência de Açúcar: $124.30 \mathrm{~kg} /$ ton de cana

Número de empregos gerados atualmente na safra:

Área industrial: 250 divididos em três turnos.

Área agrícola: 1200

Área administrativa: 45

Figura 6. Caracterização da usina Alta Paulista (USALPA) 


\subsection{Organização da dissertação}

A presente dissertação está organizada em sete capítulos.

No capítulo 1, faz-se um levantamento da importância do setor sucroalcooleiro no Brasil destacando-se algumas estatísticas e seus principais problemas de competitividade. Nele também se encontra o objetivo do trabalho, a metodologia de pesquisa utilizada e as hipóteses assumidas para o desenvolvimento da dissertação.

O capítulo 2 inicia com um estudo através de fluxogramas do sistema agroindustrial do açúcar e do álcool. Nele está a descrição das etapas de produção desde a fase agrícola até chegar à etapa de comercialização, destacando-se características importantes nos processos de negociação em mercados futuros de açúcar e álcool.

No capítulo 3 é feito o levantamento da revisão bibliográfica e referencial teórico, separando-os em duas partes: na primeira encontra-se o referencial para a etapa agrícola e industrial e na segunda o referencial para etapa de comercialização dos produtos acabados. Faz-se ainda nessa segunda parte um estudo de modelos de otimização de carteiras de investimento a fim de se escolher o que melhor se adapte às negociações comerciais de açúcar e álcool dentro das condições do setor sucroalcooleiro.

O capítulo 4 é dedicado às explicações de cálculos de custos associados aos processos de produção e comercialização, rendimentos industriais e ainda cálculos de receitas obtidas com as vendas dos produtos. Com referenciação ao Apêndice B, o capítulo remete aos parâmetros das etapas agrícola, industrial e comercial a se acrescentar no modelo matemático e cálculos de custos de estocagem dos produtos acabados.

No capítulo 5 estão os modelos matemáticos de otimização propostos para a definição do hedge de açúcar e álcool em cada semana e o modelo matemático denominado SOVTICE para a etapa de produção e comercialização.

O capítulo 6 é reservado para a descrição dos resultados alcançados com os modelos propostos fazendo-se ainda um estudo comparativo entre alguns cenários possíveis a fim de se testar coerências lógicas com o caso real. Neste capítulo se encontra também a 
análise de viabilidade de implementação do modelo e sua validação através de pesquisa junto a gestores de um grupo de usinas.

O capítulo 7 á reservado às conclusões do trabalho, discorrendo sobre o potencial do modelo de planejamento agregado desenvolvido e as perspectivas para pesquisas futuras.

No apêndice A, é feito ainda um levantamento do panorama histórico do setor sucroalcooleiro no Brasil da época da colonização aos dias atuais, destacando-se problemas que ainda hoje se fazem presentes neste importante setor da economia.

No apêndice B, são descritas as fórmulas de cálculos de custos agrícolas, rendimentos agroindustriais, custos comerciais e de estocagem e receitas comerciais obtidas com as vendas dos produtos acabados.

Os anexos contêm os dados de entrada necessários para rodar o modelo e resultados encontrados com a aplicação do mesmo. 


\section{O SISTEMA AGROINDUSTRIAL DA CANA E OS PROCESSOS DE PRODUÇÃO E COMERCIALIZAÇÃO}

\subsection{Sistema agroindustrial da cana-de-açúcar}

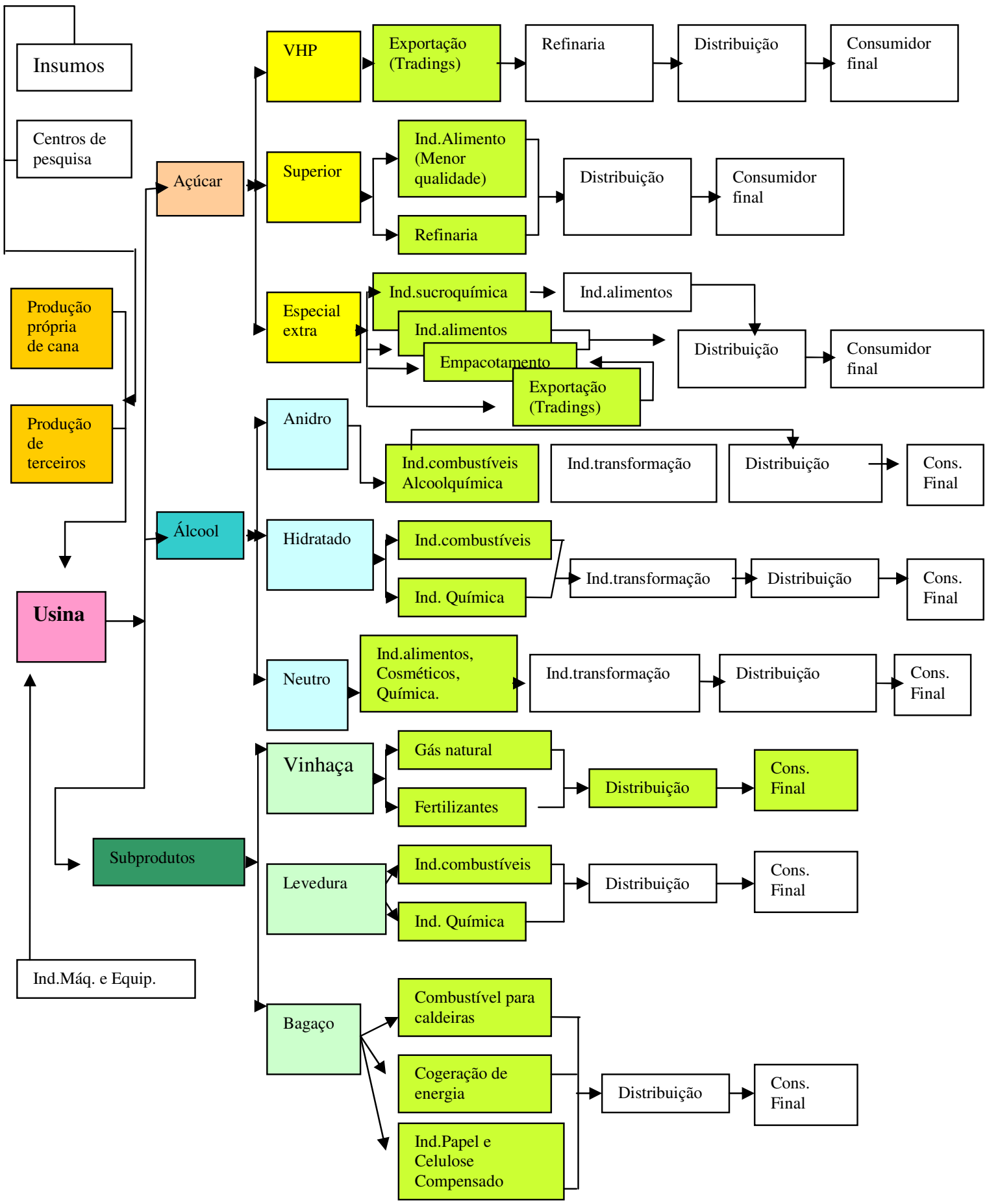

Figura 7. Sistema agroindustrial da cana-de-açúcar Adaptado de WAACK et al (1998) 
Podemos observar na figura 7 uma ampla possibilidade de mix de produtos com que a usina de açúcar e álcool pode trabalhar. Junto a isso se destaca também a grande variedade de canais de comercialização. A usina pode comercializar seus produtos diretamente com as indústrias no mercado à vista através de negociação de contratos de fornecimento contínuo e contratos por encomenda. Pode negociar com corretoras de açúcar e álcool, sendo que estas funcionam como atravessadores de seus produtos. Há a possibilidade de negociação de açúcar e álcool no mercado futuro através de fundos de comercialização chamados de Hedge (descrito em mais detalhes no item 2.5.2). Pode negociar ainda uma produção maior visando mercado interno ou mercado externo.

Percebe-se assim uma grande rede de canais de comercialização, que se por um lado dificulta os processos de negociação, por outro abre novos caminhos e estratégias de comercialização que podem melhorar a margem de contribuição agroindustrial das usinas. Trata-se até onde se sabe com as pesquisas bibliográficas realizadas de assunto pouco explorado na literatura acadêmica e com boas perspectivas de resultados futuros no auxílio à tomada de decisão.

\subsection{Os tipos de açúcar, álcool e subprodutos na Usina Alta Paulista}

Os processos de produção de açúcar e álcool possuem etapas idênticas até a fase de separação do caldo, que neste trabalho será intitulada SC. A partir daí ocorrem as distinções entre os processos, que levarão à formação dos vários tipos de açúcares e de álcool. Neste trabalho, os tipos de açúcar, álcool e subprodutos que serão estudados no processo produtivo e de comercialização são:

- VHP: Açúcar de polarização elevada

- AEAC: Álcool etílico anidro carburante

- AEHC: Álcool etílico hidratado carburante

- M: Melaço

A correta caracterização dos tipos de produtos e suas especificações é muito importante para todas as empresas e no caso das usinas de açúcar e álcool em particular, já que esse procedimento definirá com quais empresas a usina poderá comercializar seus produtos sem incorrer em ações legais por não conformidade de seus produtos às especificações. 


\subsection{Processos de produção da etapa agrícola}

\subsubsection{Fluxograma da Etapa agrícola}

A safra da cana-de-açúcar é sazonal. No centro-sul do Brasil, inicia no começo de março e termina em meados de dezembro. Com o amadurecimento, as canas passam a ser cortadas de forma planejada. Neste trabalho, a etapa agrícola avança até o corte e o carregamento da cana no campo segundo o fluxograma simplificado a seguir.

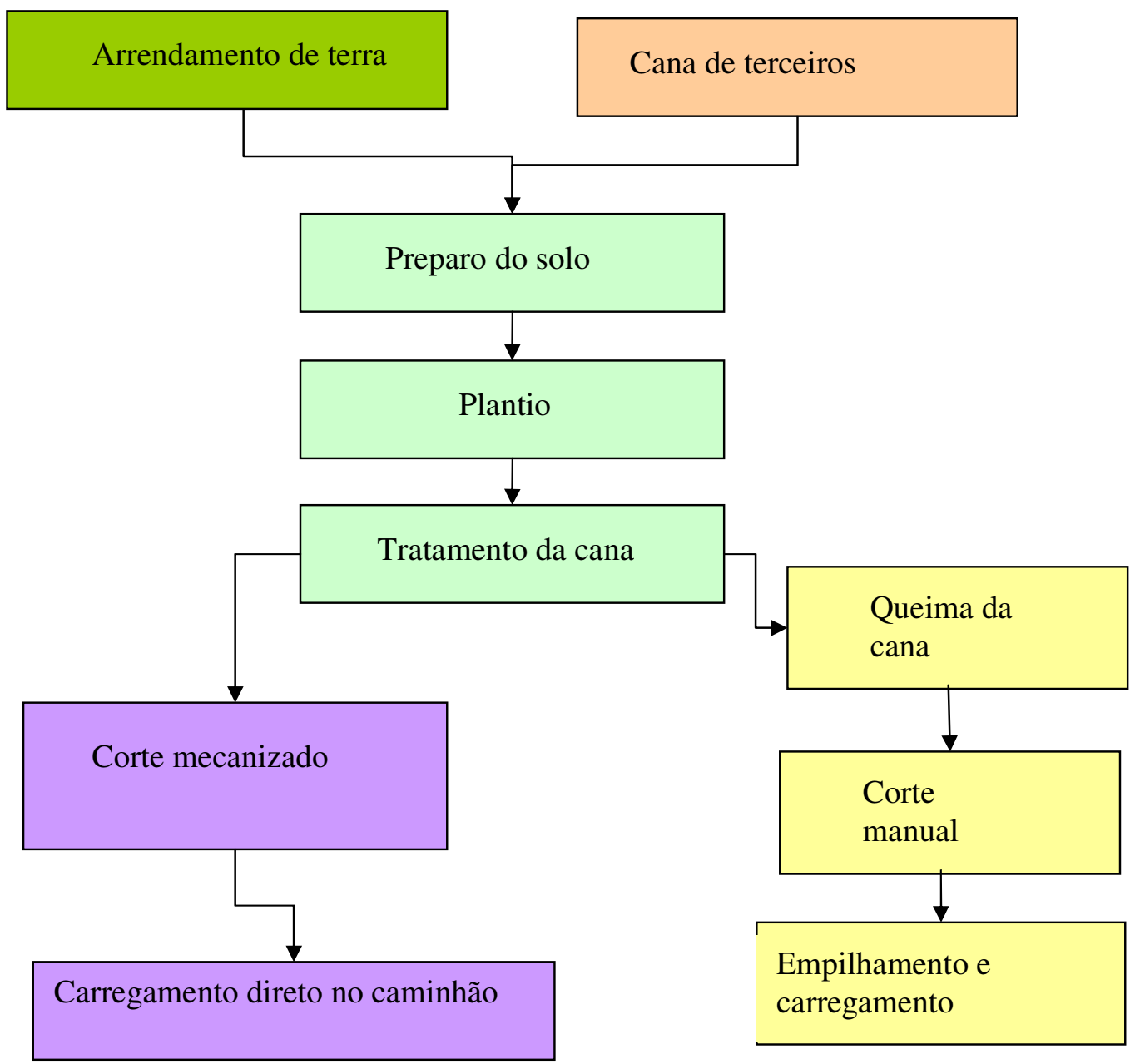

Figura 8. Fluxograma simplificado da etapa agrícola de produção de cana-de-açúcar. 


\subsubsection{Plantio da cana}

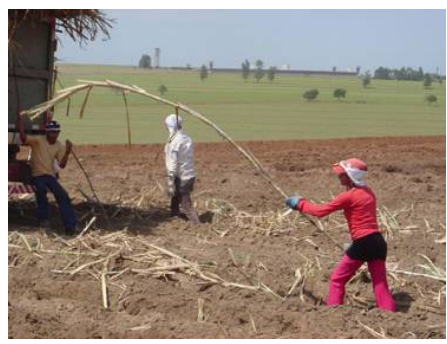

Figura 9. Plantio manual

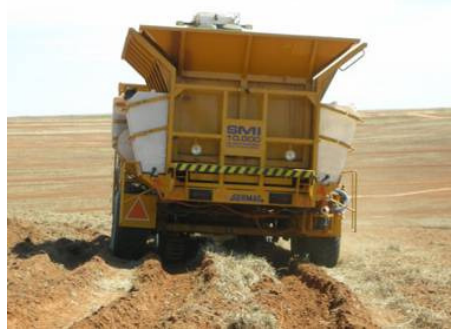

Figura 10. Plantio mecanizado

Segundo Fernandes (2002), a cana-de-açúcar uma vez em contato com o solo em condições favoráveis de umidade e temperatura, brota por intermédio da gema (figura 11), a qual irá formar novos colmos. Ao mesmo tempo da germinação, das zonas radiculares (figura 12), situadas nos nós da cana, brotam raízes finas, numerosas e de natureza fibrosa nos novos colmos. O tipo de fibra presente é um dos fatores que interferem nos índices de eficiência industrial. Na parte que está sob o solo também surgirão raízes que formarão um sistema radicular do tipo fasciculado, cujo tamanho e profundidade está diretamente ligado à variedade, ao preparo de solo, à idade e ao número de cortes da planta, porém a maior parte das raízes se encontra nos primeiros 50 centímetros de profundidade.

Os colmos, caracterizados por nós bem marcados e entrenós distintos, são espessos e repletos de suco açucarado segundo cada variedade.

Dependendo da espessura da cana e teor de fibras presentes haverá maior ou menor produtividade na moagem. Regra geral, quanto menos fibrosa é a cana mais fácil se torna a moagem. Logo, a variedade da cana é fator importante na análise de produtividade neste trabalho. 


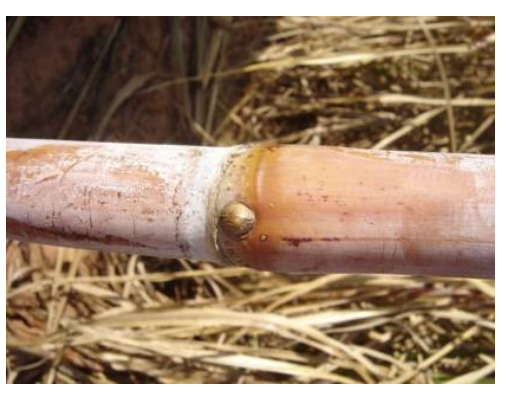

Figura 11. Gema da cana

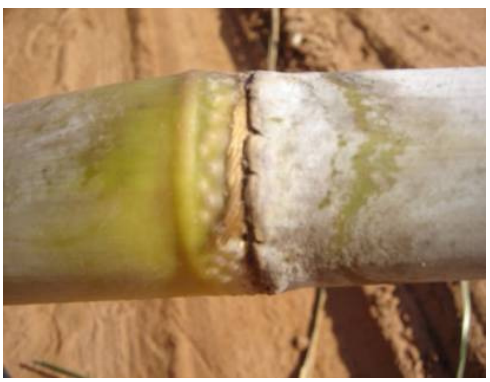

Figura 12. Zona radicular da cana

\subsubsection{Corte da cana}

Através do controle e planejamento dos canaviais, é montado um programa de corte baseado na maturação da cana. Dessa forma, têm-se áreas com canas plantadas que estarão próprias para o corte em momentos diferentes, o que permite seu manejo durante a safra. No centro-sul, o corte feito manualmente representa $50 \%$ da cana colhida. Os outros $50 \%$ são colhidos por colheitadeiras (safra 2008, UNICA), figura 14, o mesmo ocorrendo na Usina Alta Paulista.

\section{A queimada antes do corte}

A queima antecipada (figura 13) ou o corte tardio após a queima possibilita a permanência da cana cortada por mais de 24 horas no campo aguardando o carregamento e o transporte. No entanto, uma variável importante a se estudar é o tempo de queima da cana, já que isso interfere diretamente no teor de ATR da cana que entra na usina.

Consumada a queima da cana, o que é realizado como uma operação de limpeza da cana, seguem-se as operações de corte, carregamento e transporte. É de grande importância que a cana seja processada o mais rápido possível, estabelecendo-se como prazo satisfatório um período entre 24 e 36 horas, pois passando desse prazo as perdas podem ser significativas. Ao ser cortada, a cana é exposta ao tempo, sofre uma desidratação que ocasiona perda de peso (aumento da respiração do colmo com a perda 
de açúcares) e, após o prazo anteriormente citado, com grande frequência a deterioração assumirá proporções elevadas rapidamente, o que comprometerá totalmente a qualidade da matéria-prima.

A escolha do tipo de corte dos colmos depende de inúmeros fatores, tais como: disponibilidade de mão-de-obra, condições de campo onde está implantado o canavial, do sistema de carregamento a ser utilizado e da interferência no processo de moagem, por exemplo (PARANHOS, 1987).

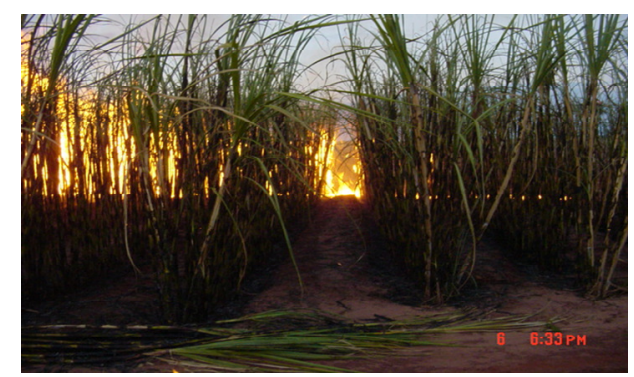

Figura 13. Queima da cana antes do corte

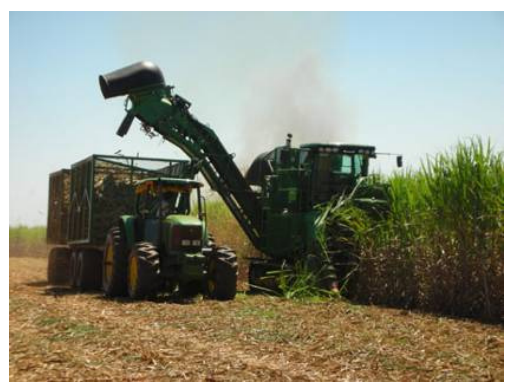

Figura 14. Colheita mecanizada

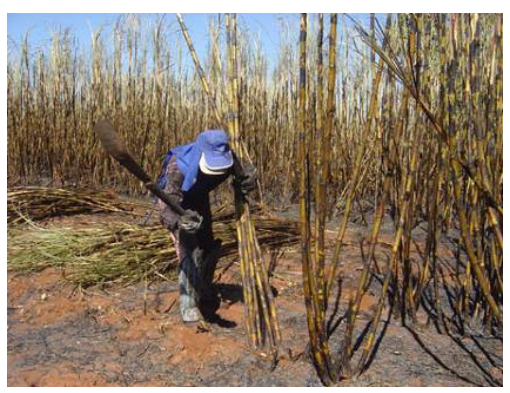

Figura 15. Corte manual pós-queimada

Cabe ressaltar que embora a queimada ainda seja uma prática comum nas usinas, tratase de prática que afeta negativamente a qualidade do ar nas proximidades da região em que ocorre, contribuindo ainda para o aumento do efeito estufa. Várias pesquisas estão sendo desenvolvidas para o desenvolvimento de máquinas colheitadeiras que possam entrar também em terrenos de relevo mais acidentado, onde a queimada é prática frequente. 


\section{Colheita e Corte da cana-de-açúcar na Usina Alta Paulista}

Segundo a diretoria agrícola da USALPA, a colheita da usina inicia-se no começo de abril e estende-se até dezembro, período em que a cana-de-açúcar atinge o seu ponto de maturação. Sempre que possível, é recomendável antecipar o fim da safra de maneira a evitar o período chuvoso, que dificulta o transporte da matéria-prima e com isso faz cair o rendimento industrial.

Na usina, em parte o corte é feito de forma manual (figura 15) e, para a colheita da cana, primeiramente é preciso efetuar sua queima para facilitar o processo.

Antes de iniciar a queima, é preciso fazer o aceiro (separação de duas ou três ruas para que a queima seja restrita a uma determinada área). O corte é feito em duas frentes de trabalho para que se facilite o transporte. É chamada de frente 1 a frente que trabalha de 0 a15 km, e de frente 2 aquela que trabalha de 15 a $40 \mathrm{~km}$. A colheita também é feita em parte de forma manual e utiliza a técnica dos "eixos de 5", na qual separam-se 5 ruas para cada cortador, com linhas de 7,5 metros e corte de no máximo $2,5 \mathrm{~cm}$ do solo ao toco da cana, onde as porções de cana são arrumadas e limpas e já despontadas com o intuito de diminuir o índice de impurezas minerais na unidade industrial. Nessa técnica, cada homem corta uma média de 7 a 10 toneladas por dia. O preço que se paga para cada cortador varia de acordo com a produtividade dos talhões (determinada área de cana) a serem cortados, e é dado pela manhã, quando são iniciados os trabalhos.

Cabe ressaltar aqui que embora os cuidados com segurança no trabalho sejam seguidos, o trabalho no corte de cana é um dos trabalhos mais extenuantes para os trabalhadores. Espera-se assim o surgimento de novas tecnologias e novos estudos de dinâmica de trabalho na área de colheita que ao mesmo tempo permitam aumento de produtividade e de qualidade de vida no ambiente laboral.

\subsubsection{Carregamento e transporte da cana}

$\mathrm{Na}$ USALPA, a frota de transporte de cana é composta por cerca de 20 caminhões próprios sendo ainda contratados caminhões terceirizados, os quais são do tipo Romeu e Julieta e Treminhões.

De acordo com a composição de transporte e o tipo da carroceria utilizada, variam a capacidade de carga, as velocidades de deslocamento (vazio e carregado), o tipo de carregamento no campo e o tipo de descarga na usina. Caso o dimensionamento do transporte não esteja adequado, poderão ocorrer problemas de abastecimento de cana na usina. 
Tradicionalmente, é estabelecida uma quantidade fixa de veículos por frente de corte, que apenas é alterada caso haja alguma mudança operacional, por exemplo, devido a uma quebra generalizada de máquinas ou alteração da distância média até a usina.

\section{Carregamento no campo}

Após o corte da cana, é feito o carregamento. Primeiramente, os caminhões chegam à frente de cana inteira e se dirigem ao ponto de engate e desengate, onde fazem o desacoplamento das suas carretas (Romeu e Julieta e Treminhão) que são então atreladas aos tratores-reboque (figura 16).

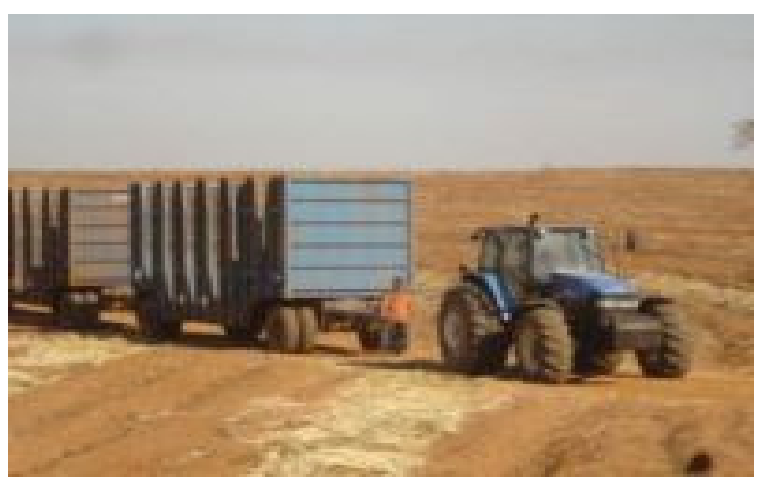

Figura 16. Trator reboque e conjunto Romeu e Julieta.

Na sequência, os caminhões desengatados e os tratores com as carretas acopladas se dirigem para alguma carregadora dentro da área de colheita. A escolha se dá em função da ociosidade da carregadora. As carregadoras permanecem paradas junto à cana disposta em montes ou esteirada. O caminhão ou o trator é posicionado ao lado da carregadora (figura 17) e esta se movimenta, coletando a cana com suas garras e depositando o feixe na carroceria do caminhão ou reboque. Após essa operação, as pontas de cana são aparadas pelos trabalhadores (figura 18).

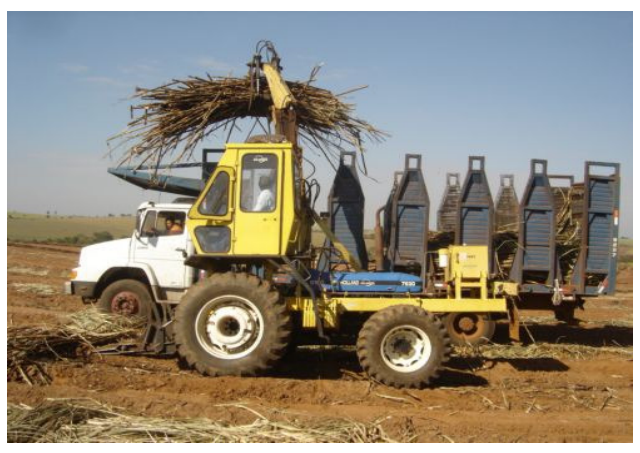

Figura 17. Carregamento do caminhão 


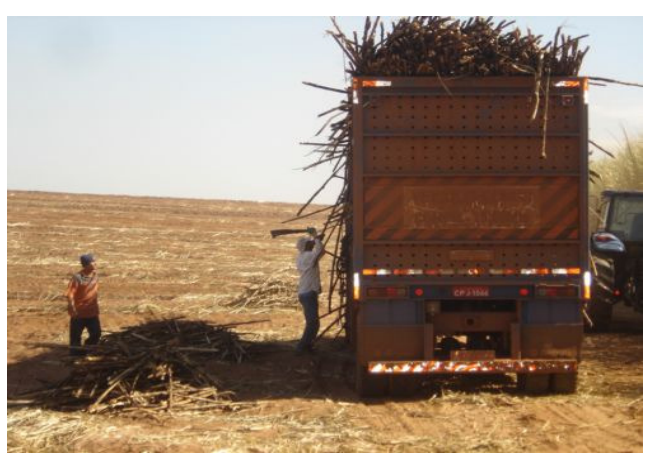

Figura 18. Cana sendo aparada

Em Ianonni e Morabito (2006) encontramos um trabalho abrangente envolvendo simulação discreta sobre as melhores escolhas de caminhões para o transporte da cana do campo à usina. Nesta dissertação, a variável transporte da cana do campo à usina será incluída no modelo matemático visando a escolha de quantidades de cana em cada semana transportada por caminhões próprios ou terceirizados.

\section{$\mathrm{O}$ retorno à usina}

Após a conclusão da carga, os caminhões e os tratores-reboque que puxam as carretas se dirigem ao ponto de engate e desengate, onde as carretas são desatreladas dos tratores. Os tratores seguem para atrelar alguma carreta vazia ou, simplesmente, aguardam a sua chegada. As carretas carregadas são atreladas aos caminhões para formar novamente a composição de transporte completa (Romeu e Julieta e Treminhão). Após a montagem do caminhão é feito o acerto de carga (figura 18), quando as pontas da cana são aparadas rente à carroceria, além da amarração da carga. Feito isso, o caminhão retorna à usina.

\subsubsection{Recepção da cana na usina}

$\mathrm{Na}$ usina, os caminhões possuem uma rota bem definida descrita através do roteiro de quatro passos a seguir.

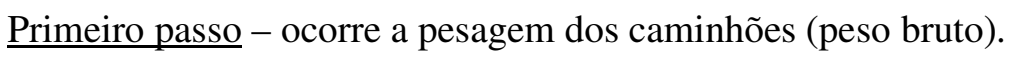

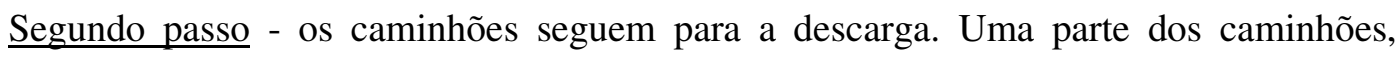
porém, segue para a sonda onde amostras da carga são retiradas para o levantamento da análise tecnológica (teor de sacarose, quantidade de impurezas, etc.). Este procedimento é feito por sorteio, no entanto, todos os caminhões de cana de terceiros são sondados. 


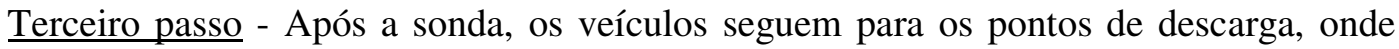
podem descarregar diretamente na esteira da moenda ou no pátio (apenas cana inteira). De acordo com o responsável pelo transporte e carregamento na usina, a manutenção de grandes estoques de cana no pátio (figura 19) prejudica a qualidade do material processado pela elevação das horas de armazenamento, além da queima que acontece antes do corte. Apesar disso, o estoque de cana garante a alimentação das moendas nos momentos de descontinuidade. Geralmente, o estoque de cana é formado ao longo do dia, sendo esvaziado à noite, quando a entrega dos fornecedores diminui; ou nos intervalos das trocas de turno, nos horários de restrição ou paradas para refeição. Também pode haver estoque em caminhões em fila.

Quarto passo - Realizada a descarga, os veículos seguem direto para a balança. Porém, os veículos de cana inteira passam primeiramente por um processo de limpeza de carroceria, quando restos de cana são retirados do seu interior. Na balança, o caminhão é pesado novamente e retorna ao campo para mais uma viagem (figura 21).
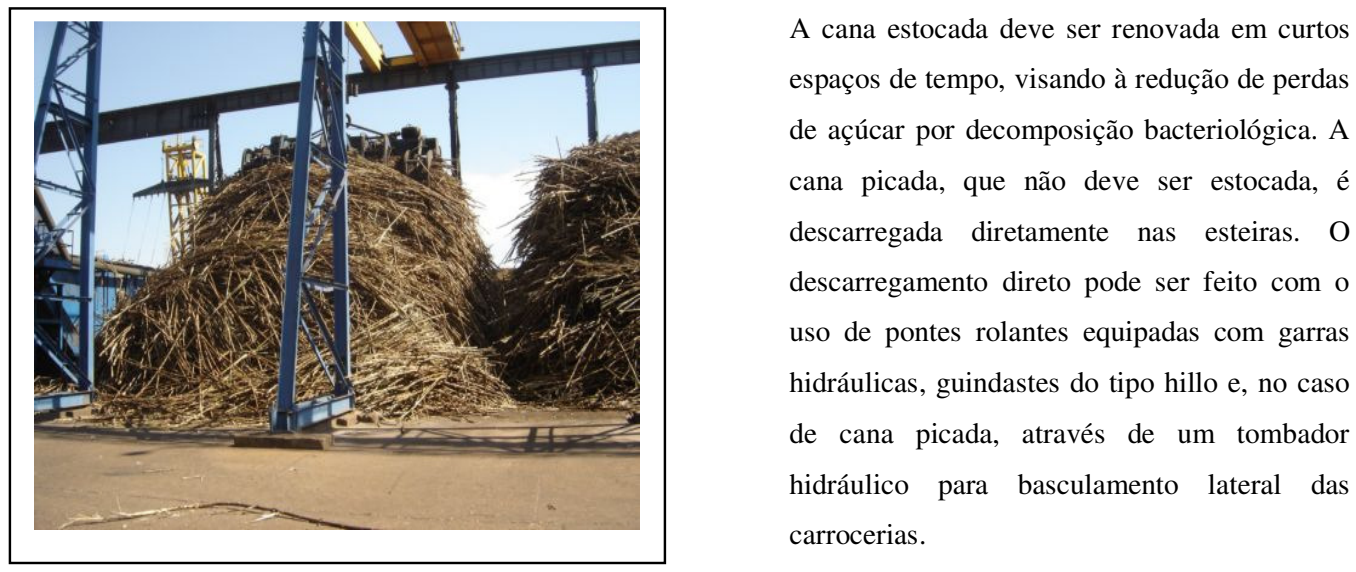

Figura 19. Estoque de cana no pátio da usina

Todo o planejamento do transporte de cana na usina é feito de forma estratégica pelo departamento de trânsito da empresa no início do plantio quando é arrendada uma propriedade. Primeiramente uma equipe formada por três pessoas, um topógrafo e dois auxiliares fazem a demarcação do perímetro do terreno, curvas de níveis, APP (Área de Preservação Permanente) e carreadores, os quais servirão para facilitar o escoamento da matéria prima e as divisões dos talhões (figura 20). 


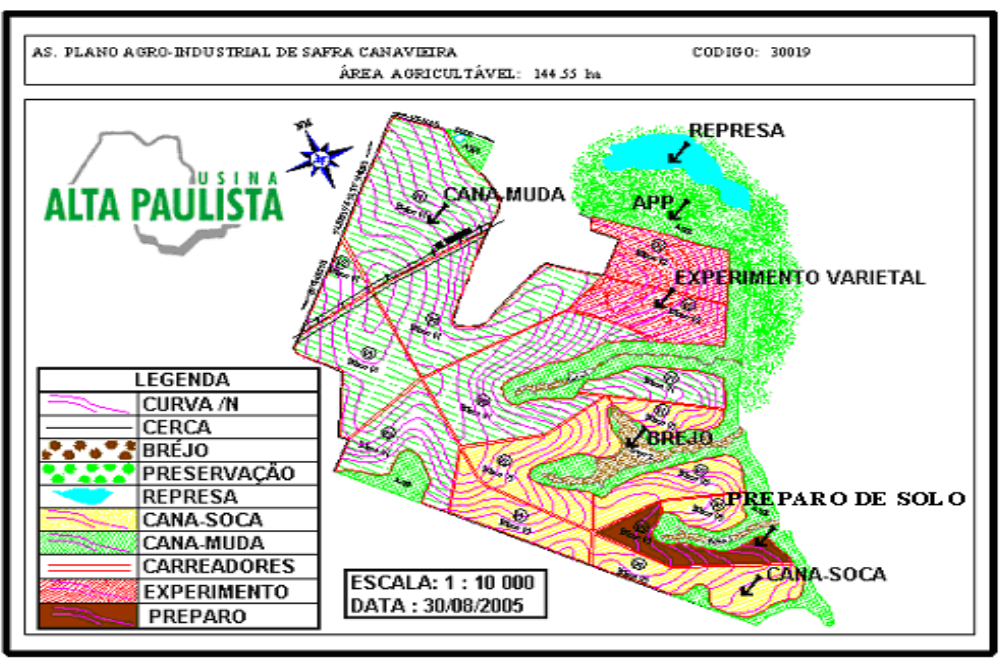

Figura 20. Topografia da área a ser plantada. Fonte: Usina Alta Paulista (2008).

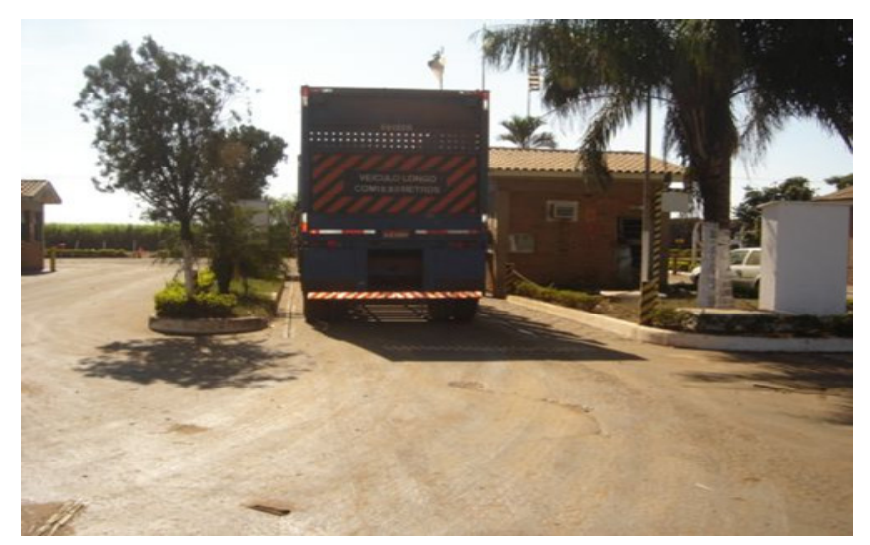

Figura 21. Caminhão voltando para o campo, o que encerra a etapa agrícola.

\subsection{Processos de produção da etapa industrial}

A cana que chega à unidade industrial é processada o mais rápido possível. Este sincronismo entre o corte, transporte e moagem é muito importante, pois a cana é uma matéria-prima sujeita a contaminações e consequentemente de fácil deterioração. No fluxograma a seguir (figura 22) é demonstrado, com apresentação dos centros produtivos, o processo de produção de açúcar e álcool. 


\subsubsection{Fluxograma da Etapa industrial com centros produtivos}

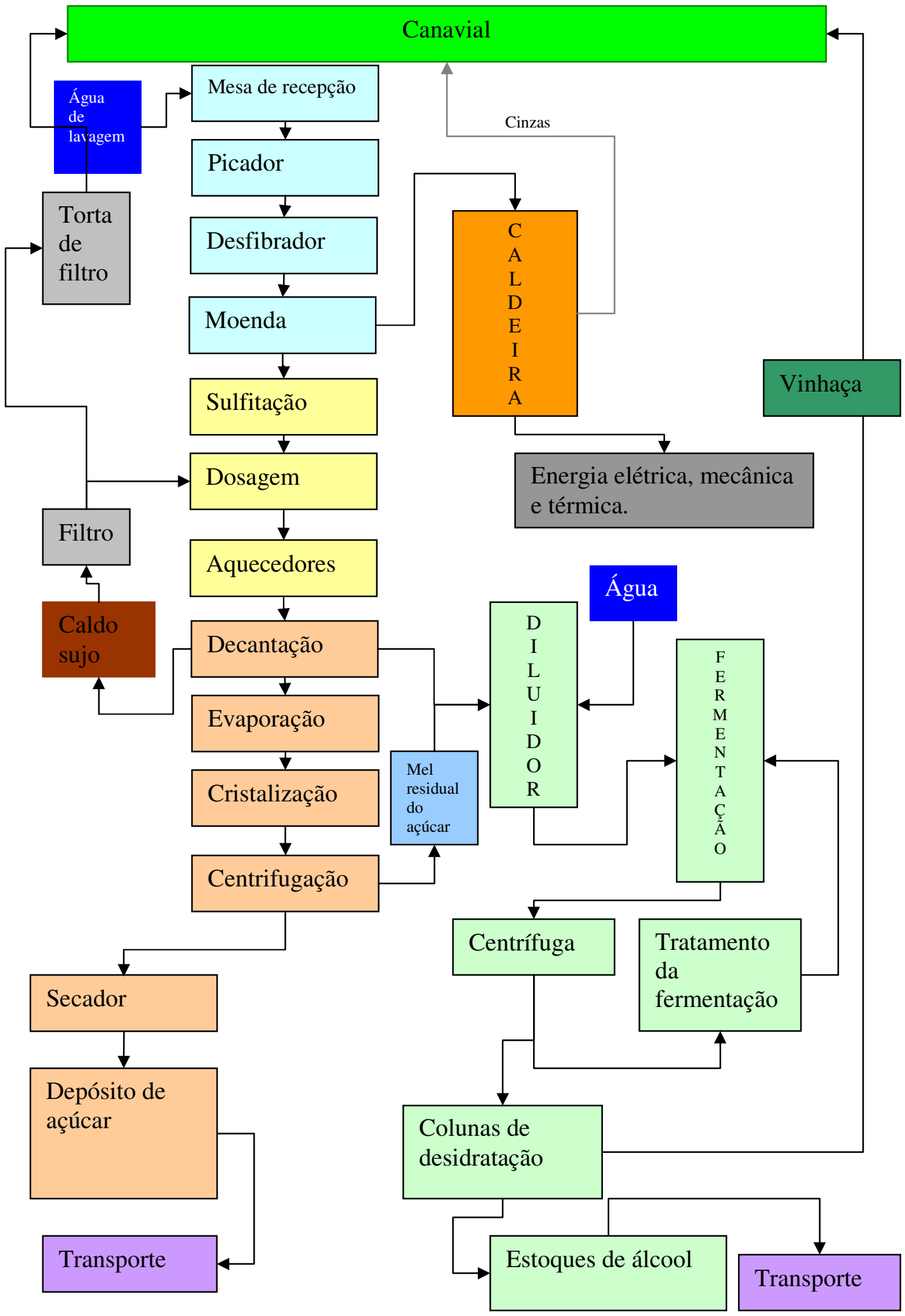

Figura 22. Fluxograma da etapa industrial com centros produtivos 


\subsubsection{Lavagem da cana}

Antes da moagem, a cana inteira é lavada nas mesas alimentadoras para retirar a terra proveniente da lavoura. Após a lavagem, a cana passa por picadores que trituram os colmos, preparando-a para a moagem. Cabe aqui ressaltar que quando a cana colhida é picada esta não passa pelo processo de lavagem indo diretamente para a moenda.

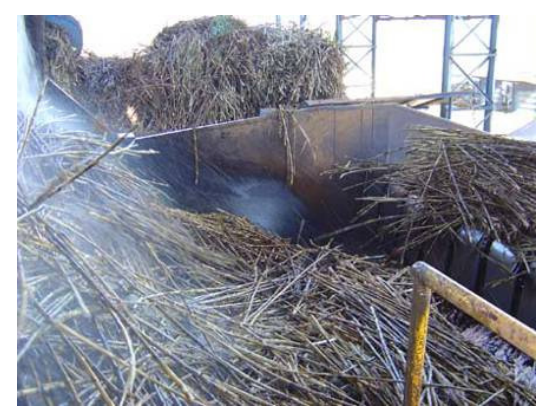

Figura 23. Lavagem da cana

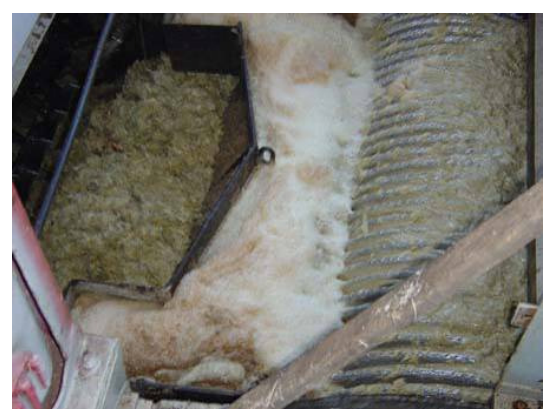

Figura 24. Extração do caldo da cana-de-açúcar

\subsubsection{Moagem}

A cana é constituída basicamente de caldo e fibra, sendo o açúcar dissolvido no caldo. O objetivo principal é extrair a maior parte possível desse caldo. Em escala industrial existem dois processos de extração: a moagem e a difusão. Na Alta Paulista o processo utilizado é o da moagem.

A moagem é um processo estritamente volumétrico e consiste em deslocar o caldo contido na cana. Este deslocamento é conseguido fazendo a cana passar entre dois rolos, submetidos à determinada pressão e rotação, sendo o volume gerado menor que o volume da cana. O excesso volumétrico, desprezando-se o volume de caldo reabsorvido pelo bagaço, deve ser deslocado, correspondendo, portanto, a um volume de caldo extraído.

Um objetivo secundário da moagem, porém importantíssimo, é a produção de um 
bagaço final em condições de propiciar uma queima rápida nas caldeiras. Na primeira unidade de moagem ocorre a maior parte da extração global, simplesmente pelo deslocamento do caldo. A cana tem aproximadamente sete partes de caldo para cada parte de fibra; já no primeiro bagaço essa proporção cai para duas a duas vezes e meia e fica fácil de perceber que, se não utilizarmos algum artifício, logo as moendas posteriores não terão condições de deslocar caldo algum, mesmo que se aumente a pressão na camada de bagaço. $\mathrm{O}$ artifício utilizado é a embebição, que será explicada a seguir.

Cada conjunto de rolos de moenda, montados numa estrutura denominada "castelo", constitui um terno de moenda. O número de ternos utilizados no processo de moagem varia de quatro a sete e cada um deles é formado por três rolos principais denominados: rolo de entrada, rolo superior e rolo de saída. Normalmente as moendas contam com um quarto rolo, denominado rolo de pressão, que melhora a eficiência de alimentação. A carga que atua na camada de bagaço é transmitida por um sistema hidráulico que atua no rolo superior.

\subsubsection{Embebição}

A cana, ao passar sucessivamente pelos vários ternos da moenda, tem o seu caldo removido ou extraído. $\mathrm{O}$ artifício de adicionar água ao bagaço é denominado embebição e tem como finalidade diluir o caldo remanescente no bagaço, aumentando a extração de sacarose.

O processo mais generalizado é a embebição composta, que consiste em adicionar água entre os dois últimos ternos e fazer retornar o caldo extraído deste último para o anterior e assim sucessivamente até o segundo terno.

Normalmente os caldos provenientes dos dois primeiros ternos são misturados e constituem o denominado caldo misto. Com este sistema, consegue-se extração de $92 \%$ a $96 \%$, e umidade final do bagaço de aproximadamente $50 \%$. Durante a passagem da cana pelas moendas ocorre uma queda de fragmentos de cana ou bagaço, denominados bagacilho. A quantidade de bagacilho deve ser controlada periodicamente, uma vez que a queda excessiva indica deficiência no ajuste das moendas.

O bagacilho que deixa as moendas junto com o caldo misto deve ser peneirado e 
retornar ao sistema de moagem, enquanto o caldo misto, já livre do bagacilho, é enviado para o setor de fabricação.

\subsubsection{Geração de vapor e energia}

Após a extração do caldo, obtém-se o material denominado bagaço, constituído de fibra (46\%), água (50\%) e sólidos dissolvidos (4\%). A quantidade de bagaço obtida varia de $240 \mathrm{~kg}$ a $280 \mathrm{~kg}$ de bagaço por tonelada de cana, sendo que o açúcar nele contido representa uma das perdas do processo.

O bagaço alimentará as caldeiras, onde é queimado, e a energia liberada transforma água em vapor. $\mathrm{O}$ vapor gerado nesses equipamentos, com pressão média de 18$21 \mathrm{kgf} / \mathrm{cm}^{2}$ (caldeiras modernas já operam com pressões entre 40 e $100 \mathrm{kgf} / \mathrm{cm}^{2}$ ), é utilizado no acionamento das turbinas a vapor, onde ocorrerá a transformação da energia térmica em energia mecânica.

Estas turbinas são responsáveis pelo acionamento dos picadores, desfibradores, moendas e etc., bem como pelo acionamento dos geradores para a produção da energia elétrica necessária nos vários setores da indústria. $\mathrm{O}$ vapor liberado por estas turbinas é de baixa pressão $\left(1,3-1,7 \mathrm{kgf} / \mathrm{cm}^{2}\right)$ denominado vapor de escape, que é reaproveitado como a energia básica necessária no processo de fabricação de açúcar e de álcool. O total de energia gerado na USALPA é de 2,88 MWh, valor totalmente consumido na própria usina. 


\subsubsection{Fabricação de açúcar}

\section{Tratamento do caldo}

O caldo extraído da moenda, tanto o caldo primário quanto o secundário, são constituídos por impurezas. É necessário que eles passem por um processo de clarificação para retirada de sólidos em suspensão.

Logo após a moagem, o caldo passa por um tratamento de retirada de impurezas através de um aquecimento a uma temperatura de $70^{\circ} \mathrm{C}$. Feito isso, o caldo segue para a torre de sulfitação, onde é colocado para reagir com elementos químicos, produzindo gases anídricos e sulforosos oriundos da queima de enxofre. Esse processo serve para a retirada de colóides (moléculas grandes, ceras e pigmentação) ainda presentes, purificando assim o caldo. Esse processo aumenta sensivelmente a acidez da mistura, que cai para um $\mathrm{Ph}$ 4, sendo que o ideal classifica-se entre 6,9 e 7,2. A reversão nesse índice é feita com aplicação de hidróxido de cálcio, a chamada caiação do processo para aumento do Ph.

Concluídas as etapas de sulfitação e caiação, as máquinas dão seqüência no processo de fabricação do açúcar, levando o caldo para novo aquecimento, dessa vez a uma temperatura de $105^{\circ} \mathrm{C}$. Esse procedimento, que é conhecido como decantação do caldo (figura 24), é feito aplicando-se polímeros e ácido fosfórico para deslocar todos os resíduos sólidos da mistura para o fundo. Nessa etapa, a diferença na coloração do caldo já é visível, deixando seu aspecto original de cor caramelizada. Após a dosagem, o caldo é aquecido a $107^{\circ} \mathrm{C}$ em aquecedores verticais e enviado aos clarificadores, que retêm o caldo por aproximadamente 3 horas em regime contínuo. Neste tempo de retenção, ocorrem reações de floculação e precipitação do material em suspensão, o qual é retirado na forma de lodo. O caldo clarificado e limpo segue o processo para evaporação e o lodo irá para filtração a vácuo, onde é recuperada a sacarose ainda ali existente. Como esse lodo possui altas concentrações de açúcares, palha, terra, cera e outros resíduos provenientes do processo de moagem, o caldo que fica da decantação precisa passar por um filtro rotativo com placas que retêm a passagem desses resíduos, formando uma massa chamada de torta. O caldo recuperado no filtro passa novamente pela decantação e a torta é levada para ser utilizada como adubo orgânico no campo. Por sua composição rica em Fósforo, Potássio e Magnésio, esse composto é usado nas lavouras de cana-de-açúcar da própria usina (figura 25). Para cada tonelada de cana-de- 
açúcar produzida, produzem-se em média $40 \mathrm{~kg}$ de Torta de filtro, segundo os técnicos da fábrica de açúcar. O caldo límpido que agora segue seu caminho para se tornar açúcar precisa passar por dois novos processos denominados de pré-evaporação e evaporação.

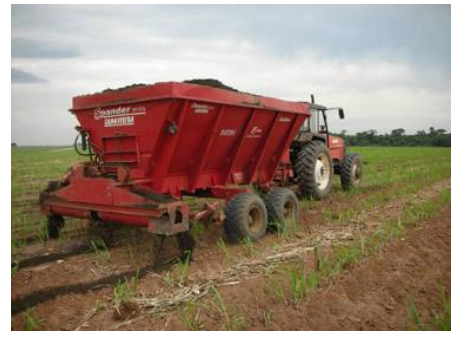

Figura 25. Fertilização da lavoura de cana com torta de filtro proveniente da usina, um aproveitamento de subproduto do processo de fabricação de açúcar e álcool.

\section{Pré-evaporação e Evaporação}

O objetivo agora deixa de ser a purificação e passa a ser o processo de eliminação do excedente de água para aproveitamento da sacarose. O caldo clarificado, com aproximadamente $15^{\circ}$ Brix, entra em um conjunto de evaporadores de múltiplo efeito para a retirada da maior parte da água, concentrando até cerca de $65^{\circ} \mathrm{Brix}$, tomando consistência de um xarope. Este xarope é bombeado aos tachos de cozimento para a cristalização do açúcar (figura 26).

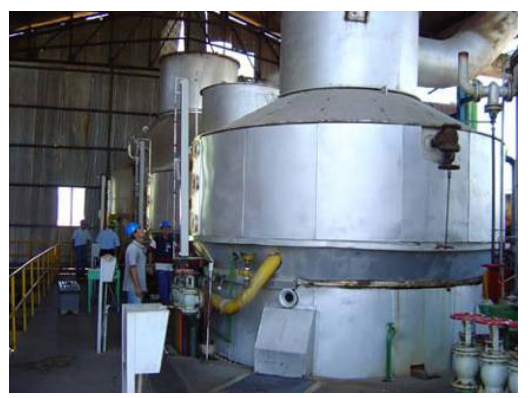

Figura 26. Tacho de cozimento de açúcar

\section{Cozimento da massa A}

Os tachos de cozimento são equipamentos que continuam a evaporação do xarope, tornando o meio supersaturado e propiciando as condições necessárias à cristalização da sacarose. O produto obtido neste cozimento é a massa A. Esta massa A é uma mistura de cristais de açúcar e o seu correspondente licor-mãe (mel), de onde foi obtida a cristalização do açúcar. 


\section{Cozimento da massa B}

No cozimento B é onde se formam os cristais para o cozimento A. Os tachos de cozimento $\mathrm{B}$ recebem o mel A e por um processo de nucleação, produzem-se os pequenos cristais, de modo controlado e padronizado. Este processo é fundamental na qualidade do produto final, onde todos os cristais são induzidos a uma formação conjunta e uniforme, chamado de semeamento total. A massa B, da mesma forma que a massa A, é uma mistura de cristais de açúcar e o seu correspondente licor-mãe (mel) de onde foram obtidos os cristais.

\section{Centrifugação da massa A}

A massa A é um produto que contém cristais de aproximadamente $0,5 \mathrm{~mm}$ envolvidos numa película de mel. Na centrifugação ocorre a separação do mel, denominado mel A, que irá para os tachos de cozimeto $\mathrm{B}$, e açúcar propriamente dito, que é enviado ao secador de açúcar.

\section{Centrifugação da massa $B$}

A massa B é um produto que contém cristais de aproximadamente $0,2 \mathrm{~mm}$ e melaço. $\mathrm{Na}$ centrifugação, os cristais são separados do mel B (ou melaço) onde o magma (cristais de açúcar B) será utilizado como núcleo para o cozimento A e o melaço é enviado para a fabricação do álcool.

\section{Lavagem dos cristais}

Saindo da centrífuga, o açúcar já está quase pronto, mas ainda falta uma última etapa que consiste na lavagem dos cristais com água superaquecida a uma temperatura de $103^{\circ} \mathrm{C}$, procedimento que serve para retirada dos excedentes de mel dos cristais. Conforme ocorreu nas etapas anteriores, o mel volta para a evaporação e o cristal segue para a centrífuga novamente, saindo com umidade próxima de 0,05\%. Aí, o açúcar passa por uma secagem que retira mais $0,02 \%$ de sua umidade. Está pronto assim o açúcar VHP. Para o processo de fabricação do açúcar cristal, a massa vai para um cristalizador em forma de taxo com grandes dimensões, que tem a função de agregar ou desagregar os cristais em diferentes tamanhos, conforme as especificações do comprador.

\section{Secagem do açúcar}

Nesta etapa, o açúcar passa no secador para a retirada da umidade contida nos cristais. Na saída do secador, o açúcar é enviado por esteiras sanitárias até a moega de açúcar (reservatório próprio para açúcar), onde é feito o ensacamento. 


\section{Ensaque, pesagem e armazenamento do açúcar}

Do secador, o açúcar é recolhido a uma moega com fundo afunilado, que o despeja de forma descontínua, diretamente no saco localizado em cima de uma balança, realizando, portanto, a operação de ensaque e pesagem. Máquinas de costura industriais realizam o fechamento do saco, que está pronto para a armazenagem. O açúcar é armazenado em sacos de $50 \mathrm{~kg}$ e em locais previamente determinados, facilitando o controle de qualidade.

Um cuidado muito importante na estocagem é o controle da temperatura, condições de umidade e luminosidade para evitar o empedramento do açúcar. Isso implica naturalmente em mais custos para o mantenedor do estoque.

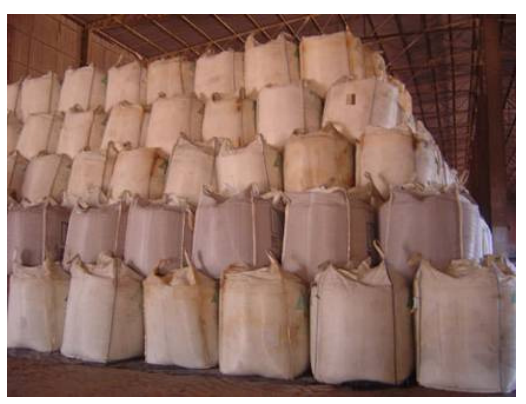

Figura 27. Estocagem do açúcar

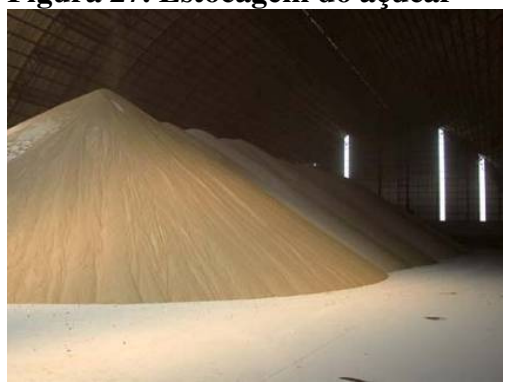

Figura 28. Depósito de açúcar

\section{Produção de açúcar}

A produção diária de açúcar da Usina USALPA gira em torno de 7.000 sacos de $50 \mathrm{~kg}$.

\subsubsection{Fabricação de álcool}

A fabricação de álcool da Usina Alta Paulista ocorre em uma unidade anexa. O processo de moagem de cana é o mesmo já descrito para a fabricação de açúcar.

\section{Tratamento do Caldo}

Parte do caldo é desviada para tratamento específico para fabricação de álcool (a proporção desviada é definida pelos planos de produção de açúcar e álcool definidos semana a semana pela usina). Este tratamento consiste em aquecer o caldo a $105^{\circ} \mathrm{C}$ sem 
adição de produtos químicos, e após isto, decantá-lo. Após a decantação, o caldo clarificado irá para a pré-evaporação e o lodo para novo tratamento, semelhantemente com o que foi feito no lodo do açúcar.

\section{Pré-evaporação}

Na pré-evaporação o caldo é aquecido a $115^{\circ} \mathrm{C}$, evapora água e é concentrado a $20^{\circ}$ Brix. Este aquecimento favorece a fermentação por fazer uma "esterilização" das bactérias e leveduras selvagens que concorreriam com a levedura do processo de fermentação.

\section{Preparo do mosto}

Mosto é o material fermentescível previamente preparado. O mosto na Usina Alta Paulista é composto de caldo clarificado, melaço e água. $\mathrm{O}$ caldo quente que vem do pré-evaporador é resfriado a $30^{\circ} \mathrm{C}$ em trocadores de calor do tipo placas, e enviado às dornas de fermentação. No preparo do mosto definem-se as condições gerais de trabalho para a condução da fermentação, como regulagem da vazão, teor de açúcares e temperatura. Densímetros, medidores de vazão e controladores de Brix automáticos monitoram este processo.

\section{Fermentação}

A fermentação é contínua e feita sob agitação, consistindo de 4 estágios em série, composta de três dornas no primeiro estágio, duas dornas no segundo, uma dorna no terceiro e uma dorna no quarto estágio. Com exceção do primeiro, o restante possui agitador mecânico. As dornas têm capacidade volumétrica de 400.000 litros cada.

É na fermentação que ocorre a transformação dos açúcares em etanol, ou seja, do açúcar em álcool. Utiliza-se uma levedura especial para fermentação alcoólica, a Saccharomyces uvarum. No processo de transformação dos açúcares em etanol há desprendimento de gás carbônico e calor, e, portanto, é necessário que as dornas sejam fechadas para recuperar o álcool arrastado pelo gás carbônico e o uso de trocadores de calor para manter a temperatura nas condições ideais para as leveduras. A fermentação é regulada para 28 a $30^{\circ} \mathrm{C}$. O mosto fermentado é chamado de vinho. Esse vinho contém cerca de 9,5\% de álcool. O tempo de fermentação é de 6 a 8 horas.

\section{Centrifugação do vinho}

Após a fermentação, a levedura é recuperada do processo por centrifugação, em separadores que separam o fermento do vinho. O vinho delevurado irá para os aparelhos de destilação onde o álcool é separado, concentrado e purificado. O fermento, com uma concentração de aproximadamente $60 \%$, é enviado às cubas de tratamento. 


\section{Tratamento do fermento}

A levedura, após passar pelo processo de fermentação, se "desgasta", por ficar exposta a teores alcoólicos elevados. Após a separação do fermento do vinho, o fermento a $60 \%$ é diluído a 25\% com adição de água. Regula-se o pH em torno de 2,8 a 3,0 adicionandose ácido sulfúrico que também tem efeito desfloculante e bacteriostático. O tratamento é contínuo e tem um tempo de retenção de aproximadamente uma hora. O fermento tratado volta ao primeiro estágio para começar um novo ciclo fermentativo; eventualmente é usado bactericida para controle da população contaminante. Nenhum nutriente é usado em condições normais.

\section{Destilação propriamente dita}

A destilação é processada em três colunas superpostas. Nestas, o etanol é separado do vinho (inicialmente com $7^{\circ}$ a $10^{\circ} \mathrm{GL}$ ) e sai com a flegma (vapores com $40^{\circ} \mathrm{GL}$ a $50^{\circ} \mathrm{GL}$ ). O tronco de destilação elimina ainda impurezas (ésteres e aldeídos). O vinho é alimentado no topo da primeira coluna, descendo pelas bandejas e sofrendo a epuração (o mesmo que destilação), sendo a flegma retirada no fundo desta coluna e enviada à segunda coluna. Os voláteis, principalmente ésteres e aldeídos, são concentrados na terceira coluna e retirados no seu topo, sendo condensados em dois condensadores, onde uma fração deste líquido (90\% a 95\%) retorna ao topo dessa mesma coluna e a outra é retirada como álcool de $2^{\mathrm{a}}$, com graduação de aproximadamente $92^{\circ} \mathrm{GL}$, ou retornado à dorna volante. Uma coluna tem por finalidade esgotar a maior quantidade possível de álcool do seu produto de fundo, que é denominado vinhaça. A vinhaça, retirada em uma proporção aproximada de 13 litros para cada litro de álcool produzido, é constituída principalmente de água, sais sólidos em suspensão e solúveis e é utilizada na lavoura como fertilizante, sendo seu calor parcialmente recuperado pelo vinho em um trocador de calor. A sua graduação alcoólica não deve ser superior a $0,03^{\circ} \mathrm{GL}$.

Os voláteis retirados no topo da segunda coluna passam por uma sequência de condensadores onde parte do calor é recuperada pelo vinho, uma fração do condensado é reciclada e outra retirada como álcool de $2^{\mathrm{a}}$. Do fundo da segunda coluna é retirada uma solução aquosa chamada flegmaça, que foi esgotada e que pode ser reciclada no processo ou eliminada. Os álcoois homólogos superiores, denominados óleos fúsel e alto, são retirados de bandejas próximas à entrada da flegma. O óleo alto retorna à dorna volante e o óleo fúsel é resfriado, lavado, decantado e armazenado para posterior 
comercialização. O aquecimento da coluna é realizado pela injeção de vapor, como na epuração. A última etapa no processo consiste na desidratação do álcool hidratado para formação do álcool anidro ou etanol de $99,5^{0} \mathrm{GL}$, praticamente isento de água. O álcool anidro é atualmente um produto de destaque nas exportações do setor sucroalcoleiro.

\section{Armazenagem do álcool}

Os álcoois produzidos, hidratado e anidro, são quantificados através de medidores de vazão ou tanques calibrados e resfriados em trocadores de calor para que possam ser enviados para armazenagem em tanques próprios de grande volume, situados em parques de tanques, onde aguardam sua comercialização e posterior remoção por caminhões. Algumas usinas também optam por armazenar parte do álcool produzido em tanques de terceiros aguardando assim o melhor momento para a venda. O cuidado com controle de corrosão dos tanques é fundamental para evitar a contaminação do álcool e alteração das características do produto produzido.

\subsection{Dinâmicas da etapa comercial}

\subsubsection{O departamento comercial das usinas}

Para melhor entendimento da dinâmica de funcionamento da etapa de comercialização dos produtos nas usinas de açúcar e álcool, dá-se a seguir o significado de algumas expressões corriqueiramente utilizadas pelo setor.

- Mercado Spot: trata-se do mercado consumidor com o qual as usinas ou mantêm contratos de fornecimento ou negociam diretamente sua produção com os preços vigentes na época da negociação. Nesses termos, a negociação pode ocorrer em mercado interno ou mercado externo, daí as denominações Mercado Spot Interno e Mercado Spot Externo.

- Corretoras: empresas especializadas nas intermediações nacionais ou internacionais das negociações dos produtos fabricados pelas usinas. Muitas vezes cobram uma porcentagem de corretagem sobre os valores negociados e prestam serviços também de análise de tendências de preços de açúcar e álcool nos mercados consumidores.

- Contratos futuros: contratos que são firmados entre as usinas e empresas compradoras pelo qual são fixados preços de venda, quantidade comercializada, nível de qualidade dos produtos comercializados, prazos de entrega e locais de retirada.

- Contratos futuros BM\&F: contratos futuros que são regidos pelas regras e estatutos da Bolsa de mercadorias e Futuros. 
- Contratos futuros ESALQ: contratos futuros que seguem os indicadores de preços da ESALQ (Escola Superior de Agronomia Luiz de Queiroz) e podem ser regidos pelas regras da $\mathrm{BM} \& \mathrm{~F}$.

Nas usinas que comercializam sua produção, pode-se afirmar de forma simplificada que o fluxograma de comercialização de seus produtos ocorre como na figura 29:

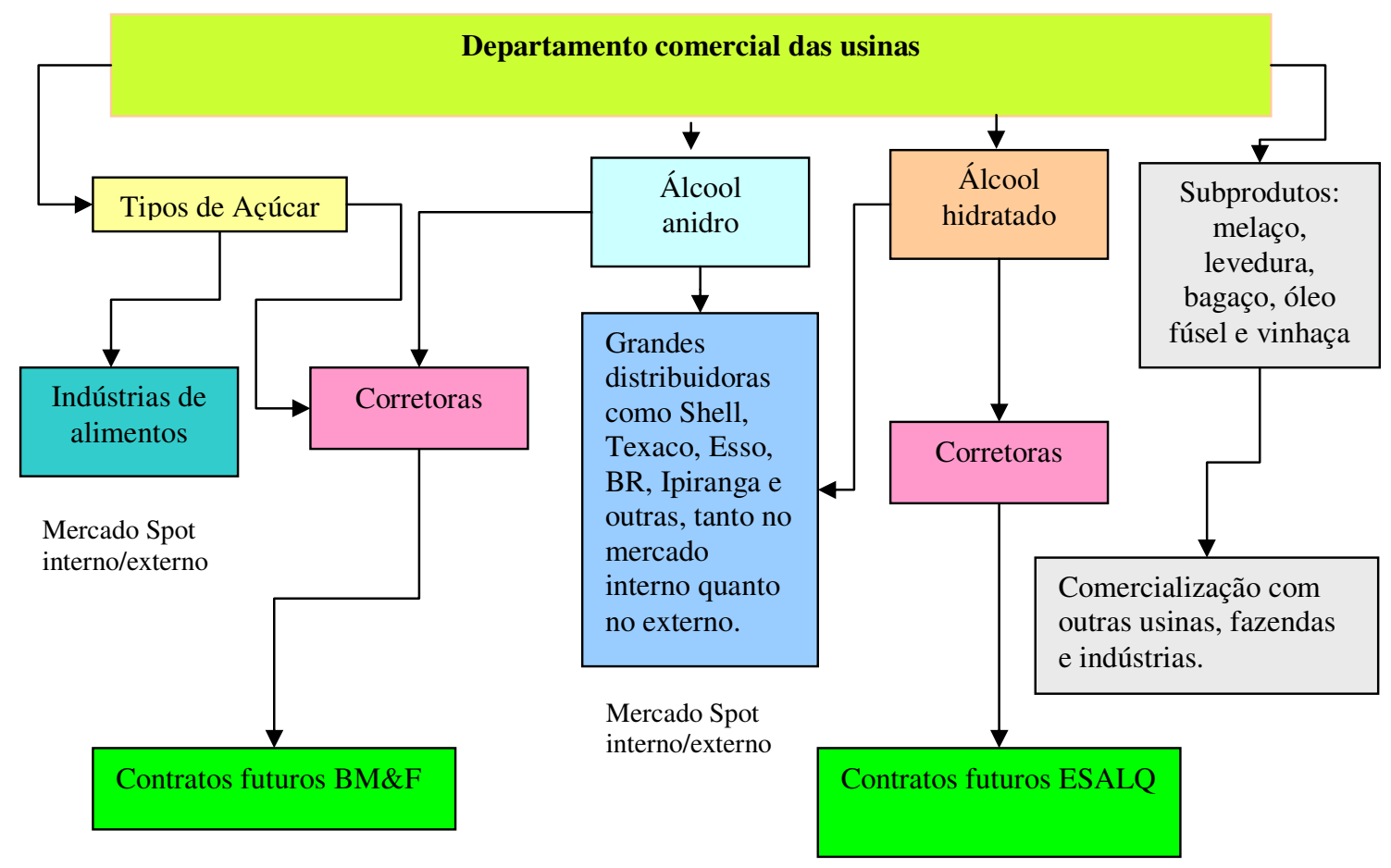

Figura 29. O funcionamento do departamento comercial das usinas de açúcar e álcool

Importantes decisões nesta etapa referem-se a quanto destinar de cada produto comercializado para o mercado à vista tanto interno quanto externo e quanto destinar para o mercado futuro de maneira a se aproveitar as melhores condições de preços de venda no mercado e cumprir com as obrigações de pagamentos. Observam-se também decisões referentes a quanto de cada produto deve ser estocado aguardando uma alta em seus preços, o que certamente interfere na distribuição de lucros e custos na fase de comercialização. Tem-se assim um importante elo entre as decisões comerciais a se tomar e as decisões de planejamento, programação e controle da produção. Dessa forma, departamentos industriais e comerciais devem estar em constante sintonia para que se consiga chegar ao ótimo da solução previsto pelo modelo. 
Isso tudo no meio sucroalcooleiro é feito em grande parte com o auxílio de corretoras, consultorias comerciais especializadas e também através da experiência e sensibilidade dos gestores das usinas. Mas em muitas situações ocorre um desbalanceamento entre o que o setor comercial deseja como plano de negócio e o que os setores industrial e agrícola conseguem fornecer dos produtos requeridos a custos competitivos e no tempo e quantidades corretos. Na presente dissertação procura-se um modelo de otimização que integre as etapas agrícola, industrial e comercial maximizando o lucro das unidades empresariais.

No fluxo de operações (figura 30), os vendedores (no caso as usinas), autorizam as ordens de venda de açúcar e álcool para suas corretoras, definindo quantidades e prazos de entrega. As corretoras repassam as ordens de venda das quantidades estipuladas de açúcar e álcool para os operadores dos pregões na BM\&F, os quais negociam a venda. A corretora identifica os clientes compradores e formaliza a compra junto à $B M \& F$. Assim, ambas as partes, comprador e vendedor, estão garantidos em preço pela instituição. Então as corretoras recebem o valor da transação, debitam as taxas de corretagem (que nesta dissertação são chamadas de taxas de comercialização) e transferem o resultado para as usinas.

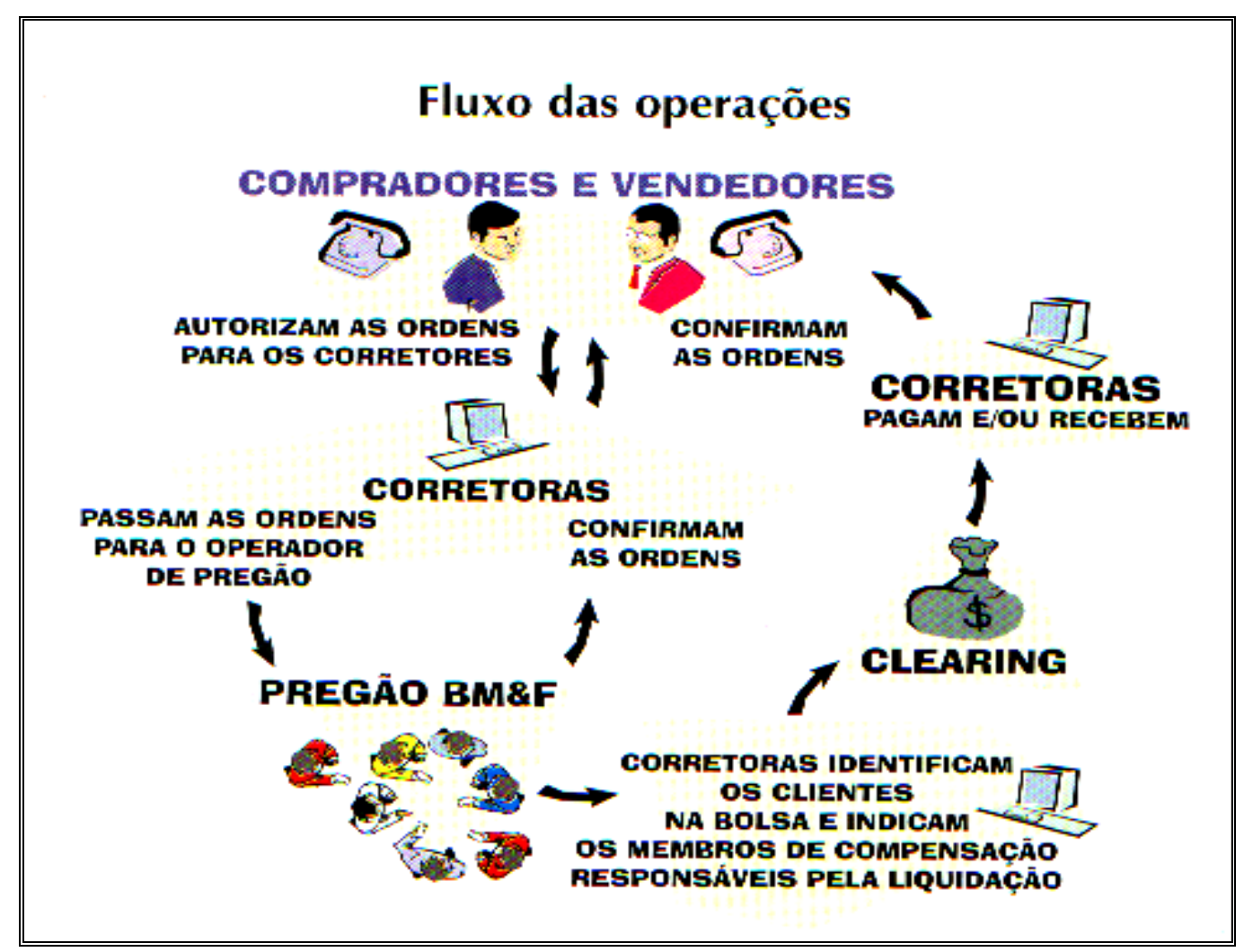

Figura 30. Operações de compra e venda no pregão da BM\&F. Fonte: Marques et al (2006) 
$\mathrm{Na}$ figura 30, CLEARING se refere a câmaras ou prestadoras de serviços de compensação e liquidação de ordens eletrônicas de débito e crédito. Essas câmaras realizam a compensação multilateral das obrigações entre os participantes. Compensação multilateral é o procedimento destinado à apuração das somas dos resultados bilaterais devedores e credores de cada participante em relação aos demais.

\subsubsection{Negociação de açúcar e álcool em mercados futuros}

O processo de livre negociação nos mercados de açúcar e álcool no Brasil remonta ao início dos anos 1990, quando da extinção do Instituto do Açúcar e do Álcool (IAA), órgão governamental que regulava o complexo industrial sucroalcooleiro e promovia estímulos à produção de álcool. A finalidade do IAA era assegurar o equilíbrio interno no fornecimento de açúcar e fomentar a fabricação de álcool, devido à alta dos preços do petróleo no mercado internacional.

Em 1995, a BM\&F, em sintonia com o setor sucroalcooleiro, lançou o contrato futuro de açúcar cristal. Há contratos futuros em negociação nos Estados Unidos (New York Board of Trade) e na Europa (Euronext.Liffe), mas com base em açúcar Demerara e refinado, respectivamente. Vale ressaltar que o açúcar negociado na BM\&F é o cristal especial, que é de qualidade superior ao Demerara e inferior à do refinado.

No ano 2000, a Bolsa colocou em mercado o contrato futuro de álcool anidro carburante, o primeiro contrato derivativo dessa commodity no mundo. Em março de 2005, a Chicago Board of Trade introduziu o contrato futuro de etanol ("Futuro de açúcar e álcool”, BM\&F, Relatório técnico, 2007).

Antes da década de 90, esse tipo de transação financeira não era necessário, pois os preços eram tabelados pelo Estado e, assim, não havia como tentar evitar os riscos das variações de preços. Os contratos futuros mudaram essa dinâmica comercial.

Os contratos futuros de açúcar e álcool são padronizados. Cada contrato de açúcar cristal corresponde a 270 sacas de $50 \mathrm{~kg}$, com qualidade e locais de entrega prédeterminados pela BM\&F. Já cada contrato de álcool anidro carburante corresponde a $30 \mathrm{~m}^{3}$, também com qualidade e locais de entrega pré-determinados pela Bolsa.

Os mercados futuros de açúcar e álcool constituem-se em ferramentas extremamente úteis na administração dos estoques e fluxo de caixa das usinas, que reconhecem a enorme utilidade das operações de hedge para o gerenciamento dos riscos da atividade. Muitas usinas possuem seu próprio departamento comercial, outras delegam a maior parte dessa atividade a empresas especializadas e muitas outras usinas ainda não fazem uso dos contratos futuros e podemos discutir algumas hipóteses para essas escolhas. 
Uma delas seria a falta de conhecimento dos possíveis operadores (produtores) com relação aos mercados futuros, aliada à fragilidade de divulgação dos mercados de derivativos agrícolas no país. A maioria dos nossos produtores ainda sente dificuldade na hora da negociação e não compreende bem a lógica dos mercados de derivativos, preferindo manter operações financeiras mais tradicionais a direcionar recursos para o mercado futuro, no qual ou não confiam ou não entendem muito bem seu funcionamento.

O foco desta dissertação recai sobre as usinas que negociam diretamente seus produtos com o mercado sem a intermediação de consórcios de negociação, como cooperativas e pool de usinas, ou seja, elas mesmas negociam as quantidades vendidas de seus produtos e tratam em que tempo vendê-las.

\subsubsection{A operação dos contratos futuros de álcool anidro (hedge da venda de álcool)}

Suponha-se uma usina que defina seu planejamento de produção de álcool anidro no começo da safra de cana-de-açúcar (março). Dentro de seu processo de programação da produção, estabeleceu, por exemplo, que produzirá no mês de setembro $30.000 \mathrm{~m}^{3}$ de álcool anidro. Como não pretende correr risco de preço, a usina consulta sua corretora quanto à cotação do álcool anidro na BM\&F para o vencimento em setembro, visando realizar uma operação de proteção de preço no mercado futuro de álcool.

No pregão da Bolsa, a cotação do produto para aquele vencimento é: oferta compradora por $\mathrm{R} \$ 800,00 / \mathrm{m}^{3}$ e oferta vendedora por $\mathrm{R} \$ 810,00 / \mathrm{m}^{3}$, com o último negócio fechado em $\mathrm{R} \$ 805,00$.

Como o preço praticado cobre seu custo de produção e ainda lhe proporciona algum lucro, em março a usina transmite ordem à corretora para vender 1.000 contratos futuros de álcool para o vencimento em setembro, a preço de mercado. A corretora fecha o negócio por $\mathrm{R} \$ 805,00 / \mathrm{m}^{3}$. Como cada contrato futuro equivale a $30 \mathrm{~m}^{3}$ de álcool, a venda de 1.000 contratos visa proteger os $30.000 \mathrm{~m}^{3}$ que a usina pretende produzir em setembro. Esta é a operação típica de hedge, ou seja, independentemente do que ocorrer no mercado de álcool até o vencimento do contrato futuro, a usina assegurou previamente seu preço de venda (adaptado de "Futuros de açúcar e álcool", BM\&F, Relatório técnico, 2007).

Como ocorre variação nos preços de açúcar e álcool em cada semana e também variação nos custos de produção dos mesmos produtos, a usina procura "hedgear" quantidades mais elevadas dos produtos que contribuem com a maior margem. 


\subsubsection{A operação dos contratos futuros de açúcar (hedge de venda de açúcar)}

Suponha que uma usina de açúcar e álcool tenha custo de produção de US $\$ 5,00 /$ saca de açúcar cristal e que queira fazer proteção de preço de uma carga de 54.000 sacas. Como não deseja correr risco de preço da commodity nos períodos futuros, nem da variação cambial, alguns fatores de risco terão de ser administrados.

Para neutralizar o risco de preço da commodity, a usina utilizará o mercado futuro de açúcar cristal e, para “hedgear” o efeito da variação cambial, utilizará o contrato futuro de taxa de câmbio de reais por dólar.

Logicamente, são diferentes os períodos de tempo entre a fabricação do açúcar e a venda efetiva do produto no mercado.

A situação de risco da usina pode residir na queda do preço do açúcar cristal e na valorização do real. Por conseguinte, a usina pode decidir fazer uma operação de hedge na BM\&F contra as oscilações adversas de preços do açúcar e da taxa cambial, com as seguintes cotações nos respectivos mercados futuros:

- açúcar cristal = US\$10,00/saca

- dólar = R \$3,10/US\$1,00

Com o hedge de venda de contratos futuros de açúcar cristal por US\$10,00/saca, a usina trava sua rentabilidade em US\$5,00 (pois seu custo de produção foi de US\$5,00). Essa trava é equivalente a US\$540.000,00 (54.000 sacas de açúcar $\times$ US\$10,00). Mas esse valor também está sujeito a risco, pois, dependendo da evolução do câmbio até a ocasião do faturamento, a operação poderá reduzir sua lucratividade em reais.

Logo, o hedge no mercado futuro se resume à venda de 200 contratos futuros de açúcar cristal por US $\$ 10,00 /$ saca e à venda de aproximadamente 11 contratos futuros de dólar (cada contrato é de US\$50.000,00) por R $\$ 3,10$ o dólar.

O hedge da usina em reais será, então, de:

$540.000 \times 3,10=\mathrm{R} \$ 1.674 .000,00$

Admite-se, agora, que, no momento do faturamento, os preços do açúcar e do câmbio estejam nos seguintes patamares: o do açúcar em US\$8,00/saca e o do dólar na razão $\mathrm{R} \$ 2,90 / \mathrm{US} \$ 1,00$.

No mercado futuro, os ajustes diários acumulados totalizariam:

- açúcar $=(10,00-8,00) \times 270 \times 200 \times 2,90=R \$ 313.200,00$

- dólar $=(3,10-2,90) \times 50.000 \times 11=\mathrm{R} \$ 110.000,00$

O faturamento da venda do açúcar no mercado físico seria de 8,00 $\times 54.000 \times 2,90=$ $\mathrm{R} \$ 1.252 .800,00$. 
O resultado consolidado global da operação da empresa (receita de faturamento + ganho no futuro de dólar + ganho no futuro de açúcar) seria de $\mathrm{R} \$ 1.252 .800,00$ + $\mathrm{R} \$ 110.000,00+\mathrm{R} \$ 313.200,00$, totalizando $\mathrm{R} \$ 1.676 .000,00$.

Como pode ser verificado, o valor de faturamento é praticamente igual ao valor “hedgeado". A diferença de $\mathrm{R} \$ 2.000,00$ deve-se à aproximação do número de contratos vendidos no contrato futuro de taxa de câmbio (adaptado de "Futuro de açúcar e álcool, Relatório técnico, BM\&F”, 2007).

\subsubsection{A operação de comercialização de álcool hidratado}

A maioria das usinas comercializa diretamente o álcool hidratado com grandes distribuidoras, como Shell, Texaco, BR, Esso, Ipiranga e outras. Existem contratos de entrega com preços e qualidade fixados pelos índices da ESALQ/BM\&F sendo os cálculos para ajustes de preços realizados da mesma forma como efetuados no caso do álcool anidro na BM\&F.

Embora não haja oficialmente contratos futuros para álcool hidratado negociados na $\mathrm{BM} \& \mathrm{~F}$, nesta dissertação esses contratos terão comportamento de mercado futuro como no caso de álcool anidro, já que seguem as mesmas regras do último na comercialização quando efetuados através de contratos particulares. 


\section{REVISÃO BIBLIOGRÁFICA E REFERENCIAL TEÓRICO}

\subsection{Referencial teórico relativo às etapas CCT (carregamento, corte e transporte) e industrial}

No Brasil, principalmente a partir da década de 90, com a desregulamentação do setor, pode-se perceber o surgimento de algumas contribuições acadêmicas para melhorias de processos e redução de custos em usinas de açúcar e álcool. Nesta seção, são destacados principalmente os trabalhos relacionados aos métodos quantitativos desenvolvidos na indústria sucroalcooleira. A tabela $2 \mathrm{~A}$ relaciona trabalhos desenvolvidos sobre o tema.

Tabela 2A. Referencial teórico relativo às etapas CCT e industrial

\begin{tabular}{|c|c|c|c|}
\hline Autores & Tipo de problema estudado & Variáveis & $\begin{array}{l}\text { Método } \\
\text { empregado }\end{array}$ \\
\hline Barata (1992) & $\begin{array}{l}\text { Corte e reforma de canaviais. } \\
\text { Avaliação técnico-econômica. }\end{array}$ & $\begin{array}{l}\text {-Talhões, época da } \\
\text { reforma e do corte e área } \\
\text { plantada. }\end{array}$ & $\begin{array}{l}\text { Programação } \\
\text { linear }\end{array}$ \\
\hline $\begin{array}{l}\text { Mathew \& } \\
\text { Rajendram } \\
\text { (1993) }\end{array}$ & $\begin{array}{l}\text { Manutenção em usinas de açúcar e } \\
\text { álcool na Austrália }\end{array}$ & $\begin{array}{l}\text {-Intervalo entre paradas } \\
\text { para manutenção }\end{array}$ & $\begin{array}{l}\text { Simulação } \\
\text { discreta. }\end{array}$ \\
\hline Grisotto (1995) & Transporte rodoviário de cana. & $\begin{array}{l}\text {-Tipos de caminhões e } \\
\text { capacidades. }\end{array}$ & $\begin{array}{l}\text { Programação } \\
\text { linear }\end{array}$ \\
\hline $\begin{array}{l}\text { Yoshizaki et al. } \\
\text { (1996) }\end{array}$ & $\begin{array}{l}\text { Distribuição de álcool no sudeste } \\
\text { do Brasil. }\end{array}$ & $\begin{array}{l}\text {-Capacidades de } \\
\text { caminhões, pontos de } \\
\text { transbordo, rotas. }\end{array}$ & $\begin{array}{l}\text { Programação } \\
\text { linear }\end{array}$ \\
\hline Yamada (1999) & $\begin{array}{l}\text { Atividades produtivas nas usinas de } \\
\text { açúcar e álcool. }\end{array}$ & $\begin{array}{l}\text {-Seqüiências dos processos } \\
\text { nas etapas de produção de } \\
\text { açúcar e álcool. }\end{array}$ & $\begin{array}{l}\text { Redes de Petri } \\
\text { atemporizadas }\end{array}$ \\
\hline $\begin{array}{l}\text { Colin et al. } \\
\text { (1999) }\end{array}$ & $\begin{array}{l}\text { Distribuição e armazenamento de } \\
\text { açúcar considerando um depósito } \\
\text { central e vários secundários. }\end{array}$ & $\begin{array}{l}\text {-Tipos de caminhões, } \\
\text { locais de transbordo e } \\
\text { localização de depósitos. }\end{array}$ & $\begin{array}{l}\text { Programação } \\
\text { linear }\end{array}$ \\
\hline Saito (2000) & $\begin{array}{l}\text { Cadeia agroindustrial da cana-de- } \\
\text { açúcar }\end{array}$ & $\begin{array}{l}\text {-Variáveis de oferta e } \\
\text { demanda e Efeito } \\
\text { Forrester }\end{array}$ & $\begin{array}{l}\text { Simulação com } \\
\text { sistemas } \\
\text { dinâmicos. }\end{array}$ \\
\hline $\begin{array}{l}\text { Cock et al. } \\
(2000)\end{array}$ & $\begin{array}{l}\text { Escolha de variedades de cana-de- } \\
\text { açúcar para plantio. }\end{array}$ & $\begin{array}{l}\text {-Custos das variedades de } \\
\text { cana-de-açúcar. }\end{array}$ & $\begin{array}{l}\text { Estudo } \\
\text { metodológico }\end{array}$ \\
\hline
\end{tabular}


Tabela 2A. Referencial teórico relativo às etapas CCT e industrial (continuação)

\begin{tabular}{|c|c|c|c|}
\hline $\begin{array}{l}\text { Autores do } \\
\text { estudo }\end{array}$ & $\begin{array}{l}\text { Tipo de problema } \\
\text { estudado }\end{array}$ & Variáveis em jogo & $\begin{array}{l}\text { Método } \\
\text { empregado }\end{array}$ \\
\hline $\begin{array}{l}\text { Caixetta } \\
\text { Filho et al. } \\
(2002)\end{array}$ & $\begin{array}{l}\text { Planejamento } \\
\text { agrícola/comercial numa } \\
\text { propriedade de cultivo de } \\
\text { lírios. }\end{array}$ & $\begin{array}{l}\text {-Época de plantio, quantidade de } \\
\text { bulbos a comprar, quantidade de } \\
\text { bulbos a se plantar. }\end{array}$ & $\begin{array}{l}\text { Programação } \\
\text { linear }\end{array}$ \\
\hline $\begin{array}{l}\text { Caliari et al. } \\
\text { (2005) }\end{array}$ & $\begin{array}{l}\text { Colheita da cana-de-açúcar } \\
\text { com ênfase na recuperação } \\
\text { máxima de açúcar }\end{array}$ & $\begin{array}{l}\text {-Indicadores de produtividade da } \\
\text { cana-de-açúcar e tempo de colheita. }\end{array}$ & $\begin{array}{l}\text { Programação } \\
\text { matemática e } \\
\text { Simulação }\end{array}$ \\
\hline $\begin{array}{l}\text { Iannoni e } \\
\text { Morabito } \\
\text { (2006) }\end{array}$ & Transporte de cana & $\begin{array}{l}\text {-Variáveis relacionadas ao sistema de } \\
\text { recepção de cana nas usinas. }\end{array}$ & $\begin{array}{l}\text { Simulação } \\
\text { discreta }\end{array}$ \\
\hline $\begin{array}{l}\text { Paiva } \\
(2006)\end{array}$ & $\begin{array}{l}\text { Planejamento agregado da } \\
\text { produção numa usina de } \\
\text { açúcar e álcool }\end{array}$ & $\begin{array}{l}\text {-Quantidade de caminhões, tipos de } \\
\text { fornecedores de cana, tipos de } \\
\text { processos industriais de produção, } \\
\text { tipos de estocagem de açúcar e } \\
\text { álcool. }\end{array}$ & $\begin{array}{l}\text { Programação } \\
\text { linear }\end{array}$ \\
\hline $\begin{array}{l}\text { Higgins } \\
(2006)\end{array}$ & $\begin{array}{l}\text { Integração do corte de cana } \\
\text { com o transporte até a usina. }\end{array}$ & $\begin{array}{l}\text {-Talhões, tipos de caminhões, } \\
\text { estoque de cana. }\end{array}$ & $\begin{array}{l}\text { Programação } \\
\text { linear }\end{array}$ \\
\hline $\begin{array}{l}\text { Torres et al. } \\
\text { (2007) }\end{array}$ & $\begin{array}{l}\text { Planejamento agregado da } \\
\text { produção numa usina de } \\
\text { açúcar e álcool em Cuba. }\end{array}$ & $\begin{array}{l}\text {-Quantidade para venda de açúcar e } \\
\text { álcool, custos de produção. }\end{array}$ & $\begin{array}{l}\text { Programação } \\
\text { linear }\end{array}$ \\
\hline $\begin{array}{l}\text { Paiva } \\
(2009)\end{array}$ & $\begin{array}{l}\text { Planejamento agregado da } \\
\text { produção em usinas do setor } \\
\text { sucroenergético. }\end{array}$ & $\begin{array}{l}\text { Tipos de processos industriais de } \\
\text { produção, tipos de estocagem de } \\
\text { açúcar e álcool, aproveitamento } \\
\text { comercial da co-geração de energia. }\end{array}$ & $\begin{array}{l}\text {-Programação } \\
\text { linear } \\
\text {-Otimização } \\
\text { robusta }\end{array}$ \\
\hline
\end{tabular}

Analisando as publicações acima, percebe-se que existe um esforço constante e crescente em desenvolver e aplicar modelos e métodos quantitativos para auxiliar nas principais operações do setor sucroalcooleiro. Em frequência bastante elevada estão os modelos de planejamento da colheita, modelo de programação do transporte de cana, de distribuição e armazenagem de açúcar e álcool e de programação da reforma do canavial. A maioria desses trabalhos está voltada para a etapa agrícola, etapa de corte, carregamento e transporte (CCT) e localizações de estoque de produtos finais. No artigo de Caliari et al. (2005) ocorre a maximização da produção de açúcar por área colhida 
através de simulação da colheita da cana-de-açúcar com ajuda de programação matemática.

$\mathrm{Na}$ etapa industrial, os esforços que vêm sendo empregados para modelar o processo de produção de açúcar, álcool e subprodutos estão mais restritos às áreas da engenharia química, engenharia de alimentos e engenharia elétrica. Estes estudos estão focados na representação das transformações químicas e físicas que acontecem nas diversas operações unitárias de produção de açúcar e álcool, embasando análises de investimentos e de melhorias de projetos de equipamentos (PAIVA, 2006).

No entanto, existe uma carência de trabalhos que utilizem modelos e métodos quantitativos no estudo das inter-relações dos processos produtivos na cadeia de produção de uma usina de açúcar e álcool que cheguem até a etapa comercial. Percebese assim a importância de se desenvolver e aplicar modelos quantitativos de planejamento da produção e otimização de portfólios de forma mais agregada nos processos, para que se possa atingir, da melhor forma possível, os objetivos de maximização da margem de contribuição agroindustrial/comercial das usinas. Ao se levar em conta a etapa de comercialização, a carência de trabalhos fica ainda mais evidente. Comercializar bem o açúcar e o álcool significa definir quantidades ótimas de produção e estoque desses produtos nos períodos de safra, entressafra e períodos futuros sujeitos às variações de preços dos mercados com os quais as usinas trabalham, definir qualidade e quantidade da matéria-prima, capacidade de produção, fluxo de caixa etc. No entanto, os trabalhos publicados não fazem a integração da etapa comercial com as demais etapas do processo produtivo. Cabe ressaltar que em Paiva e Morabito (2006) ocorre um grande delineamento do planejamento agregado da produção fazendo interação entre variáveis do campo e industrial. Em Torres et al. (2007) é feita uma abordagem técnico-econômica sobre a produção de açúcar, álcool e energia numa usina sucroalcooleira em Cuba visando maximizar o lucro de acordo com o mix de produção. No entanto, são fixados vários custos de produção e preços de açúcar e álcool, o que limita a análise realizada.

Já na tese de doutorado de Paiva (2009) faz-se uma análise detalhada de processos de produção de açúcar, álcool, melaço e energia elétrica, estabelecendo-se planejamento hierárquico entre usinas cooperadas e planejamento tático de uma das cooperadas. Explora-se também a aplicação de técnicas de otimização robusta para tratar incertezas inerentes aos parâmetros utilizados nos processos decisórios da cooperativa e de cada usina. O presente trabalho pretende fazer uma integração do processo produtivo 
agroindustrial de açúcar e álcool com a etapa de comercialização visando a maximização da margem de contribuição agroindustrial de uma usina de açúcar e álcool.

\subsection{Referencial teórico relativo à etapa comercial}

Tabela 2B. Referencial teórico relativo à etapa comercial

\begin{tabular}{|c|c|c|c|}
\hline Autores do estudo & $\begin{array}{l}\text { Tipo de problema } \\
\text { estudado }\end{array}$ & Variáveis em jogo & $\begin{array}{l}\text { Método } \\
\text { empregado }\end{array}$ \\
\hline $\begin{array}{l}\text { Konno e Yamazaki } \\
\text { (1991) }\end{array}$ & $\begin{array}{l}\text { Desenvolvimento de } \\
\text { modelos de otimização de } \\
\text { carteiras de investimento. }\end{array}$ & $\begin{array}{l}\text { Desvio absoluto médio de } \\
\text { preços de ações. }\end{array}$ & $\begin{array}{l}\text { Programação não } \\
\text { linear }\end{array}$ \\
\hline $\begin{array}{l}\text { Markowitz, Todd, Xu } \\
\text { e Yamane, } 1992\end{array}$ & $\begin{array}{l}\text { Desenvolvimento de } \\
\text { modelos de otimização de } \\
\text { carteiras de investimento. }\end{array}$ & $\begin{array}{l}\text { Semi-variância de preços } \\
\text { de ações. }\end{array}$ & $\begin{array}{l}\text { Programação não } \\
\text { linear }\end{array}$ \\
\hline Edwards e Ma, 1992 & $\begin{array}{l}\text { Desenvolvimento de } \\
\text { modelos de otimização de } \\
\text { carteiras de investimento. }\end{array}$ & $\begin{array}{l}\text { Variância e semi-variância } \\
\text { de preços de ações. }\end{array}$ & $\begin{array}{l}\text { Programação não } \\
\text { linear }\end{array}$ \\
\hline Young (1998) & $\begin{array}{l}\text { Desenvolvimento de } \\
\text { modelos de otimização de } \\
\text { carteiras de investimento. }\end{array}$ & $\begin{array}{l}\text { Rentabilidade mínima de } \\
\text { um conjunto de ações }\end{array}$ & $\begin{array}{l}\text { Programação } \\
\text { linear }\end{array}$ \\
\hline $\begin{array}{r}\text { Speranza } \\
\text { et al.(2000) }\end{array}$ & $\begin{array}{l}\text { Seleção de um portfólio de } \\
\text { ações com custos fixos na } \\
\text { transação em vários } \\
\text { períodos }\end{array}$ & $\begin{array}{l}\text {-Seleção de portfólio ótimo } \\
\text { de ações, custos de } \\
\text { transação, determinação do } \\
\text { tamanho do lote de ações }\end{array}$ & $\begin{array}{l}\text { Programação } \\
\text { linear }\end{array}$ \\
\hline $\begin{array}{l}\text { Burnquist et al. } \\
\text { (2002) }\end{array}$ & $\begin{array}{l}\text { Análise de comercialização } \\
\text { dos produtos do setor } \\
\text { sucroalcooleiro }\end{array}$ & $\begin{array}{l}\text {-Comparativos entre } \\
\text { rentabilidades de açúcar e } \\
\text { álcool } \\
\text {-Custos de produção }\end{array}$ & $\begin{array}{l}\text { Métodos de } \\
\text { previsão de } \\
\text { preços }\end{array}$ \\
\hline Marzano, 2004 & $\begin{array}{l}\text { Desenvolvimento de } \\
\text { modelos de otimização de } \\
\text { carteiras de investimento. }\end{array}$ & $\begin{array}{l}\text { Desvios com relação aos } \\
\text { valores esperados de preços } \\
\text { de ações. }\end{array}$ & $\begin{array}{l}\text { Programação por } \\
\text { metas }\end{array}$ \\
\hline Medeiros (2006) & $\begin{array}{l}\text { Análise e previsão de } \\
\text { preços de açúcar e álcool. }\end{array}$ & $\begin{array}{l}\text {-Variabilidade de preços de } \\
\text { açúcar e álcool. }\end{array}$ & $\begin{array}{l}\text { Software Crystal } \\
\text { Ball Predictor }\end{array}$ \\
\hline $\begin{array}{l}\text { Takeuchi et al. } \\
\text { (2008) }\end{array}$ & $\begin{array}{l}\text { Estudo de correlação de } \\
\text { preços do açúcar nos } \\
\text { mercados à vista e futuro. }\end{array}$ & $\begin{array}{l}\text {-Preços do açúcar no } \\
\text { mercado à vista e futuro. }\end{array}$ & Econometria \\
\hline
\end{tabular}


Em Speranza et al. (2000) é desenvolvido um trabalho para determinar o mix ótimo de um lote de ações visando sua rentabilidade máxima e minimização dos desvios abaixo da média, o que se mostrou bastante promissor para aplicação no setor sucroalcooleiro.

Em Burnquist et al. (2002) é feita uma análise das variações de preços de açúcar e álcool visando estabelecer períodos de maior rentabilidade de cada produto no período de safra. A seguir alguns modelos de otimização de portfólios de investimentos que podem ser relacionados com a etapa comercial desta dissertação.

\subsection{Modelos de otimização de portfólios e a etapa comercial}

Por muitos anos o problema central para a utilização prática de modelos de otimização para a construção de carteiras de investimento eficientes foi de natureza computacional, diante do tamanho dos problemas considerados, combinado às limitações computacionais então existentes. Estes problemas foram amplamente superados nos anos oitenta (NEMHAUSER; RINNOOY; TODD, 1989), especialmente diante do uso de modelos com formulações matemáticas que facilitavam a otimização dos problemas, reduzindo o tempo de execução e facilitando a armazenagem e acesso a dados, como ilustrado por Markowitz, Todd, Xu e Yamane (1992).

Dos anos noventa para os dias de hoje os modelos de otimização para estruturação de carteiras de investimento eficientes ficaram bem mais sofisticados, como ilustrado pelas propostas dos modelos Média-Desvio Absoluto (KONNO; YAMAZAKI,1991) e Média - Semivariância (MARKOWITZ, 1993).

Dentre os modelos de otimização usados para estruturar carteiras de investimento, aqueles que são utilizados para a obtenção de um hedge ótimo merecem atenção especial. O problema de hedge ótimo pode ser definido como a busca da minimização da exposição a risco de mercado de uma carteira de investimento visando determinada margem de lucro. Nesta classe de problemas de finanças merecem destaque os hedges de mínima variância e mínima semi-variância usando contratos futuros (EDWARDS; MA, 1992). Trata-se de uma ferramenta que pode ser utilizada de forma muito útil para o setor sucroalcooleiro se integrada à programação e controle da produção das usinas, uma das propostas desta dissertação.

A seguir apresentamos alguns modelos encontrados na literatura para estruturação de carteiras de investimentos eficientes e que podem ser utilizados para a fase de modelagem da etapa comercial quanto à decisão pelo hedge dos produtos em empresas do setor sucroalcooleiro. Muito importante é a escolha do modelo que ofereça a melhor 
métrica para medir risco e rentabilidade e melhor se adapte às necessidades do setor em estudo. A seguir alguns dos modelos estudados através do referencial teórico.

\section{Modelo Média-Variância de Markowitz}

A construção de carteiras de investimento eficientes foi um problema inicialmente estudado nos anos cinquenta, quando do surgimento do modelo Média-Variância (MARKOWITZ, 1959). O resultado almejado com o uso do modelo Média-Variância na prática do mercado financeiro era oferecer ao gestor de recursos (próprios ou de terceiros) um conjunto de carteiras que:

1. Para um determinado nível de risco (medido pelo desvio padrão dos retornos), tivesse o máximo nível de retorno (medido pela média dos retornos).

2. Para um determinado nível retorno, tivesse o mínimo nível de risco.

Utiliza as medidas estatísticas de valor esperado e variância da distribuição dos retornos para descrever, respectivamente, o retorno e o risco do investimento.

\section{Formulação matemática}

$\operatorname{Min} \quad z=\sum_{i=1}^{n} \sum_{j=1}^{n} x_{i} \cdot x_{j} \cdot \sigma_{i, j}$

sujeito a

$\sum_{i=1}^{n} x_{i} \cdot \mu_{i}=T$

$\sum_{i=1}^{n} x_{i}=1$

$x_{i} \geq 0 \quad, \quad i=1, \ldots, n$

\section{Simbologia utilizada}

- $\mathrm{n}$ : número de ativos candidatos a compor o portfólio;

- $\mathrm{x}_{\mathrm{i}}$ : porcentagem do capital a ser aplicado no ativo $\mathrm{i}$;

- $\mathrm{x}_{\mathrm{j}}$ : porcentagem do capital a ser aplicado no ativo $\mathrm{j}$;

- $\sigma_{i, j}$ : covariância entre os ativos i e j;

- $\mu_{i}$ :valor esperado dos retornos do ativo i;

- T: rentabilidade alvo desejada pelos investidores. 


\section{Explicação do modelo}

Neste modelo é assumido que a função objetivo (1) modela o risco do portfólio, o qual se quer minimizar. A restrição (2) representa o valor esperado com o portfólio escolhido, o qual deve ser igual a determinada rentabilidade T escolhida pelo investidor. A restrição (3) garante que todo o capital disponível seja investido e a restrição (4) impede que as variáveis $\mathrm{x}_{\mathrm{i}}$ sejam negativas.

Apesar da progressiva disseminação do modelo Média-Variância no mercado financeiro, ele não tem sido usado em sua forma original para construção de portfólios de larga escala. Algumas razões para isso são a dificuldade computacional associada ao alcance de uma solução ótima para problemas de otimização quadrática com uma matriz de covariância muito grande (KONNO; YAMAZAKI, 1991) e o fato de a métrica variância não ser muito adequada para medir o risco do portfólio, pois ela penaliza tanto desvios abaixo da média quanto desvios acima da média.

\section{Modelo Desvio Absoluto Médio (MAD)}

Kono e Yamazaki (1991) propuseram como medida de risco o desvio absoluto médio para formulação de problemas de otimização de portfólio de grande porte. O modelo do desvio absoluto médio (MAD) é uma alternativa à média-variância de Markowitz, cujo modelo de risco lida com problemas de programação linear quadrática (TAVARES, 2008).

\section{Formulação matemática}

$\operatorname{Min} \quad z=\frac{1}{s} \sum_{s=1}^{s} y_{s}$

sujeito a

$$
\begin{aligned}
& y_{s} \geq-\sum_{i=1}^{n}\left(r_{i, s}-\mu_{i}\right) \cdot x_{i}, s=1, \ldots, S \\
& y_{s} \geq \sum_{i=1}^{n}\left(r_{i, s}-\mu_{i}\right) \cdot x_{i}, s=1, \ldots, S \\
& \sum_{i=1}^{n} x_{i} \cdot \mu_{i}=T \\
& \sum_{i=1}^{n} x_{i}=1 \\
& x_{i} \geq 0 \quad, \quad i=1, \ldots, n
\end{aligned}
$$




\section{Simbologia utilizada}

- n: número de ativos candidatos a compor o portfólio;

- S: número de cenários utilizados para representar as incertezas com relação aos retornos dos ativos candidatos a compor o portfólio;

- $\mathrm{x}_{\mathrm{i}}$ : porcentagem do capital a ser aplicado no ativo $\mathrm{i}$;

- $\mu_{i}$ : valor esperado dos retornos do ativo i a compor o portfólio;

- T: rentabilidade alvo desejada pelos investidores;

- $\mathrm{r}_{\mathrm{i}, \mathrm{s}}$ : retorno do i-ésimo ativo candidato a compor o portfólio sob o cenário s;

- $\mathrm{y}_{\mathrm{s}}$ : variável auxiliar utilizada na modelagem para representar o desvio absoluto médio.

\section{Explicação do modelo}

No modelo MAD é assumido que a função objetivo (1) minimiza o desvio absoluto médio. As restrições (2) e (3) foram incluídas para representar o desvio absoluto médio. A restrição (4) representa o valor esperado obtido com os investimentos, o qual deve ser igual à rentabilidade alvo (T) pretendida. A restrição (5) garante que todo o capital disponível seja atendido e a restrição (6) é a restrição de não negatividade das variáveis. A formulação do modelo MAD considera assim que as incertezas com relação aos retornos dos ativos são representadas de forma discreta através de cenários. Se tivermos então $\mathrm{S}$ cenários equiprováveis e $\mathrm{r}_{\mathrm{i}, \mathrm{s}}$ representar o retorno do i-ésimo ativo candidato a

compor o portfólio sob o cenário s, teremos $\mu_{i}=\frac{1}{S} \sum_{s=1}^{S} r_{i, s}$ e o desvio absoluto médio dado por $\frac{1}{S} \sum_{s=1}^{S}\left|\sum_{i=1}^{n}\left(r_{i, s}-\mu_{i}\right) \cdot x_{i}\right|$.

Como vantagens do modelo MAD, Kono e Yamazaki (1991) destacam que esse modelo não requer a estimação de matrizes de covariância e o mesmo é linear, o que faz com que sua solução seja mais rápida e eficiente do que a solução do modelo quadrático de Markowitz.

Uma medida de risco alternativa, porém equivalente ao desvio absoluto médio, é a empregada por Speranza (2003), que trabalhou apenas com valores absolutos dos desvios negativos em relação à média (semi-desvio absoluto médio). A equivalência de tais métricas está no fato de o desvio absoluto médio ser simétrico em relação à média. Logo, o semi-desvio absoluto médio é a metade do desvio absoluto médio e atende à necessidade de se minimizar o que se está abaixo da média de rentabilidades. 


\section{Modelo de programação por metas}

Uma parte da tomada de Decisão Multi-critério é a Programação por metas (SCHRAGE, 2007; MARZANO, 2004), e se baseia no conceito de se encontrar valores factíveis o mais próximos possíveis de determinadas metas.

Um conjunto de metas é definido pelo tomador de decisão. Desvios em relação a estas metas são penalizados de modo a se encontrar uma solução satisfatória.

O peso atribuído a cada uma das metas é definido de acordo com sua importância relativa, isto é, metas mais importantes recebem pesos maiores. Minimiza-se então a soma destes pesos multiplicados pelos afastamentos das metas. Pesos nulos são atribuídos a desvios que não devem ser penalizados (por exemplo, desvios positivos em relação ao retorno esperado do portfólio).

Uma versão simplificada da Programação por Metas é apresentada a seguir. O objetivo do modelo é definir a composição de um portfólio de modo que o retorno esperado do investidor seja no mínimo T e o risco máximo por ele aceitável seja Risk $k_{\max }$. Riscos maiores e retornos esperados menores que os valores requeridos pelo investidor são penalizados. Desvios negativos de risco e positivos de valor esperado não são penalizados. Nenhuma medida particular de risco é especificada, assume-se apenas que o risco do portfólio é uma combinação linear dos riscos dos ativos que o compõem (MARZANO, 2004).

\section{Formulação matemática}

Min $z=w_{1} n_{1}+w_{2} p_{2}$

sujeito a

$$
\begin{aligned}
& \sum_{i=1}^{n} x_{i} \mu_{i}+n_{1}-p_{1}=T \\
& \sum_{i=1}^{n} \operatorname{Risk}_{i} \cdot x_{i}+n_{2}-p_{2}=\text { Risk }_{\max } \\
& \sum_{i=1}^{n} x_{i}=1 \\
& n_{1}, n_{2}, p_{1}, p_{2} \geq 0, x_{i} \geq 0 \quad, \quad i=1, \ldots, n
\end{aligned}
$$




\section{Simbologia utilizada}

- $\mathrm{w}_{1}$ : penalização atribuída a desvios negativos em relação ao valor esperado requerido pelo investidor;

- $\mathrm{n}_{1}$ : desvio negativo em relação ao valor esperado requerido pelo investidor;

- $\mathrm{w}_{2}$ : penalização atribuída a desvios positivos em relação ao risco requerido pelo investidor;

- $\mathrm{p}_{2}$ : desvio positivo em relação ao risco requerido pelo investidor;

- n: número de ativos candidatos a compor o portfólio;

- $\mathrm{x}_{\mathrm{i}}$ : porcentagem do capital a ser aplicado no ativo $\mathrm{i}$;

- $\mu_{i}$ : valor esperado dos retornos do ativo i a compor o portfólio;

- T: rentabilidade alvo desejada pelos investidores;

- $\mathrm{p}_{1}$ : desvio positivo em relação ao valor esperado requerido pelo investidor;

- Risk $\mathrm{i}_{\mathrm{i}}$ : risco do i-ésimo ativo candidato a compor o portfólio;

- $\mathrm{n}_{2}$ : desvio negativo em relação ao risco requerido pelo investidor;

- Risk $_{\max }$ : risco máximo do portfólio requerido pelo investidor.

\section{Explicação do modelo}

Em (1), assume-se que a função objetivo pretende minimizar o risco associado com o valor esperado. Em (2), caso o valor esperado seja menor que T, a variável $\mathrm{n}_{1}$ assume valor não nulo, havendo então uma penalização na função objetivo. A restrição (3) está associada com o risco do portfólio. Como o investidor requer um nível de risco máximo, se o risco for maior que o requerido a variável $\mathrm{n}_{2}$ assume valor não nulo, não havendo entretanto penalização na função objetivo. A restrição (4) garante que todo o capital disponível seja investido e a restrição (5) garante a não negatividade das variáveis $\mathrm{n}_{1}, \mathrm{n}_{2}, \mathrm{p}_{1}, \mathrm{p}_{2}$ e que não haja investimento negativo.

\section{Modelo MaxMin}

Um modelo de seleção de portfólio que utiliza o retorno mínimo como medida de risco foi apresentado por Young (1998). O portfólio ótimo encontrado neste modelo é a solução de um problema simples de programação linear, e é definido como aquele que maximiza o retorno do pior cenário, sujeito a um nível de retorno esperado. 


\section{Formulação matemática}

$\max Z=\operatorname{Re}_{p}$

sujeito a

$\sum_{i=1}^{n} x_{i} \cdot r_{i c}-\operatorname{Re}_{p} \geq 0 \quad, \quad c=1, \ldots, C$

$\sum_{i=1}^{n} x_{i} \cdot \mu_{i} \geq T$

$\sum_{i=1}^{n} x_{i}=1$

$x_{i} \geq 0 \quad, \quad i=1, \ldots, n$

\section{Simbologia utilizada}

- $\operatorname{Re}_{\mathrm{p}}$ : retorno esperado do pior cenário;

- n: número de ativos candidatos a compor o portfólio;

- $\mathrm{x}_{\mathrm{i}}$ : porcentagem do capital a ser aplicado no ativo $\mathrm{i}$;

- $\mu_{i}$ :valor esperado dos retornos do ativo i a compor o portfólio;

- $\mathrm{r}_{\mathrm{i}, \mathrm{c}}$ : retorno do i-ésimo ativo candidato a compor o portfólio sob o cenário $\mathrm{C}$;

- C: número de cenários utilizados para representar as incertezas com relação aos retornos dos ativos candidatos a compor o portfólio;

- T: rentabilidade mínima desejada pelos investidores;

\section{Explicação do modelo}

A função objetivo (1) maximiza $\mathrm{Re}_{\mathrm{p}}$. A restrição (2) denota $\mathrm{Re}_{\mathrm{p}}$ como o resultado do pior cenário. A restrição (3) estabelece que a rentabilidade almejada pelos investidores deve ser maior que um mínimo T aceitável. A restrição (4) garante que todo o capital disponível seja investido e a restrição (5) garante que não haja investimento negativo. 


\section{Modelo Value-at-Risk (VAR)}

Value-at-Risk (VaR) tornou-se uma medida de risco de larga utilização e aceitação em instituições financeiras de todo mundo. $\mathrm{O}$ modelo VaR é um método de mensuração de risco que utiliza técnicas estatísticas padrões e é de fácil compreensão para o controle de riscos (JORION, 2001). O VaR mede o pior valor esperado da perda que uma instituição financeira está sujeita a sofrer ao longo de um determinado horizonte de tempo, a um dado nível de confiança.

Em outras palavras, com certa probabilidade, as perdas não excederão o $\mathrm{VaR}$, ou seja, o VaR a nível de confiança 95\% está associado a um nível de perda cuja probabilidade de esta perda ser excedida é igual a 5\% (MARZANO, 2004).

\section{Formulação matemática}

Min $Z=\alpha$

sujeito a

$$
\begin{aligned}
& -\sum_{i=1}^{n} x_{i} \cdot r_{i c}-M \cdot y_{c} \leq \alpha \quad, \quad c=1, \ldots, C \\
& \sum_{c=1}^{C} y_{C}=(1-\beta \%) \cdot C \\
& \sum_{i=1}^{n} x_{i} \cdot \mu_{i}=T \\
& \sum_{i=1}^{n} x_{i}=1 \\
& x_{i} \geq 0 \quad, \quad i=1, \ldots, n \\
& y_{c} \in\{0,1\} \quad, \quad c=1, \ldots, C
\end{aligned}
$$

\section{Simbologia utilizada}

- $\mathrm{n}$ : número de ativos candidatos a compor o portfólio;

- $\quad \beta$ : nível de confiança para o cálculo do VaR;

- $\alpha$ : variável que fornece o VaR do potfólio com um nível de confiança $\beta \%$;

- $\mathrm{x}_{\mathrm{i}}$ : porcentagem do capital a ser aplicado no ativo $\mathrm{i}$;

- $\mu_{i}$ :valor esperado dos retornos do ativo i a compor o portfólio;

- $\mathrm{r}_{\mathrm{i}, \mathrm{c}}$ : retorno do i-ésimo ativo candidato a compor o portfólio sob o cenário s; 
- C: número de cenários utilizados para representar as incertezas com relação aos retornos dos ativos candidatos a compor o portfólio;

- T: rentabilidade mínima almejada pelos investidores;

- M: número muito grande diante da grandeza dos números presentes na equação em questão;

- $\mathrm{y}_{\mathrm{c}}$ : variável binária auxiliar para o cálculo do VaR

\section{Explicação do modelo}

O modelo VaR assume que na função objetivo (1) ocorre a minimização do VaR do portfólio. A restrição (2) utiliza uma variável binária auxiliar $\mathrm{y}_{\mathrm{c}}$ que assume o valor 1

quando o cenário c apresentar perda ( representada pelo termo $-\sum_{i=1}^{n} x_{i} \cdot r_{i c}$ ) maior que $\alpha(\mathrm{VaR})$. Nos demais cenários a perda pode ser no máximo $\alpha$ e a variável $\mathrm{y}_{\mathrm{c}}$ fica igualada a zero. Na restrição (3) observa-se o número de cenários que podem assumir perdas maiores que VaR. A restrição (4) assegura que o valor esperado do retorno do portfólio seja igual a um dado nível (T) definido pelo investidor. A restrição (5) garante que todo o capital disponível seja investido, a restrição (6) garante que não haja investimento negativo e a (7) que $\mathrm{y}_{\mathrm{c}}$ é binária.

\section{Modelo da Semi-variância com Análise de Cenários de Markowitz}

Apesar da variância (ou do desvio padrão) ser uma das principais medidas de risco utilizadas em finanças, um dos seus principais problemas consiste no fato de dar pesos iguais para possibilidades situadas tanto abaixo quanto acima da média. Porém, investidores avessos ao risco estão mais preocupados com o risco de queda do que com o "risco de alta". A semivariância é uma medida estatística que pode exprimir o risco de queda, sendo definida como a esperança das diferenças em torno da média ao quadrado para valores situados abaixo da média. A seguir observa-se um modelo que utiliza a semi-variância conjuntamente com uma análise de cenários (SCHRAGE, 2007). 


\section{Formulação matemática}

$\operatorname{Min} \quad Z=\sum_{s=1}^{S} P_{s}\left(D V L_{s}\right)^{2}$

sujeito a

$$
\begin{aligned}
& R_{s}=\sum_{i=1}^{n} X_{i} r_{i, s} \quad, \quad s=1, \ldots, S \\
& D V U_{s}-D V L_{s}=R_{s}-\mu, \quad s=1, \ldots, S \\
& \sum_{i=1}^{n} X_{i}=1 \\
& \mu=\sum_{s=1}^{S} P_{s} \cdot R_{s} \\
& \mu \geq T \\
& x_{i} \geq 0 \quad, \quad i=1, \ldots, n
\end{aligned}
$$

\section{Simbologia utilizada}

- $\mathrm{P}_{\mathrm{s}}$ : Probabilidade associada ao cenário s;

- T: Rentabilidade alvo almejada pelos investidores;

- $\mathrm{r}_{\mathrm{i}, \mathrm{s}}$ : retorno do i-ésimo ativo candidato a compor o portfólio sob o cenário s;

- $\mathrm{X}_{\mathrm{i}}$ : porcentagem do capital a ser aplicado no ativo $\mathrm{i}$;

- $\mathrm{DVU}_{\mathrm{s}}$ : desvio acima da média;

- $\mathrm{DVL}_{\mathrm{s}}$ : desvio abaixo da média;

- $\mathrm{R}_{\mathrm{s}}$ : retorno associado a cada cenário e ativo i;

- $\mu$ : Média de todos os retornos associados com as probabilidades respectivas dos cenários;

\section{Explicação do modelo}

A função objetivo em (1) minimiza o desvio quadrático dos retornos abaixo da rentabilidade alvo. Em (2) temos o retorno associado a todos os cenários $\mathrm{S}$ e ativos i. $\mathrm{Na}$ restrição (3), observa-se que o desvio abaixo da média (DVL) é colocado no subtraendo para que possa ser minimizado na função objetivo. Em (4), a soma das porcentagens de investimentos vale 100\%. Na restrição (5), a média é igual ao somatório das probabilidades de cada cenário com seus retornos respectivos. Em (6), a média é imposta maior ou igual ao alvo T. A restrição (7) garante que não haja investimento negativo. 


\section{CUSTOS E RECEITAS ASSOCIADOS AOS PROCESSOS DE PRODUÇÃO E COMERCIALIZAÇÃO}

\subsection{Custos associados à etapa agrícola}

\subsubsection{Planejamento da etapa agrícola}

Nos cálculos dos custos com a aquisição da cana-de-açúcar por parte da usina, os fatores de ponderação utilizados foram:

-as porcentagens de participação de cana-de-açúcar própria e de terceiros em relação ao total de cana-de-açúcar moída em cada período de análise;

-as porcentagens de participação de cada variedade de cana na colheita total de cana própria e de terceiros em cada período;

$\mathrm{Na}$ etapa agrícola não se pretendeu nesta dissertação analisar os custos relacionados às etapas de corte e carregamento, o que pode ser encontrado em detalhes em Paiva (2006), priorizando-se assim a análise dos canais de fornecimento, o tipo de transporte (próprio ou terceirizado) e o estudo das produtividades agrícolas e rendimentos industriais das variedades de cana-de-açúcar.

No Brasil, assim como em outros países produtores de cana-de-açúcar, variedades de cana têm sido continuamente desenvolvidas e testadas com os objetivos de aumentar a produtividade agrícola/industrial, obter uma maior resistência às pragas e doenças e uma melhor adaptação às variações de clima, tipos de solos, técnicas de corte ou manejo.

$\mathrm{Na}$ usina Usalpa, utilizada para análise de processos, coletas de dados e validação da pesquisa, as variedades de cana utilizadas em terras arrendadas e variedades de cana de terceiros com suas respectivas áreas de cultivo e produtividades médias, em toneladas de cana por hectare (TCH), na safra 2008/2009, podem ser vistas respectivamente nas tabelas 3 e 4. 
Tabela 3. Disponibilidade de cada variedade de cana própria

\begin{tabular}{|c|c|c|c|}
\hline Variedade & Area(ha) & Produção(t) & TCH(t/ha) \\
\hline RB72454 & 1362,34 & 84718,09 & 62,19 \\
SP813250 & 1081,17 & 95978,44 & 88,77 \\
SP791011 & 733,83 & 63407,253 & 86,41 \\
RB835486 & 649,49 & 61355,259 & 94,47 \\
SP832847 & 546,69 & 68765,79 & 125,79 \\
SP801842 & 3142,95 & 63190,19 & 20,11 \\
RB855536 & 2492,45 & 194656,725 & 78,10 \\
RB867515 & 1166,29 & 112681,56 & 96,62 \\
RB855113 & 345,74 & 29264,745 & 84,64 \\
RB825336 & 147,65 & 12052,66 & 81,63 \\
RB928064 & 361,92 & 45606,28 & 126,01 \\
RB855035 & 456,78 & 57456,79 & 125,79 \\
RB765418 & 356,76 & 43234,56 & 121,19 \\
RB739735 & 236,78 & 26876,78 & 113,51 \\
RB855453 & 598,55 & 75155,25 & 125,56 \\
\hline TOTAL & 13679,39 & 1034400,372 & \\
\hline
\end{tabular}

Fonte: Departamento agrícola - USALPA (safra 2008/2009)

Tabela 4. Disponibilidade de cada variedade de cana de terceiros

\begin{tabular}{|c|c|c|c|}
\hline Variedade & Area(ha) & Pro dução(t) & TCH(t/ha) \\
\hline RB72454 & 177,56 & 10207,34 & 57,49 \\
SP813250 & 408,17 & 30550,69 & 74,85 \\
SP791011 & 224,15 & 17653,04 & 78,76 \\
RB835486 & 16,5 & 1035,47 & 62,76 \\
SP801842 & 530,34 & 64578,89 & 121,77 \\
RB855536 & 275,82 & 25589,655 & 92,78 \\
RB867515 & 73,3 & 7049,105 & 96,17 \\
RB855113 & 648,89 & 60987,89 & 93,99 \\
RB825336 & 160,02 & 13701,28 & 85,62 \\
RB928064 & 987,45 & 120765,56 & 122,30 \\
RB739735 & 786,67 & 89897,64 & 114,28 \\
RB765418 & 567,89 & 61234,89 & 107,83 \\
RB855035 & 435,62 & 49678,98 & 114,04 \\
RB855453 & 913,34 & 119675,908 & 131,03 \\
\cline { 1 - 2 } TOTAL & 6205,72 & 672606,338 & \\
\cline { 1 - 2 }
\end{tabular}

Fonte: Departamento agrícola - USALPA (safra 2008/2009)

Nesta dissertação, cada variedade de cana em cada fonte de fornecimento e em cada semana de safra será estudada quanto aos seguintes indicadores tecnológicos e de produção (tabela 5):

-Pol: Quantidade de sacarose encontrada em $100 \mathrm{~g}$ de caldo de cana;

-Brix: Porcentagem, em peso, de sólidos solúveis no caldo de cana;

-AR: Quantidade de glicose e levulose encontrada em 100g de caldo de cana;

-ATR: Resultado da diferença entre os açúcares redutores da cana que entram na usina e o que é perdido no processamento industrial; 
-Pureza: Porcentagem de sacarose contida nos sólidos solúveis presentes no caldo de cana;

-Disponibilidade de colheita: quantidade em toneladas disponível para colheita de cada variedade de cana.

Os indicadores acima foram disponibilizados pelo departamento agrícola da usina Alta Paulista e pelo laboratório de análises tecnológicas da mesma usina. Durante a safra 2008/2009, um trabalho de coleta de dados por parte dos técnicos agrícolas e de laboratório da usina ocorreu para determinar as características analisadas tanto das variedades de cana própria da usina quanto das variedades de cana compradas de terceiros. Em cada semana, uma amostra era retirada de cada variedade de cana e suas características tecnológicas eram registradas em relatórios técnicos. A pedido da diretoria da usina, alguns indicadores foram trocados entre as variedades.

Tabela 5. Composição tecnológica média de 5 variedades de cana

\begin{tabular}{|l|l|l|l|l|l|}
\hline Variedade & Pol & Brix(\%) & AR(\%) & ATR(kg/t) & Pureza(\%) \\
\hline RB72454 & 14,94 & 20,5 & 1,21 & 132 & 83 \\
\hline SP813250 & 15,35 & 21,2 & 1,19 & 140 & 89 \\
\hline SP791011 & 14,63 & 19,4 & 1,17 & 123 & 91 \\
\hline RB835486 & 13,45 & 23,1 & 1,18 & 132 & 90 \\
\hline SP832847 & 16,56 & 20,2 & 1,21 & 145 & 89 \\
\hline
\end{tabular}

Cada variedade de cana, com seus diferentes fatores tecnológicos em cada semana, possui um custo diferente de aquisição para a usina em cada semana. Torna-se então importante definir no planejamento agregado as variedades e fontes de fornecimento em cada semana que minimizam os custos da etapa agrícola e maximizam o retorno na recuperação de açúcar e álcool na etapa industrial.

Com o auxílio da gerência agrícola, de técnicos agrícolas e do laboratório da usina Usalpa, de dados coletados durante a elaboração desta dissertação e de adaptações a partir de Paiva (2006), e Fernandes (2003), foi possível montar uma estrutura de análise de custos da etapa agrícola.

Na figura 31, observam-se as decisões a serem tomadas pelos gestores da usina. Em SCAG (separação de contratos agrícolas) ocorre a determinação da quantidade de terra que a usina irá arrendar e então cultivar sua própria cana e também a quantidade de cana que a usina irá comprar de fornecedores para a safra (aqui chamada cana de terceiros). 
Após toda a fase de cultivo da cana-de-açúcar, em SFV (separação de fonte de fornecimento e variedades de cana) ocorre a determinação em cada semana quanto aos talhões de cana que serão cortados e enviados até a usina. Esta decisão depende de fatores tecnológicos de cada variedade de cana, custos de arrendamento de terra e contratos de fornecimento e se constitui em cada semana em uma variável de decisão no modelo desenvolvido nesta dissertação. O sistema atual de planejamento de colheita da usina se baseia no uso de um software especializado em índices de maturidade da cana para o corte procurando definir o melhor momento para o corte, mas não está integrado com os rendimentos de cada variedade na recuperação do açúcar na etapa industrial.

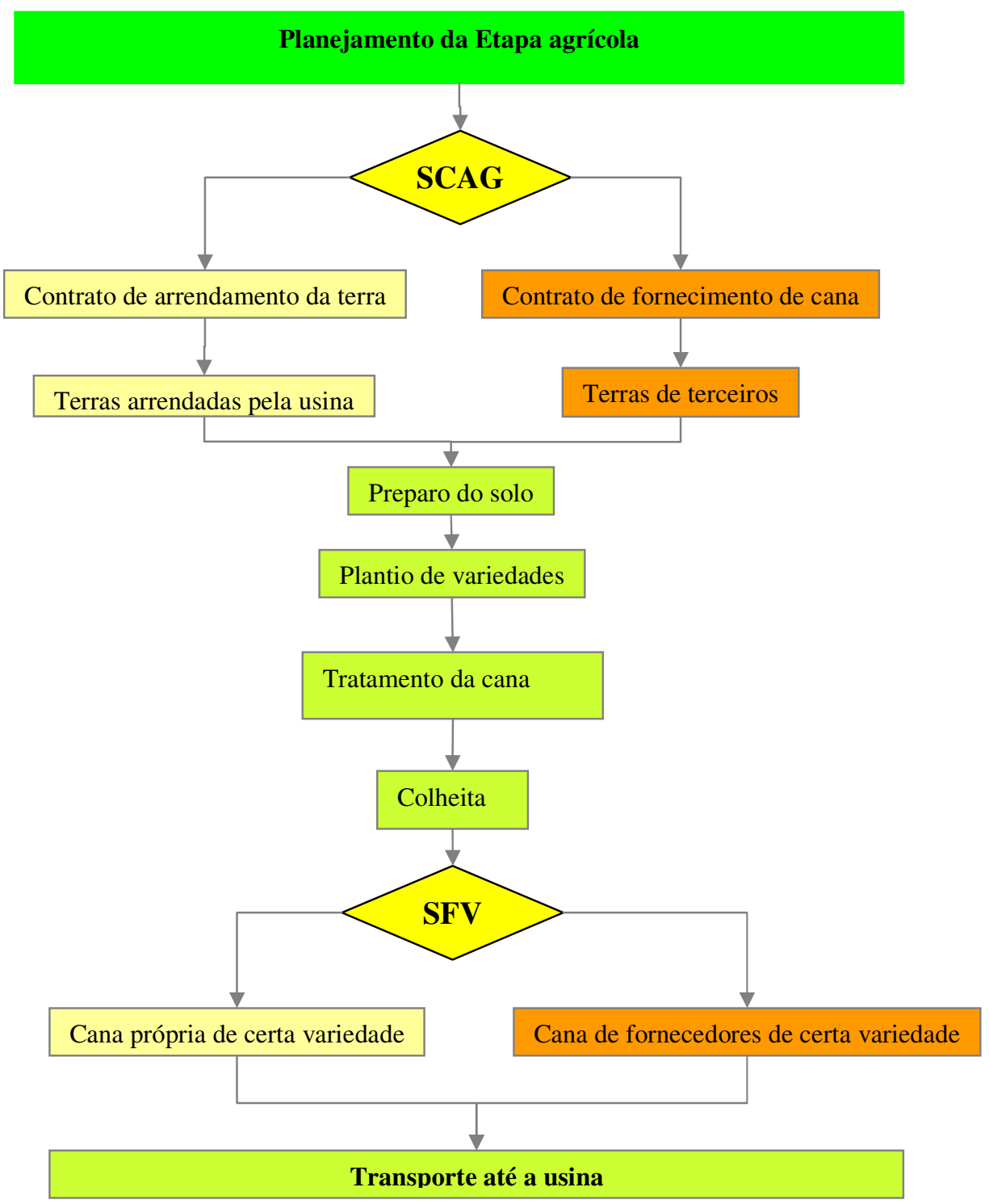

Figura 31. Fluxograma de planejamento da Etapa agrícola 
No apêndice B, item I, encontram-se os parâmetros de entrada para os cálculos dos custos agrícolas e respectivas equações.

\subsection{Custos associados à etapa industrial}

\subsubsection{Alternativas de produção na etapa industrial}

Quando comparados entre si, os processos produtivos das usinas brasileiras não são muito diferentes. Algumas se especializam em determinado tipo de açúcar ou álcool, outras produzem uma variedade maior de produtos, mas sem grandes alterações nos processos industriais. Para adaptar este modelo de otimização para cada caso basta incluir outros índices para os demais tipos de açúcar e álcool. Quanto à etapa industrial há que se tomar cuidado com peculiaridades nos processos de cada usina. Paiva (2006) desenvolveu modelagem da etapa industrial de uma usina de açúcar e álcool sem a separação do caldo primário e secundário devido às características de funcionamento da usina estudada pelo autor.

$\mathrm{Na}$ usina USALPA, utilizada para a modelagem da etapa de produção e testes nesta dissertação, partindo da modelagem realizada em Paiva (2006), e com o auxílio da gerência industrial da usina USALPA e usina Coruripe, estipularam-se os valores presentes a seguir para os parâmetros estudados.

A usina utilizada neste estudo separa o caldo de primeira moagem (CP: caldo primário, não embebido em água) dos demais caldos (CS: caldo secundário, que é o caldo embebido em água). Isso então deve ser levado em conta na modelagem, já que o teor de açúcar no caldo primário é maior que o teor de açúcar do caldo secundário.

Para a realização da modelagem dos processos utilizados na usina, de acordo com discussões com a gerência industrial, admite-se que a separação do caldo primário possa assumir os valores 0,$3 ; 0,6$ e 0,9 (SCP na figura 32) quanto à destinação do caldo para a fábrica de açúcar e destilaria (o valor 0,3 significa que $30 \%$ do caldo primário será destinado à fábrica de açúcar e 70\% à destilaria) e que a separação do caldo secundário possa assumir os valores 0,2 e 0,8 (SCS na figura 32) quanto à destinação do caldo para a fábrica de açúcar e a destilaria (o valor 0,2 significa que 20\% do caldo secundário será destinado à fábrica de açúcar e $80 \%$ à destilaria).

Para modelar esta usina, serão utilizadas para a destinação do melaço para a destilaria as possibilidades 0,8 e 1,0 (SM na figura 32). O valor 0,8 significa que $80 \%$ do melaço 
será destinado à fabricação de álcoois e $20 \%$ será destinado à reserva de melaço para comercialização.

$\mathrm{Na}$ fermentação do mosto e posterior passagem pelas colunas de desidratação, assumimos que os valores destinados à fabricação de álcool hidratado são 0,4 e 0,8 (SA na figura 32). O valor 0,4 significa que $40 \%$ do mosto é destinado à fabricação de álcool hidratado e $60 \%$ destinado à fabricação de álcool anidro.

Temos assim um total de $3 \times 2 \times 2 \times 2=24$ processos partindo-se de combinações de caldo primário e caldo secundário. Logo, o total de processos/caminhos de produção que irá modelar a usina na etapa industrial será igual a 24. As possibilidades de separação de porcentagens para produção de açúcar e álcool são representativas dos processos de produção que realmente são efetivados na usina em estudo. Evidentemente perdem-se outras possibilidades de separações industriais quando se pensa num conjunto contínuo de possibilidades para as mesmas. Mas isso tornaria o número de processos infinito, inviabilizando a modelagem matemática no tocante ao tempo de execução do modelo. As proporções definidas acima dependem de operações de abertura e fechamento de válvulas. Não se consideram nesta dissertação custos referentes às operações de setup e os tempos necessários para se efetuar as trocas de processos em cada semana. O tempo de setup pode ser considerado de segunda ordem sem perdas significativas de precisão, dadas as aproximações de tempo de funcionamento da usina em cada semana. Ou seja, ele está embutido no tempo que se perde quando a usina está parada. 


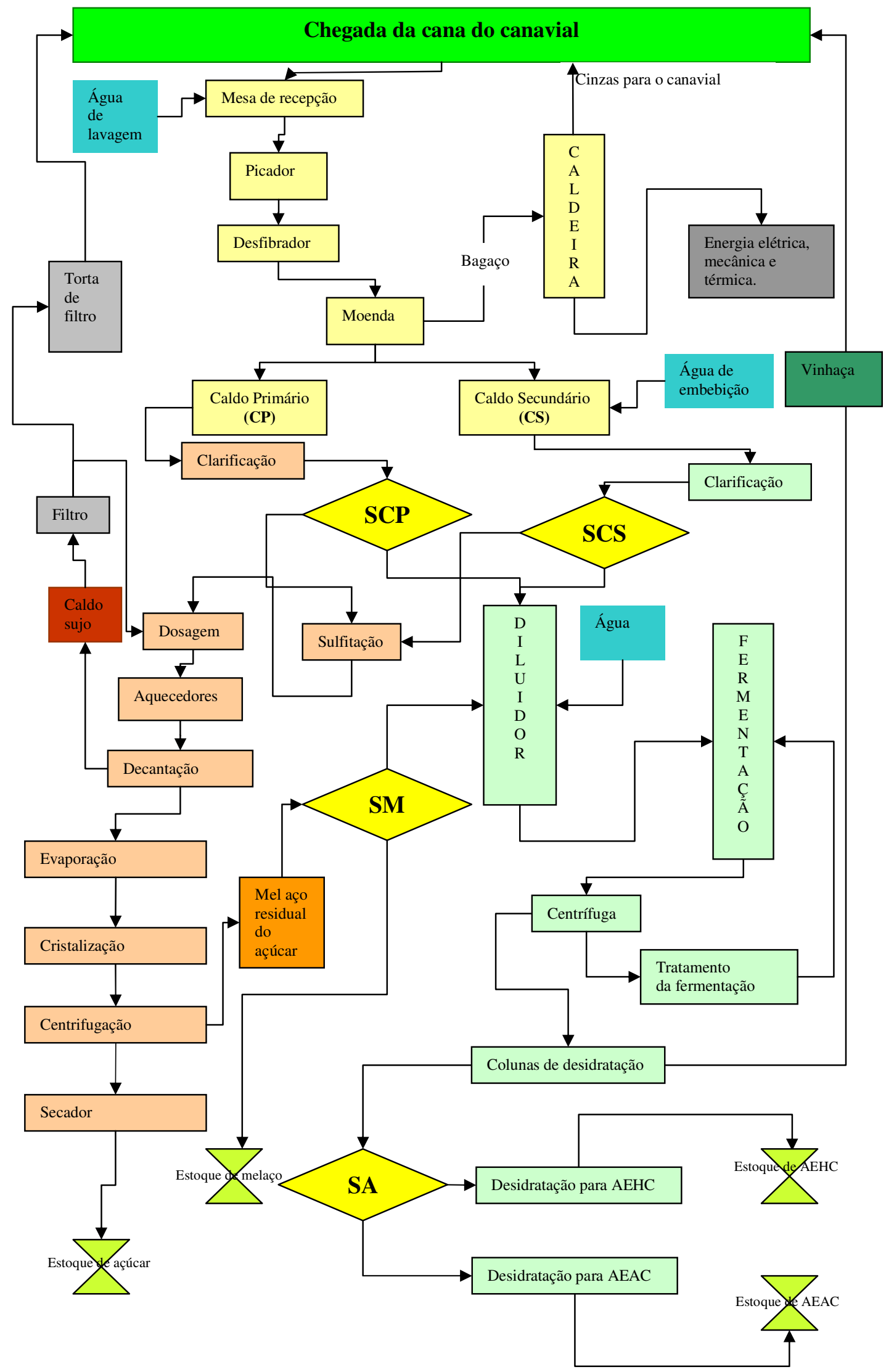

Figura 32. Fluxograma dos caminhos de produção de açúcar, álcool e melaço 
Adaptações quanto ao número de processos podem facilmente ser implantadas mudando os valores de porcentagens e número de possibilidades, incorrendo, no entanto, em maior dificuldade de aplicação computacional devido ao aumento no número de variáveis a se estudar e ao fato de se tratar de um problema de programação linear inteira mista.

No Apêndice B, item II, podem ser vistos os cálculos referentes aos rendimentos agroindustriais e custos industriais relativos a cada processo e variedade de cana escolhida.

\subsection{Custos e receitas associados às etapas comercial e de estocagem}

Para a determinação das quantidades de cada produto comercializadas nos mercados interno e externo à vista (Spot) e no mercado futuro (Hedge) e também quantidade de cada produto estocada em cada semana, utilizaram-se os dados de fluxo de caixa da usina estudada, conceitos de "Futuro de açúcar e álcool", Relatório técnico, BM\&F, 2007 e dados do sistema de previsão de preços presente nesta dissertação (preços de açúcar e álcool da BM\&F e ESALQ), custos de comercialização nos mercados correspondentes e custos de estocagem.

\subsubsection{Alternativas de comercialização}

A proposta do modelo é estabelecer inicialmente em cada semana o quanto se deve travar da produção com hedge de açúcar, álcool anidro e hidratado para cobrir os custos semanais da usina. Isto é feito através das projeções dos preços futuros de açúcar e álcool e definição do mix de produção pelo modelo denominado "Semi-variância com análise de cenários de Markowitz". Como os custos semanais de produção e comercialização são conhecidos pela usina, é possível saber quanto produzir de açúcar e álcool em cada semana para o hedge. Pode ser mais vantajoso um hedge mais açucareiro ou mais alcooleiro, isso vai depender dos preços futuros alcançados pelos produtos em cada semana. Definido esse parâmetro, que funcionará como uma demanda futura, em cada semana o modelo percorre os preços de açúcar e álcoois à vista nos mercados interno e externo. A partir dos estoques em cada semana e capacidade de produção, o modelo então escolhe o caminho de produção/comercialização que maximiza a margem na safra respeitando os compromissos assumidos no hedge e pedidos já efetuados, destinando uma quantidade spot maior para mercado interno ou 
para mercado externo de cada produto dependendo de condições mais vantajosas de cada um deles.

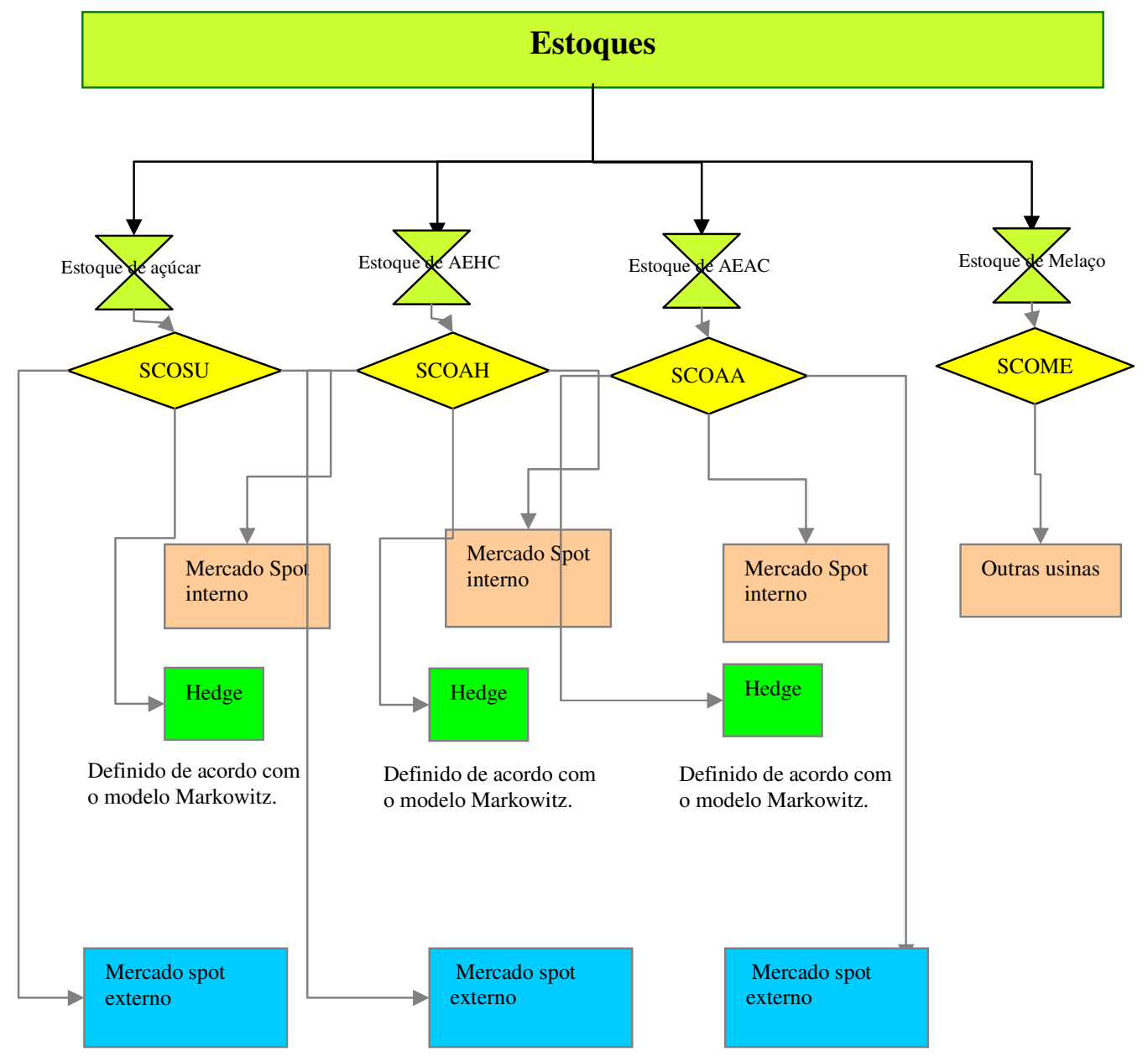

Figura 33. Administração do estoque e comercialização dos produtos nas usinas

No fluxograma acima, após a produção de cada produto que a usina comercializa (açúcar VHP, álcool AEHC, álcool AEAC e melaço), em cada semana eles são enviados para estoques próprios ou de terceiros e deve então ocorrer a venda desses produtos para cada mercado.

Para o melaço, há a possibilidade em cada semana de se efetuar a venda a usinas próximas para posterior industrialização ou a própria usina utilizá-lo na fabricação de álcool. 
No caso de açúcar VHP, álcool AEHC e álcool AEAC, esses produtos podem ser "hedgeados" e assim em cada semana eles passarão pelos canais de comercialização abaixo e na ordem especificada:

1. Atender o hedge estabelecido de cada produto para cobrir os custos semanais de produção agroindustrial;

2. Partir diretamente para a venda no mercado Spot interno ou externo através de corretoras e tradings;

3. Aguardar em estoque pelo melhor preço em período futuro.

Todas essas decisões estão vinculadas a restrições de fluxo de caixa da usina, métodos de previsão de preço dos produtos comercializados nos respectivos mercados, custos de estocagem própria e de terceiros, atendimento dos hedges travados e taxas de negociação nos mercados futuros de açúcar e álcool. Se na etapa industrial o objetivo era a minimização dos custos, na etapa comercial o objetivo é a maximização da margem de lucro da empresa vinculada às flutuações de preços de açúcar e álcool.

Em cada semana o mix do hedge para açúcar VHP, álcool AEHC e álcool AEAC é feito segundo o modelo "Semi-variância com análise de cenários de Markowitz".

\section{Índices do planejamento comercial}

- $\mathrm{c}$

- $\mathrm{e}$

- $\quad \mathrm{Z}$ canais de comercialização;

tipos de estoque: próprio ou terceirizado;

processos comerciais de destinação dos produtos para mercado spot interno ou externo;

- $\quad$ MSI mercado spot interno;

- MSE mercado spot externo;

- $\quad \mathrm{SCOSU}$ Separação comercial do açúcar;

- $\quad$ SCOAH Separação comercial do álcool hidratado;

- $\quad$ SCOAA Separação comercial do álcool anidro;

- SCOME Separação comercial do melaço.

No índice SCOSU (figura 33), tem-se a destinação comercial que será realizada com o açúcar em cada semana. Para a realização da modelagem dos processos utilizados na usina e também por motivo de redução do número final de processos comerciais, SCOSU assume os valores 0,6 e 0,4 . O valor 0,6 , por exemplo, significa que $60 \%$ do que sobra do açúcar depois de retirada a parcela destinada ao hedge deve ser comercializado por mercado Spot externo e $40 \%$ comercializado no mercado Spot 
interno na mesma semana da produção. Dependendo das condições de mercado, pode ocorrer priorização ora para mercado externo, ora para mercado interno na venda dos produtos.

Segundo dados do departamento comercial da usina em estudo e dados relativos à safra 2008/2009 da União das Destilarias do Oeste Paulista (UDOP), na comercialização de álcoois com o mercado externo ainda existem fortes restrições relativas a contratos de fornecimento e dificuldades nos canais de comercialização e distribuição. Assim, quanto a SCOAH e SCOAA tem-se os valores 0,6 e 0,8 de estratégias de comercialização. Significa em 0,6 que 60\% do tipo de álcool será destinado para mercado Spot externo (MSE) e 40\% para comercialização no mercado Spot interno (MSI). Em SCOME a única decisão é comercializar o melaço que sobrou na semana e assume assim o valor único 1,0, ou seja, $100 \%$ do excedente de produção deve ser comercializado na mesma semana de produção no mercado interno.

As separações comerciais acima definem um total de $2 \times 2 \times 2 \times 1=8$ possibilidades de comercialização em cada semana para cada tipo de mercado, interno ou externo. Encontra-se assim um total de 2 × $8=16$ processos de comercialização. Analisando conjuntamente com a etapa industrial encontra-se um total de 24 (número de processos industriais em cada semana) multiplicado por 16 (número de processos ou escolhas comerciais em cada semana) processos, o que resulta em 384 alternativas de processos de industrialização/comercialização para se escolher em cada semana de safra visando maximizar a margem de contribuição.

No Apêndice B, item III, encontram-se os cálculos referentes aos custos comerciais, de estocagem e receitas obtidas com as vendas de cada produto. 


\section{O MODELO GLOBAL DO PROBLEMA}

\subsection{Fluxo de informações e produção do modelo global de otimização}

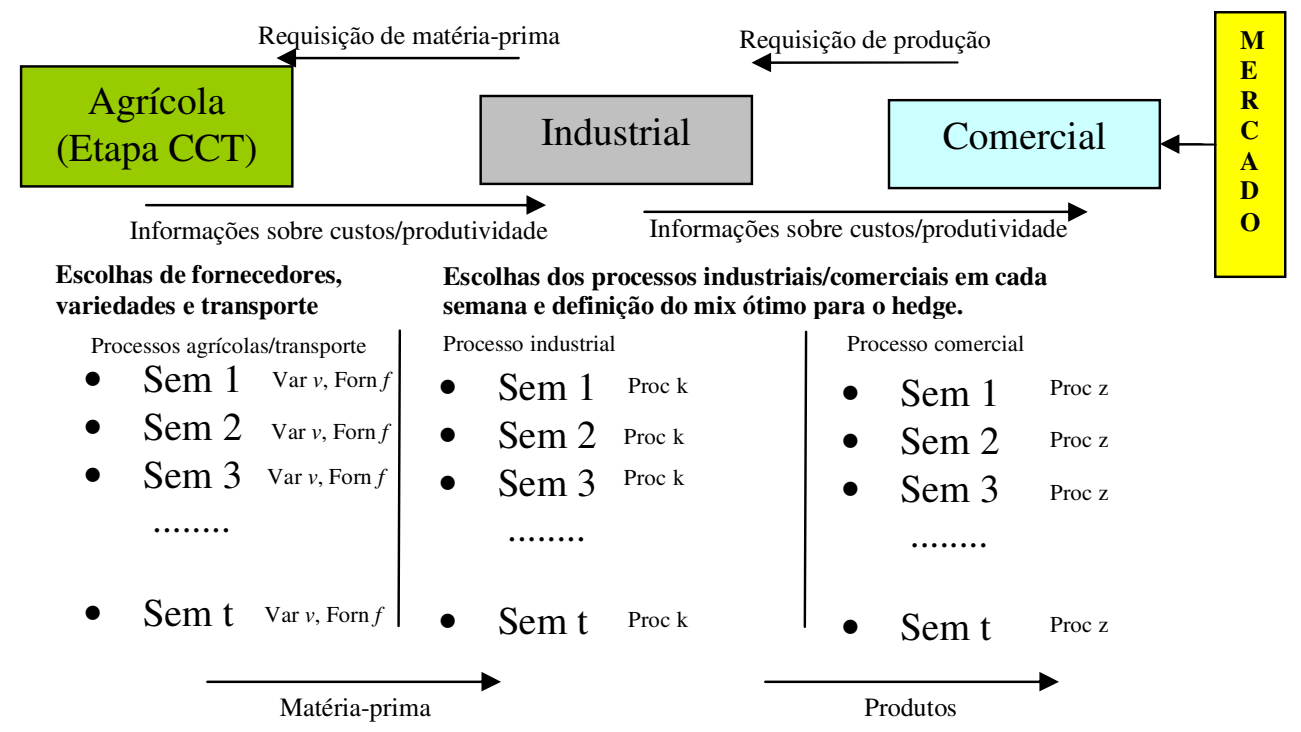

Figura 34. O modelo global do problema com suas três etapas

Como pode ser observado na figura 34, a idéia do modelo de otimização presente nesta dissertação é a integração de decisões das etapas agrícola, industrial e comercial. O mercado atua interferindo na demanda e nas dinâmicas de preços de açúcar e álcool, o que implica em mudanças em todo o planejamento de vendas, programação industrial e programação agrícola.

\section{Explicação do modelo proposto}

A seguir, é descrito o que ocorre em cada etapa do sistema produtivo e de negociação.

$\mathrm{Na}$ etapa agrícola, significando neste trabalho corte, carregamento e transporte da canade-açúcar, as variáveis de decisão em cada semana são as decisões pelo corte de variedades de cana-de-açúcar e a origem de fornecimento de cana em cada semana durante o período de safra. Para cada semana, pode ser utilizada qualquer das variedades de cana, as quais podem ter origem a partir de cana própria ou cana de terceiros. Toda a cana disponível no campo segundo a previsão inicial de safra deve ser moída na safra. Para este trabalho, tem-se 15 variedades de cana possíveis com duas opções de fonte de fornecimento, o que totaliza 30 variáveis de decisão em cada semana de safra. O estoque 
de cana no campo é atualizado retirando-se da semana anterior a quantidade de cana no campo fornecida à usina nessa mesma semana. Deve-se ainda aqui decidir pela forma de transporte de cana, que pode ser feito com frota própria ou terceirizada. Para que haja compatibilidade entre a quantidade de cana colhida em cada semana, a quantidade de cana transportada e a quantidade de cana moída, estabelece-se a igualdade dessas três quantidades em cada semana.

Na etapa industrial, a variável de decisão é a escolha dos processos de produção pelos quais podem passar os produtos fabricados, determinando um mix de produção em cada semana mais voltado para açúcar ou um mix priorizando álcool (e dentro deste produto mais voltado para AEHC ou para AEAC) dependendo do processo escolhido. É feita a separação entre caldo primário e caldo secundário de moagem para obedecer às condições de trabalho da usina em estudo. Admite-se para cada semana a utilização de apenas um processo industrial. Tem-se aqui 24 processos industriais para serem escolhidos em cada semana. Esse número de processos, embora numa quantidade que poderia ser aumentada para modelar mais possibilidades na realidade, foi escolhido em função de representar grande parte do que ocorre nos ajustes de direcionamento da produção ora mais para açúcar, ora mais para álcool. Devem-se respeitar os limitantes de moagem mínima e máxima das usinas referentes à geração de vapor para funcionamento da usina e capacidade máxima de operação, o que está contemplado nesta dissertação. Faz-se uso também de um parâmetro para se regular a moagem máxima, o que confere maior controle do modelador diante de mudanças na capacidade de moagem em cada semana, seja por quebra de máquinas, seja por condições climáticas adversas que diminuam a colheita no campo.

$\mathrm{Na}$ etapa comercial, a variável de decisão é a escolha das alternativas de comercialização para cada produto, destinando-se uma quantidade maior de produto para mercado interno ou mercado externo após atendimento do hedge. Isso irá definir quantidades dos produtos em cada canal de comercialização e também o quanto estocar de cada produto em cada semana. O número de processos de separações comerciais é igual a 16, o que engloba situações de priorização de venda para mercado interno ou externo. Chega-se assim ao modelo das etapas agrícola, industrial e comercial denominado SOVTICE (sigla que significa seleção de Origem, Variedade, transporte, processo industrial, processo Comercial e tipo de estocagem). 
No desenvolvimento do modelo SOVTICE, decidiu-se juntar os processos industriais e comerciais num só processo, chegando-se ao total de 24 × $16=384$ processos para tomada de decisão semanal. Se por um lado isso facilita a montagem do modelo e seu processo de resolução, pois dessa maneira o mesmo fica linear, por outro limita os números escolhidos de processos para as etapas industrial e comercial. Tentou-se separar os processos industriais e comerciais, recaindo-se assim num modelo não-linear, pois envolvia o produto de duas variáveis binárias. Dessa maneira, a complexidade do modelo aumentava muito e não se obteve solução factível com aproximação de $0,5 \%$ com relação à solução ótima num tempo de funcionamento de $18 \mathrm{~h}$, inviabilizando deixar separados os processos industriais e comerciais. Foram pesquisadas ainda na bibliografia (MORABITO e YANASSE, 2008 e WILLIAMS, PAUL, 1999) formas de se linearizar o produto de variáveis binárias. Embora possível, a complexidade do modelo também aumentava quando comparada ao modelo linear SOVTICE desta dissertação. Com aproximação de $0,3 \%$ da solução ótima, o modelo SOVTICE rodou num tempo de aproximadamente 43 minutos, tempo aceitável para um modelo de planejamento agregado, optando-se assim em manter os processos industriais e comerciais juntos na modelagem do problema.

Paralelamente a este modelo, existe ainda o modelo de determinação de hedge de cada produto em cada semana, que define quantidades de açúcar e álcoois que serão reservadas para o hedge em cada semana, funcionando dessa maneira como dado de entrada para o modelo SOVTICE.

No modelo de determinação do hedge de cada produto, diferentemente das etapas agrícola e industrial/comercial, tem-se um modelo não-linear de otimização, sendo a não-linearidade presente apenas na função objetivo, que por ser quadrática não provoca complexidade acentuada no momento de rodar o modelo. Dados de previsão de preços futuros de açúcar e álcool da BM\&F e CEPEA/ESALQ e custos médios de produção de açúcar VHP, álcool AEHC e álcool AEAC na usina são os parâmetros de entrada para este modelo. De posse destes dados, calculam-se em cada semana as rentabilidades para os produtos que terão seus preços travados no hedge visando cobrir determinado valor de custo na usina numa semana futura com minimização da variância abaixo da média da rentabilidade almejada. Os dados de saída deste modelo são as quantidades de açúcar VHP (em toneladas) e álcoois AEHC e AEAC $\left(\mathrm{em} \mathrm{m}^{3}\right)$ que se devem produzir em cada semana para cobrir os custos determinados. Estes valores por sua vez alimentam o 
modelo de otimização da etapa de produção/comercialização com as demandas para hedge.

Analisando o modelo em todas as 36 semanas de planejamento, temos um total de

$36 \times(30+24 \times 16)=14904$ variáveis de decisão no período de safra relacionadas com escolhas de origem/variedade de cana e processos industriais/comerciais.

\subsection{O problema do mix de produção no PPCP das usinas e a etapa comercial}

Um dos principais problemas do PPCP (planejamento, programação e controle da produção) numa usina de açúcar e álcool é a decisão pelo mix de produção em cada período de safra. As constantes variações nos preços de açúcar e álcool nos mercados interno e externo e nos custos de produção dos mesmos produtos trazem dificuldades no planejamento, programação e controle da produção nas usinas, o que comumente provocam tomadas de decisões que se afastam muito da solução ótima quando da venda dos produtos finais.

Aliado a isso, uma restrição importante nas operações de hedge, estocagem e venda spot é a administração do fluxo de caixa da usina, o que faz com que o empresário procure se proteger para honrar com seus compromissos.

No horizonte móvel de planejamento, definir qual o melhor mix de produção para comercialização Spot, qual o melhor mix no hedge e quais as melhores quantidades em estoque nas usinas é primordial para a maximização do lucro das usinas sucroalcooleiras. Os parâmetros que definirão isso serão os preços (dados secundários) de açúcar e álcool futuro segundo projeções de órgãos especializados (CEPEA/ESALQ, BM\&F) e de corretoras especializadas (CMA, SCA, CZARNIKOW e outras), que utilizam o método Delphi de previsão. A análise de sensibilidade do modelo proposto, ou seja, o quanto pode variar o preço do açúcar e do álcool mantendo a solução ótima estabelecida no hedge e estabelecida para os mercados interno e externo, é uma ferramenta útil para a tomada de decisões gerenciais. Isso pode ajudar as decisões dos gestores fazendo com que a programação da produção fique mais próxima do ótimo segundo a função objetivo de maximização do lucro.

\subsection{O modelo Semi-variância com análise de cenários de Markowitz para a decisão de mix de produção no hedge de usinas de açúcar e álcool}

Realizar previsões é uma das etapas mais importantes em muitos sistemas produtivos. Para muitas organizações, nenhuma outra atividade exerce influência tão imediata na lucratividade, na qualidade de serviço ao cliente e na produtividade como um bom 
sistema de previsão. Sendo assim, as previsões são essenciais para todos os planos e decisões porque nada acontece sem que alguém faça uma previsão (SANDERS, 1995; DE LURGIO, 1998; PINDYCK; RUBINFELD, 2006).

Modelos de previsão de portfólio estão relacionados com operações onde há tipicamente dois critérios: retorno esperado e risco. Há uma variedade de medidas de risco e a mais popular dessas medidas tem sido a variância sobre o retorno. No entanto, muitos a criticam por levar em conta não só variabilidade para baixo do valor esperado como também para cima (SCHRAGE, 2007, EDWARDS; MA, 1992). O interesse dos empresários é diminuir o risco abaixo do valor esperado de seu investimento.

Dessa maneira, nesta dissertação é utilizada como medida de risco a semi-variância aliada ao modelo de análise de cenários (SCHRAGE, L, 2007, EDWARDS; MA, 1992), que mede o quanto os valores estão se deslocando abaixo da média, o que aqui significa risco de preço. A escolha por esse modelo de otimização de portfólios se deve à possibilidade de se estabelecer cenários de acordo com os preços previstos de açúcar e álcool em cada semana, permitindo ainda o estabelecimento de probabilidades de ocorrência para cada cenário e também devido ao fato de responder bem às necessidades de minimização de risco abaixo da média. Dependendo das probabilidades alocadas a cada cenário, o modelo de mix ótimo pode se adaptar a um perfil mais conservador ou mais moderado de quem o utiliza. Trata-se de um ponto importante deste modelo, já que os gestores das usinas, com suas equipes do departamento comercial e assessorias especializadas do mercado, devem definir as probabilidades associadas a cada cenário interferindo no mix estabelecido para o hedge dos produtos. Embora a formulação se trate de um modelo não-linear (a não linearidade ocorre na função objetivo), os algoritmos para programação linear podem ser aplicados para a programação quadrática com modestas modificações. A razão disso é que a primeira derivada de uma função quadrática é uma função linear (SCHRAGE, 2007). No caso das operações de hedge com açúcar e álcool, o empresário deseja se proteger de variações inesperadas no câmbio e nos preços para baixo dos produtos. Deve ainda atentar para o cumprimento dos prazos de entrega e controle do fluxo de caixa. 


\subsubsection{Modelo de hedge proposto}

\section{A proposta de um modelo de hedge nas usinas de açúcar e álcool}

É comum as usinas estipularem uma cota para hedge próxima daquela que cobre parte dos custos da usina em cada semana, deixando o restante para se negociar no mercado spot, ou seja, negociação na própria semana com canais de venda como corretoras, representantes comerciais e tradings. Logicamente são estipulados valores monetários a se proteger que não superem a capacidade máxima de produção da usina em cada semana.

O uso adequado deste mecanismo de proteção pode proporcionar às empresas do setor sucroalcooleiro um planejamento mais eficiente e seguro da atividade, assim como a visão da tendência das opções de melhores comercializações futuras. Mas para fazer este tipo de negócio as empresas necessitam de capital disponível para arcar com os ajustes financeiros exigidos, o que deve estar incluído no capital de giro da empresa.

Suponha-se que a rentabilidade sobre o mix de produtos negociados no hedge que a usina busque em cada semana seja de T. Esse então será o valor de rentabilidade alvo que o departamento comercial da usina deverá buscar em suas operações de hedge procurando ainda minimizar os riscos da operação. Para tanto, será melhor priorizar o hedge com relação a açúcar, álcool anidro ou álcool hidratado? A presente dissertação propõe nessa parte da etapa comercial um modelo de programação quadrática que determina qual o mix ótimo no hedge para os produtos acima citados de maneira a se atingir a rentabilidade almejada $\mathrm{T}$ minimizando o desvio abaixo da média sobre o retorno. 


\section{Formulação matemática}

Min $Z=\sum_{s=1}^{5} P R B_{s}\left(D V L_{s}\right)^{2}$

sujeito a

$$
\begin{aligned}
& R_{s}=\sum_{p=1}^{3} X_{p} . V E_{p, s} \quad, \quad s=1, \ldots, 5 \\
& D V U_{s}-D V L_{s}=R_{s}-\mu \quad, \quad s=1, \ldots, 5 \\
& \sum_{p=1}^{3} X_{p}=1 \\
& X_{p} \geq P M_{p} \quad, \quad p=1,2,3 \\
& \mu=\sum_{s=1}^{5} P R B_{s} \cdot R_{s} \\
& \mu>T \\
& X_{p} \geq 0 \quad, \quad p=1, \ldots, 3
\end{aligned}
$$

\section{Simbologia utilizada}

- $\mathrm{PRB}_{\mathrm{s}}$ : Probabilidade associada ao cenário s;

- T: Rentabilidade alvo almejada pelos gestores da usina;

- p: índice referente aos produtos que irão compor o hedge, a saber, açúcar VHP, álcool AEAC e álcool AEHC;

- $\mathrm{VE}_{\mathrm{p}, \mathrm{s}}:$ Valor esperado do produto $\mathrm{p}$ a compor o mix sob o cenário $\mathrm{s}$;

- $\mathrm{X}_{\mathrm{p}}$ : porcentagem do produto $\mathrm{p}$ a compor o hedge;

- $\mathrm{PM}_{\mathrm{p}}$ : participação mínima(\%) do produto p no hedge;

- $\mathrm{DVU}_{\mathrm{s}}$ : desvio das rentabilidades acima da média sob o cenário s;

- DVL $_{\mathrm{s}}$ : desvio das rentabilidades abaixo da média sob o cenário s;

- $\mathrm{R}_{\mathrm{s}}$ : rentabilidade associada a todos os produtos $\mathrm{p}$ sob o cenário $\mathrm{s}$;

- $\quad \mu$ : Média de todos os retornos associados com as probabilidades respectivas dos cenários; 


\section{Explicação do modelo}

A função objetivo em (1) minimiza o desvio dos retornos abaixo da rentabilidade alvo. Em (2) tem-se a rentabilidade associada a todos os cenários s e produtos $\mathrm{p}$.

Na restrição (3), observa-se que o desvio abaixo da média $\left(\mathrm{DVL}_{\mathrm{s}}\right)$ para cada cenário é colocado no subtraendo para que possa ser minimizado na função objetivo. Em (4), a soma das porcentagens de cada produto no hedge vale $100 \%$. Na restrição (5) existe um limite inferior impedindo que cada produto tenha sua participação no hedge inferior a PM (\%),uma participação mínima. Na restrição (6), a média $\mu$ é igual ao somatório das probabilidades de cada cenário com suas respectivas rentabilidades. Em (7), a média é imposta maior ou igual à rentabilidade alvo T. A restrição (8) garante que não haja participação negativa dos produtos no hedge. Essa restrição foi mantida caso o modelador queira excluir a restrição (5).

Tabela 6. Previsões de preços dos produtos e cenários

\begin{tabular}{|c|c|c|c|}
\hline Meses & $\begin{array}{l}\text { Preço do açúcar } \\
\text { (R\$/sc de } 50 \mathrm{~kg} \text { ) }\end{array}$ & $\begin{array}{c}\text { Preço do álcool } \\
\text { hidratado } \\
\left(\mathrm{R} \$ / \mathrm{m}^{3}\right)\end{array}$ & $\begin{array}{l}\text { Preço do álcool } \\
\text { anidro }\left(\mathrm{R} \$ / \mathrm{m}^{3}\right)\end{array}$ \\
\hline Fev & 28,97 & 580 & 673 \\
\hline Mar & 26,87 & 590 & 680 \\
\hline$A b r$ & 25,83 & 600 & 685 \\
\hline Mai & 26,1 & 588 & 679 \\
\hline Jun & 26,8 & 592 & 682 \\
\hline Jul & 27,4 & 587 & 675 \\
\hline Ago & 28,3 & 582 & 674 \\
\hline Set & 29 & 579 & 670 \\
\hline Out & 31,5 & 586 & 676 \\
\hline
\end{tabular}

Para elucidar melhor o significado dos cinco cenários s presentes no modelo acima, considere-se a tabela 6, que mostra uma previsão de preços de açúcar, álcool hidratado e álcool anidro para os meses de fevereiro a outubro de determinado ano. Suponha-se que a usina queira estabelecer um hedge para o mês de abril. Cada mês de fevereiro a junho (num total de cinco meses) é considerado como um cenário e são então associadas probabilidades de ocorrências para os preços dos produtos em cada um desses cenários, dois deles antes de abril e dois depois de abril, obtendo-se assim um preço médio para cada produto. Dessa forma, os gestores das usinas podem alocar probabilidades iguais a todos os cenários, ou priorizar determinado cenário com probabilidade mais elevada, assumindo assim risco maior caso os preços previstos realmente não se efetivem. 


\section{Quantidades (t ou m³) "hedgeadas" de açúcar e álcoois}

Após a determinação da porcentagem do mix ótimo para o hedge de açúcar e álcoois, é necessário determinar que quantidades de açúcar (em toneladas) e álcoois (em $\mathrm{m}^{3}$ ) entrarão no hedge para cobrir os custos especificados em cada semana. É interessante observar que isso confere ao gestor da usina um perfil mais conservador ou mais agressivo quanto à forma de se lidar com riscos dependendo da quantidade de produtos produzidos pela usina que ele comprometerá no hedge. Já que o preço fixado no hedge na semana t será o preço recebido e cobrirá os custos especificados, a decisão recai sobre quais os produtos mais rentáveis para cobrir os custos e que valor de custo semanal deve ser coberto.

De acordo com os gestores da usina utilizada para validação da pesquisa, isso é feito muitas vezes de forma subjetiva e pelo que há de informação no mercado. Admitindo que em uma determinada semana se queira cobrir custos de $\mathrm{R} \$ 200.000,00$ com hedge, como determinar que quantidades de açúcar, álcool anidro e hidratado devem entrar no hedge nessa semana de maneira a minimizar o risco com rentabilidade sobre os produtos?

Após rodar o modelo "Semi-variância com análise de cenários de Markowitz", em uma determinada semana t podemos obter como resultado para o mix ótimo os valores $60 \%$ para açúcar VHP, $40 \%$ para AEAC e $20 \%$ para AEHC. É necessário dimensionar a produção para cobrir custos de $\mathrm{R} \$ 200.000,00$ de tal modo que $60 \%$ x $200.000=$ $\mathrm{R} \$ 120.000$ venha da venda de açúcar VHP, 40\% x $200.000=\mathrm{R} \$ 80.000$ venha de AEAC e $20 \%$ x $200.000=\mathrm{R} \$ 40.000$ venha de AEHC.

Suponha-se que os preços travados na semana t para o hedge de açúcar VHP, álcool

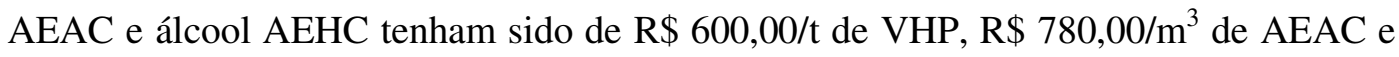
$\mathrm{R} \$ 715,00 / \mathrm{m}^{3}$ de AEHC. Logo, deve-se produzir para hedge um total de 120.000/600 = 200 t de açúcar VHP, 80.000/780 = 102,6 $\mathrm{m}^{3}$ de álcool AEAC e $56 \mathrm{~m}^{3}$ de álcool AEHC. 
5.4 O modelo matemático de otimização para a etapa de produção/comercialização

\section{Índices utilizados no modelo}

- $\quad v \quad$ variedades de cana, num total de 15 variedades;

- $p$ produtos comercializados no mercado Spot interno e mercado Spot externo: açúcar VHP, AEHC, AEAC e melaço. Este índice também se refere aos produtos produzidos pela usina.

- $t \quad$ semana em estudo, no horizonte de 52 semanas a partir do início da safra;

- $\quad f f$ fonte de fornecimento, que pode ser própria ou de terceiros. Juntando aqui os tipos de variedades, temos um total de 30 fontes de fornecimento.

- $f f t$ fonte de fornecimento de terceiros, totalizando 15 opções juntamente com as variedades;

- If tipo de frota, a qual pode ser própria ou terceirizada, o que resulta em 2 possibilidades;

- $f p \quad$ frota própria;

- $k$ processos industriais/comerciais de produção de açúcar, álcool e melaço;

- $e$ tipos de estoque, os quais podem ser próprios ou terceirizados.

\section{Objetivo e Restrições}

Maximização da margem de contribuição agroindustrial/comercial em usinas de açúcar e álcool. Para se alcançar esse objetivo, serão determinados a moagem semanal de cada variedade de cana por fonte de fornecimento, o processo industrial/comercial a se utilizar em cada semana e o nível de estoque dos produtos em cada semana. As restrições consideradas são de fluxo de caixa semanal mínimo, moagem mínima de cana, moagem máxima de cana, capacidade de estocagem máxima de cada produto, capacidade de transporte com frota própria, obediência aos hedges comerciais estabelecidos e contratos de fornecimento de açúcar e álcool. 


\section{Dados de entrada para o modelo}

- $\quad$ ValorPSpotI $\mathrm{p}_{\mathrm{t}, \mathrm{t}}$ semana $t\left(\mathrm{R} \$ / \mathrm{t}\right.$ ou $\left.\mathrm{R} \$ / \mathrm{m}^{3}\right)$;

- $\quad$ ValorPSpotE $\mathrm{E}_{\mathrm{p}, \mathrm{t}}$ semana $t\left(\mathrm{R} \$ / \mathrm{t}\right.$ ou $\left.\mathrm{R} \$ / \mathrm{m}^{3}\right)$;

- $\quad$ ValorPHedge $\mathrm{p}_{\mathrm{p}, \mathrm{t}}$ $\left(\mathrm{R} \$ / \mathrm{t}\right.$ ou $\left.\mathrm{R} \$ / \mathrm{m}^{3}\right)$;

- $\quad$ MoagemMin

- $\quad$ MoagemMax
Valor no mercado Spot interno do produto $p$ na Valor no mercado Spot externo do produto $p$ na Valor no mercado Futuro do produto $p$ na semana $t$ Moagem mínima de cana (t/sem); Moagem máxima de cana (t/sem);

Os dois parâmetros anteriores acima se referem à capacidade de moagem da usina e à exigência mínima de moagem para geração de vapor para as caldeiras.

- $\mathrm{CG}_{\mathrm{t}} \quad$ Capital de giro necessário por semana para que a usina cumpra com os compromissos assumidos $(\mathrm{R} \$)$;

- $\quad$ CapEst $_{\mathrm{p}, \mathrm{e}, \mathrm{e}} \quad$ Capacidade de estocagem do produto $p$ na semana $\mathrm{t}$ no tipo de estoque e;

- $\quad \mathrm{PTU}_{\mathrm{t}}$ Porcentagem de tempo útil de funcionamento da usina durante as semanas de análise $t$;

- Dem $\quad$ Dedge,, $\mathrm{t}$ Demanda pelo produto $p^{\prime}$ em cada semana $t(\mathrm{t} / \mathrm{sem}$ ou $\mathrm{m}^{3} / \mathrm{sem}$ ) ocasionada pelo hedge do produto $\mathrm{p}$;

- $\quad$ Dem $_{\text {Spot,p,t }}$

Demanda Spot interno pelo produto $p$ em cada semana $t\left(\mathrm{t} / \mathrm{sem} \mathrm{ou} \mathrm{m}^{3} / \mathrm{sem}\right)$;

- RAGI $_{\mathrm{p}, \mathrm{v}, \mathrm{k}, \mathrm{t}} \quad$ Rendimentos agroindustriais ( $\mathrm{t}$ ou $\mathrm{m}^{3}$ ) de cada produto $\mathrm{p}$ obtido a partir da variedade de cana $\mathrm{v}$, pelo processo $\mathrm{k}$ e na semana $\mathrm{t}$;

- $\quad$ EInic $_{\mathrm{p}} \quad$ Estoque inicial do produto $\mathrm{p}$;

- PlanSafra ${ }_{\mathrm{v}, \mathrm{ff}} \quad$ Disponibilidade de cana de variedade v segundo a fonte de fornecimento $f f$ na semana zero. Trata-se aqui da previsão de safra para cada variedade de cana e fonte de fornecimento;

- CustoOrigvar $r_{\mathrm{v}, \mathrm{ff}, \mathrm{t}} \quad$ Custos agrícolas ( $\$ / \mathrm{t}$ de cana) da variedade de cana $v$ pela origem de fornecimento ff na semana $t$; Como cada variedade possui um custo de processamento industrial diferente, esse custo é repassado para a parte de custos agrícolas;

- CustoProcIC $\mathrm{k}_{\mathrm{k}, \mathrm{t}}$ Custos de cada processo industrial/comercial $(\mathrm{R} \$ / \mathrm{t}$ ou $\mathrm{R} \$ / \mathrm{m}^{3}$ ) $k$ em cada semana $t$; 
- $\quad$ RendIndCom

Rendimento industrial/comercial de cada produto $\mathrm{p}$, em cada processo $\mathrm{k}$ e em cada semana $\mathrm{t}$;

- $\mathrm{TCO}_{\mathrm{p}, \mathrm{z}, \mathrm{t}}$ Taxas de comercialização $\left(\mathrm{R} \$ / \mathrm{t}\right.$ ou $\left.\mathrm{R} \$ / \mathrm{m}^{3}\right)$ do produto $p$ pelo processo comercial z na semana $t$;

- Cest $_{\mathrm{p}, \mathrm{e}, \mathrm{t}} \quad$ Custo de estocagem do produto $\mathrm{p}\left(\mathrm{R} \$ / \mathrm{t}\right.$ ou $\left.\mathrm{R} \$ / \mathrm{m}^{3}\right)$ no tipo de estoque $e$ na semana $t$;

- alfa Porcentagem de cana permissível proveniente de terceiros;

- CapTranspP Capacidade de transporte da frota própria da usina;

- CustoFrota $\mathrm{tf}_{\mathrm{t}, \mathrm{t}} \quad$ Custo de transportar cada tonelada de cana segundo o tipo de frota(própria ou terceirizada) em cada semana t;

- RcomerciaisHedge $\mathrm{k}_{\mathrm{k}, \mathrm{t}} \quad$ Receitas comerciais obtidas com a soma dos hedges dos produtos p' a partir de cada processo k e em cada semana t;

- RcomerciaisSpot $\mathrm{I}_{\mathrm{k}, \mathrm{t}} \quad$ Receitas comerciais obtidas com a soma das vendas no mercado Spot interno dos produtos p a partir de cada processo k e em cada semana $\mathrm{t}$;

- RcomerciaisSpotE $E_{k, t} \quad$ Receitas comerciais obtidas com a soma das vendas no mercado Spot externo dos produtos p a partir de cada processo k e em cada semana t; 


\section{Variáveis de decisão do modelo (Dados de saída)}

- $\mathrm{QCP}_{\mathrm{k}, \mathrm{t}}$ : Variável de decisão da quantidade de cana processada segundo o processo industrial $\mathrm{k}$ na semana $t$ (t/semana);

- $\quad \mathrm{QCF}_{\mathrm{v}, \mathrm{ff}, \mathrm{t}}$ Variável de decisão da quantidade de cana de variedade $v$ colhida por semana (t/semana) obtida em cada origem de fornecimento ff e em cada semana $t$;

- QCT $_{\mathrm{tf}, \mathrm{t}} \quad$ Variável de decisão de quantidade de cana transportada segundo o tipo de frota (própria ou terceirizada) em cada semana $t$.

- $\quad$ PosEst $_{\mathrm{p}, \mathrm{t}} \quad$ Variável de decisão da quantidade de cada produto $\mathrm{p}$ em estoque no final de cada semana t.

- $\mathrm{X}_{\mathrm{k}, \mathrm{t}}$ : Variável binária de escolha de processos industriais/comerciais. Decisão de utilizar $\left(\mathrm{X}_{\mathrm{kt}}=1\right)$ ou não $\left(\mathrm{X}_{\mathrm{kt}}=0\right)$ o processo $k$ na semana $t$;

- $\quad$ DispCana $_{\mathrm{v}, \mathrm{ff}, \mathrm{t}} \quad$ Disponibilidade de cada variedade $v$ de cana no campo no início de cada semana $t$ e segundo cada fonte de fornecimento ff (própria ou terceiros).

- $\quad$ QCPhedge $_{\mathrm{k}, \mathrm{t}} \quad$ Quantidade(t) de cana processada pelo processo industrial $\mathrm{k}$ para atender as quantidades travadas no Hedge em cada semana t.

- $\quad$ QCPspotI $\mathrm{k}_{\mathrm{k}, \mathrm{t}} \quad$ Quantidade de cana(t) processada pelo processo industrial $\mathrm{k}$ para atender o mercado Spot interno em cada semana $\mathrm{t}$.

- $\quad$ QCPspotE $_{\mathrm{k}, \mathrm{t}} \quad$ Quantidade de cana(t) processada pelo processo industrial $\mathrm{k}$ para atender o mercado Spot externo em cada semana t.

- $\quad \mathrm{MC}_{\mathrm{t}} \quad$ Margem de contribuição da usina em cada semana $\mathrm{t}$

\section{O modelo matemático}

Agora que já se tem os índices utilizados no modelo, os dados de entrada e as variáveis de decisão, podem-se apresentar as equações do modelo desta dissertação denominado SOVTICE (Seleção de origem de fornecimento, de variedade de cana, tipo de transporte, de processos industriais, de processos de comercialização e tipo de estoque). Não se consideraram aqui custos de setup por estes serem de segunda ordem neste nível de análise. 


\section{Função objetivo}

Maximização da margem de contribuição de uma usina de açúcar e álcool.

$$
\begin{aligned}
& \max Z=\sum_{p} \sum_{k} \sum_{t} \text { rcomerciaisHedge }_{p, k, t} . \text { QCPHedge }_{k, t}+\sum_{p} \sum_{t} \text { ValorPSpotI }_{p, t} \text {.Vendas }_{p, t} \\
& +\sum_{p} \sum_{t} \text { ValorPSpot }_{p, t} \text {.Vendas }_{p, t}-\sum_{f f} \sum_{t} \text { CustoOrigVar }_{f f, t} \cdot Q C F_{f f, t}- \\
& \sum_{t f} \sum_{t} \text { CustoFrota }_{t f, t} \cdot Q C T_{t f, t}-\sum_{k} \sum_{t} \text { Custo ProcIC } C_{k, t} \cdot Q C P_{k, t}-\sum_{p} \sum_{e} \sum_{t} \text { Cest }_{p, e, t} . \text { PosEst }_{p, e, t}- \\
& \sum_{p} \sum_{t} \text { Demhedge }_{p, t} . \text { ValorPHedge } e_{p, t} \text {.TCOHedge } e_{p, t}- \\
& \sum_{p} \sum_{t} \text { VendasI }_{p, t} \text {.ValorPSpotI }_{p, t} \text { TCOSpotI }_{p, t}- \\
& \sum_{p} \sum_{t} \text { Vendas }_{p, t} \text {.ValorPSpot } E_{p, t} \text {.TCOSpot } E_{p, t}
\end{aligned}
$$

\section{Restrições}

\section{Restrição 1}

Para cada processo industrial/comercial k, a variável $\mathrm{X}$ deve ser binária com a finalidade de escolha de apenas um processo industrial/comercial em cada semana t. Isso totaliza $24 \times 16=384$ processos combinados possíveis.

$$
X \in\{0,1\}
$$

Para cada semana t a variável y deve ser binária. Essa variável está relacionada com a condição de moagem mínima no período de safra. Quando não há produção, não há exigência de moagem mínima.

$Y \in\{0,1\}$

\section{Restrição 2}

Para cada processo k e semana t, a quantidade de cana processada (QCP) deve ser igual à soma da quantidade de cana processada para o hedge com a quantidade de cana processada para o mercado Spot interno e quantidade de cana processada para o mercado Spot externo.

$$
Q C P_{k, t}=Q C P H e d g e_{k, t}+Q C P S p o t I_{k, t}+Q C P S p o t E_{k, t} \quad k=1, \ldots, 384, \quad t=1, \ldots, 36
$$

\section{Restrição 3}

Restricão de fluxo de caixa. Com o que a usina vende em cada semana mais o capital de giro ela deve honrar com os compromissos financeiros assumidos 
$\sum_{p} \sum_{k} \sum_{t}$ rcomerciaisHedge $_{p, k, t}$. QCPHedge $e_{k, t}+\sum_{p} \sum_{t}$ ValorPSpotI $_{p, t}$. Vendas $_{p, t}$

$+\sum_{p} \sum_{t}$ ValorPSpot $_{p, t}$ Vendas $_{p, t}+C G \geq \sum_{f f} \sum_{t}$ CustoOrig Var $\operatorname{Vff}_{t,} \cdot Q C F_{f f, t}+$

$\sum_{t f} \sum_{t}$ CustoFrota $_{t f, t} \cdot Q C T_{t f, t}+\sum_{k} \sum_{t}$ Custo ProcIC C $_{k, t} \cdot Q C P_{k, t}+\sum_{p} \sum_{e} \sum_{t}$ Cest $_{p, e, t}$ PosEst $_{p, e, t}+$

$\sum_{p} \sum_{t}$ Demhedge $e_{p, t}$. ValorPHedge $e_{p, t}$.TCOHedge $e_{p, t}+$

$\sum_{p} \sum_{t}$ Vendas $_{p, t}$. ValorPSpot $_{p, t} \cdot$ TCOSpotI $_{p, t}+$

$\sum_{p} \sum_{t}$ Vendas $_{p, t}$.ValorPSpot $E_{p, t} \cdot$ TCOSpot $E_{p, t}$

\section{Restrição 4}

Estoque inicial e restrição de balanceamento de estoque dos produtos $p$ no tipo de estoque $e$ no final de cada semana $t$.

PosEst $_{p, e, t}=$ Einic $_{p, e, t}, \quad t=0$

$\sum_{e}$ PosEst $_{p, e, t}=\sum_{e}$ PosEst $_{p, e, t-1}+\sum_{p} \sum_{k} \sum_{t} \operatorname{Re}$ ndIndcomSpotI $_{p, k, t} \cdot$ QCPSpotI $_{k, t}+$

$\sum_{p} \sum_{k} \sum_{t} \operatorname{Re} n d I n d c o m S p o t E_{p, k, t}$. QCPSpot $_{k, t}-$ DemHedge $_{p, t}-$ Vendas $_{p, t}-$ Vendas $_{p, t}$, $t=1, \ldots, 36$

\section{Restrição 5}

A demanda Hedge de cada produto sempre deve ser atendida em cada semana, o que ocorre pela produção da própria semana.

$\sum_{t} \sum_{k}\left(\operatorname{Re} n d I n d \operatorname{comSpotI} I_{V H P, k, t}+\operatorname{Re} n d I n d \operatorname{comSpot} E_{V H P, k, t}\right) \cdot Q C P H e d g e V H P_{k, t}$

$=$ DemHedge $e_{V H P, t}$

$\sum_{t} \sum_{k}\left(\operatorname{Re} n d I n d \operatorname{lom} \operatorname{SpotI}_{A E A C, k, t}+\operatorname{Re}\right.$ ndIndcomSpot $\left.E_{A E A C, k, t}\right) . Q C P H e d g e A E A C_{k, t}$

$=$ DemHedge $_{A E A C, t}$

$\sum_{t} \sum_{k}\left(\operatorname{Re} n d I n d \ln \operatorname{spotI}_{A E H C, k, t}+\operatorname{Re} n d I n d \operatorname{comSpot} E_{A E H C, k, t}\right) . Q C P H e d g e A E H C_{k, t}$

$=$ DemHedge $_{A E H C, t}$ 


\section{Restrição 6}

A quantidade de cana processada para hedge é obtida pela soma da quantidade de cana processada para hedge para VHP, AEAC e AEHC.

$Q C P H e d g e=Q C P H e d g e V H P+Q C P H e d g e A E A C+Q C P H e d g e A E H C$

\section{Restrição 7}

As vendas para mercado interno e externo devem ser maiores que as demandas respectivas para mercado interno e externo.

VendasI $_{p, t}>=$ DemSpotI $_{p, t}$

Vendas $E_{p, t}>=$ DemSpot $_{p, t}$

\section{Restrição 8}

As vendas efetuadas para mercado interno não podem superar a capacidade de produção mais valor presente em estoque.

$$
\sum_{e} \text { PosEst }_{p, e, t-1}+\sum_{p} \sum_{k} \sum_{t} \operatorname{Re} \text { ndIndcomSpotI }_{p, k, t} \cdot \text { QCPSpotI }_{k, t}-\text { DemHedge }_{p, t} \geq \text { VendasI }_{p, t}
$$

\section{Restrição 9}

As vendas efetuadas para mercado externo não podem superar a capacidade de produção mais valor presente em estoque.

$$
\sum_{e} \text { PosEst }_{p, e, t-1}+\sum_{p} \sum_{k} \sum_{t} \operatorname{Re} n d I n d c o m S p o t E_{p, k, t} . \text { QCPSpot }_{k, t}-\text { DemHedge }_{p, t} \geq \text { Vendas }_{p, t}
$$

\section{Restrição 10}

Restrição referente à previsão de safra para cada variedade de cana e cada tipo de fornecimento.

$$
\text { DispCana }_{f f, 1}<=\text { PlanSafra }_{f f}
$$

\section{Restrição 11}

Restrições de balanceamento de estoque de cana no campo.

$$
\text { DispCana }_{v, f f, t}=\text { DispCana }_{v, f f, t-1}-Q C F_{v, f f, t-1}
$$




\section{Restrição 12}

A quantidade de cana fornecida/colhida de cada variedade/fonte de fornecimento em cada semana deve ser menor ou igual à disponibilidade de cana no campo naquela semana daquele tipo de variedade/fonte de fornecimento;

$Q C F_{v, f f, t} \leq$ DispCana $_{v, f f, t}$

\section{Restrição 13}

Restrição referente à compatibilidade entre quantidade de cana de cada variedade/fonte de fornecimento colhida e quantidade de cana de cada variedade/fonte de fornecimento transportada em cada semana t.

$$
\sum_{f f} \sum_{t} Q C F_{v, f f, t}=\sum_{f f} \sum_{t} Q C T_{v, f f, t}
$$

\section{Restrição 14}

Compatibilidade entre quantidade de cana transportada de cada variedade/fonte de fornecimento e quantidade de cana processada de cada variedade/fonte de fornecimento.

$$
\sum_{f f} \sum_{t} Q C T_{v, f f, t}=\sum_{k} \sum_{t} Q C P_{v, k, t}
$$

\section{Restrição 15}

Limitante para moagem mínima em cada semana $\mathrm{t}$ a partir do processo k necessária para geração de energia para rodar as máquinas da usina. A constante $\mathrm{M}$ é um número suficientemente grande.

$\sum_{k} \sum_{t} Q C P_{k, t} \geq$ MoagemMin $_{t}-M \cdot y$

\section{Restrição 16}

Caso a variável binária y seja 1, PTU deve ser zero e assim não há exigência para moagem mínima.

$$
P T U_{t} \leq M \cdot(1-y)
$$

\section{Restrição 17}

Limitante para Moagem máxima com o fator PTU, o qual se refere à porcentagem de tempo útil de funcionamento da usina em cada semana.

$$
\sum_{k} \sum_{t} Q C P_{k, t} \leq \text { MoagemMax }_{t} \cdot P T U_{t}
$$




\section{Restrição 18}

Restrição que regula a quantidade de cana comprada de terceiros em cada semana t.

$\sum_{f f t} \sum_{t} Q C F_{f f t, t} \leq\left(\right.$ alfa / 100). $\sum_{k} \sum_{t} Q C P_{k, t}$

\section{Restrição 19}

Restrição relativa à capacidade de transporte por frota própria da usina em cada semana t.

$\sum_{f p} \sum_{t} Q C T_{f p, t} \leq$ CapTranspP $P_{t}$

\section{Restrição 20}

Restrição para associar a moagem de cana em cada semana t a cada processo industrial/comercial $\mathrm{k}$ escolhido.

$Q C P_{k, t} \leq$ Moagem $\max _{t} . P T U_{t} . X_{k, t}$

\section{Restrição 21}

Restrição para alocação de apenas um processo industrial/comercial k em cada semana t.

$\sum_{k} \sum_{t} X_{k, t}=1$

\section{Restrição 22}

Restrição de capacidade de estocagem de cada produto p em cada tipo de estoque e em cada semana t.

$$
\text { PosEst }_{p, e, t} \leq \text { CapEst }_{p, e}
$$

\section{Restrição 23}

Toda a cana processada na safra deve ser menor ou igual à toda a cana disponível na safra.

$$
\sum_{k} \sum_{t} Q C P_{k, t}<=\sum_{f f} \text { PlanSafra }
$$

\section{Restrição 24}

Restrições de não negatividade das variáveis

$$
\begin{aligned}
& Q C P_{k, t} \geq 0 \quad, Q C F_{f f, t} \geq 0 \quad, Q C T_{t f, t} \geq 0 \quad, \text { PosEst }_{p, t} \geq 0 \quad, \text { DispCana }_{f f, t} \geq 0 \text {, } \\
& \text { QCPHedge }_{k, t} \geq 0 \quad, \text { QCPSpotI }_{k, t} \geq 0 \quad, \text { QCPSpot }_{k, t} \geq 0 \quad, M C_{t} \geq 0
\end{aligned}
$$




\section{RESULTADOS COMPUTACIONAIS COM OS MODELOS PROPOSTOS}

\subsection{Exemplo ilustrativo do modelo de análise de cenários a partir de semi-variância}

de Markowitz numa usina de açúcar e álcool

Os dados a seguir se referem aos preços futuros de açúcar VHP, álcool anidro (AEAC) e álcool hidratado (AEHC) obtidos junto ao CEPEA, BM\&F e ESALQ com data de previsão do dia 31/03/2009. Para este exemplo ilustrativo, para facilitar a coleta de dados de previsão é analisado período mensal ao invés de período semanal.

Tabela 7. Preços futuros de açúcar, álcool anidro e álcool hidratado segundo indicadores CEPEA/ESALQ/BMF

\begin{tabular}{|c|c|c|c|}
\hline Meses(2009) & $\begin{array}{c}\text { Preço do açúcar(R } \$ \text { /sc de } \\
50 \mathrm{~kg})\end{array}$ & $\begin{array}{c}\text { Preço do álcool anidro } \\
\left(\mathbf{R} \$ / \mathbf{m}^{3}\right)\end{array}$ & $\begin{array}{l}\text { Preço do álcool hidratado } \\
\left(\mathrm{R} \$ / \mathrm{m}^{3}\right)\end{array}$ \\
\hline Abril & 28,97 & 673,00 & 580,00 \\
\hline Maio & 26,87 & 680,00 & 590,00 \\
\hline Junho & 25,83 & 685,00 & 600,00 \\
\hline Julho & 26,10 & 679,00 & 588,00 \\
\hline Agosto & 26,80 & 682,00 & 592,00 \\
\hline Setembro & 27,40 & 675,00 & 587,00 \\
\hline Outubro & 28,30 & 674,00 & 582,00 \\
\hline Novembro & 29,00 & 670,00 & 579,00 \\
\hline Dezembro & 31,50 & 676,00 & 586,00 \\
\hline
\end{tabular}

Segundo dados obtidos junto à usina estudada, as projeções de custos médios de produção de açúcar, álcool anidro e álcool hidratado para a safra de 2009 são respectivamente iguais a $\mathrm{R} \$ 14,11 / \mathrm{saca}$ de $50 \mathrm{~kg}, \mathrm{R} \$ 442,00 / \mathrm{m}^{3}$ e $\mathrm{R} \$ 397,8 / \mathrm{m}^{3}$. Tomando-se como base esses valores, as rentabilidades dos três produtos em cada mês seguem na tabela a seguir. 
Tabela 8. Rentabilidades futuras de açúcar, álcool anidro e álcool hidratado segundo indicadores CEPEA/ESALQ/BMF

\begin{tabular}{|l|c|c|c|}
\hline \multicolumn{1}{|c|}{ Meses(2009) } & $\begin{array}{c}\text { Rentabilidade do } \\
\text { açúcar }\end{array}$ & $\begin{array}{c}\text { Rentabilidade do álcool } \\
\text { anidro }\end{array}$ & $\begin{array}{c}\text { Rentabilidade do álcool } \\
\text { hidratado }\end{array}$ \\
\hline Abril & 1,05 & 0,52 & 0,46 \\
\hline Maio & 0,90 & 0,54 & 0,48 \\
\hline Junho & 0,83 & 0,55 & 0,51 \\
\hline Julho & 0,85 & 0,54 & 0,75 \\
\hline Agosto & 0,90 & 0,54 & 0,75 \\
\hline Setembro & 0,94 & 0,53 & 0,75 \\
\hline Outubro & 1,01 & 0,52 & 0,46 \\
\hline Novembro & 1,06 & 0,52 & 0,46 \\
\hline Dezembro & 1,23 & 0,53 & 0,47 \\
\hline
\end{tabular}

Suponha-se que o departamento comercial da usina, através de sua corretora ou dos índices CEPEA, BM\&F e ESALQ tenha as projeções da tabela acima e que o tempo presente seja março de 2009. A empresa deseja fazer um hedge para o mês de julho de 2009 minimizando seus riscos e ainda conseguindo determinada rentabilidade. Entendemos da tabela acima que no mês de julho a rentabilidade do açúcar seria de $85 \%$, do álcool anidro de $75 \%$ e do hidratado de $54 \%$. Para determinar o hedge para o mês de julho, além dos dados desse mês serão tomados dados de dois meses antes de julho e dois meses depois, técnica que pode ser tomada como análise de cenários (SCHRAGE, 2007). Trata-se de uma média móvel para os dados de previsão. A partir daí, pode-se entrar com esses dados de previsão no modelo de otimização.

\section{Implementação no LINGO}

Utilizando a linguagem de modelagem do Lingo (ver anexo C), foi estruturado o seguinte código:

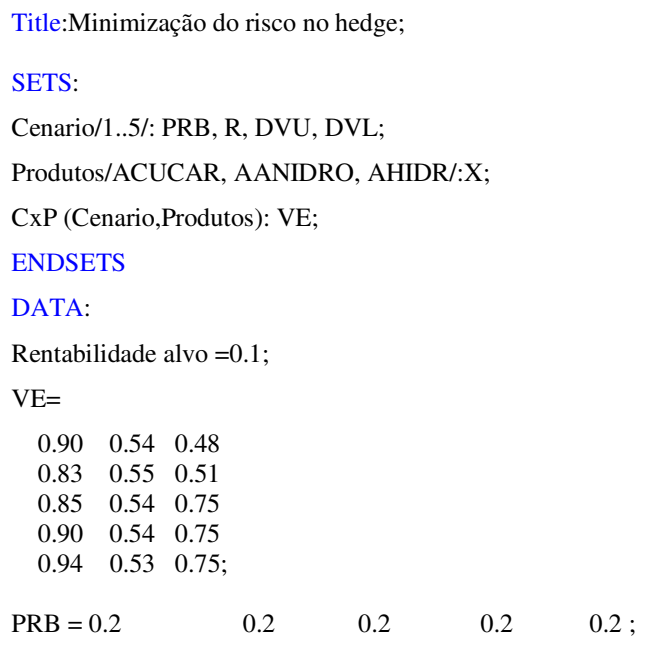


@ FOR $(\operatorname{Cenario}(\mathrm{S}): \mathrm{R}(\mathrm{S})=@ \operatorname{SUM}(\operatorname{Produtos}(\mathrm{J}): \mathrm{VE}(\mathrm{S}, \mathrm{J}) * \mathrm{X}(\mathrm{J}))$;

DVU(S)-DVL(S) =R(S)-Media;);

@ SUM (Produtos:X)=1;

Media=@SUM (Cenario: PRB*R);

Media $>$ Rentabilidade alvo;

!Função objetivo;

$\mathrm{MIN}=@$ SUM (Cenario: PRB*DVL^2);

END

No modelo acima, é admitido que nos cenários de preços dos 5 meses todos os preços têm igual probabilidade de ocorrer, daí os valores que aparecem como 0.2.Cada cenário assim se refere aos dados de previsão de determinado mês. No exemplo acima, o cenário 1 se refere aos valores de rentabilidades de açúcar, álcool anidro e hidratado respectivamente iguais a $0.90,0.54$ e 0.48 . E o cenário 5 aos valores $0.94,0.53$ e 0.75 de rentabilidades de açúcar, álcool anidro e hidratado respectivamente. A escolha de cenários dessa maneira permite que se determine o produto de maior rentabilidade que também possua o menor desvio abaixo da rentabilidade alvo.

\section{Resultados I}

Do relatório de análise de sensibilidade do software Lingo, foi obtido um desvio abaixo da rentabilidade alvo de $0,000113 \%$, o que indica um baixo risco. A porcentagem de hedge do açúcar seria de aproximadamente $11 \%$, a de álcool anidro de $87 \%$ e a de álcool hidratado seria igual a $2 \%$. Observa-se pelo custo reduzido das variáveis porcentagem de açúcar e porcentagem de álcool hidratado na solução ótima valores muito pequenos, o que permite certa mobilidade na escolha por quantidades maiores dos produtos no hedge sem afetar significativamente o objetivo de minimização do risco no hedge.

\begin{tabular}{|c|c|c|}
\hline \multicolumn{3}{|c|}{$\begin{array}{l}\text { Model Title: Minimização do risco no hedge } \\
\text { Global optimal solution found. }\end{array}$} \\
\hline Objective val & & $0.1135928 \mathrm{E}-05$ \\
\hline Extended solv & teps: & 0 \\
\hline Total solver & tions: & 12 \\
\hline Variable & Value & Reduced Cost \\
\hline RENT.ALVO & 0.1000000 & 0.000000 \\
\hline MEDIA & 0.5799713 & 0.000000 \\
\hline$X($ ACUCAR $)$ & 0.1101709 & $0.2856609 \mathrm{E}-08$ \\
\hline X( AANIDRO $)$ & 0.8706393 & 0.000000 \\
\hline X( AHIDR) & 0.1918981E-01 & $0.1638952 E-07$ \\
\hline
\end{tabular}

Após várias análises juntamente à gerência e diretoria comercial e industrial da usina estudada e conversas informais com gerentes e diretores das usinas Coruripe, Branco Peres, Alcídia e Califórnia chegou-se à conclusão que estabelecer limites inferiores para 
as porcentagens de escolhas de açúcar, álcool anidro e álcool hidratado seria um procedimento que modelaria melhor a realidade dos hedges efetuados pelas usinas no centro-sul do Brasil. Isto porque cada usina, no momento de efetuar o hedge procura obter seu capital de proteção não só com um único produto, mas com uma quantidade mínima com cada um deles devido a contratos estabelecidos. Decidiu-se então estabelecer em $15 \%$ a quantidade mínima a se efetuar no hedge para cada produto em cada semana, chegando-se assim ao código a seguir.

\section{Código no software Lingo}

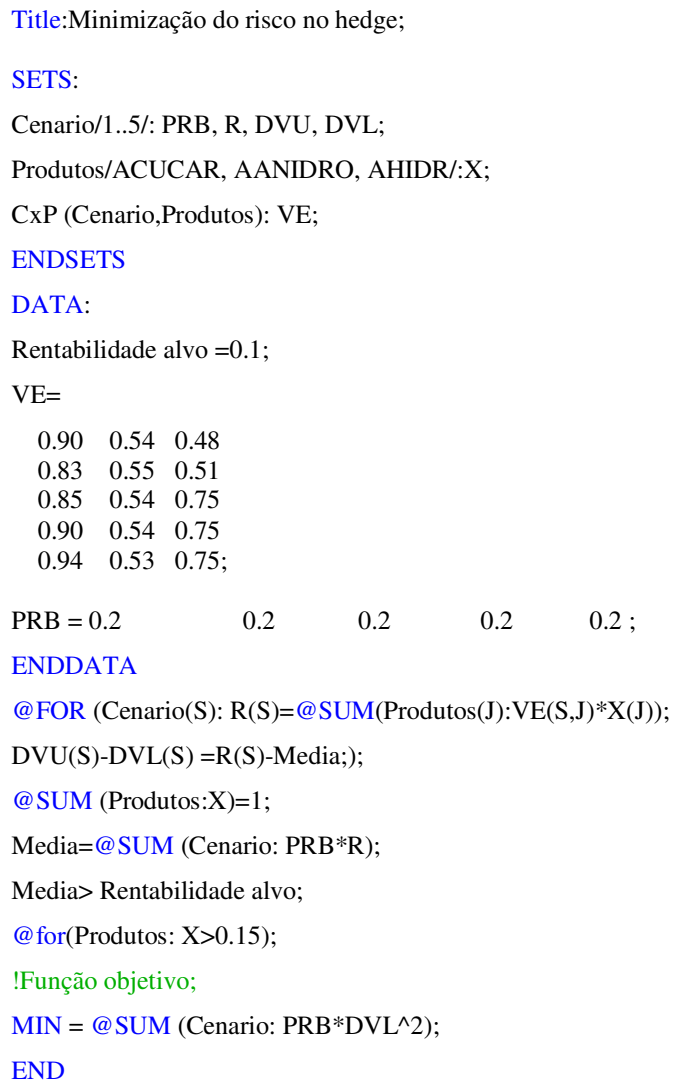

\section{Resultados II}

Do relatório de análise de sensibilidade do software Lingo, foi obtido um desvio abaixo da rentabilidade alvo de $0,019 \%$, o que indica um risco acima do risco anterior, mas ainda assim com baixo valor. A porcentagem de hedge do açúcar seria de aproximadamente $15 \%$, a de álcool anidro de $70 \%$ e a de álcool hidratado seria igual a $15 \%$ segundo relatório do LINGO apresentado abaixo. 
Model Title : Minimização do risco no hedge

Global optimal solution found.

Objective value:

Extended solver steps:

Total solver iterations:

0.1990170E-03

Variable Value $\quad$ Reduced Cost

RENT.ALVO $\quad 0.1000000 \quad 0.000000$

MEDIA $\quad 0.6078001 \quad 0.000000$

$\begin{array}{lll}X(\text { ACUCAR }) & 0.1500003 & 0.000000\end{array}$

$\begin{array}{lll}X(\text { AANIDRO }) & 0.6999997 & 0.000000\end{array}$

$\begin{array}{lll}X(\text { AHIDR }) & 0.1500000 & 0.000000\end{array}$

Observa-se que embora tenha aumentado o risco aumentou também a média de rentabilidade sobre os produtos. Os gestores das usinas devem optar assim por maior risco e maior retorno ou menor risco e menor retorno.

\subsection{Exemplo ilustrativo do minimodelo de produção industrial/comercialização e verificações de consistências lógicas.}

Para dar maior consistência aos resultados obtidos com a aplicação do modelo SOVITCE, nesta seção é feito um estudo em miniatura relativo à aplicação no estudo de caso real. Na tabela 9, comparam-se as dimensões do minimodelo e do modelo real.

Tabela 9. Dados de comparação entre Minimodelo e Modelo Real

\begin{tabular}{|l|cc|}
\hline Formas de transporte da cana & $\mathbf{2}$ & $\mathbf{2}$ \\
\hline Tipos de estoque & $\mathbf{2}$ & $\mathbf{2}$ \\
\hline Produtos acabados & $\mathbf{4}$ & $\mathbf{4}$ \\
\hline Processos industriais & $\mathbf{5}$ & $\mathbf{2 4}$ \\
Processos comerciais & $\mathbf{8}$ & $\mathbf{1 6}$ \\
\hline Processosindustriais/comerciais & $\mathbf{4 0}$ & $\mathbf{3 8 4}$ \\
Semanas analisadas & $\mathbf{5}$ & $\mathbf{5 2}$ \\
\hline Número de variáveis & $\mathbf{9 8 8 6}$ & $\mathbf{4 1 1 9 3 7}$ \\
Número de variáveis binárias & $\mathbf{4 8 6}$ & $\mathbf{2 0 4 0 5}$ \\
Número de restrições & $\mathbf{1 0 7 7 8}$ & $\mathbf{4 5 2 5 2 5}$ \\
\hline & & \\
\hline
\end{tabular}

No minimodelo, consideram-se 2 origens da cana-de-açúcar (cana cultivada pela própria usina e cana de terceiros); duas variedades hipotéticas de cana (Cana RB e Cana SP); duas formas de transportar a cana do campo à usina (frota própria e frota terceirizada); dois tipos de estocar os produtos derivados da cana (estoque próprio e estoque terceirizado); quatro produtos acabados (açúcar VHP, melaço, álcool anidro e álcool hidratado); cinco processos industriais e oito processos comerciais perfazendo um total de $5 \times 8=40$ processos industriais/comerciais e cinco semanas analisadas. 


\subsubsection{Cenário Base}

\subsubsection{Dados}

Para a análise do cenário base, consideram-se os valores das tabelas a seguir.

Tabela 10. Porcentagem de utilização de cana de terceiros

\begin{tabular}{|cc} 
Porcentagem de cana de terceiros $(\%)$ & \\
Sem0 & 0 \\
Sem1 & 100 \\
Sem2 & 100 \\
Sem3 & 100 \\
Sem4 & 100 \\
Sem5 & 100
\end{tabular}

Devido a contratos comerciais firmados, admite-se que a usina deva utilizar nas cinco semanas de análise toda a produção de cana de terceiros.

O tempo útil de moagem (PTU) para as cinco semanas de análise é admitido igual a $100 \%$.

Tabela 11. Capacidade de transporte (t) da frota própria

$\begin{array}{cc}\text { Capacidade de transporte da frota própria (tc por semana) } & \\ \text { Sem0 } & 0 \\ \text { Sem1 } & 45000 \\ \text { Sem2 } & 45000 \\ \text { Sem3 } & 45000 \\ \text { Sem4 } & 45000 \\ \text { Sem5 } & 45000\end{array}$

A capacidade de transporte da frota própria é admitida em seu valor máximo e constante durante as cinco semanas de análise.

Tabela 12. Moagem mínima (t) de cana por semana Moagem mínima por período (t de can a por semana)

$\begin{array}{cc}\text { Sem0 } & 0 \\ \text { Sem1 } & 20000 \\ \text { Sem2 } & 20000 \\ \text { Sem3 } & 20000 \\ \text { Sem4 } & 20000 \\ \text { Sem5 } & 20000\end{array}$

Admite-se uma moagem mínima em cada semana de análise de 20.000 toneladas de cana.

Tabela 13. Moagem máxima (t) de cana por semana

$\begin{array}{cc}\text { Moagem máxima por período (t de cana por semana) } & 0 \\ \text { Sem0 } & 43000 \\ \text { Sem1 } & 43000 \\ \text { Sem2 } & 43000 \\ \text { Sem3 } & 43000 \\ \text { Sem4 } & 43000\end{array}$

Admite-se uma moagem máxima em cada semana de análise de 43.000 toneladas de cana. 


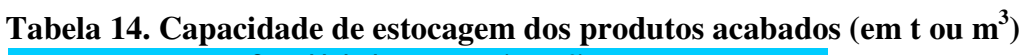
Capacidade de estocagem ( $\mathrm{t}$ ou $\mathrm{m} 3$ )

$\begin{array}{ccc} & \text { Eprop } & \text { Eterc } \\ \text { VHP } & 15000 & 20000 \\ \text { melaço } & 0 & 0 \\ \text { AEHC } & 14000 & 40000 \\ \text { AEAC } & 14000 & 30000\end{array}$

Consideram-se constantes em todas as semanas de análise os valores da tabela 14 referentes a estoque próprio e estoque terceirizado. A capacidade de estocagem de melaço é admitida igual a zero devido à inviabilidade econômica de estocagem desse produto. Dessa forma, todo o melaço produzido ou é comercializado na própria semana ou é convertido em álcoois.

Tabela 15. Custos semanais de duas variedades de cana hipotéticas

\begin{tabular}{|c|c|c|c|c|c|c|}
\hline & Semo & Sem 1 & Sem2 & Sem3 & Sem4 & Sem5 \\
\hline cpropriaRB & 0 & 28,04 & 28,04 & 28,09 & 28,09 & 28,09 \\
\hline cfornecidaRB & 0 & 31,4175126 & 41,30558 & 41,66522 & 31,46262 & 43,28198 \\
\hline cpropriaSP & 0 & 39,3610402 & 39,21295 & 39,72376 & 39,61626 & 41,22114 \\
\hline cfornecidaSP & 0 & 39,8801841 & 39,73209 & 40,2429 & 40,14628 & 41,75116 \\
\hline
\end{tabular}

São admitidas as variedades de cana hipotéticas RB e SP e na tabela 15 encontram-se os custos $(\mathrm{R} \$ / \mathrm{t})$ para se adquirir cada uma seja cultivada pela própria usina, seja por compras de terceiros (cana fornecida).

Tabela 16. Custos em estoque próprio e terceirizado dos produtos acabados

\begin{tabular}{|ccccccc|}
\hline Custo de estocagem R\$ por t (ou m3) & & & & \\
& Sem0 & Sem1 & Sem2 & Sem3 & Sem4 & Sem5 \\
VHP.Eprop & 0 & 10 & 10 & 10 & 10 & 10 \\
VHP.Eterc & 0 & 40 & 40 & 40 & 40 & 40 \\
melaço.Eprop & 0 & 50 & 50 & 50 & 50 & 50 \\
melaço.Eterc & 0 & 60 & 60 & 60 & 60 & 60 \\
AEHC.Eprop & 0 & 16 & 16 & 16 & 16 & 16 \\
AEHC.Eterc & 0 & 40 & 40 & 40 & 40 & 40 \\
AEAC.Eprop & 0 & 18 & 18 & 18 & 18 & 18 \\
AEAC.Eterc & 0 & 45 & 45 & 45 & 45 & 45 \\
\hline
\end{tabular}

Os custos de estocagem, em reais por tonelada ou reais por $\mathrm{m}^{3}$, são mostrados na tabela 16. Observam-se valores sempre mais elevados de estocagem em terceiros obedecendo ao que ocorre nos preços reais de estocagem.

Tabela 17. Custos semanais que se pretende proteger com o mecanismo do hedge Custo semanal (R\$) coberto no hedge $\quad$ sem1 sem2 sem3 sem4 sem5

Admite-se constante e igual a $\mathrm{R} \$ 200.000,00$ o custo semanal da usina a ser coberto pelo hedge de açúcar VHP, álcool anidro e álcool hidratado. Esse valor é determinado pelos gestores das usinas e depende de que fração do capital o empresário deseja proteger. 
Tabela 18. Preços (em $R \$ / t$ ou $\left.R \$ / \mathrm{m}^{3}\right)$ dos produtos que a usina irá travar no hedge

\begin{tabular}{|c|c|c|c|c|c|c|}
\hline \multicolumn{7}{|c|}{ Valores travados dos produtos no mercado Hedge por semana ( $\mathrm{R} \$$ port ou $\mathrm{m} 3$ ) } \\
\hline & Semo & Sem1 & Sem2 & Sem3 & Sem4 & Sem5 \\
\hline VHP & 0 & 600 & 600 & 600 & 600 & 600 \\
\hline melaço & 0 & 0 & 0 & 0 & 0 & 0 \\
\hline AEHC & 0 & 715 & 715 & 715 & 715 & 715 \\
\hline AEAC & 0 & 780 & 780 & 780 & 780 & 780 \\
\hline
\end{tabular}

Os valores presentes na tabela 18 referem-se aos preços travados pelos gestores das usinas nas bolsas de negociações. Caso haja uma queda nos preços, o usineiro já protegeu parte de sua produção com esses preços negociados.

Tabela 19. Saída do Minimodelo Markowitz

\begin{tabular}{lcccccc} 
& \multicolumn{7}{c}{ Demanda Hedge dos produtos por semana (\%) } \\
VHP & Sem0 & Sem1 & Sem2 & Sem3 & Sem4 & Sem5 \\
AEHC & & 0,431775 & 0,389336 & 0,15 & 0,7 & 0,7 \\
AEAC & & 0,15 & 0,15 & 0,661469 & 0,15 & 0,15 \\
& & 0,418225 & 0,460664 & 0,188531 & 0,15 & 0,15
\end{tabular}

Os valores da tabela 19 são obtidos após rodar o minimodelo Markowitz presente no Anexo B. Cada valor da tabela a partir da semana 1 refere-se a uma porcentagem ótima de açúcar VHP, AEAC e AEHC a compor o hedge.

Tabela 20. Valores monetários obtidos com os hedges dos produtos Total de vendas(R\$) por produto no hedge

\begin{tabular}{ccccccc}
\multicolumn{7}{c}{ Total de vendas(R\$) por produto no hedge } \\
VHP & Sem0 & Sem1 & Sem2 & Sem3 & Sem4 & Sem5 \\
AEHC & 0 & 86355,08 & 77867,3 & 30000 & 140000 & 140000 \\
AEAC & 0 & 30000 & 30000 & 132293,7 & 30000 & 30000 \\
& 0 & 83644,92 & 92132,7 & 37706,27 & 30000 & 30000
\end{tabular}

Em cada coluna da tabela 20, a partir da semana 1, a soma dos valores é igual a $\mathrm{R} \$$ 200.000,00, valor que se pretende proteger. Na coluna da semana 1, cada valor é obtido como segue: $86355,08=0,431775 \times 200000,30000=0,15 \times 200000 \mathrm{e}$

$83644,92=0,418225 \times 200000$.

Tabela 21. Quantidade de cada produto para atender o hedge em cada semana

\begin{tabular}{|c|c|c|c|c|c|c|}
\hline Demanda Hedge dos produtos & Sem0 & Sem1 & Sem2 & Sem 3 & Sem4 & Sem5 \\
\hline VHP & & 143,92513 & 129,7788 & 50 & 233,3333 & $\begin{array}{r}233,3333 \\
0\end{array}$ \\
\hline $\begin{array}{l}\text { AETlaço } \\
\text { AEHC }\end{array}$ & & 41,95804 & 41,9580 & 185,0262 & 41,95804 & 41,95804 \\
\hline AEAC & & 107,23707 & $118,1188 \mathrm{~g}>\mathrm{l}$ & 48,34137 & 38,46154 & 38,46154 \\
\hline
\end{tabular}

$\mathrm{Na}$ tabela 21, as quantidades de cada produto para hedge podem ser entendidas como demandas hedge de cada produto em cada semana e são obtidas dividindo-se o total de vendas de cada produto (tabela 20) pelo preço travado do hedge de cada produto em cada semana.

Tabela 22. Valores dos produtos $\left(R \$ / t\right.$ ou $\left.R \$ / m^{3}\right)$ no mercado interno em cada semana

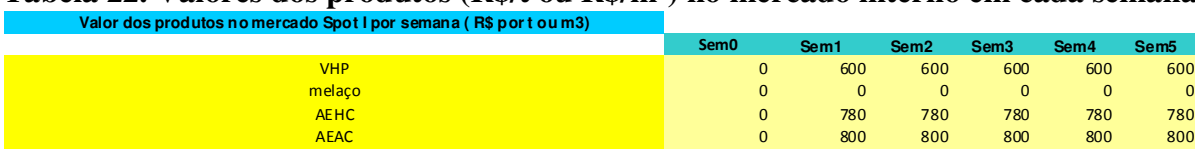

Neste exemplo ilustrativo, consideram-se constantes os valores dos produtos no mercado spot interno para as cinco semanas de análise, conforme tabela 22. 
Tabela 23. Valores dos produtos $\left(R \$ / t\right.$ ou $\left.R \$ / m^{3}\right)$ no mercado externo em cada semana Valor dos produtos no mercado Externo por semana ( $\mathrm{R}$ p por $\mathrm{t}$ ou $\mathrm{m} 3$ )

$\begin{array}{crrrrrr} & \text { Sem0 } & \text { Sem1 } & \text { Sem2 } & \text { Sem3 } & \text { Sem4 } & \text { Sem5 } \\ \text { VHP } & 0 & 600 & 600 & 600 & 600 & 600 \\ \text { melaço } & 0 & 0 & 0 & 0 & 0 & 0 \\ \text { AEHC } & 0 & 780 & 780 & 780 & 780 & 780 \\ \text { AEAC } & 0 & 800 & 800 & 800 & 800 & 800\end{array}$

Como visto na tabela 23, consideram-se constantes os valores dos produtos no mercado spot externo para as cinco semanas de análise e iguais aos valores do mercado spot interno. A idéia é verificar se o modelo reagirá em outros cenários a variações de preços nos dois mercados.

Tabela 24. Demandas dos produtos no mercado interno

\begin{tabular}{|c|c|c|c|c|c|c|}
\hline Demanda Spotl dos produtos por semana ( $t$ ou $n$ & & & & & & \\
\hline & Semo & Sem1 & Sem2 & Sem3 & Sem 4 & Sem5 \\
\hline VHP & 0 & 500 & 1000 & 1000 & 1000 & 1000 \\
\hline melaço & 0 & 0 & 0 & 0 & 0 & 0 \\
\hline AEHC & 0 & 1000 & 400 & 400 & 400 & 200 \\
\hline AEAC & 0 & 500 & 200 & 200 & 2000 & 200 \\
\hline
\end{tabular}

Admitem-se constantes os valores de demanda para mercado spot interno dos produtos acabados em cada semana.

Tabela 25. Demandas dos produtos no mercado externo

\begin{tabular}{|crrrrrrr|} 
Demanda SpotE dos produtos por semana (t ou m3) & Sem0 & Sem1 & Sem2 & Sem3 & \multicolumn{1}{c}{ Sem4 } & Sem5 \\
VHP & & 0 & 500 & 1000 & 1000 & 1000 & 1000 \\
melaço & 0 & 0 & 0 & 0 & 0 & 0 \\
AEHC & 0 & 1000 & 400 & 400 & 400 & 200 \\
AEAC & & 0 & 500 & 200 & 200 & 2000 & 200
\end{tabular}

Admitem-se constantes os valores de demanda para mercado spot externo dos produtos acabados em cada semana e iguais aos valores de demanda para mercado spot interno.

Tabela 26. Estoque inicial $\left(\mathrm{t} \mathrm{ou}^{3}\right)$ de cada produto acabado

\begin{tabular}{|cc}
\hline Estoque in icial (t ou m3) & Elnic \\
& 300 \\
VHP.Eprop & 0 \\
VHP.Eterc & 0 \\
melaço.Eprop & 0 \\
melaço.Eterc & 100 \\
AEHC.Eprop & 0 \\
AEHC.Eterc & 100 \\
AEAC.Eprop & 0 \\
AEAC.Eterc &
\end{tabular}

Consideram-se os estoques iniciais próprios de açúcar VHP, AEHC e AEAC diferentes de zero para modelar uma sobra de estoque da safra anterior.

Tabela 27. Previsão de safra (t) de cada variedade de cana Planejamento de colheita para toda a safra $(e m t)$

$$
\begin{aligned}
& \text { cproprRB } \\
& \text { cfornecidaRB } \\
& \text { cproprSP } \\
& \text { cfornecidaSP }
\end{aligned}
$$

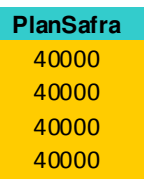

Encontram-se na tabela acima os valores hipotéticos (em toneladas de previsão) de safra para as variedades hipotéticas RB e SP. 
Tabela 28. Taxas de corretagem para os produtos acabados nos mercados spot

\begin{tabular}{|c|c|c|}
\hline Taxas de comercialização spot & Interno & Externo \\
\hline $\mathrm{T} \cos (\mathrm{SU})(\%)$ & 0,032 & $\overline{0,041}$ \\
\hline $\mathrm{T} \cos (\mathrm{me})(\%)$ & 0,000 & 0 \\
\hline TCOS(alcool hidratado)(\%) & 0,030 & 0,045 \\
\hline TCOS(alco ol anidro)(\%) & 0,030 & 0,045 \\
\hline
\end{tabular}

Para a negociação dos produtos acabados através de corretoras, existem taxas de corretagem para mercado interno e para mercado externo, valores presentes na tabela 28. Na tabela, TCOS (SU) indica a taxa de comercialização de açúcar no mercado spot.

Tabela 29. Taxas de corretagem para os produtos acabados na operação de hedge

\begin{tabular}{|l|c|}
\hline \multicolumn{1}{|c|}{ Taxas de comercialização Hedge } & Valores \\
\hline $\mathrm{TCOS}(\mathrm{SU})(\%)$ & 0,096 \\
\hline $\mathrm{TCOS}(\mathrm{me})(\%)$ & 0,000 \\
\hline $\mathrm{TCOS}(\mathrm{alcool}$ hidratado)(\%) & 0,096 \\
\hline $\mathrm{TCOS}($ alcool anidro)(\%) & 0,096 \\
\hline
\end{tabular}

Para se efetuar o hedge, a usina também paga taxas de corretagem para empresas contratadas e para a Bolsa de valores, valores presentes na tabela 29.

Tabela 30. Características técnicas de cada processo industrial no Minimodelo

\begin{tabular}{|c|c|c|c|c|}
\hline \multirow[b]{2}{*}{ Processo } & \multicolumn{4}{|c|}{$\begin{array}{c}\text { Caminhos de } \\
\text { produção }\end{array}$} \\
\hline & SCP & SCS & SM & SA \\
\hline Procl1 & 0,3 & 0,2 & 1 & 0,4 \\
\hline Procl2 & 0,3 & 0,8 & 1 & 0,4 \\
\hline Procl3 & 0,9 & 0,2 & 1 & 0,4 \\
\hline Procl4 & 0,3 & 0,2 & 1 & 0,8 \\
\hline Procl5 & 0,9 & 0,8 & 1 & 0,8 \\
\hline
\end{tabular}

A tabela 30 apresenta as separações industriais utilizadas em cada processo industrial. Para o processo ProcI1, por exemplo, o valor 0,3 para SCP (Separação do caldo primário) indica que $30 \%$ do caldo primário será destinado para a fábrica de açúcar e $70 \%$ para a destilaria de álcool; o valor 0,2 para SCS(Separação do caldo secundário) indica que $20 \%$ do caldo secundário será destinado para a fábrica de açúcar e $80 \%$ para a destilaria de álcool; o valor 1 para SM (Separação do melaço) indica que $100 \%$ do melaço será destinado para a destilaria e $0 \%$ para estoque; o valor 0,4 para SA significa que $40 \%$ do mosto fermentado será destinado para a produção de álcool hidratado e $60 \%$ para a produção de álcool anidro. 
Tabela 31. Características técnicas de cada processo comercial no Minimodelo

\begin{tabular}{|c|c|c|c|c|}
\cline { 2 - 5 } \multicolumn{1}{c|}{} & \multicolumn{4}{c|}{ Caminhos de comercialização } \\
\hline Processo & \multicolumn{1}{c|}{ SCOSU } & \multicolumn{1}{c|}{ SCOAH } & \multicolumn{1}{c|}{ SCOAA } & SCOME \\
\hline ProcC1 & 0,6 & 0,8 & 0,8 & 1 \\
ProcC2 & 0,4 & 0,8 & 0,8 & 1 \\
ProcC3 & 0,6 & 0,6 & 0,8 & 1 \\
ProcC4 & 0,4 & 0,6 & 0,8 & 1 \\
ProcC5 & 0,6 & 0,8 & 0,6 & 1 \\
ProcC6 & 0,4 & 0,8 & 0,6 & 1 \\
ProcC7 & 0,6 & 0,6 & 0,6 & 1 \\
ProcC8 & 0,4 & 0,6 & 0,6 & 1 \\
\end{tabular}

A tabela 31 apresenta as separações comerciais utilizadas no minimodelo. Para o processo ProcC5, por exemplo, o valor 0,6 para SCOSU (Separação comercial do açúcar) indica que $60 \%$ do açúcar deve ser comercializado para mercado externo e $40 \%$ para mercado interno. A mesma interpretação se dá para SCOAH (Separação comercial de álcool hidratado) e SCOAA (Separação comercial de álcool anidro). Para SCOME (Separação comercial do melaço), com valores iguais a 1 em todos os processos, significa que $100 \%$ do melaço deve ser negociado no mercado interno. Dessa forma, combinando-se os processos industriais com os processos comerciais chega-se a 5 x $8=$ 40 processos no total estudados neste minimodelo. Destes, apenas um é escolhido em cada semana.

\section{Resultados}

Tabela 32. Estoque $\left(\mathrm{t} \mathrm{ou} \mathrm{m}^{3}\right)$ dos produtos acabados em cada semana no minimodelo Variável de estoque no fim de cada semana

\begin{tabular}{|c|c|c|c|c|c|c|}
\hline & Semo & Sem1 & Sem2 & Sem3 & Sem4 & Sem5 \\
\hline VHP.Eprop & 300 & 1537,798 & 1149,503 & 2194,556 & 1233,333 & 0 \\
\hline VHP.Eterc & 0 & 0 & 0 & 0 & 0 & 0 \\
\hline melaço.Eprop & 0 & 0 & 0 & 0 & 0 & 0 \\
\hline melaço.Eterc & 0 & 0 & 0 & 0 & 0 & 0 \\
\hline AEHC.Eprop & 100 & 9,765778 & 585,0262 & 441,958 & 241,958 & $\overline{0}$ \\
\hline AEHC.Eterc & 0 & 0 & 0 & 0 & 0 & 0 \\
\hline AEAC.Eprop & 100 & 214,5792 & 248,3414 & 2482,271 & 238,4615 & 0 \\
\hline AEAC.Eterc & 0 & 0 & 0 & 0 & 0 & 0 \\
\hline
\end{tabular}

A tabela 32 apresenta a variação de estoque dos produtos acabados em cada semana.

Observa-se que na última semana todos os estoques são iguais a zero, exigência do desenvolvimento do modelo matemático de maximização da margem de contribuição nas cinco semanas estudadas. Na figura 35 observam-se graficamente os mesmos resultados da tabela 32. Como o custo de estocagem própria é inferior ao custo de 
estocagem em terceiros e existe capacidade suficiente para estocagem própria, observam-se estoques em terceiros nulos.

Pela tabela 32, verifica-se um aumento na demanda por açúcar VHP da semana 1 para a semana 2, o que pode ser verificado na figura 35 pela diminuição de estoque da semana 1 para a semana 2. Com álcool AEHC e álcool AEAC observa-se aumento nos estoques da semana 1 para a semana 2 , já que ocorre diminuição na demanda por esses produtos no intervalo citado.

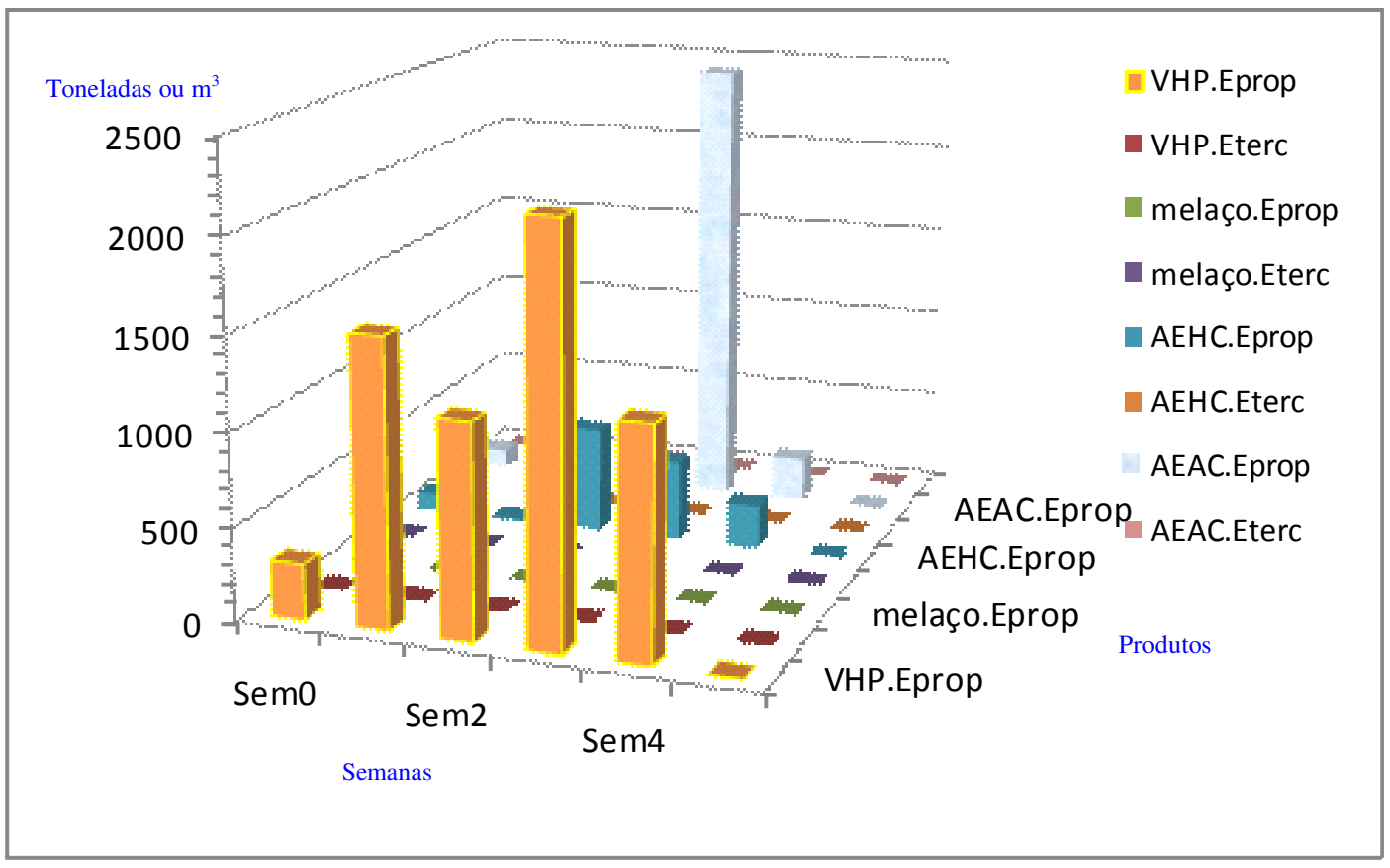

Figura 35. Quantidades de cada produto em estoque em cada semana

Tabela 33. Disponibilidade (t) de cana no campo no início de cada semana no minimoddelo Disponibilidade de cana no campo no início de cada semana

\begin{tabular}{ccc|ccccc|} 
& Sem0 & Sem1 & Sem2 & Sem3 & Sem4 & Sem5 \\
\cline { 2 - 6 } & cproprRB & 40000 & 40000 & 40000 & 40000 & 20254,65 & 20254,65 \\
cfornecidaRB & 40000 & 40000 & 25465,19 & 25465,19 & 25465,19 & 0 \\
cproprSP & 40000 & 40000 & 40000 & 23254,65 & 0 & 0 \\
cfornecidaSP & 40000 & 40000 & 11534,81 & 0 & 0 & 0 \\
\hline
\end{tabular}

Devido aos contratos de fornecimento da cana, toda a cana presente no campo deve ser moída até o final da safra. Assim, observa-se conjuntamente com as tabelas 33 e 34 que para todas as variedades ocorre esgotamento do estoque de cana no campo até a semana 5. Como existem diferenças de produtividade das variedades nos períodos do ano, o modelo matemático pretende determinar em que período, em qual quantidade e de que variedade se deve fazer o corte. 
Tabela 34. Quantidade (t) de cada variedade de cana moída em cada semana Variável de decisão de quantidade de cana por fonte de fornecimento e variedade

\begin{tabular}{|c|c|c|c|c|c|c|}
\hline & Semo & Sem 1 & Sem2 & Sem3 & Sem4 & Sem5 \\
\hline \multirow{4}{*}{$\begin{array}{l}\text { cproprRB } \\
\text { cfornecidaRB } \\
\text { cproprSP } \\
\text { cfornecidaSP }\end{array}$} & 0 & 0 & 0 & 19745,35 & 0 & 20254,65 \\
\hline & 0 & 14534,81 & 0 & 0 & 25465,19 & 0 \\
\hline & 0 & 0 & 16745,35 & 23254,65 & 0 & 0 \\
\hline & $\overline{0}$ & 28465,19 & 11534,81 & $\overline{0}$ & $\overline{0}$ & $\overline{0}$ \\
\hline
\end{tabular}

Tabela 35. Quantidade (t) de cana transportada por frota própria e terceirizada em cada semana Variável de decisão de quantidade de cana transportada

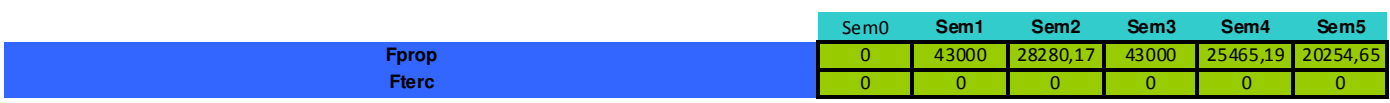

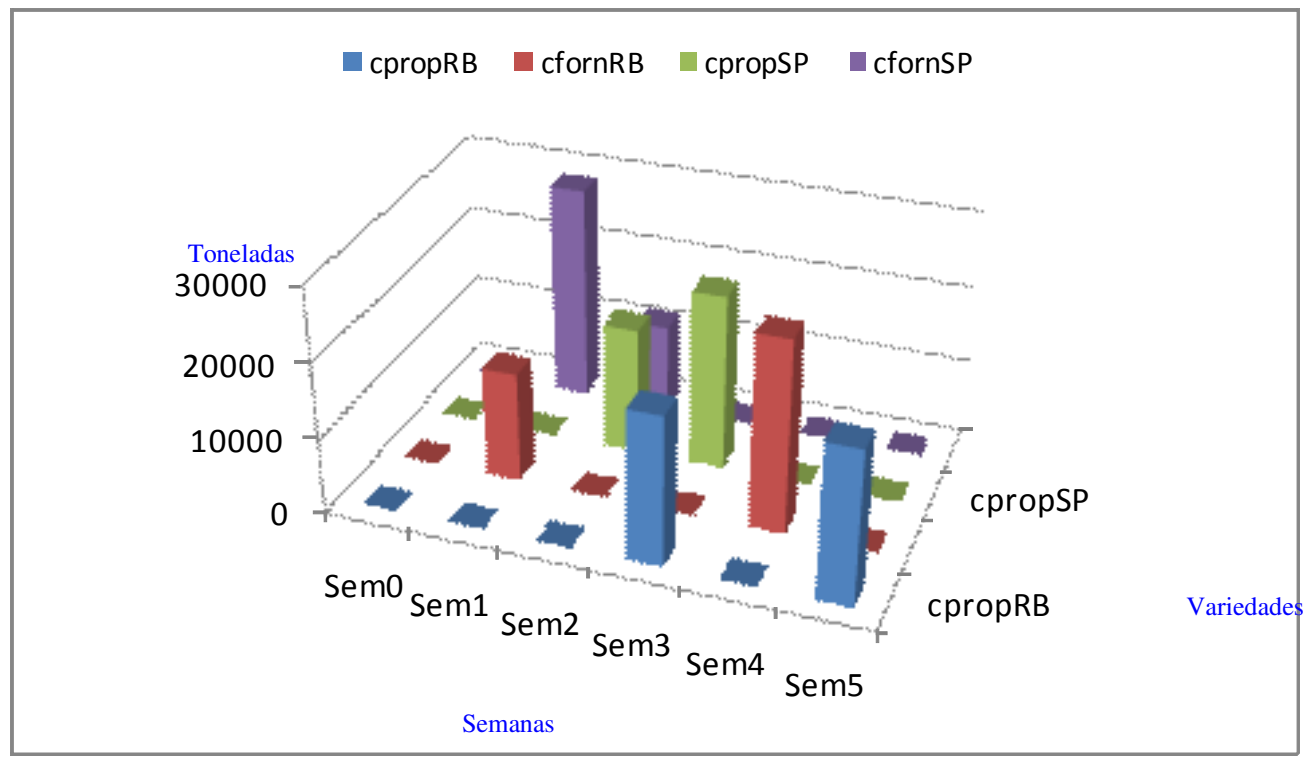

Figura 36. Quantidade de cana colhida de cada variedade em cada semana

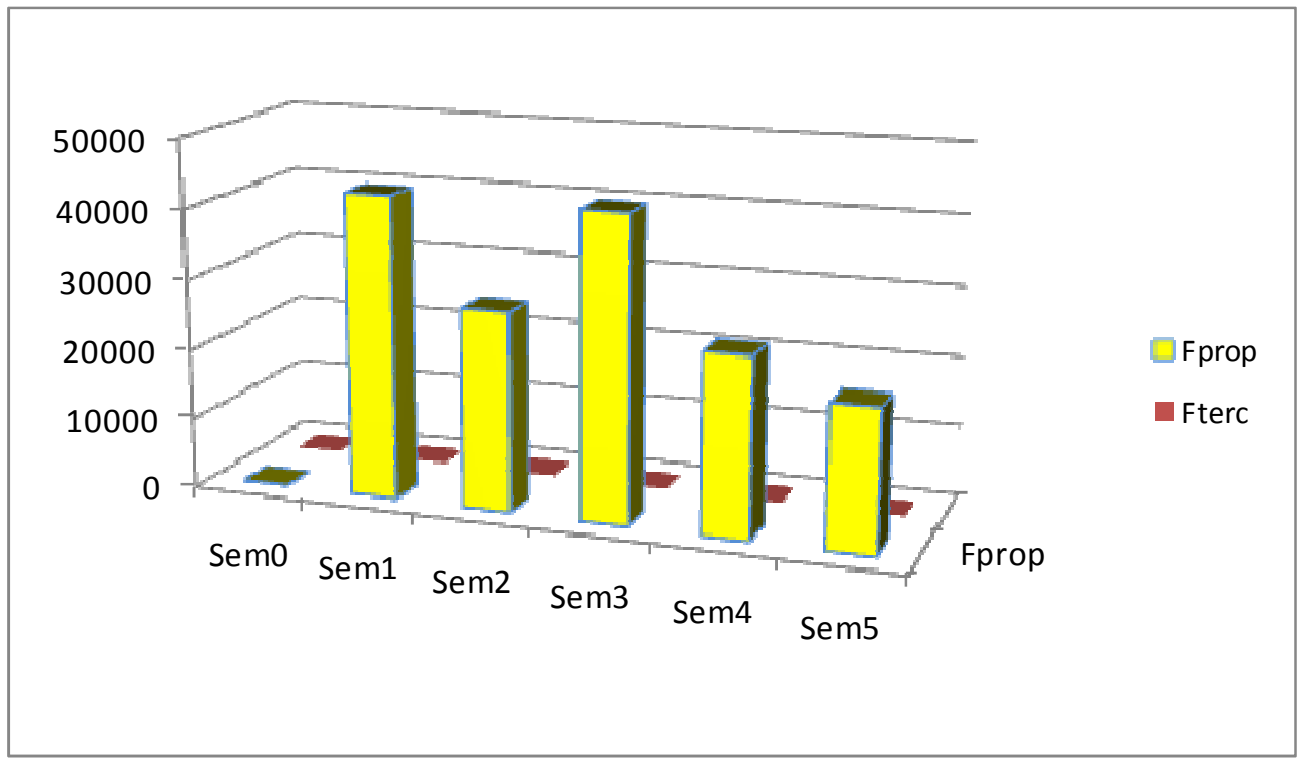

Figura 37. Quantidade transportada de cana por frota própria ou terceirizada 
Tabela 36. Escolha de processos industriais/comerciais em cada semana

$\begin{array}{ccccccc}\text { Processos } & \text { Sem0 } & \text { Sem1 } & \text { Sem2 } & \text { Sem3 } & \text { Sem4 } & \text { Sem5 } \\ \cdots . & 0 & 0 & 0 & 0 & 0 & 0 \\ \text { Proc|3C5I } & 0 & 1 & 0 & 1 & 0 & 0 \\ \text { Proc|3C5E } & 0 & 0 & 0 & 0 & 1 & 1 \\ \quad \ldots & & & & & & \\ \text { ProcI4C5I } & 0 & 0 & 1 & 0 & 0 & 0\end{array}$

Na tabela 36, a sigla ProcI3C5I significa processo industrial 3 combinado com o processo comercial 5 e porcentagens de separação para mercado interno. A sigla ProcI3C5E significa processo industrial 3 combinado com o processo comercial 5 e porcentagens de separação para mercado externo,sendo esta complementar com relação a mercado interno. Decidiu-se efetuar essa separação em processos para mercado interno e externo para facilitar a modelagem matemática do problema. Tem-se assim em ProcI3C5I as porcentagens para mercado interno de 60\% da separação da produção de açúcar, $80 \%$ de separação de álcool hidratado, $60 \%$ de separação de álcool anidro e $100 \%$ de melaço.

Observa-se ainda a utilização em maior frequência do processo industrial 3, que pela tabela 30 indica $90 \%$ de separação do caldo primário para a fábrica de açúcar, $20 \%$ de separação do caldo secundário para a fábrica de açúcar, $100 \%$ de separação de melaço para a destilaria e $40 \%$ de separação de mosto fermentado para a produção de álcool hidratado. Juntando esses dados com as separações comerciais da tabela 31, dados de demanda das tabelas 24 e 25 e os resultados encontrados nas tabelas 37 e 38 chega-se a uma consistência lógica das separações do modelo.

Tabela 37. Vendas $\left(\mathrm{t}\right.$ ou $\left.\mathrm{m}^{3}\right)$ para mercado interno de cada produto acabado

\begin{tabular}{ll|c|ccccc|} 
Vendas I & \multicolumn{1}{c}{ Sem0 } & Sem1 & Sem2 & Sem3 & Sem4 & Sem5 \\
\hline & VHP & 0 & 500 & 1000 & 1000 & 1000 & 1000 \\
\hline Melaco & 0 & 0 & 0 & 0 & 0 & 0 \\
AEHC & & 0 & 1000 & 400 & 400 & 400 & 200 \\
AEAC & 0 & 1050,837 & 200 & 200 & 2000 & 200
\end{tabular}

Tabela 38. Vendas $\left(\mathrm{t} \mathrm{ou} \mathrm{m}^{3}\right.$ ) para mercado externo de cada produto acabado Vendas E

\begin{tabular}{|c|c|ccccc|}
\multicolumn{1}{c|}{} & \multicolumn{1}{c}{ Sem0 } & \multicolumn{1}{c}{ Sem1 } & Sem2 & Sem3 & Sem4 & Sem5 \\
VHP & 0 & 500 & 1000 & 1000 & 1000 & 1000 \\
Melaco & 0 & 0 & 0 & 0 & 0 & 0 \\
AEHC & 0 & 1000 & 400 & 1294,308 & 647,82 & 706,3542 \\
AEAC & 0 & 1821,71 & 1193,708 & 1018,374 & 2000 & 1422,583
\end{tabular}

Para este cenário base, a margem de contribuição ficou em $\mathrm{R} \$ 10.363 .577,03$.

A fim de se analisar demais consistências do modelo, nos cenários seguintes são realizadas modificações em alguns parâmetros de entrada e então são estudados os 
resultados obtidos. Em cada cenário, modifica-se apenas um parâmetro de cada vez para se testar modificações com relação ao cenário base.

\subsubsection{Cenário1- Mudança na composição da frota de transporte da cana}

Neste cenário, eliminou-se toda a capacidade de transporte da frota própria, esperandose diminuição no valor da função objetivo e uso integral de transporte da cana por frota de terceiros.

Tabela 39. Quantidade de cana transportada (t) sob o cenário 1 Variável de decisão de quantidade de cana transportada

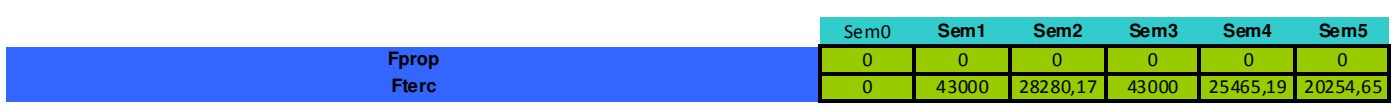

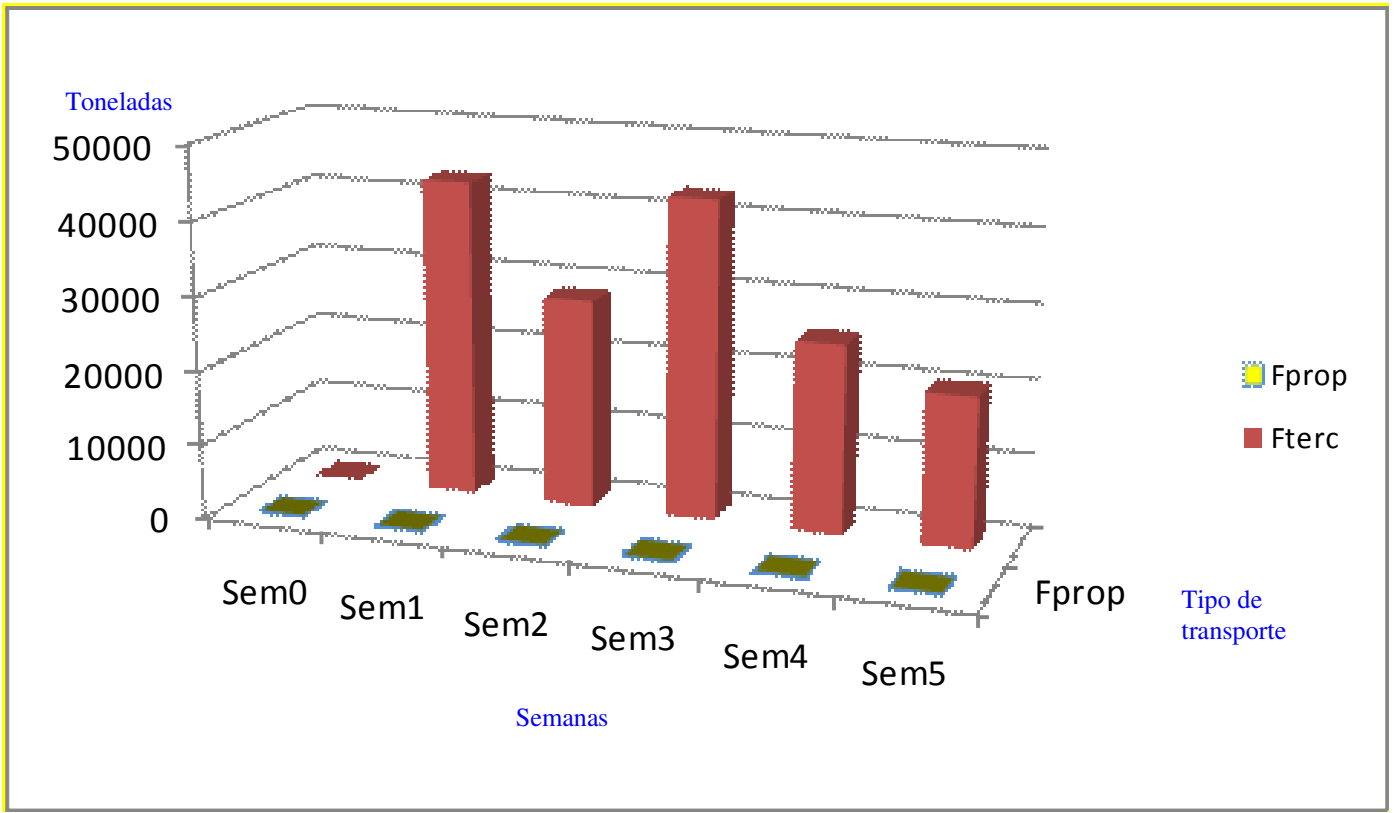

Figura 38. Transporte (t) por frota própria e terceirizada

Pelos resultados da tabela 39, observa-se utilização total de frota de terceiros. O valor da função objetivo passou de $\mathrm{R} \$ 10.363 .577,03$ para $\mathrm{R} \$ 9.403 .577,03$, resultados coerentes com os valores esperados.

\subsubsection{Cenário 2- Valorização do preço para mercado interno}

Alterando-se o preço dos produtos comercializados para mercado interno na semana 5, espera-se que ocorra venda em maior quantidade desses produtos nessa semana e priorização de processo com maior porcentagem de separação para mercado interno, além de aumento no valor da função objetivo. 
Tabela 40. Vendas $\left(\mathrm{t}\right.$ ou $\left.\mathrm{m}^{3}\right)$ dos produtos para mercado interno em cada semana sob o cenário 2 Vendas I

\begin{tabular}{c|c|cccccc|}
\multicolumn{1}{c}{ Sem0 } & Sem1 & Sem2 & Sem3 & Sem4 & Sem5 \\
VHP & 0 & 500 & 1000 & 1000 & 1000 & 1407,029 \\
Melaco & 0 & 0 & 0 & 0 & 0 & 0 \\
AEHC & 0 & 1000 & 400 & 400 & 400 & 1455,28 \\
AEAC & 0 & 500 & 200 & 200 & 2000 & 4015,504
\end{tabular}

Tabela 41. Vendas (t ou $\left.\mathrm{m}^{3}\right)$ dos produtos para mercado externo em cada semana sob o cenário 2

\begin{tabular}{|c|c|c|c|c|c|c|}
\hline & Sem0 & Sem1 & Sem2 & Sem3 & Sem4 & Sem5 \\
\hline VHP & 0 & 500 & 1000 & 1000 & 1000 & 1000 \\
\hline Melaco & 0 & 0 & 0 & 0 & 0 & 0 \\
\hline AEHC & 0 & 1000 & 400 & 400 & 400 & 695,1227 \\
\hline AEAC & 0 & 500 & 200 & 200 & 2000 & 1399,963 \\
\hline
\end{tabular}

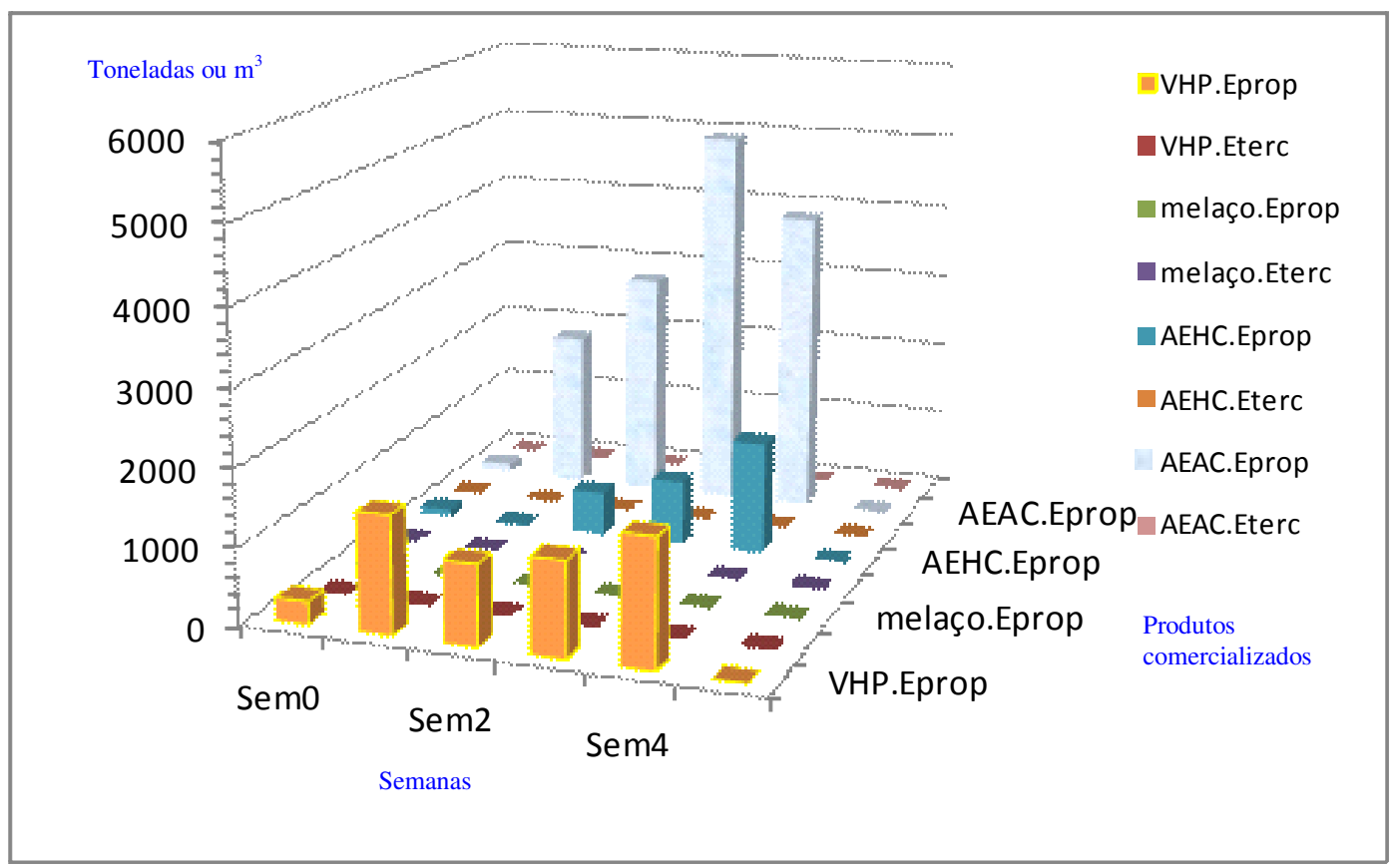

Figura 39. Quantidade estocada de cada produto

Pelos resultados das tabelas 40 e 41 , observam-se valores mais elevados de comercialização para mercado interno dos produtos acabados. Pela figura 39 nota-se acúmulo maior de estoque de AEHC e AEAC na semana 4 visando uma especulação com preços dos produtos mais elevados na semana 5. 
Tabela 42. Lista de processos referentes ao cenário 2

$\begin{array}{ccccccc}\text { Processos } & \text { Sem0 } & \text { Sem1 } & \text { Sem2 } & \text { Sem3 } & \text { Sem4 } & \text { Sem5 } \\ \ldots & 0 & 0 & 0 & 0 & 0 & 0 \\ \text { Procl3C5I } & 0 & 1 & 0 & 1 & 1 & 1 \\ \text { Procl3C5E } & 0 & 0 & 0 & 0 & 0 & 0 \\ \ldots & & & & & & \\ \text { Procl4C5I } & 0 & 0 & 1 & 0 & 0 & 0\end{array}$

Pela tabela 42 observa-se priorização do processo ProcI3C5I, o qual destina maior quantidade de produtos para mercado interno, coerente com resultados esperados, já que ocorre incidência maior de preços para mercado interno (ver tabela 22). A margem de contribuição passou de $\mathrm{R} \$ 10.363 .577,03$ no cenário base para $\mathrm{R} \$ 11.158 .575,45$ no cenário 2 , aumento devido ao maior preço para mercado interno na semana 5.

\subsubsection{Cenário 3- Valorização do preço para mercado externo}

Aumento do valor de preço dos produtos para mercado externo na semana 1. Espera-se que o modelo venda mais para mercado externo nessa semana priorizando processos que separem mais produtos para mercado externo nessa semana.

Tabela 43. Vendas $\left(\mathrm{t}\right.$ ou $\left.\mathrm{m}^{3}\right)$ dos produtos para mercado interno em cada semana sob o cenário 3 Vendas I

\begin{tabular}{|c|c|ccccc|}
\multicolumn{1}{c}{} & \multicolumn{1}{c}{ Sem0 } & Sem1 & Sem2 & Sem3 & Sem4 & Sem5 \\
VHP & 0 & 500 & 1000 & 1000 & 1000 & 1000 \\
Melaco & 0 & 0 & 0 & 0 & 0 & 0 \\
AEHC & 0 & 1000 & 400 & 400 & 400 & 200 \\
AEAC & 0 & 820,8683 & 200 & 200 & 2000 & 200
\end{tabular}

Tabela 44. Vendas (t ou $\left.\mathrm{m}^{3}\right)$ dos produtos para mercado externo em cada semana sob o cenário 3 Vendas $\mathrm{E}$

\begin{tabular}{|c|c|ccccc|}
\multicolumn{1}{c|}{} & \multicolumn{1}{c}{ Sem0 } & \multicolumn{1}{c}{ Sem1 } & Sem2 & Sem3 & Sem4 & Sem5 \\
VHP & 0 & 572,3965 & 1000 & 1000 & 1000 & 1000 \\
Melaco & 0 & 0 & 0 & 0 & 0 & 0 \\
AEHC & 0 & 1000 & 400 & 1294,308 & 570,9378 & 706,3542 \\
AEAC & 0 & 2029,052 & 1395,389 & 863,3056 & 2000 & 1422,583
\end{tabular}

Observa-se pela tabela 44 maior quantidade sendo comercializada na semana 1 para mercado externo relativamente ao cenário base e consequentemente alocação de processo com maior priorização de separação para mercado externo nessa semana. 


\subsubsection{Cenário 4- Aumento na demanda hedge dos produtos acabados}

Comparando-se as tabelas 21 e 47 do cenário base com a tabela 46, nota-se um aumento na demanda hedge de açúcar, AEHC e AEAC na semana 1. Espera-se como resultado um aumento na produção para hedge nessa semana neste cenário.

Tabela 45. Custo semanal (R\$) coberto pelo hedge em cada semana

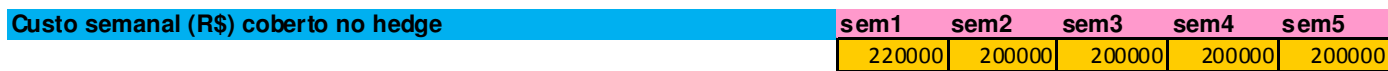

Tabela 46. Demanda hedge $\left(\mathrm{t}\right.$ ou $\left.\mathrm{m}^{3}\right)$ de cada produto em cada semana

\begin{tabular}{|c|c|c|c|c|c|c|}
\hline Demanda Hedge dos produtos & & & & & & \\
\hline & Semo & Sem1 & Sem2 & Sem3 & Sem 4 & Sem5 \\
\hline VHP & & 158,317652 & 129,7788 & 50 & 233,3333 & 233,3333 \\
\hline melaço & & 0 & 0 & 0 & 0 & 0 \\
\hline AEHC & & 46,1538462 & 41,95804 & 185,0262 & 41,95804 & 41,95804 \\
\hline AEAC & & 117,960781 & 118,1188 & 48,34137 & 38,46154 & 38,46154 \\
\hline
\end{tabular}

Tabela 47. Quantidade de cana em toneladas destinada para hedge cenário base e cenário 4

Cenário base

Variável de decisão de quant. de cana (hedge) por processo
\begin{tabular}{|l|c|c|c|c|c|c|} 
Processos & Sem0 & Sem1 & Sem2 & Sem3 & Sem4 & Sem5 \\
\hline Procl3C5I & 0 & 2451,192 & 0 & 2627,124 & 0 & 0 \\
\hline Procl3C5E & 0 & 0 & 0 & 0 & 4417,6 & 4239,859 \\
\hline Procl4C5I & 0 & 0 & 2738,2646 & 0 & 0 & 0
\end{tabular}

Cenário 4

\begin{tabular}{c|c|c|c|c|c|c|c} 
Variável de decisão de quant. de cana (hedge) por processo \\
Processo & Sem0 & \multicolumn{1}{c}{ Sem1 } & Sem2 & Sem3 & Sem4 & Sem5 \\
\hline Procl3C5I & 0 & 2696,311 & 0 & 2627,124 & 0 & 0 \\
\hline Procl3C5E & 0 & 0 & 0 & 0 & 4417,6 & 4239,859 \\
\hline Procl4C5I & 0 & 0 & 2738,2646 & 0 & 0 & 0
\end{tabular}

Observando-se a tabela 47 para cenário base e cenário 4, nota-se aumento na quantidade de cana destinada para hedge no cenário 4, confirmando consistência do modelo.

\subsubsection{Cenário 5- Mudança no custo de estocagem}

Custo de estocagem em terceiros na semana 2 menor que custo de estocagem em estoque próprio. Espera-se que o modelo envie quantidades diferentes de zero para estoques terceirizados nessa semana. 
Tabela 48. Estoque $\left(\mathrm{t}\right.$ ou $\left.\mathrm{m}^{3}\right)$ no fim de cada semana de cada produto sob o cenário 5

\begin{tabular}{|c|c|c|c|c|c|c|}
\hline & Sem0 & Sem1 & Sem2 & Sem3 & Sem4 & Sem5 \\
\hline VHP.Eprop & 300 & 1537,798 & 0 & 2194,556 & 1233,333 & 0 \\
\hline VHP.Eterc & 0 & 0 & 1149,503 & 0 & 0 & 0 \\
\hline melaço.Eprop & 0 & $\overline{0}$ & $\overline{0}$ & 0 & 0 & 0 \\
\hline melaço.Eterc & 0 & 0 & 0 & 0 & 0 & 0 \\
\hline AEHC.Eprop & 100 & 9,765778 & 0 & \begin{tabular}{|l|}
441,958 \\
\end{tabular} & 241,958 & 0 \\
\hline AEHC.Eterc & 0 & 0 & \begin{tabular}{|l|}
585,0262 \\
\end{tabular} & 0 & 0 & 0 \\
\hline AEAC.Eprop & 100 & 214,5792 & 0 & 2482,271 & 238,4615 & 0 \\
\hline AEAC.Eterc & 0 & 0 & 248,3414 & 0 & 0 & 0 \\
\hline
\end{tabular}

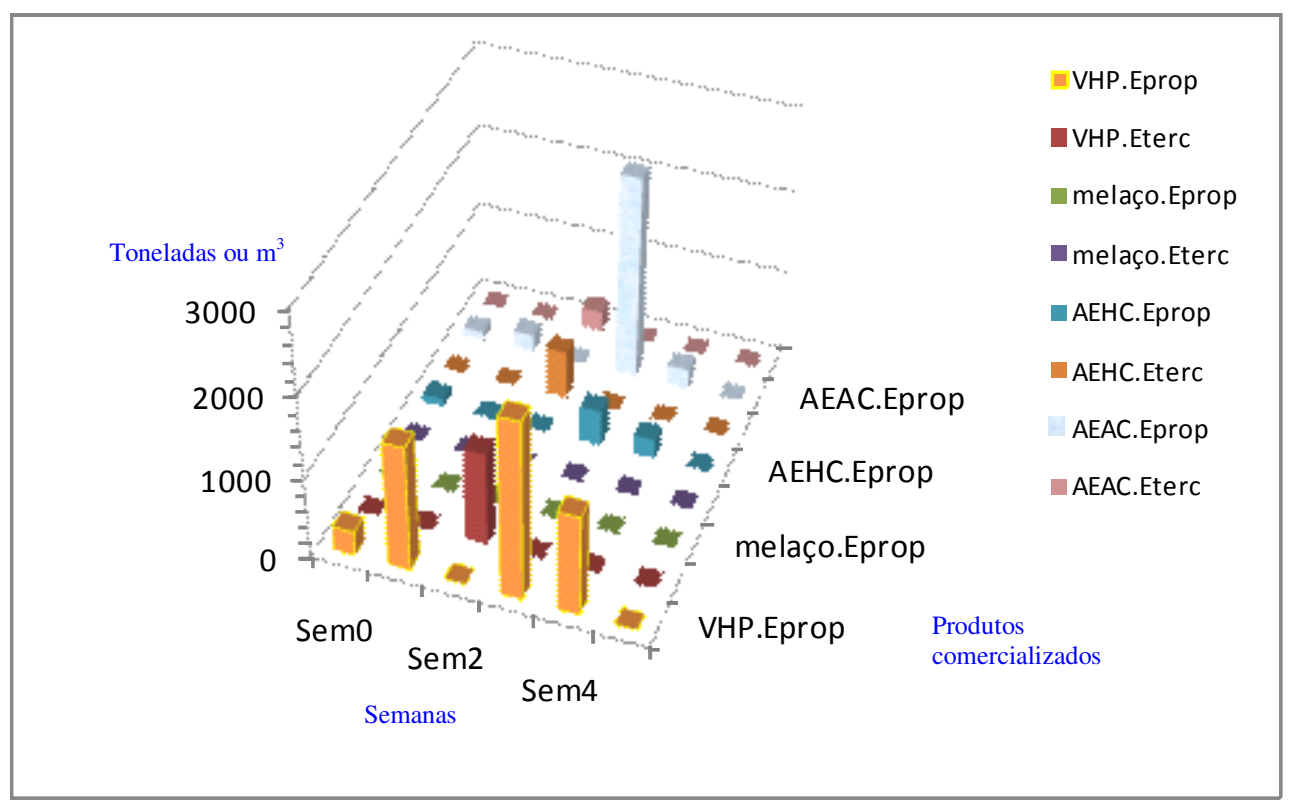

Figura 40. Quantidade estocada de cada produto

Observa-se pela tabela 48 e pela figura 40 que na semana 2 houve uma troca de estocagem própria por estocagem terceirizada devido a uma redução nos preços nessa última forma de se estocar os produtos.

\subsubsection{Cenário 6- Produção nula em determinada semana}

Eliminação da produção nas semanas 4 e 5. Espera-se que não haja cana transportada nem cana moída nessas semanas, mas haja produtos em estoque na semana 4 para aguardar melhor momento para a venda. Aumentaram-se os preços dos produtos acabados nas semanas 4 e 5 . 
Tabela 49. Tempo útil de moagem sob o cenário 6 Porcentagem de tempo útil para moagem(PTU)

$\begin{array}{ll}\text { Sem0 } & 0 \\ \text { Sem } 1 & 1 \\ \text { Sem2 } & 1 \\ \text { Sem } 3 & 1 \\ \text { Sem } 4 & 0 \\ \text { Sem5 } & 0\end{array}$

Tabela 50. Preços dos produtos no mercado spot interno sob o cenário 6

\begin{tabular}{|c|c|c|c|c|c|c|}
\hline Us prouutos nu mercauo & Sem0 & Sem1 & Sem2 & Sem3 & Sem4 & Sem5 \\
\hline VHP & 0 & 600 & 600 & 600 & 1000 & 1000 \\
\hline melaço & 0 & 0 & 0 & 0 & 0 & 0 \\
\hline AEHC & 0 & 780 & 780 & 780 & 850 & 850 \\
\hline AEAC & 0 & 800 & 800 & 800 & 950 & 950 \\
\hline
\end{tabular}

Tabela 51. Quantidade de cana transportada (t) sob o cenário 6 Variável de decisão de quantidade de cana transportada

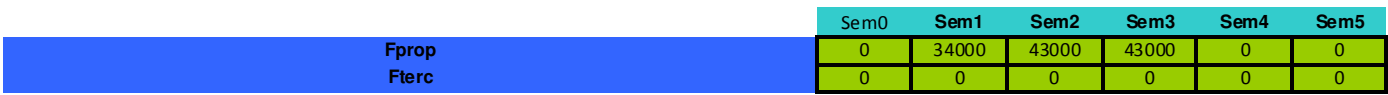

Tabela 52. Estoque de cana (t) no fim de cada semana sob o cenário 6

Variável de estoque no fim de cada semana

$$
\begin{aligned}
& \text { VHP.Eprop } \\
& \text { VHP.Eterc } \\
& \text { melaço.Eprop } \\
& \text { melaço.Eterc } \\
& \text { AEHC.Eprop } \\
& \text { AEHC.Eterc } \\
& \text { AEAC.Eprop } \\
& \text { AEAC.Eterc }
\end{aligned}
$$

Sem0
\begin{tabular}{|c|c|c|c|c|c|}
\hline 3000 & Sem1 & Sem2 & Sem3 & Sem4 & Sem5 \\
\hline 0 & 0 & 0 & 0 & 0 & 0 \\
\hline 0 & 0 & 0 & 0 & 0 & 0 \\
\hline 0 & 0 & 0 & 0 & 0 & 0 \\
\hline 3000 & 2293,102 & 3134,442 & 3885,682 & 400 & 0 \\
\hline 0 & 0 & 0 & 0 & 0 & 0 \\
\hline 3000 & 4585,039 & 7463,639 & 10515,94 & 400 & 0 \\
\hline 0 & 0 & 0 & 0 & 0 & 0 \\
\hline
\end{tabular}

Observa-se um aumento na quantidade estocada dos produtos no final da semana 3 visando a venda com preços mais vantajosos nas semanas 4 e 5.

\subsubsection{Cenário 7 - Assumindo maior risco}

Neste cenário, o usineiro assume maior risco nas operações de hedge na semana 1 alocando probabilidade maior para o cenário em que a rentabilidade de açúcar é maior e fixando uma rentabilidade alvo maior que a do cenário base. Espera-se que o modelo altere as proporções de hedge com relação ao cenário base na semana 1 priorizando proporções maiores de açúcar.

Tabela 53. Saída do Minimodelo Markowitz para o cenário 7 Saída Modelo Markowitz

$\begin{array}{ccccccc} & \text { Sem0 } & \text { Sem1 } & \text { Sem2 } & \text { Sem3 } & \text { Sem4 } & \text { Sem5 } \\ \text { VHP } & & 0,431775 & 0,389336 & 0,15 & 0,7 & 0,7 \\ \text { AEHC } & & 0,15 & 0,15 & 0,661469 & 0,15 & 0,15 \\ \text { AEAC } & & 0,418225 & 0,460664 & 0,188531 & 0,15 & 0,15\end{array}$


Tabela 54. Saída do Minimodelo Markowitz para o cenário base

Saída Modelo Markowitz

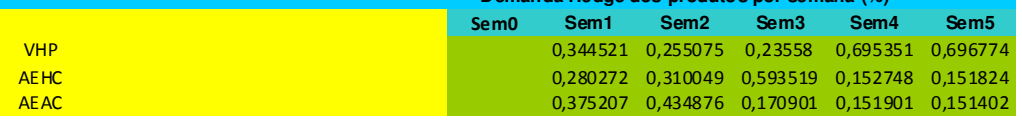

Observa-se pelas tabelas 53 e 54 que para o cenário 7 houve proporção maior de escolha no hedge para açúcar quando comparado ao cenário base. Ocorreu ainda grande alteração nas proporções para hedge quanto aos produtos acabados nas semanas 1, 2 e 3 devido também ao aumento na rentabilidade alvo de um mínimo de $10 \%$ no cenário base para um mínimo de $30 \%$ no cenário 7.

\subsection{O modelo completo e a análise de resultados}

\subsubsection{Dados iniciais}

Para a análise de resultados, inicialmente faz-se a apresentação dos dados utilizados no modelo matemático SOVTICE (Seleção de origem, variedade, transporte, processo industrial, processo comercial e estocagem).

Neste modelo trabalhou-se com um capital de giro de $\mathrm{R} \$ 500.000,00$. Em todas as 36 semanas de safra permitiu-se $100 \%$ de colheita de cana de terceiros e a porcentagem de tempo útil de moagem também ficou em 100\% durante as 36 semanas. Fixou-se a capacidade de transporte por frota própria durante as 36 semanas de safra em 60.000 toneladas de cana. A moagem mínima na usina ficou em 40.000 toneladas de cana por semana e a moagem máxima em 50.000 toneladas de cana por semana. Dados de entrada com variação em cada semana podem ser visualizados no anexo E.

Quanto à capacidade de estocagem de produtos acabados, observam-se os valores na tabela 55.

Tabela 55. Capacidade de estocagem dos produtos acabados em $\mathrm{t}$ ou $\mathrm{m}^{3}$.

$\begin{array}{cccc}\text { Capacidade de estocagem (t ou m3) } & & \\ \text { VHP } & \text { Eprop } & \text { Eterc } \\ \text { melaço } & 15000 & 20000 \\ \text { AEHC } & 0 & 0 \\ \text { AEAC } & 14000 & 40000 \\ & 14000 & 30000\end{array}$

Em todas as 36 semanas de safra fixaram-se os custos de transporte (em reais por tonelada de cana transportada) por frota própria e terceirizada respectivamente em $\mathrm{R} \$ 7,24 / \mathrm{t}$ e $\mathrm{R} \$ 10,00 / \mathrm{t}$. 
No apêndice B estão os custos dos processos industriais/comerciais. Para efeito de ilustração, nesta dissertação são apresentadas apenas as 12 primeiras semanas.

No apêndice B também se encontram os custos de aquisição de cada variedade de cana por fonte de fornecimento em reais por tonelada de cana, os rendimentos dos processos industriais/comerciais (em toneladas ou $\mathrm{m}^{3}$ ) por tonelada de cana dos produtos comercializados, os valores de demanda hedge dos produtos comercializados para as 36 semanas de safra, os preços no mercado spot interno e mercado spot externo para os produtos comercializados nas 52 semanas de estudo.

Os custos de estocagem (em reais por tonelada ou $\mathrm{m}^{3}$ ) são admitidos constantes durante todas as 52 semanas em estudo e seguem na tabela 56 .

Tabela 56. Custos de estocagem $\left(R \$ / t\right.$ ou $\left.R \$ / m^{3}\right)$ dos produtos no modelo completo

\begin{tabular}{|c|c|c|}
\hline Custo de estocagem u.m. por t (ou m3) & \multicolumn{1}{c|}{ Sem1 } & ... \\
\hline & 10 & \\
VHP.Eprop & 40 & \\
VHP.Eterc & 15 & \\
melaço.Eprop & 40 & \\
melaço.Eterc & 16 & \\
AEHC.Eprop & 40 & \\
AEHC.Eterc & 18 & \\
AEAC.Eprop & 40 & \\
AEAC.Eterc & \\
\hline
\end{tabular}

\subsubsection{Resultados com o modelo completo SOVTICE}

Tempo computacional necessário para rodar o modelo SOVTICE e modificações de parâmetros no LINGO

Utilizando-se um computador pessoal INTEL CORE DUO de 2GB de memória RAM e sistema operacional Windows Vista, o tempo necessário para rodar o modelo SOVTICE com uma diferença com relação à solução ótima de $0,4 \%$ foi de 43 min e 15 s. Para aplicações no planejamento agregado em cada semana, entende-se tratar de um tempo de resolução viável e com boa aproximação com relação à solução ótima.

\section{Resultados com o modelo SOVTICE}

Observando-se a figura 41, em algumas das semanas analisadas observa-se acúmulo de estoque para posterior negociação nas semanas seguintes. Isto está coerente com o modelo matemático SOVTICE desenvolvido nesta dissertação, já que a idéia era fazer com que o modelo entendesse o melhor período para negociação de açúcar e álcool. 


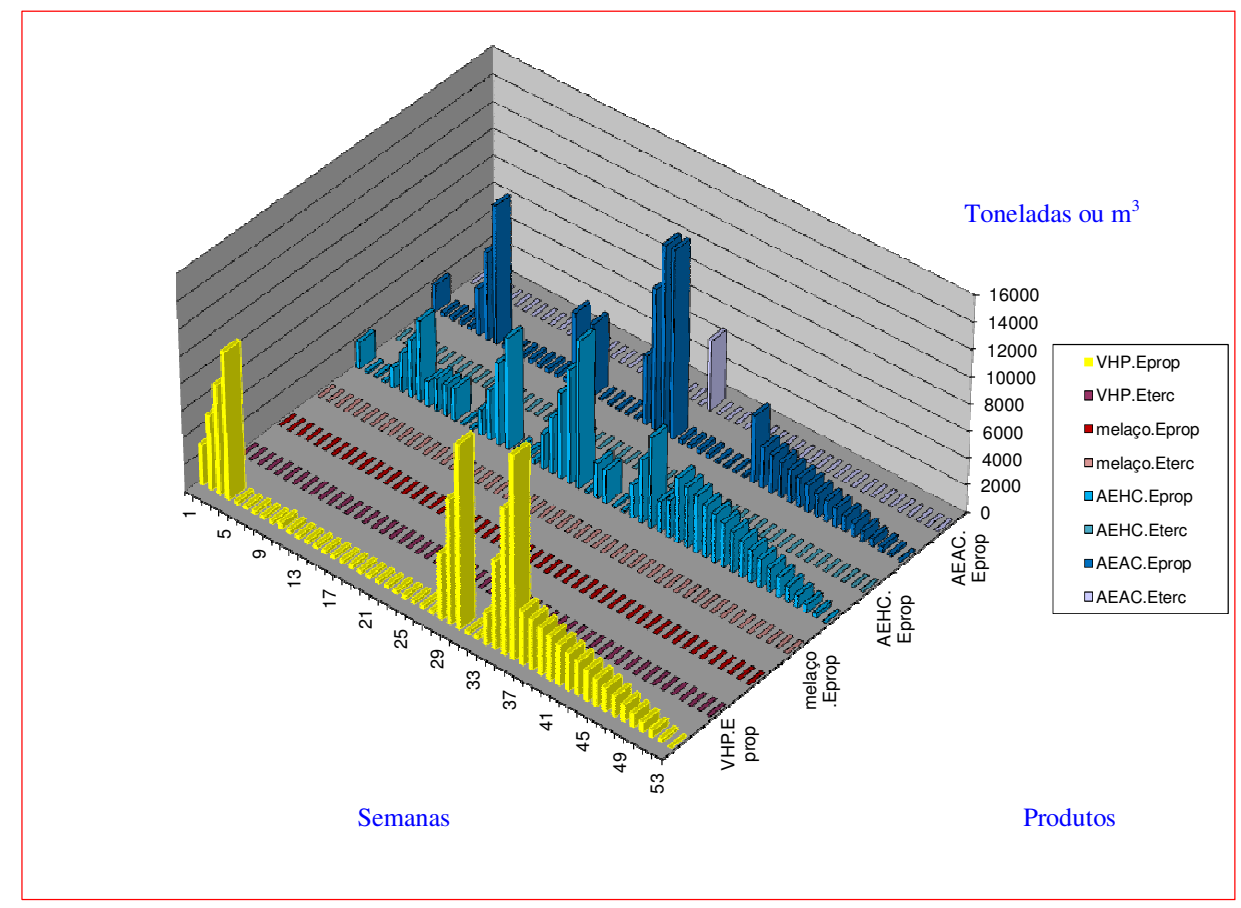

Figura 41. Quantidade estocada de cada produto em cada semana

Tabela 57. Processos utilizados em cada semana no modelo SOVTICE

\begin{tabular}{|c|c|c|c|c|c|c|c|c|c|c|c|c|c|c|}
\hline & Sem0 & Sem1 & Sem2 & Sem3 & Sem4 & Sem5 & Sem6 & Sem7 & Sem8 & Sem9 & Sem10 & Sem11 & Sem12 & \\
\hline Procl1C1E & 0 & 1 & 1 & 1 & 0 & 1 & $\overline{0}$ & $\overline{0}$ & $\overline{0}$ & 0 & 0 & 0 & $\overline{0}$ & \\
\hline Procl24C5I & 0 & 0 & 0 & 0 & 1 & 0 & 0 & 0 & 0 & 1 & 0 & 0 & 0 & \\
\hline Procl1C4E & 0 & 0 & 0 & 0 & 0 & 0 & 1 & 0 & 0 & 0 & 0 & 0 & 0 & \\
\hline Procl20C6I & 0 & 0 & 0 & 0 & 0 & 0 & 0 & 1 & 0 & 0 & 0 & 0 & 0 & \\
\hline Procl24C6I & 0 & 0 & 0 & 0 & 0 & 0 & 0 & 0 & 1 & 0 & 0 & 0 & 0 & \\
\hline \multirow[t]{2}{*}{ Procl10C4E } & 0 & 0 & 0 & 0 & 0 & 0 & 0 & 0 & 0 & 0 & 1 & 1 & 1 & \\
\hline & Sem13 & Sem14 & Sem15 & Sem16 & Sem17 & Sem18 & Sem19 & Sem20 & Sem21 & Sem22 & Sem23 & Sem24 & Sem25 & \\
\hline \multirow{7}{*}{$\begin{array}{l}\text { Procl1C1E } \\
\text { Procl24C3I } \\
\text { Procl24C1I } \\
\text { Procl23C6I } \\
\text { Procl23C4I } \\
\text { Procl23C7I }\end{array}$} & 1 & 0 & 0 & 0 & 0 & 0 & 0 & 0 & 0 & 0 & 0 & 1 & 1 & \\
\hline & 0 & 1 & 0 & 0 & 0 & 0 & 0 & 0 & 0 & 1 & 0 & 0 & 0 & \\
\hline & 0 & 0 & 1 & 0 & 0 & 0 & 0 & 0 & 0 & 0 & 0 & 0 & 0 & \\
\hline & 0 & 0 & 0 & 1 & 0 & 1 & 0 & 0 & 0 & 0 & 0 & 0 & 0 & \\
\hline & 0 & 0 & 0 & 0 & 1 & 0 & 0 & 0 & 1 & 0 & 1 & 0 & 0 & \\
\hline & 0 & 0 & 0 & 0 & 0 & 0 & 1 & 1 & 0 & 0 & 0 & 0 & 0 & \\
\hline & Sem26 & Sem27 & Sem28 & Sem29 & Sem30 & Sem31 & Sem32 & Sem33 & Sem34 & Sem35 & Sem36 & Sem37 & Sem38 & \\
\hline \multirow{7}{*}{$\begin{array}{c}\text { Procl1C8E } \\
\text { Procl1C1E } \\
\text { Procl24C4I } \\
\text { Procl1C5E } \\
\text { Procl1C3I } \\
\text { Procl1C6I }\end{array}$} & 1 & 1 & 1 & 0 & 0 & 0 & $\overline{0}$ & $\overline{0}$ & $\overline{0}$ & 1 & 1 & 0 & 0 & \\
\hline & 0 & 0 & 0 & 1 & 1 & 1 & 1 & 0 & 0 & 0 & 0 & 0 & 0 & \\
\hline & 0 & 0 & 0 & 0 & 0 & 0 & 0 & 1 & 0 & 0 & & 0 & 0 & \\
\hline & 0 & 0 & 0 & 0 & 0 & 0 & 0 & 0 & 1 & 0 & 0 & 0 & 0 & \\
\hline & 0 & 0 & 0 & 0 & 0 & 0 & 0 & 0 & 0 & 0 & 0 & 1 & 0 & \\
\hline & 0 & 0 & 0 & 0 & 0 & 0 & 0 & 0 & 0 & 0 & 0 & 0 & 1 & \\
\hline & Sem39 & Sem40 & Sem41 & Sem42 & Sem43 & Sem44 & Sem45 & Sem46 & Sem47 & Sem48 & Sem49 & Sem50 & Sem51 & Sem52 \\
\hline \multirow{3}{*}{$\begin{array}{l}\text { Procl1C3l } \\
\text { Procl1C1E } \\
\text { Procl6C3E }\end{array}$} & 1 & 1 & 1 & 1 & 1 & 1 & 0 & 0 & 0 & 0 & 0 & 0 & 0 & 1 \\
\hline & 0 & 0 & 0 & 0 & 0 & 0 & 1 & 1 & 1 & 1 & 0 & 0 & 0 & 0 \\
\hline & 0 & 0 & 0 & 0 & 0 & 0 & 0 & 0 & 0 & 0 & 1 & 1 & 1 & 0 \\
\hline
\end{tabular}

Na tabela 57, ProcI1C1E significa que foi utilizado o processo industrial 1 e comercial 1 com destinação de porcentagens da tabela de separações comerciais (tabela 64, anexo E) para mercado externo. Observa-se a ocorrência com grande freqüência desse processo, o que pode ser explicado pelos preços mais elevados no mercado externo relativamente ao açúcar e álcool anidro (vide tabela 70, anexo E). Nas semanas 4, 7, 8, 9, 14 a 23 ocorre 
destinação maior para mercado interno, o que se explica ora pela demanda maior para mercado interno por açúcar VHP e álcool AEHC (tabela 72, anexo E), ora pelo preço maior de álcool AEHC no mercado interno quando comparado ao preço no mercado externo ( tabelas 69 e 70, anexo E).

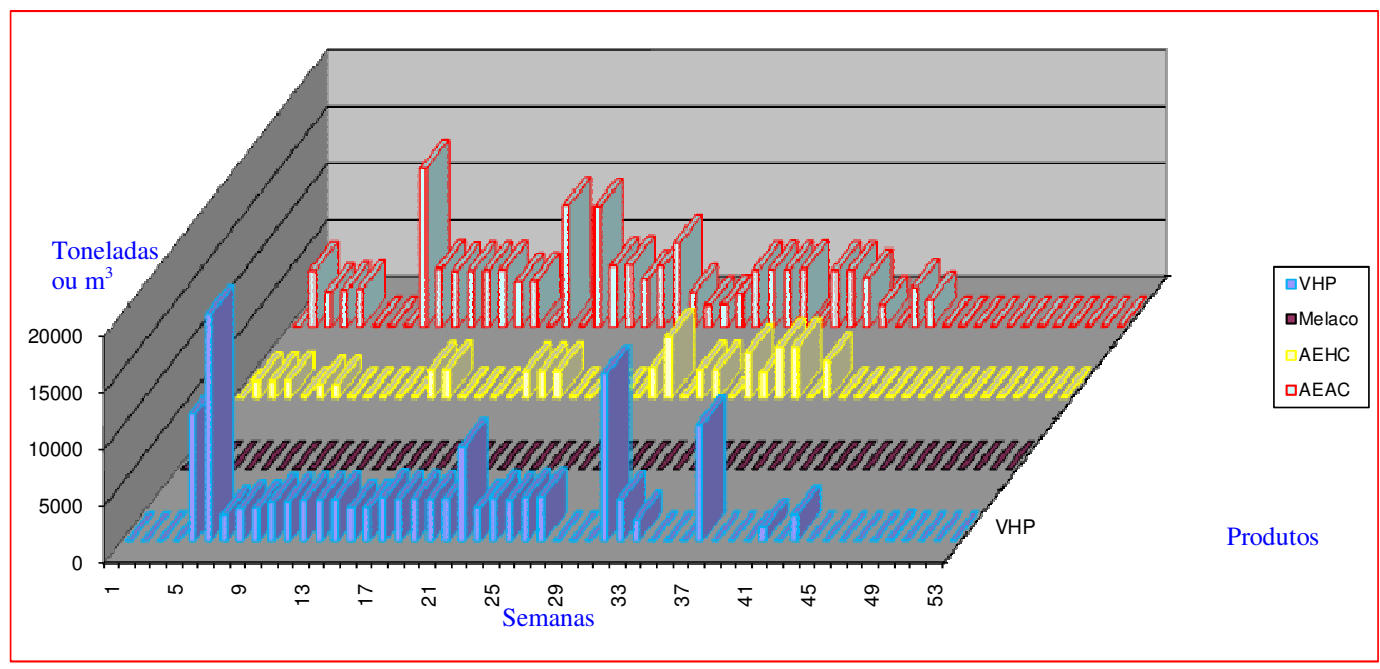

Figura 42. Quantidade comercializada de cada produto em cada semana no mercado interno

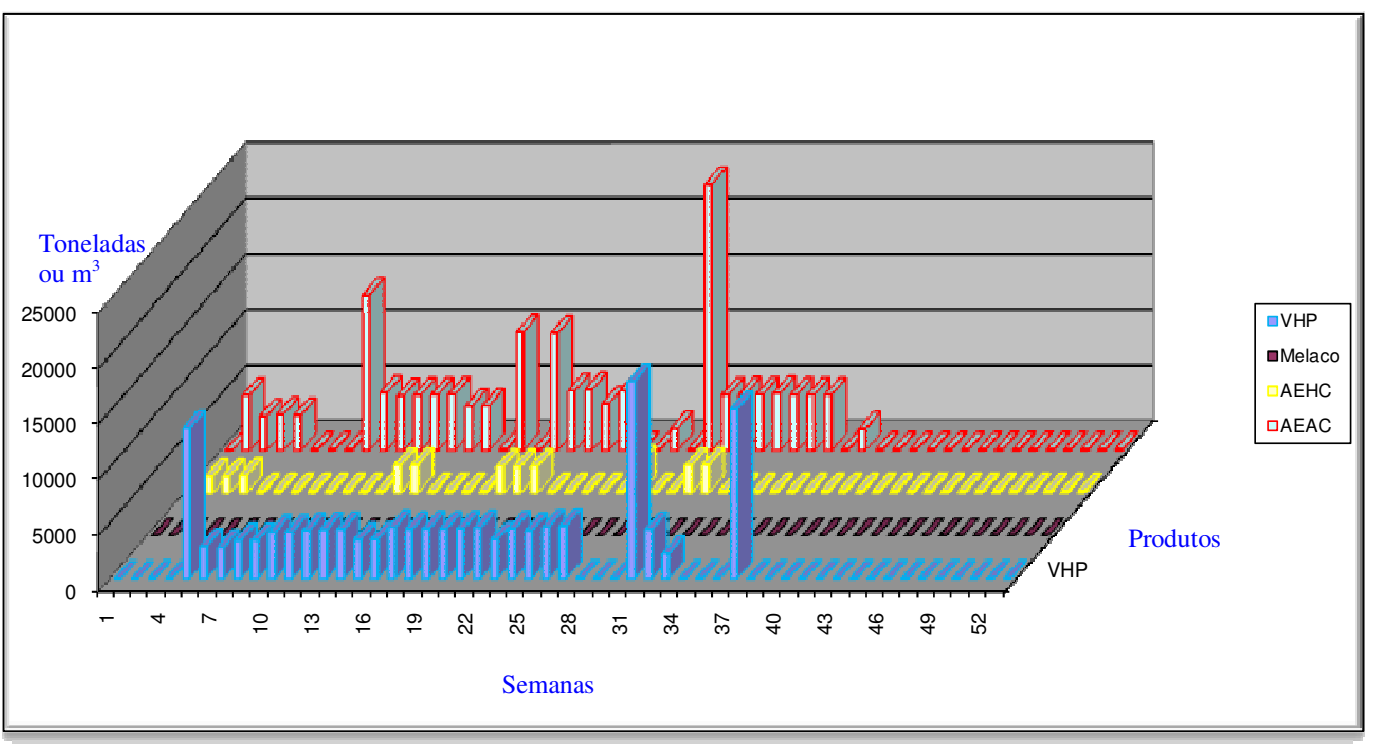

Figura 43. Quantidade comercializada de cada produto em cada semana no mercado externo

Pelas figuras 42 e 43, observa-se ora concentração maior de venda dos produtos para mercado interno, ora maior para mercado externo. Esse resultado está coerente com o modelo matemático SOVTICE de maximização da margem de contribuição das usinas. Compreende-se assim que o modelo entende qual o melhor momento para negociação 
de cada produto e também qual o melhor mercado para a venda de determinada quantidade de produto.

\subsubsection{Comparação entre os resultados da aplicação do modelo SOVTICE e resultados da USALPA}

Para se estabelecer comparações entre os resultados alcançados com a aplicação do modelo SOVTICE e resultados alcançados pela usina utilizada para validação da pesquisa, foram tomados como saída para o caso real da usina USALPA o planejamento de safra estipulado pelos gestores da usina, o plano de produção previsto de açúcar e álcoois na safra 2008/2009, o planejamento comercial de venda de açúcar e álcoois na safra 2008/2009 e os planos de estocagem para os produtos acabados considerados (açúcar VHP, AEHC, AEAC e melaço). Para efeito de comparação, os custos na aplicação do modelo e no caso real são os mesmos. Os indicadores escolhidos para compor a base de comparação são os valores comerciais efetivados, como as quantidades de venda de açúcar VHP, álcool AEHC, álcool AEAC e melaço para mercado interno e mercado externo. É feita também comparação entre as margens de contribuição, as quais foram divididas por uma constante a pedido da usina estudada. 
Tabela 58. Comparação de resultados USALPA x SOVTICE

\begin{tabular}{|c|c|c|c|}
\hline Indicadores & RU (Resultado USALPA) & RS (Resultado SOVTICE) & $(\mathrm{RS}-\mathrm{RU}) / \mathrm{RU}$ \\
\hline Gastos na etapa agrícola & 335,6 & 321,4 & $-4,2 \%$ \\
\hline $\begin{array}{l}\text { Venda de açúcar VHP } \\
\text { para mercado interno }\end{array}$ & 231.435 sacas de $50 \mathrm{Kg}$ & 62.345 sacas de $50 \mathrm{Kg}$ & $-73,1 \%$ \\
\hline $\begin{array}{l}\text { Venda de AEHC } \\
\text { para mercado interno }\end{array}$ & $33.789 .232 \mathrm{~m}^{3}$ & $28.345 .323 \mathrm{~m}^{3}$ & $-16,1 \%$ \\
\hline $\begin{array}{l}\text { Venda de AEAC } \\
\text { para mercado interno }\end{array}$ & $13.789 .232 \mathrm{~m}^{3}$ & $8.345 .323 \mathrm{~m}^{3}$ & $-39,5 \%$ \\
\hline Venda de melaço & 0 & 0 & $0 \%$ \\
\hline $\begin{array}{l}\text { Venda de açúcar VHP } \\
\text { para mercado externo }\end{array}$ & 986.544 sacas de $50 \mathrm{Kg}$ & 1.234 .346 sacas de $50 \mathrm{Kg}$ & $+25,1 \%$ \\
\hline $\begin{array}{l}\text { Venda de AEHC } \\
\text { para mercado externo }\end{array}$ & $3.234 .224 \mathrm{~m}^{3}$ & $2.345 .784 \mathrm{~m}^{3}$ & $-27,5 \%$ \\
\hline $\begin{array}{l}\text { Venda de AEAC } \\
\text { para mercado externo }\end{array}$ & $10.349 .247 \mathrm{~m}^{3}$ & $18.332 .245 \mathrm{~m}^{3}$ & $+77,1 \%$ \\
\hline Hedge de VHP & $\begin{array}{c}23,4 \\
\text { unidades monetárias }\end{array}$ & $\begin{array}{c}123,5 \\
\text { unidades monetárias }\end{array}$ & 4,3 \\
\hline Hedge de AEHC & $\begin{array}{c}0 \\
\text { unidades monetárias }\end{array}$ & $\begin{array}{c}45,6 \\
\text { unidades monetárias }\end{array}$ & - \\
\hline Hedge de AEAC & $\begin{array}{c}25,6 \\
\text { unidades monetárias }\end{array}$ & $\begin{array}{c}98,5 \\
\text { unidades monetárias }\end{array}$ & 2,8 \\
\hline Margem de contribuição & $\begin{array}{c}1105 \\
\text { unidades monetárias }\end{array}$ & $\begin{array}{c}1181,1 \\
\text { unidades monetárias }\end{array}$ & $+6,9 \%$ \\
\hline
\end{tabular}

Podem-se observar pelos resultados da tabela acima grandes diferenças de destinação de comercialização dos produtos acabados para mercado interno e mercado externo. Na venda de AEAC para mercado externo, por exemplo, ocorre uma diferença de $77,1 \%$ a mais no modelo SOVTICE quando comparado com o planejamento dos gestores da USALPA. Juntando-se a isso o aumento de 6,9\% na margem de contribuição quando usado o modelo SOVTICE, revelam-se promissoras possibilidades de aproveitamento desse tipo de modelo de planejamento da produção vinculado a estratégias de comercialização.

Os resultados da tabela 58 mostram boas possibilidades de aproveitamento desse tipo de modelo de planejamento agregado integrando as etapas agrícola, industrial e comercial 
de uma usina de açúcar e álcool. Além de ocorrer economia com custos agrícolas, ocorre aumento na margem de contribuição quando aplicado o modelo SOVTICE.

\subsubsection{Validação do modelo através de pesquisa de opinião junto a um grupo de usinas}

Para análise de viabilidade e validação da pesquisa proposta nesta dissertação, através de visitas agendadas foram feitas entrevistas com gestores das usinas Usalpa (município de Junqueirópolis), Alcídia (município de Teodoro Sampaio), Branco Peres (município de Adamantina), Califórnia (município de Tupã), Coruripe (município de Dracena) e Clealco (município de Clementina). As usinas Usalpa, Alcídia, Branco Peres, Califórnia e Clealco negociam sua produção através de corretoras e tradings especializadas, enquanto as usinas do grupo Coruripe negociam elas mesmas sua própria produção através de um departamento comercial central. A proposta de modelo de planejamento agregado desta dissertação poderia auxiliar os dois tipos de negociação, ora pelo acompanhamento de tendências do mercado e renegociações com as corretoras (caso das primeiras usinas citadas), ora pela necessidade de um planejamento ótimo inicial (caso das usinas do grupo Coruripe).

Uma sugestão de um diretor comercial do grupo Coruripe e de gestores da usina Clealco foi a consideração de restrição relativa a contratos de fornecimento de açúcar e álcool para mercado interno e mercado externo. Isso é facilmente contornável pela adição no modelo matemático de tais restrições, assim como foi feito para restrições relativas às quantidades de hedge para açúcar e álcool. Sugeriram ainda a possibilidade de implementação no modelo de mecanismo que permita a recompra do hedge efetuado por parte da usina caso o preço futuro no mercado à vista seja mais vantajoso na época da venda.

Diretores e gerentes industriais da usina Alcídia sugeriram a consideração de custos de setup na construção do modelo, já que nas trocas de processos ocorrem perdas importantes devido às alterações de proporções de açúcar e álcool. Pode-se implementar isso no modelo vinculando cada troca de processo a esse custo de setup.

Gerentes industriais das usinas Califórnia e Branco Peres sugeriram a expansão no modelo de mais processos industriais, permitindo ajustes mais finos nas proporções de açúcar e álcool. Esbarra-se aqui no problema da multiplicação de variáveis binárias na função objetivo tornando o modelo não linear e de tamanho não executável no software escolhido num tempo razoável. 
Finalmente, os gerentes agrícolas da usina USALPA salientaram que em aplicações reais do modelo torna-se necessário que cada usina ou grupo de usinas desenvolvam em seus laboratórios mecanismos de comparação de produtividade de variedades de cana e melhor momento para corte, aprimorando a idéia desenvolvida nesta dissertação. O diretor comercial achou viável o modelo de otimização de escolha de produtos para mercado interno ou para mercado externo, servindo como um norte a guiar as decisões de planejamento de vendas conjuntamente com a área industrial.

\section{CONCLUSÕES}

Procurou-se desenvolver esta dissertação seguindo a estrutura metodológica presente nos ensinamentos de Bertrand e Fransoo em seu artigo "Operations management research methodologies using quantitative modeling" e também no trabalho de Mirtroff et al.(1974), estabelecendo-se assim cinco fases para o projeto. Os capítulos 1 e 2 desenvolvem a conceituação do problema, delimitando o objeto estudado, no caso o desenvolvimento de um modelo de planejamento agregado que integrasse as etapas agrícola, industrial e comercial de usinas de açúcar e álcool. No capítulo 3 ocorre a fundamentação teórica, através de uma ampla pesquisa bibliográfica de trabalhos relacionados com as etapas agrícola, industrial e comercial. Para a execução da modelagem do problema, no capítulo 4 são levantados os parâmetros necessários de custos e receitas que funcionaram como dados de entrada para os modelos de otimização presentes no capítulo 5. No capítulo 6 faz-se a análise e discussão de resultados com estudo de cenários para verificação de consistências do modelo proposto e faz-se também uma comparação do resultado encontrado com aplicação do modelo desenvolvido e o que ocorre no planejamento da usina estudada.

Pode-se dizer que cada modelo de planejamento, para ter resultados satisfatórios, precisa estar em constante processo de atualização e constante atendimento das necessidades que estão por vir. O modelo proposto nesta dissertação não foge à regra e pode e deve ser adaptado à realidade de cada usina ou grupo de usinas, mostrando-se com bom potencial para ajudar em importantes decisões nas etapas agrícola, industrial e comercial. 


\subsection{Perspectivas para pesquisas futuras}

O setor "sucroenergético" (nomenclatura mais atual em substituição à consagrada "sucroalcooleiro") no Brasil está em franca expansão e passa por um período de novas pesquisas que tem por finalidade manter o país na vanguarda de conhecimento e ganhos de eficiência e lucratividade. São várias as possibilidades de pesquisas futuras no setor. $\mathrm{Na}$ etapa agrícola, pode-se destacar o acréscimo no modelo da escolha de insumos/fertilizantes para adubação definindo-se proporções ótimas para o aumento de produtividade das variedades de cana; a escolha do tipo de corte da cana picada, já que isso interfere diretamente no rendimento da moagem e no número de paradas da moenda e consequentemente da usina; a adição no modelo da escolha da quantidade de cana a se colher de acordo com seu estágio de corte (primeiro corte, segundo corte, terceiro corte, quarto corte ou quinto corte).

$\mathrm{Na}$ etapa de transporte da cana do campo até a usina, acrescentar no modelo a escolha do tipo de caminhão, além da escolha de frota própria/terceirizada, pode ter bons resultados na margem de contribuição.

Quanto ao aproveitamento da matéria-prima, incorporar no modelo o aproveitamento do subproduto bagaço para co-geração de energia elétrica, que já é importante fonte de renda para muitas usinas espalhadas pelo país.

$\mathrm{Na}$ área contábil, um estudo detalhado que monitore os direcionadores de custos, visando sempre melhorar a qualidade das informações gerenciais, já que estudos como os desta dissertação dependem diretamente de informações como essas.

$\mathrm{Na}$ parte metodológica do trabalho, o desenvolvimento de um estudo envolvendo os vários parâmetros de rendimentos agroindustriais, tais como os conhecidos Copersucar, Unicop e outros que sejam representativos das usinas brasileiras para que possam ser utilizados como padrões para desenvolvimento de trabalhos desta natureza.

$\mathrm{Na}$ área mercadológica, desenvolver o trabalho num pool de usinas, verificando a adequabilidade do modelo é um passo importante para ganhos de eficiência de grupos empresariais.

A integração do modelo desenvolvido com a etapa de distribuição é outra vertente para pesquisas futuras.

Finalmente, no ambiente de estudo de Pesquisa Operacional, desenvolver um modelo que separe a escolha de processos da etapa industrial da etapa comercial trará ganhos no refinamento do estudo e possíveis aumentos na margem de contribuição. 


\section{REFERÊNCIAS BIBLIOGRÁFICAS}

ANDRADE, Manuel Correia de. A expansão da Agricultura Canavieira e seu

Impacto Ecológico e Social. São Paulo, Editora Unesp, 2002.

ANDRIETTA, SÍLVIO. Modelagem, simulação e controle de fermentação alcoólica em função contínua em escala industrial. Tese de doutorado. FEA/Unicamp.

ARENALES, M., ARMENTANO, V., MORABITO, R. YANASSE, Horacio. Pesquisa Operacional. Abepro/Editora Campus/Elsevier, $1^{\text {a }}$ edição 2007.

ARAÚJO, S.A; ARENALES, M.N. \& CLARCK, A. R. Dimensionamento de lotes e programação do forno numa fundição de pequeno corte. Gestão e Produção, v.11, n.2, p. 165-176, 2004.

AUDSLEY, E. The development of operational research at the National Institute of Agricultural Engineering. Journal of the Operational Research Society, 36(2), p.117-123, 1985.

AZEVEDO FILHO, A.J.B.V., NEVES, E.M. O uso de programação matemática na análise de investimento na pecuária de corte: técnicas intensivas $\mathbf{x}$ mercado de capitais. Anais do I Congresso Latino-Americano de Pesquisa Operacional e Engenharia de Sistemas. Rio de janeiro: Sobrapo, 1982, p. 41-55.

AZEVEDO FILHO, A.J.B.V., NEVES, E.M. Pesquisa Operacional na Agricultura brasileira. $11^{\mathrm{a}}$ reunião da Sociedade Brasileira de Matemática Aplicada à Computação (SBMAC). Botucatu, 9 de junho de 1988.

BACCHI, M. R. P \& MARJOTTA-MAISTRO, M.C. (1999), “Comportamento do preço do açúcar no Estado de São Paulo”, Preço Agrícola, V. XIV, n. 158, pp.1113.

BACCHI, M.R.P ,Gerenciamento do risco de preço no mercado doméstico de açúcar e álcool, Preços Agrícolas, Piracicaba, v. 119, p. 2-7, setembro, 2007 
BAER, W. A Economia Brasileira, Editora Nobel, São Paulo, 1996.

BALASTREIRE, L.A. Sugar cane harvesting optimization using microcomputers. First International Conference on Agricultural Systems Engineering. Changchun: China Machine Press, 11-14 August, 1987, p.557-566.

BALLOU, RONALD H. Business Logistics management. Englewood Cliffs NJ: Prentice Hall. $5^{\mathrm{a}}$ edição, 2004.

BARATA, M.Q.F. Otimização econômica do corte e reforma de canaviais. Dissertação (Mestrado em Agronomia ). Piracicaba: Esalq, 1992.

BOZA ARCE, R. Otimização de um projeto hidroagrícola no município de Guairá (SP) utilizando programação linear. Dissertação (Mestrado em Agronomia)-Escola Superior de Agricultura Luiz de Queiroz. Piracicaba: USP, 1990.

BRUGNARO, C., HEISE, C.E., GIL, O.F, PERES, F.C., Maximização da produção de uma usina de açúcar. Brasil Açucareiro, 106(5-6), p.2-8, 1988.

BM\&F, "Futuro de açúcar e álcool”, Relatório técnico, 2007

DEPARTAMENTO DE AGRICULTURA E AGROPECUÁRIA

(daa.agricultura.gov.br), março de 2008.

BUENO, A.R.S, KINPARA, D.I., CAIXETA FILHO, J.V. Development of mathematical models for forest management: a survey. Anais do XXV Simpósio Brasileiro de Pesquisa Operacional. Campinas: Sobrapo, Nov. 1993. p.82-87.

BURNQUIST, H.L., BACCHI, M.R.P., MARJOTTA, M.C. Análise da comercialização dos produtos do setor sucroalcooleiro brasileiro: Evolução, contexto institucional e desempenho. Agroindústria canavieira no Brasil: evolução, desenvolvimento e desafios. São Paulo, Atlas, 2002.

BUTTERWORTH, K. Practical application of linear/integer programming in agriculture. Journal of the Operational Research Society, 36(2), p.99-107. 
CAIXETA FILHO, J.V. Transporte e logística no sistema agroindustrial. Preços Agrícolas, Piracicaba, v. 119, p. 2-7, setembro 1996.

CAIXETA FILHO, J.V.; GAMEIRO, A.H. (Org.) Transporte e logística em sistemas agroindustriais. São Paulo: Atlas, 2001. 218 p.

CAIXETA FILHO, V.J.Optimization of the production planning and trade of Lily Flowers at Jan de Wit Company. Interfaces, vol. 32. n.1, p. 35-46, 2002.

CALIARI, M., SORES, M., SERRA, G. Programação matemática aplicada à colheita de cana-de-açúcar com ênfase na recuperação máxima de açúcar. Pesquisa Agropecuária Tropical, p. 1-8, volume 1, 2005

CHASE, RICHARD e outros. Administração da produção para a vantagem competitiva - Bookman- Décima edição.

CHEN S.S., LEE C. E SHRESTHA K. "Futures Hedge Ratios: A Review". Quarterly Review of Economics and Finance, 43, 433-465, 2003.

CHIODI,L. , MANSINI, R., SPERANZA,M.G, Semi-absolute deviation rule for mutual funds portfolio selection, Annals of Operations Research 124, 245-265, 2003.

CHOPRA, SUNIL. Gerenciamento da cadeia de suprimentos, Pearson, 2004.

COCK, J.H; LUNA, C.A. \& PALMA, A. The trade-off between total harvestable production and concentration of the economically useful yield component: cane tonnage and sugar content. Fields Crops Research, v.67, n.3, p.257-262, 2000.

COLIN, E.C.; CIPPARRONE, F.A.M. \& SHIMIZU, T. Otimização do custo de transporte na distribuição-armazenagem de açúcar. Produção, v.9, n.1, p.23-30, 1999. 
CUSATIS P. E THOMAS M., Hedging Instruments and Risk Management: How to Use Derivatives to Control Financial Risk in Any Market. McGraw-Hill, New York, 2005.

EDWARDS F.R. E MA C.W., Futures \& Options. McGraw-Hill, New York, 1992. Cusatis e Thomas (2005)

FERNANDES, Antônio Carlos. Cálculos na agroindústria da cana - de-açúcar, STAB, 2003.

FERNANDES, Alfredo José. Manual da Cana-de-açúcar. Piracicaba: Editora Livroceres, 2002.

FNP CONSULTORIA \& COMÉRCIO.Agrianual, 2006: Anuário da Agricultura Brasileira, São Paulo, 2005. p.262-277.

FOKKENS, B., PULYAERT, M. A linear programming model for daily harvesting operations at the large-scale grain farm of the IJsselmeerpolders development authority. Journal of the Operational Research Society, 32(7), p.535547, 1981.

GRISOTTO, M.E. Otimização do transporte de cana-de-açúcar por caminhões. Campinas, 1995. Dissertação (Mestrado em Matemática Aplicada) IMECC/UNICAMP.

GUALDA, N.D.F., TONDO, C.M. A large l.p. model for sugarcane crop planning. Paper apresentado no TIMS XXX - Sobrapo XXIII Joint International Meeting, Rio de Janeiro : Sobrapo 15-17 July 1991.

GUERREIRO, MARCO ANTONIO. Sistema especialista para projeto e dimensionamento de destilaria de álcool. Tese de doutorado. FEA/Unicamp.

GURGEL, FLORIANO C. A. Administração dos fluxos de materiais e produtos. São Paulo: Atlas, 1996. 
HIGGINS, A.J. \& DAVIELS, I. A simulation model for capacity planning in sugarcane transport. Computers and Eletronics in Agriculture, v.47, n. 2, p. 85$102,2005$.

HILLIER, F.S. E LIEBERMAN, G.L., Introduction to Operations Research. McGraw-Hill, New York, 1995.

HANKE, J.E., REISCHT, A.G., Business Forecasting, Prentice Hall, Upper Saddle River, New Jersey, 1998.

IANNONI, A.P. \& MORABITO.R. A discrete simulation analysis of a logistics supply system. Transportation Research, Part E: Logistics and Transportation Review, v. 42, n. 43, p. $191-210,2006$.

JORION, P, Value at Risk, second edition, Mc Graw-Hill, 2001

KELLERER,H., MANSINI,R., SPERANZA, M.G. Selecting portfolios with fixed costs and minimum transaction lots, Annals of Operations Research 99, 287304, 2000.

KONNO H. E YAMAZAKI H., "Mean-Absolute Deviation Portfolio Optimization Model and Its Application to Tokyo Stock Market.” Management Science, 37, 519-531, 1991.

LINDO Systems, Inc., 1999, LINGO Optimization Modeling Language (User Manual), Chicago, IL.

MARKOWITZ H.M., Portfolio Selection: Efficient Diversification of Investments. Wiley, New York, 1959.

MARKOWITZ H.M., TODD P., XU G. E YAMANE Y. "Fast Computation of Mean-Variance Efficient Sets Using Historical Covariances." Journal of Financial Engineering, 1, 117-132, 1992. 
MARKOWITZ H.M., "Computation of Mean-Semivariance Efficient Sets by the Critical Line Algorithm.” Annals of Operations Research, 45, 307-317, 1993.

MAKRIDAKIS, S., WHEELWRIGHT, S.C., Forecasting-Methods and Applications, $3^{\circ}$ ed, Wiley, New York, 1998.

MARQUES, P.V.; MELLO, P. C.; MARTINES, J.G. Mercados Futuros e de Opções Agropecuárias. Piracicaba, S.P. Departamento de Economia, Administração e Sociologia da Esalq/USP, 2006, Série Didática nº D-129.

MARZANO B., Luiz Guilherme; “Otimização de Portfólio de Contratos de Energia em Sistemas Hidrotérmicos com Despacho Centralizado", tese de doutorado, PUC-Rio, 2004.

MATHEW,J.\&RAJENDRAM,C.Scheduling of maintenance in a sugar industry using simulation. Computers in industry, v.21, n.3, p.331-334, 1993.

MAUGERI FILHO, FRANCISCO. "Modelagem matemática de fermentação alcoólica em função da temperatura”. XI Sinafrem, 31 de julho a 2 de agosto de 1996, UFSCAR, p. 658-963.

MEDEIROS, F. Processos de fabricação de açúcar. Apostila de treinamento e consultoria, disponível na Usina Santa Clotilde, 2005.

MEDEIROS, A.L., SOUZA, A.L.C., MONTEVECHI, J.A.B. Análise e previsão de preços de commodities do setor sucroalcooleiro. Enegep, 2006, 9 a 11 de outubro de 2006. 
MEIRELES, ANTONIO J.A. Processos industriais de desidratação de álcool com ênfase no modelo BSM - Unicamp.

MOREY, R.V., ZACHARIAH, G.L., PEART, R.M. Optimum policies for corn harvesting. Transactions of the ASAE, 14(5), p. 787-792, 1971.

NEMHAUSER G.L., RINNOOY A.H.G. E TODD M.J., Diversification of Investments and fast computation. Operations Research and Management Science: Optimization. North Holland, Amsterdam, 1989.

OCDE, Análise da viabilidade de produção de álcool, Relatório técnico, julho de 2008. In www.oecd.org

PAIVA, R.P.O. Um modelo baseado em seleção de processos e dimensionamento de lotes para o planejamento agregado da produção em usinas de açúcar e álcool. São Carlos, 2006. 182 p. Dissertação (Mestrado em Engenharia de Produção)- DEP/UFSCAR.

PAIVA, R.P.O. Modelagem do planejamento agregado da produção em usinas cooperadas do setor sucroenergético utilizando programação matemática e otimização robusta. São Carlos, 2009, 240 páginas. Tese (Doutorado em Engenharia de Produção)- DEP/UFSCAR.

PARANHOS, Sergio Bicudo. Cana-de-açúcar cultivo e utilização. Fundação Cargill. Editora Cidade, 1987

PEART, R.M., OGILVIE, J.R., BARRET, J.R., BENDER, D.A. Some examples of the use of simulation in U.S. and Canadian agriculture. Journal of the Operational Research Society, 36 (2), p.109-115, 1985.

PINA, H. (1972), A Agroindústria Açucareira e sua Legislação, Apec, São Paulo. 
PINDYCK, ROBERT S.; RUBINFELD, DANIEL L. Microeconomia, sexta edição, 2006.

PRADO, Darci Santos do. Programação Linear. Belo Horizonte: Editora de Desenvolvimento Gerencial, 1999.

PRIORE, Mary Del et al.. O Livro de Ouro da História do Brasil. Rio de Janeiro: Editora Ediouro, 2001.

QINGHXEN, Z., CHANGYU, W., ZHIMIN, Z.. The application of operations research in the optimization of agricultural production Operations Research, 39(2), p.194-205, Mar. /April 1991.

RIBEIRO, C.O., MIRANDA, B., WIDONSCK, C. Redes Neurais aplicadas à previsão de volatilidade do mercado futuro de álcool. Enegep, 2005, 29 de outubro a 01 de novembro de 2005.

RODRIGUES, J.D. Fisiologia da cana-de-açúcar, UNESP, 2005.

SANDERS, D. R.; MANFREDO, M. R. Corporate Risk Management and the Role of Value-at-Risk. Conference Applied Commodity Price Analysis, Forecasting, and Market Risk Management. Chicago, pp. 39-51, 1999

SAITO, R.J. Análise de cadeias agroindustriais utilizando simulação computacional baseada na metodologia system dynamics: um estudo de caso. São Carlos, 2000( Dissertação de mestrado- 83p.,UFSCAR)

SCHRAGE, L.. Optimization modeling with lingo, 2007, Lindo Systems Inc.

SHAPIRO, J.F. Modeling the supply chain. Pacific Grove CA: Duxbury Press, 2001.

SLACK, NIGEL. Administração da produção - Atlas 2002. 
SOUZA, Izabel Miranda Garcia et al.. Suplemento da Revista SENAC Ambiental. Rio de Janeiro: Editora Senac, 2000. 46p.

SOARES, M. G.; GALVANI, P. R. C.; CAIXETA FILHO, J.V. Características do transporte de açúcar no Brasil. Preços Agrícolas, Piracicaba, v. 123, p. 19-22, janeiro 1997.

SOFFNER, R.K., MILAN, M., RIPOLI, T.C.C. Gerenciamento global de sistema agrícola em unidades sucroalcooleiras através de programação linear. STAB: açúcar, álcool e subprodutos, Piracicaba: Stab, v.11, número 5. p. 16-20, maio/junho 1993.

TAKEUCHI, R. SILVA,ROSELI. Uma análise empírica da eficiência relativa nos mercados futuro e à vista de açúcar. Ribeirão Preto, 2008, FEA, USP.

TAVARES CARNEIRO, MARIA C., Otimização sob incerteza de carteiras de investimentos: aplicação à cadeia integrada de petróleo e derivados, dissertação de mestrado, PUC-Rio, 2008.

TOLEDO, C.F.M. Problema Conjunto de dimensionamento de lotes e programação da produção. Campinas, 2005. Tese (Doutorado em Engenharia Elétrica) - Unicamp.

TONIELLO, B.L., CAIXETA FILHO, J.V. Utilização de programação linear para planejamento agrícola em propriedade da região centro-oeste. Informe GEP/DESR, 5(3), p.1-7, mar.1992.

TORRES, A., DIAZ, P. Planejamento da produção numa usina de açúcar e álcool, anais de congressos do ICIDCA (Instituto cubano de pesquisa e derivados cana-de açúcar), 2007.

TOSO, E.A.V. \& MORABITO, R. Otimização no dimensionamento e seqüenciamento de lotes de produção: um estudo de caso numa fábrica de rações. Gestão \& Produção, v.12, n.2, p.203-217, 2005. 
UNICA (União da Agroindústria canavieira de São Paulo) Informação UNICA. Ano

6, número 51, janeiro/fevereiro de 2003. Disponível em http://www.unica.com.br/files/informacaounica/unica51.pdf. Acesso em 10 de janeiro de 2008 .

VLIET, A., BOENDER, G.E., KAN, A.H.G.R. Interactive optimization of bulk sugar deliveries. Interfaces, 22(3), p.4-14, May/Jun.1992.

WAACK, R.S., NEVES, M.F. \& MORAES, S. Grupamentos estratégicos nas usinas de açúcar e álcool. In: Congresso da Sociedade Brasileira de Economia e Sociologia Rural, 36. Poços de Caldas, MG. Anais, 1998.

WISSEN,M.E.; SMEETS, J.F.C.; MULLER, A.; VERHEIJEN, P. J. T. Discrete event modeling and dynamic optimization of a sugar plant. Relatório Técnico, Delft University of Technology, 2005.

WILLIAMS, H. PAUL, Model building in mathematical programming. John Wiley \& Sons, 1999

WILLIAMS, H. PAUL, APPA, G., Handbook of modeling for discrete optimization, Springer, New York, 2006

WINSTON, W.L. Operations Research. Belmont CA: Duxbury Press, $2^{\mathrm{a}}$ edição 1997.

YAMADA, M.C. Modelagem das cadeias de atividades produtivas da indústria sucroalcooleira visando à aplicação em estudos de simulação. São Carlos, 1999.164 p. Dissertação (Mestrado em Engenharia mecânica)- EESC/USP.

YANASSE, H.H., MORABITO, R. A note on linear models for two-group and three-group two-dimensional guillotine cutting problems. International Journal of Production Research, Vol. 46, Número 21, November, 2008, 6189-6206. 
YOUNG, MARTIN R., "A MinMax portfolio selection rule with Linear

Programming solution”. Management Science, vol.44, N0. 5, 1998, p. 673 a p.683

YOSHIZAKI, H.Y., MUSCAT, A.R.N., BIAZZI, J.L. Descentralizing ethanol distribution in southeastern Brazil. Interfaces, 26(6), p. 24-34, Nov./Dec. 1996.

ZUO, M., KUO, W., MCROBERTS, K.L. Aplication of mathematical programming to a large-scale agricultural prodution and distribution system. Journal of Operational research Society, 42(8), p. 639-648, 1991.

\section{APÊNDICES}

\section{Apêndice A- Panorama histórico da cana-de-açúcar}

"A cultura da cana-de-açúcar no Brasil confunde-se com a própria história do País, tendo sido umas das primeiras - se não a primeira - das culturas agrícolas organizadas quando da colonização" (FERNANDES, 2002).

A cana-de-açúcar não é um produto originário do Brasil. Ela foi trazida pelo navegador português Martim Afonso de Souza em 1533 no Período Colonial, logo após o descobrimento do Brasil por ordem de D. João III (FERNANDES, 2002). O cultivo da cana-de-açúcar foi favorecido inicialmente na região Nordeste devido à fertilidade do solo Massapé e ao clima quente (PRIORE; VENÂNCIO, 2001).

A indústria açucareira desempenhou um papel fundamental na formação econômica do Brasil e segundo Baer (1996), o açúcar foi o primeiro produto de exportação realmente importante economicamente. No início do século XVI, o Brasil já havia se tornado o principal fornecedor de açúcar do mundo, com o produto brasileiro assumindo importância significativa no continente europeu. Contudo, Pina (1972) afirma que as safras brasileiras estavam totalmente entregues às conveniências dos mercados consumidores, principalmente ao mercado europeu e, até o século XVIII, a produção de açúcar no Brasil e em outros países se dava de forma quase artesanal nos chamados "engenhos", onde a atividade intensiva de mão-de-obra era notadamente escrava. Destacava-se como uma característica marcante da época a total ausência de controle ou ação governamental coordenada no setor açucareiro. 
No Período Colonial, foi mantido o sistema patriarcal e não houve grandes transformações no sistema tecnológico predominando na agricultura uma única variedade de cana: a crioula.

O bangüê (engenho de açúcar primitivo, anterior às usinas) movido à água ou à tração animal, com bois e éguas, ajudava na produção de açúcar mascavo para fins de exportação. O processo para clarear e tornar o açúcar menos sujo era feito de forma artesanal, no qual se transformava o açúcar mascavo em açúcar cristal (SOUZA, 2000). Algumas modificações começaram a surgir no início do século XIX (ANDRADE, 2002), com a introdução dos engenhos a vapor e a importação da cana caiana para substituir a cana crioula em nome de um rendimento em açúcar obtido bem superior. Com o surgimento de problemas jurídicos e políticos entre os industriais e lavradores (fornecedores de cana), na medida em que aumentava o número de engenhos e, conseqüentemente, a ampliação dos canaviais, resultavam profundas alterações na economia, na política e nos quadros sociais da época.

Sendo uma produção voltada para a exportação, o açúcar e a cana tiveram momentos de grande euforia, e grandes períodos de crise, como na segunda metade do século XVII (FERNANDES, 2002), com a entrada da produção das Antilhas, do Suriname e do mercado europeu e, em meados do século XIX, com a concorrência do açúcar de beterraba produzido na própria Europa.

No século XIX (ANDRADE, 2002), com a independência do Brasil e o crescimento da população, houve uma expansão da cultura da cana para áreas de maior concentração populacional. Em São Paulo, mesmo no período áureo da expansão cafeeira, a produção açucareira já começava a crescer em ritmo mais intenso.

Com a proclamação da República, os engenhos centrais começaram a enfrentar grandes dificuldades, e muitos senhores de engenho passaram a implantar fábricas modernas, chamadas de usinas. Os donos de engenhos centrais não podiam possuir terras e nem cultivá-las, limitando-se a beneficiar as canas compradas de fornecedores e não podiam também mais contar com o trabalho escravo. Já para os donos de usinas era totalmente diferente, pois podiam possuir propriedades e moer as suas próprias canas (ANDRADE, 2002).

A história brasileira relata diversos acontecimentos que impactaram a importância e a queda da cana-de-açúcar e seus reflexos na política, na economia e na questão social. Mas o Brasil, embora fosse grande produtor de açúcar desde a Colônia, teve uma grande guinada na cultura de cana-de-açúcar a partir da década de 1970. 
Para fazer frente à crise do petróleo na década de 70, o governo brasileiro implantou o programa Pró-álcool, lançado em 14 de novembro de 1975. Anunciado pelo Presidente Ernesto Geisel, consistia na instalação de destilarias de álcool principalmente no sudeste e nordeste do Brasil e melhoramento da capacidade produtiva (através de financiamento e pesquisa) das já existentes. Muitas destilarias foram instaladas e muito dinheiro investido inicialmente com subsídio governamental. Infelizmente, durante muitos anos houve descontinuidade no programa, levando a perdas de investimentos e certo descrédito com relação ao álcool como opção de combustível à gasolina.

A década de 1980 (FERNANDES, 2002) vivenciou altas e baixas do Proálcool. Os problemas, especialmente os de abastecimento, vieram a se intensificar após a promulgação da Constituição de 1988, a partir da qual teve início o processo de desregulamentação do setor sucroalcooleiro no Brasil.

Na década de 90, com a adição de álcool à gasolina como medida imposta pelo governo brasileiro para redução dos níveis de poluentes atmosféricos e maior independência do petróleo externo, o programa de incentivo ao álcool foi retomado com a participação das indústrias automobilísticas desenvolvendo e produzindo motores bicombustíveis (álcool e gasolina) e as usinas fornecendo álcool para a mistura (ver figura 44).

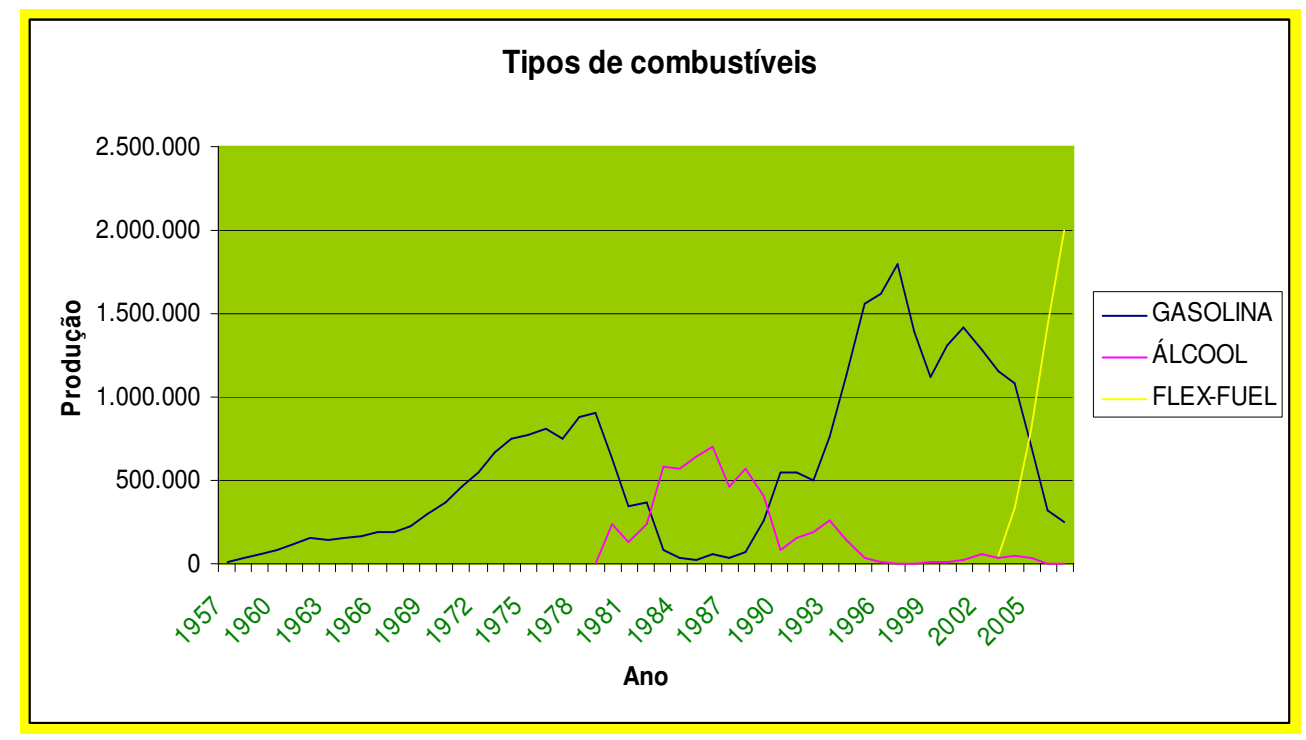

Figura 44. Produção de combustíveis ao longo dos ano no Brasil

Fonte: Associação Nacional de Veículos Automotores (ANFAVEA, 2008) 
Apesar dos vários momentos de descrédito com relação ao setor, muitas pesquisas foram realizadas no setor sucroalcooleiro, destacando-se as pesquisas realizadas no já extinto Instituto do Açúcar e do Álcool (IAA), no Centro de Tecnologia Canavieira (CTC), na Copersucar dentre outros. Isso conferiu ao Brasil liderança tanto em pesquisa de qualidade da cana quanto em tecnologia de produção e processos, o que atualmente tem despertado o interesse das superpotências mundiais.

Hoje, pode-se dizer que existem dois programas de uso de álcool no Brasil:

- Programa do álcool anidro, que é utilizado na mistura com a gasolina, atualmente num percentual de $20 \%$ (o nível de mistura pode variar entre $20 \%$ e $25 \%$, de acordo com decisão governamental);

- Programa do álcool hidratado, que é usado na frota de carros a álcool e, a partir de março de 2003, nos veículos do tipo bicombustível.

Atualmente, a produção de açúcar e álcool brasileira está concentrada no centro-sul do país $(85 \%)$, a restante localizada no nordeste (Figura 45). Mas importantes pólos de produção têm começado a sair do projeto também na região norte, próximos das fronteiras agrícolas da Amazônia.

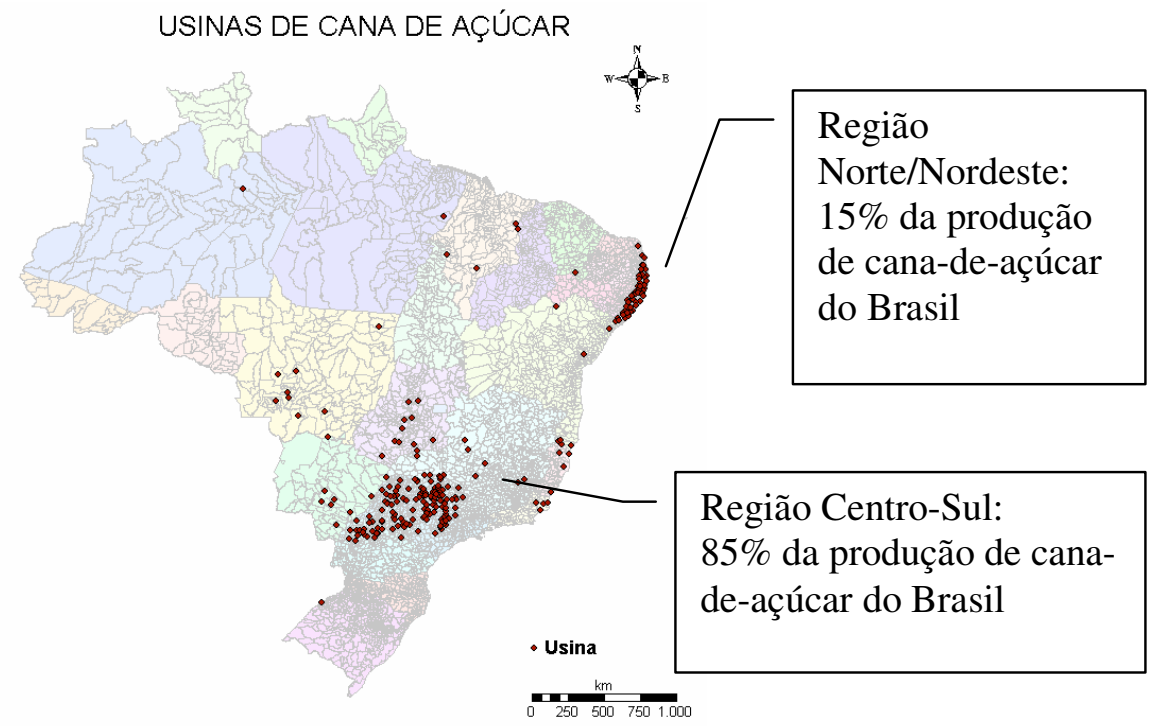

Figura 45. Onde se produz açúcar e álcool no Brasil

Fonte: daa@agricultura.gov.br, dezembro de 2008. 


\section{Apêndice B- Custos agrícolas, rendimentos agroindustriais, custos comerciais e de}

estocagem e receitas comerciais

\section{Custos agrícolas}

\section{I.1 Parâmetros de entrada para os cálculos dos custos agrícolas}

Cabe ressaltar, antes da especificação dos parâmetros, que a usina utilizada para validação do modelo proposto trabalha com dois sistemas de fornecimento de cana: cana própria da usina cultivada em terras arrendadas e cana de terceiros, ou seja, cultivada em fazendas (que não são da usina) produtoras de algumas variedades de cana-de-açúcar com as quais a usina mantém contratos de fornecimento. Nesta dissertação, em alguns tópicos a cana de fornecimento externo aparece como cana arrendada, devido à denominação dada em algumas regiões de São Paulo a esse tipo de contrato de fornecimento. A seguir a lista de siglas utilizadas e os parâmetros necessários para os cálculos dos custos agrícolas.

\section{Lista de siglas utilizadas}

- $\quad \mathbf{n}$ Índice relativo á variedade de cana em análise.

- $\quad \mathbf{S e m a n a}$ em estudo.

- $\quad \mathbf{A T R}_{\mathbf{v}, \mathbf{t}} \quad$ Açúcares totais recuperáveis (ATR) da variedade de cana $v$ na semana $t$ em $\mathrm{Kg} / \mathrm{t}$. O ATR é todo o açúcar que não se perde durante o processamento industrial da cana.

- $\quad$ pATR $_{\mathbf{t}}$ Preço do ATR fornecido na semana $t$ (dado em $\mathrm{R} \$ / \mathrm{Kg}$ ) segundo o sistema Consecana(SP): sistema que define a remuneração do produtor de cana a partir do índice ATR.

- $\quad$ VTC $_{\mathbf{v}, \mathbf{t}} \quad$ Valor em reais a ser pago pela tonelada da cana de variedade $v$ em cada semana $t$.

- VTCA $_{\text {terc }}$ Valor em reais da tonelada de cana arrendada pago aos terceirizados. Para cada variedade existe um valor constante (ocorre uma padronização do valor do ATR para cada variedade) durante a safra devido aos contratos realizados entre usina e terceirizados.

- CArrTe Custo de arrendamento das terras ( $\mathrm{R} \$$ por hectare por semana)

Este é um valor que nesta dissertação é admitido constante devido aos contratos de arrendamento realizados pela usina com os proprietários de terras. Como os valores contratados são mensais e fixos no ano, estes foram recalculados para um período 
semanal e foi então tomada a média semanal dos contratos realizados para representar esse tipo de custo.

- CArrCa Custo de "arrendamento" da cana, dado em toneladas de cana por hectare. Trata-se de uma média feita com todos os contratos de fornecimento realizados pela usina.

- CACanaProp v, $\mathrm{t}$ Custo agrícola com cana própria de variedade $\mathrm{v}$ na semana $t$, dado em $\mathrm{R} \$$ por tonelada de cana. Entende-se aqui por cana própria a canade-açúcar que a usina planta e colhe, passando por todo o processo de preparação física e química do solo. Como a usina não possui terras próprias, existe embutido aqui o custo de arrendamento das terras.

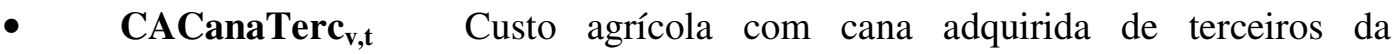
variedade $v$ na semana $t(\mathrm{R} \$ / \mathrm{t}$ de cana). Trata-se aqui de cana fornecida à usina pelas fazendas produtoras.

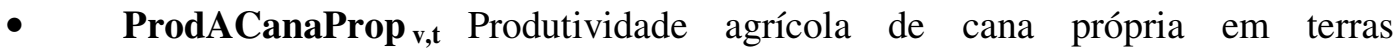
arrendadas de cada variedade $v$ em cada semana $t$ ( $\mathrm{t} / \mathrm{ha}$ ).

- $\quad$ ProdACanaTerc ${ }_{\mathrm{v}, \mathrm{t}}$ Produtividade agrícola de cana de terceiros de cada variedade $v$ em cada semana $t$ ( $\mathrm{t} / \mathrm{ha})$.

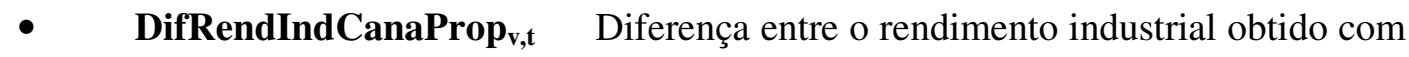
a variedade de cana $v$ cultivada pela usina e o rendimento industrial médio obtido com todas as variedades de cana $\mathrm{v}$ e todos os tipos de fornecimento, próprio ou terceirizado.

- DifRendIndCanaTerc $\mathrm{v}_{\mathrm{v}, \mathrm{t}}$ Diferença entre o rendimento industrial obtido com a variedade de cana $\mathrm{v}$ cultivada por terceiros e o rendimento industrial médio obtido com todas as variedades de cana $\mathrm{v}$ e todos os tipos de fornecimento, próprio ou terceirizado.

\section{I.2 Cálculos dos custos agrícolas}

Nesta seção estabelecem-se os cálculos dos custos agrícolas. Isso é feito por meio das equações a seguir, que estão baseadas no sistema CONSECANA-SP 2009 de pagamento da cana ao produtor, em Fernandes (2003), Paiva (2006) e na experiência dos gerentes e diretores agrícolas das usinas estudadas.

\section{Valor por tonelada de cana}

Segundo o sistema CONSECANA-SP 2009, o valor em reais a ser pago pela tonelada da cana de variedade $v$ em cada semana $t\left(\mathrm{VTC}_{\mathrm{v}, \mathrm{t}}\right)$ é calculado como

$$
V T C_{v, t}=A T R_{v, t} . p A T R_{t}, \quad t=1, \ldots, 36 ; \quad v=1, \ldots, 15
$$


$\mathrm{O}$ índice $\mathrm{ATR}_{\mathrm{v}, \mathrm{t}}$ varia de acordo com cada variedade $v$, com cada fonte de fornecimento e em cada semana $t$ devido aos fatores tecnológicos de cultivo da cana. O preço do ATR (pATR) se refere ao preço pago ao produtor pelo açúcar efetivamente extraído nos processos industriais da usina no processamento da cana. Depende da produtividade no cultivo de cada variedade de cana-de-açúcar, da eficiência dos processos industriais e do preço de venda do açúcar e do álcool obtido pelas usinas do estado de São Paulo.

\section{Custo agrícola de cana própria em terras arrendadas}

$$
\begin{aligned}
& \text { CACanaProp }_{v, t}=\text { VTC }_{v, t}+\frac{\text { CArrTe }}{\left(\text { prodaCanaProp }_{v, t}\right)}-\text { Dif RendIndCanaProp }_{v, t}, t=1, \ldots, 36 ; \\
& v=1, \ldots, 15
\end{aligned}
$$

O valor calculado para CACanaProp ${ }_{v, t}$ ( em reais por tonelada de cana) depende do valor por tonelada de cana própria, do custo de arrendamento de terras ( $\mathrm{R} \$ / \mathrm{ha})$, da produtividade agrícola de cana de cada variedade $v$ em terras arrendadas em cada semana $t(\mathrm{t} / \mathrm{ha})$ e da diferença de rendimento industrial que cada variedade de cana $\mathrm{v}$ possa ter com relação ao rendimento médio de todas as variedades.

\section{Custo agrícola de cana adquirida de terceiros}

$$
\begin{aligned}
& \text { CACanaTerc }_{v, t}=\text { VTC }_{v, t}+\frac{\text { CArrCa.VTCA }_{\text {Terc }}}{\text { prodacanaTerc }_{v, t}}-{\text { Dif } \operatorname{Re~} \text { ndIndCanaTerc }_{v, t}, \quad t=1, \ldots, 36 ;}_{v}, \\
& v=1, \ldots, 15
\end{aligned}
$$

A equação acima determina o custo agrícola da cana de terceiros (em reais por tonelada de cana) utilizando a variedade $\mathrm{v}$ em cada semana $t$. Cabe ressaltar que quanto maior a produtividade agrícola da cana de terceiros menor será esse custo de fornecimento para a usina. Dessa maneira, muitas usinas mantêm parcerias com seus fornecedores terceirizados quanto ao desenvolvimento de técnicas para o cultivo e estudo de variedades.

Para efeito de cálculo de custos, admite-se que os valores referentes à Pol da cana $\left(\mathrm{PC}_{\mathrm{v}, \mathrm{t}}\right)$, pureza da cana $\left(\mathrm{PzaC}_{\mathrm{v}, \mathrm{t}}\right)$, açúcares redutores na cana $\left(\mathrm{AR}_{\mathrm{v}, \mathrm{t}}\right)$ e Brix da cana são os mesmos independentemente do tipo de fornecedor, priorizando-se análise com relação à produtividade agrícola de cada fornecedor e rendimentos industriais obtidos. 
Com base no estudo dos custos agrícolas, será possível decidir em cada semana pela melhor fonte de fornecimento e a melhor variedade de cana quanto à minimização dos custos do planejamento agregado da safra.

Nas tabelas 66 e 67 (anexo E) encontram-se os dados de custos agrícolas (CACanaProp $\mathrm{v}, \mathrm{t}$ e CACanaTerc ${ }_{v, t}$ ) de cana própria e cana de terceiros para cada variedade $\mathrm{v}$ de cana e em cada semana t.

\section{Rendimentos e custos agroindustriais}

\section{II.1 Rendimentos agroindustriais}

Para estabelecer a quantidade de cada produto $p$ obtida pela utilização de cada variedade $v$ de cada fonte de fornecimento e pela utilização de cada processo $k$ em cada semana $t$, utilizamos a literatura de tecnologia açucareira e alcooleira (Hugot, 1997; Castro et al.,2002; Fernandes, 2003; Medeiros, 2005), Paiva e Morabito (2006), e as recomendações do sistema CONSECANA-SP (2009).

\section{Índices para os cálculos dos rendimentos agroindustriais}

$\boldsymbol{k} \quad$ Processos dentro das fábricas de açúcar e álcool: determinados de acordo com os parâmetros tecnológicos adotados na usina de açúcar e na destilaria de álcool e separações de caldo primário, secundário, melaço e álcoois (nesta dissertação varia de 1 a 24);

$\boldsymbol{v} \quad$ Variedades de cana-de-açúcar (15 variedades neste estudo);

$\boldsymbol{t}$ Períodos de análise: no caso desta dissertação, o período de análise agroindustrial corresponde ao intervalo $\mathrm{t}=1 \mathrm{a} \mathrm{t}=36$, primeira quinzena de março à primeira quinzena de dezembro, abrangendo o período de safra do centro-sul do Brasil;

Quanto aos produtos fabricados pela usina, para o cálculo dos rendimentos industriais estes produtos são subdivididos em produtos da fábrica de açúcar: açúcar VHP (Very High Polarization), açúcar bruto que permite aos clientes transformá-lo em diferentes tipos de açúcar para o consumo, produtos da destilaria de álcool: álcool etílico hidratado carburante (AEHC) e álcool etílico anidro carburante (AEAC) e subproduto: melaço. Os subíndices utilizados são ab (de açúcar bruto), al (de álcool) e me (de melaço). 


\section{Parâmetros dos cálculos dos rendimentos agroindustriais}

BMF (cte $85 \%)$

PzaMCP(cte $42 \%)$

do caldo primário.

PzaMCS(cte 46\%)

do caldo secundário.

Polz(cte $\left.99,3^{0} \mathrm{Z}\right)$
Brix do mel final adotado pela fábrica ( ${ }^{0}$ brix $)$;

Meta de pureza do mel final adotada na fábrica(\%) a partir

Meta de pureza do mel final adotada na fábrica(\%) a partir

parâmetro referente à qualidade do açúcar que se pretende produzir sendo assim uma constante para cada tipo de açúcar.

Umid(cte 0,1$) \quad$ Umidade do açúcar VHP produzido. Também é um parâmetro referente à qualidade do açúcar que se pretende produzir, sendo constante.

$\mathrm{R}_{\mathrm{al}}(67,87 \mathrm{~L} / \mathrm{Kg}$ de ART para AEHC e $65,03 \mathrm{~L} / \mathrm{Kg}$ de ART para AEAC)

Rendimento estequiométrico dos álcoois que se pretende produzir (L/100kg de ART).

\section{Variáveis de decisão na etapa industrial}

$\mathrm{SCP}_{\mathrm{k}} \quad$ Separação do caldo primário, que indica a quantidade desse caldo que vai para a fábrica de açúcar e a quantidade que vai para a destilaria dependendo de cada processo k escolhido.

$\mathrm{SCS}_{\mathrm{k}} \quad$ Separação do caldo secundário, que indica a quantidade desse caldo que vai para a fábrica de açúcar e a quantidade que vai para a destilaria dependendo de cada processo k escolhido.

$\mathrm{SM}_{\mathrm{k}} \quad$ Separação do melaço, que indica a quantidade de melaço que vai para a destilaria e a quantidade que vai ser comercializada com outras usinas dependendo de cada processo k escolhido.

$\mathrm{SA}_{\mathrm{k}} \quad$ Separação do mosto de fermentação para as colunas de desidratação quanto à destinação da produção para álcool hidratado ou álcool anidro dependendo de cada processo k escolhido.

As variáveis $\mathrm{SCP}_{\mathrm{k}}, \mathrm{SCS}_{\mathrm{k}}, \mathrm{SM}_{\mathrm{k}}, \mathrm{SA}_{\mathrm{k}}$ acima definem a quantidade de processos ou alternativas de produção que estão sendo estudados. 


\section{Parâmetros que variam com o tempo de safra}

Apresentam-se agora parâmetros que variam com o tempo de safra. Eles se referem a variações na qualidade da matéria-prima (devido a condições climáticas) e também a eficiências de processos (devido a desgastes do maquinário).

\section{Elbti $_{\mathbf{t}}$}

Eficiência em cada semana $t$ da parte comum do processo de fabricação de açúcar e álcool (\%). Corresponde às operações de Pesagem, Estocagem no pátio, Lavagem, Moagem e Clarificação do caldo, o que gera um índice de eficiência que representa as perdas ocorridas na Lavagem, no Bagaço, na Torta e as Indeterminadas (daí a sigla Elbti);

\section{$\operatorname{Efd}_{\mathbf{t}}$}

Eficiência de fermentação/centrifugação e destilação em cada semana t na produção de álcool (\%). Trata-se de um parâmetro que representa as perdas ocorridas na destilaria de álcool durante as etapas de Fermentação e Destilação (daí a sigla fd);

Admite-se para fins de simplificação que tanto Elbt quanto Efd não mudam com a mudança da variedade de cana-de-açúcar escolhida para moagem.

$\mathbf{P c}_{\mathrm{v}, \mathrm{t}}$

Pol $(\%)$ de cada variedade de cana em cada semana $t$. Parâmetro referente à qualidade da cana que se está recebendo na usina;

$\operatorname{PzaC}_{\mathrm{v}, \mathrm{t}}$

Pureza $(\%)$ de cada variedade de cana em cada semana $t$. Parâmetro referente à qualidade da cana que se está recebendo na usina;

$\mathbf{A R}_{\mathbf{v}, \mathbf{t}}$

Açúcares redutores (\%) contidos em cada variedade de cana $\mathrm{v}$ em cada semana $t$. Parâmetro referente à qualidade da cana que se está recebendo na usina;

\section{Cálculos dos rendimentos industriais de cada processo}

Definidos os dados de entrada e os índices, é possível calcular os rendimentos de cada processo por meio da formulação a seguir baseada em Fernandes (2003), Paiva e Morabito (2006) e sistema CONSECANA-SP, 2008, órgão responsável pela elaboração de cálculos de rendimentos agrícolas e industriais no Estado de São Paulo, os quais são utilizados para o pagamento da tonelada de cana ao produtor.

A usina utilizada para validação do modelo, diferentemente da usina estudada por Paiva (2006), faz diferenciação entre caldo de primeira prensagem (caldo primário) e caldo 
embebido em água (demais prensagens, chamado de caldo secundário). Logo, é importante diferenciar a pureza para cada um dos caldos, o que interfere na escolha pelos processos industriais que ocorrem na usina.

\section{Pureza do caldo primário}

$$
P z a C P_{v, t}=P z a C_{v, t}, \quad t=1, \ldots, 36 \quad, \quad k=1, \ldots, 24 \quad e \quad v=1, \ldots, 15 \quad \text { (4) }
$$

Essa equação (Castro et al., 2002; Fernandes, 2003, Paiva, 2006) fornece a pureza do caldo primário $\left(\mathrm{PzaCP}_{\mathrm{v}, \mathrm{t}} \mathrm{em} \%\right)$ para cada variedade $v$ em cada semana $t$.

\section{Pureza do caldo secundário}

$$
P z a C S_{v, t}=P z a C_{v, t}-1 \%, \quad t=1, \ldots, 36 \quad, \quad k=1, \ldots, 24 \quad e \quad v=1, \ldots, 15
$$

A equação acima (Castro et al., 2002; Fernandes, 2003, Paiva, 2006) calcula a pureza dos caldo secundário $\left(\operatorname{PzaCS}_{\mathrm{v}, \mathrm{t}}\right)$ para cada variedade $v$ em cada semana $t(\%)$. É um dado importante para caracterizar a qualidade do caldo que está sendo utilizado misturado com água. Trata-se de uma fórmula empírica do setor sucroalcooleiro (Fernandes, 2003, Paiva, 2006).

\section{Pureza do açúcar VHP}

$$
\operatorname{PzaSU}_{a b}=\frac{\text { Polz }_{a b}}{\left(1-\text { Umid }_{a b}\right)}
$$

A equação acima (adaptada de Hugot, 1997; Medeiros, 2005; Paiva, 2006) calcula a pureza do açúcar produzido VHP $\left(\mathrm{PzaS}_{\mathrm{ab}}\right)$.

\section{Recuperação dos açúcares a partir dos caldos primário e secundário}

$$
\begin{aligned}
& S U C P_{v, t}=\frac{P z a S U_{a b}\left(P z a C P_{v, t}-P z a M C P\right)}{P z a C P_{v, t}\left(P z a S U_{a b}-P z a M C P\right)} \cdot 100 \%, \\
& t=1, \ldots, 36 \quad e \quad v=1, \ldots, 15
\end{aligned}
$$

A equação acima (adaptada de Hugot, 1977; Medeiros, 2005; Castro et al.,2002; Fernandes, 2003; Paiva, 2006) calcula a recuperação do açúcar $\left(\mathrm{SUCP}_{\mathrm{v}, \mathrm{t}}\right)$, em \%, a partir de cada variedade $v$ que parte do caldo primário e em cada semana $t$. Este parâmetro indica a quantidade de açúcar que será recuperada do xarope proveniente do processo de evaporação e a quantidade de melaço que será gerada (ver figura 32). Nessa fórmula, admite-se que a pureza do xarope é igual à pureza do caldo primário. 


$$
\begin{aligned}
& \operatorname{SUCS}_{v, t}=\frac{P z a S U_{a b}\left(P z a C S_{v, t}-P z a M C S\right)}{P z a C S_{v, t}\left(P z a S U_{a b}-P z a M C S\right)} \cdot 100 \%, \\
& t=1, \ldots, 36 \quad v=1, \ldots, 15
\end{aligned}
$$

A equação acima (adaptada de Hugot, 1977; Medeiros, 2005; Castro et al.,2002; Fernandes, 2003; Paiva,2006) calcula a recuperação do açúcar $\left(\operatorname{SUCS}_{\mathrm{v}, \mathrm{t}}\right)$ em cada processo $k(\%)$ que parte do caldo secundário e em cada semana $t$. Este parâmetro indica a quantidade de açúcar que será recuperada do xarope proveniente do processo de evaporação e a quantidade de melaço que será gerada (ver figura 32). Nessa fórmula, admite-se que a pureza do xarope é igual à pureza do caldo secundário.

\section{Quantidade de sacarose no melaço a partir dos caldos primário e secundário}

$$
\begin{aligned}
& S M F C P=\frac{B M F . P \text { zaMCP }}{100}(9) \\
& S M F C S=\frac{B M F . P z a M C S}{100}
\end{aligned}
$$

As equações acima (Hugot, 1977; Medeiros, 2005; Castro et al., 2002; Fernandes,2003;

Paiva,2006) determinam a quantidade de sacarose (SMF) existente no melaço (\%), o qual pode se originar a partir do caldo primário ou do caldo secundário. Estas equações são apenas uma aplicação direta da definição de pureza de um fluido (Pza=Pol/brix), em que a pol do melaço foi definida como SMFCP ou SMFCS, o brix do melaço foi definido como BMF e a pureza do melaço foi definida ora como PzaMCP, ora como PzaMCS.

\section{Recuperação teórica de álcoois na destilaria}

$$
R T D_{a l, t}=\frac{R_{a l} \cdot E f d_{t}}{100}, \quad a l=A E H C, A E A C ; \quad t=1, \ldots, 36(11)
$$

A equação acima (Fernandes, 2003; Consecana, 2008, Paiva, 2006) determina a recuperação teórica $(\%)$ da destilaria $\left(\mathrm{RD}_{\mathrm{al}, \mathrm{t}}\right)$ para os alcoóis al em cada semana $t$.

\section{Rendimentos na fábrica de açúcar a partir dos caldos primário e secundário}

$$
\begin{aligned}
& \text { RSUCP }_{a b, v, k, t}=P c_{v, t} \cdot E l b t_{t} \cdot S U C P_{v, t} \cdot S C P_{k} \cdot 1000, \\
& a b=V H P ; \quad k=1, \ldots, 24 ; \quad t=1, \ldots, 36 \quad v=1, \ldots, 15
\end{aligned}
$$




$$
\begin{aligned}
& \operatorname{RSUCS}_{a b, v, k, t}=\text { Fator }_{C S S U} \cdot P c_{v, t} . \text { Elbt }_{t} \cdot \text { SUCS }_{v, t} . S C S_{k} .1000, \\
& a b=V H P ; \quad k=1, \ldots, 24 ; \quad t=1, \ldots, 36 \quad v=1, \ldots, 15
\end{aligned}
$$

As equações 12 e 13 (adaptadas de Fernandes, 2003; Paiva, 2006) determinam os rendimentos industriais obtidos na produção do açúcar VHP utilizando a variedade $v$ pelo processo $k$ na semana $t$. $\mathrm{O}$ valor $\mathrm{RSUCP}_{\mathrm{ab}, \mathrm{v}, \mathrm{k}, \mathrm{t}}$ se refere ao rendimento a partir de caldo primário e o valor RSUCS $_{\mathrm{ab}, \mathrm{v}, \mathrm{k}, \mathrm{t}}$ se refere ao rendimento a partir de caldo secundário. A constante Fator ${ }_{C S S U}$ que aparece em $\operatorname{RSUCS}_{\mathrm{ab}, \mathrm{v}, \mathrm{k}, \mathrm{t}}$ se refere à proporção de açúcar presente no caldo secundário quando comparada com a do caldo primário e se trata de um valor médio na safra 2008/2009. Os parâmetros $\mathrm{Pc}_{\mathrm{v}, \mathrm{t}}, \mathrm{Elbti}_{\mathrm{t}}, \mathrm{SCP}_{\mathrm{k}}$ e $\mathrm{SCS}_{\mathrm{k}}$ são dados de entrada do modelo e os parâmetros $\operatorname{SUCP}_{\mathrm{vt}}$ e $\operatorname{SUCS}_{\mathrm{vt}}$ se referem à recuperação de açúcares, calculados anteriormente nas equações 7 e 8.

$$
\begin{aligned}
& R A G I_{a b, v, k, t}=\operatorname{RSUCP}_{a b, v, k, t}+\operatorname{RSUCS}_{a b, v, k, t}, \\
& a b=V H P ; \quad k=1, \ldots, 24 ; \quad t=1, \ldots, 36 \quad v=1, \ldots, 15
\end{aligned}
$$

A equação acima determina a quantidade de açúcar VHP (valor em $\mathrm{kg}$ de açúcar por tonelada de cana) que será produzida por qualquer processo $k$ a partir de cada variedade $v$ em qualquer semana $t$.

\section{Rendimentos de melaço}

$$
\begin{aligned}
& R M C P_{m e, v, k, t}=\frac{P c_{v, t} \cdot \text { Elbti }_{t} .\left(1-S U C P_{v, t}\right) \cdot S C P_{k} \cdot\left(1-S M_{k}\right)}{S M F C P} \cdot 1000, \\
& k=1, \ldots, 24 ; \quad m e=\text { melaço; } t=1, \ldots, 36 \quad \mathrm{v}=1, \ldots, 15
\end{aligned}
$$

A equação acima (adaptada de Fernandes, 2003; Paiva, 2006) determina o rendimento industrial ( $\mathrm{RMCP}_{\mathrm{me}, \mathrm{k}, \mathrm{t}}, \mathrm{em} \mathrm{Kg}$ de mel por $\mathrm{t}$ de cana) obtido na produção do melaço me pelo processo $k$, cana de variedade $v$ na semana $t$ a partir do caldo primário.

$$
\begin{aligned}
& R M C S_{m e, v, k, t}=\text { Fator }_{C S S U} \cdot \frac{P c_{v, t} \cdot \text { Elbti }_{t} \cdot\left(1-S U C S_{v, t}\right) \cdot S C S_{k} \cdot\left(1-S M_{k}\right)}{S M F C S} \cdot 1000, \\
& k=1, \ldots, 24 ; \quad \text { me }=\text { melaço } ; \quad t=1, \ldots, 36 \quad \mathrm{v}=1, \ldots, 15
\end{aligned}
$$

A equação acima (adaptada de Fernandes, 2003; Paiva, 2006) determina o rendimento industrial ( $\mathrm{RMCS}_{\mathrm{me}, \mathrm{k}, \mathrm{t}}$ em $\mathrm{Kg}$ de melaço por t de cana) obtido na produção do melaço me pelo processo $k$, variedade $v$ na semana $t$ a partir do caldo secundário.

$$
\begin{aligned}
& R A G I_{m e, v, k, t}=R M C P_{m e, v, k, t}+R M C S_{m e, v, k, t}, \\
& k=1, \ldots, 24 ; \quad \text { me }=\text { melaço } ; \quad t=1, \ldots, 36 \quad \mathrm{v}=1, \ldots, 15
\end{aligned}
$$

A equação acima determina o rendimento obtido na produção do melaço me pelo processo $k$, variedade $v$ na semana $t$. 


\section{Rendimentos na destilaria}

$$
\begin{aligned}
& R A C P_{a l, v, k, t}=1000 *\left(\left(E l b t_{t}\right) \cdot\left(R T D_{a l, t}\right) \cdot\left(\frac{P c_{v, t}}{0,95} \cdot\left(1-S U C P_{v, t}\right)+A R_{t}\right) \cdot S C P_{k} \cdot S M_{k}+\right. \\
& \left.\left(\frac{P c_{v, t}}{0,95}+A R_{v, t}\right) \cdot\left(1-S C P_{k, t}\right)\right) \cdot S A_{k, a l}, \\
& a l=A E H C, A E A C ; \quad k=1, \ldots, 24 ; \quad t=1, \ldots, 36 ; \quad v=1, \ldots, 15
\end{aligned}
$$

A equação acima (Fernandes, 2003; Paiva, 2006) determina o rendimento industrial $\left(\mathrm{RACP}_{\mathrm{al}, \mathrm{v}, \mathrm{k}, \mathrm{t}}\right)$ obtido na produção do álcool al utilizando caldo primário de cana de variedade $v$ pelo processo $k$ na semana $t$. Determina assim a quantidade de álcoois (valores em litros por $\mathrm{t}$ de cana) que será produzida cuja origem esteja no caldo primário. $\mathrm{O}$ valor 0,95 que aparece na equação representa a conversão da sacarose em açúcares redutores (AR).

$$
\begin{aligned}
& R A C S_{a l, v, k, t}=1000 * \text { Fator }_{C S A} \cdot\left(\left(E l b t_{t}\right) \cdot\left(R T D_{a l, t}\right) \cdot\left(\frac{P c_{v, t}}{0,95} \cdot\left(1-S U C S_{k, t}\right)+A R_{t}\right) \cdot S C S_{k} \cdot S M_{k}\right. \\
& \left.+\left(\frac{P c_{v, t}}{0,95}+A R_{v, t}\right) \cdot\left(1-S C S_{k, t}\right)\right) \cdot S A_{k, a l}, \\
& a l=A E H C, A E A C ; \quad k=1, \ldots, 24 ; \quad t=1, \ldots, 36 ; \quad v=1, \ldots, 15
\end{aligned}
$$

A equação acima (adaptada de Fernandes, 2003; Paiva, 2006) determina o rendimento industrial $\left(\operatorname{RACS}_{\mathrm{al}, \mathrm{v}, \mathrm{k}, \mathrm{t}}\right)$ obtido na produção do álcool al utilizando caldo secundário de cana de variedade v pelo processo $k$ na semana $t$. A constante Fator $_{\text {CSA }}$ que aparece em $\mathrm{RACS}_{\mathrm{ab}, \mathrm{v}, \mathrm{k}, \mathrm{t}}$ se refere à proporção de álcool presente no caldo secundário quando comparada com a do caldo primário e se trata de um valor médio na safra 2008/2009. A equação determina assim a quantidade de álcoois (valores em litros por $\mathrm{t}$ de cana) que será obtida cuja origem esteja no caldo secundário. $\mathrm{O}$ valor 0,95 que aparece na equação representa a conversão da sacarose em açúcares redutores (AR).

$$
\begin{aligned}
& R A G I_{a l, v, k, t}=R A C P_{a l, v, k, t}+R A C S_{a l, v, k, t}, \\
& a l=A E H C, A E A C ; \quad k=1, \ldots, 24 ; \quad t=1, \ldots, 36 ; \quad v=1, \ldots, 15
\end{aligned}
$$

A equação acima determina o rendimento agroindustrial $\left(\mathrm{RAGI}_{\mathrm{al}, \mathrm{k}, \mathrm{t}}\right)$ obtido na produção do álcool al utilizando a variedade $v$ pelo processo $k$ na semana $t$. 


\section{II.2 Cálculos dos custos agroindustriais}

Nesta dissertação, para o cálculo dos custos dos processos industriais utilizaremos um custo unitário por kg de ART produzido e determinaremos o custo industrial a partir da multiplicação deste custo unitário de produção pela quantidade de ART produzida em cada processo. Assim, cada produto produzido deve ser convertido para esta mesma unidade de medida (ART), permitindo que se faça o cálculo do custo industrial de cada processo em estudo.

\section{Parâmetros dos cálculos dos custos agroindustriais}

\section{- $\quad$ CProc $(\mathrm{R} \$ / \mathrm{Kg}$ de ART)}

Custo de produção de cada kg de ART nos produtos finais pelos processos da usina estudada. Na usina em estudo, seu valor corresponde a $\mathrm{R} \$ 0,124 / \mathrm{Kg}$ de ART. Esse custo foi obtido através da análise do sistema gerencial de custos da usina Usalpa, departamento de contabilidade, com dados referentes à safra 2008/2009. Os valores pertencentes a esse custo são mão-de-obra, gastos com lubrificantes, manutenção, depreciação de maquinário, energia e todos os outros referentes ao funcionamento da etapa industrial da usina.

- $\quad \mathrm{AR}_{\mathrm{me}}(18 \%)$

Açúcares redutores contidos no mel final produzido pelos processos da usina (\%);

$\mathrm{O}$ valor de $\mathrm{AR}_{\mathrm{me}}$, admitido constante e igual a $18 \%$, foi obtido através do relatório gerencial da usina estudada fazendo-se uma média mensal da safra 2008/2009.

- $\quad$ FatorConval $\quad($ para $\mathrm{AEHC}=0,95415$ e para $\mathrm{AEAC}=0,99577)$

Fator de conversão dos álcoois em etanol absoluto.

Presente em Fernandes, 2003, e em Paiva, 2006, Fator ${ }_{a l}$ é uma constante estequiométrica que determina a conversão dos álcoois em etanol absoluto.

\section{Cálculos dos custos industriais}

Com os parâmetros dos cálculos dos custos industriais, é possível obtê-los por meio da seguinte formulação (Fernandes, 2003, Paiva, 2006).

\section{Conversão do açúcar VHP de caldo primário e caldo secundário em ART}

$$
\begin{aligned}
& \operatorname{ConvSU}_{a b, v, k, t}=\frac{1}{0,95} \cdot R_{S U_{a b, k, t}}\left(\text { Polz }_{a b}\right) .\left(1-\operatorname{Umid}_{a b}\right), \\
& a b=\text { açúcar VHP; } \quad k=1, \ldots, 24 ; \quad t=1, \ldots, 36 \quad v=1, \ldots, 15
\end{aligned}
$$

A equação acima determina os parâmetros de conversão do açúcar VHP em Kg de ART equivalente para cada processo $k$ proveniente de caldo primário e caldo secundário 
(equações 12 e 13), a partir de cada variedade $v$ durante cada semana $t$. Este parâmetro representa a conversão de todos os açúcares produzidos em sacarose pura (kg de sacarose) para depois ser convertido em $\mathrm{Kg}$ de ART com o fator 0,95 do denominador. Os parâmetros Polz e Umid $_{a b}$ são dados de entrada do modelo para o açúcar VHP. Caso se deseje trabalhar com mais tipos de açúcares, basta que o modelador acrescente um subíndice para o grupo estudado.

Conversão de melaço de caldo primário e caldo secundário em ART

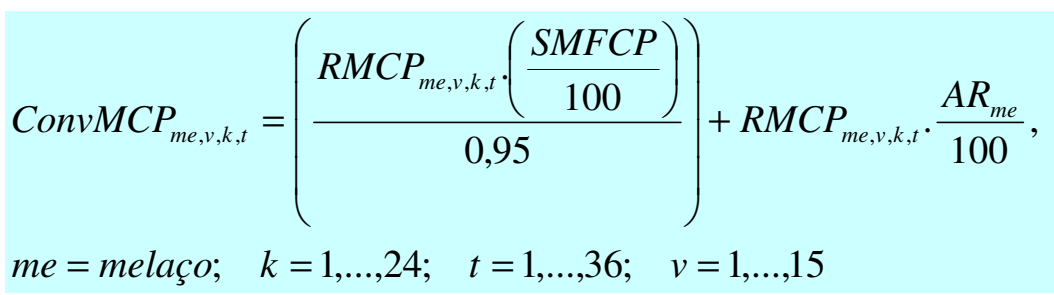

A equação acima (adaptada de Paiva, 2006) determina o parâmetro de conversão do melaço proveniente de caldo primário em $\mathrm{Kg}$ de ART equivalente para cada processo $k$, variedade $v$ e durante cada semana $t$.

$$
\begin{aligned}
& \text { ConvMCS }_{m e, v, k, t}=\left(\frac{R M C S_{m e, v, k, t} \cdot\left(\frac{S M F C S}{100}\right)}{0,95}\right)+R M C S_{m e, v, k, t} \cdot \frac{A R_{m e}}{100}, \\
& m e=\text { melaço; } \quad k=1, \ldots, 24 ; \quad t=1, \ldots, 36 ; \quad v=1, \ldots, 15
\end{aligned}
$$

A equação acima determina o parâmetro de conversão do melaço proveniente de caldo primário em $\mathrm{Kg}$ de ART equivalente para cada processo $k$, variedade $v$ e durante cada semana $t$.

$$
\begin{aligned}
& \operatorname{Conv}_{m e, v, k, t}=\operatorname{ConvMCP}_{m e, v, k, t}+\operatorname{ConvMCS}_{m e, v, k, t}, \\
& m e=\text { melaço } ; \quad k=1, \ldots, 24 ; \quad t=1, \ldots, 36 ; \quad v=1, \ldots, 15
\end{aligned}
$$

\section{Conversão de álcool em etanol absoluto}

$$
\begin{aligned}
& \text { ConvACP }_{a l, v, k, t}=\frac{1}{0,6475} \cdot \text { RACP }_{a l, v, k, t} . \text { FatorConv }_{a l} . \\
& a l=A E H C, A E A C ; \quad k=1, \ldots, 24 ; \quad t=1, \ldots, 36 ; \quad v=1, \ldots, 15
\end{aligned}
$$

A equação acima (Paiva, 2006) determina o parâmetro de conversão de álcoois al em ART $(\mathrm{Kg})$ para cada variedade $v$ utilizando o processo $k$ durante cada semana $t$. Se multiplicarmos o segundo membro dessa equação por 0,6475 teremos a conversão de álcoois al para etanol absoluto. O parâmetro FatorConv $\mathrm{al}_{\mathrm{al}}$ é dado de entrada do modelo para cada álcool al produzido pelo processo k. O parâmetro $\mathrm{RACP}_{\mathrm{al}, \mathrm{k}, \mathrm{t}}$ é o rendimento industrial dos álcoois obtidos através do caldo primário. 


$$
\begin{aligned}
& \operatorname{ConvACS}_{a l, v, k, t}=\frac{1}{0,6475} \cdot \text { RACS }_{a l, v, k, t} . \text { FatorConv }_{a l}, \\
& a l=A E H C, A E A C ; \quad k=1, \ldots, 24 ; \quad t=1, \ldots, 36 ; \quad v=1, \ldots, 15
\end{aligned}
$$

A equação acima determina o parâmetro de conversão de álcoois al em Kg de ART para cada variedade $v$ utilizando o processo $k$ durante cada semana $t$. O parâmetro FatorConv $\mathrm{al}_{\mathrm{al}}$ é dado de entrada do modelo para cada álcool al produzido pelo processo $\mathrm{k}$. O parâmetro RACS $_{\mathrm{al}, \mathrm{k}, \mathrm{t}}$ é o rendimento industrial dos alcoóis obtidos através do caldo secundário.

$$
\begin{aligned}
& \operatorname{Conv}_{a l, v, k, t}=\operatorname{ConvACP} P_{a l, v, k, t}+\operatorname{ConvACS}_{a l, v, k, t}, \\
& a l=A E H C, A E A C ; \quad k=1, \ldots, 24 ; \quad t=1, \ldots, 36 ; \quad v=1, \ldots, 15
\end{aligned}
$$

A equação acima determina o parâmetro de conversão de álcoois al em Kg de ART para cada variedade $v$ utilizando o processo $k$ durante cada semana $t$.

\section{ART em cada processo}

$$
\begin{aligned}
& \text { ARTproc }_{k, v, t}=\sum_{\substack{a b \\
m e \\
a l}}\left(\operatorname{ConvSU}_{a b, v, k, t}+\operatorname{Conv}_{m e, v, k, t}+\operatorname{Conv}_{a l, v, k, t}\right), \\
& k=1, \ldots, 24 ; \quad t=1, \ldots, 36 ; \quad a b=V H P ; \quad \text { me =melaço; } ; \quad a l=A E H C, A E A C ;(28) \\
& v=1, \ldots, 15
\end{aligned}
$$

A equação acima calcula o valor total do ART (kg/t de cana) produzido em cada processo proveniente da cana de variedade v e em cada semana t. (Fernandes, 2003, Paiva, 2006).

\section{Custo industrial de cada processo}

$$
C I_{k, v, t}=\text { ARTproc }_{k, v, t} . \text { Proc }, \quad k=1, \ldots, 24 ; \quad t=1, \ldots, 36 ; \quad v=1, \ldots, 15
$$

A equação acima calcula o custo industrial de cada processo $k$ utilizando a variedade $v$ em cada semana $t$. O valor CProc, custo de produção de cada kg de ART, é um dado de entrada para o sistema de custos implantado. 


\section{Custos e receitas das etapas comercial e de estocagem}

\section{III.1 Cálculos dos custos de estocagem e comercialização}

Parâmetros dos custos de estocagem e comercialização

Os valores referentes às taxas de estocagem própria e em terceiros de açúcar e álcool foram obtidos do relatório gerencial de apontamentos de custos da usina durante a safra 2008/2009.

$\mathrm{TEP}_{\mathrm{ab}, \mathrm{t}}$

$\mathrm{TEP}_{\mathrm{al}, \mathrm{t}}$ semana $t\left(\mathrm{R} \$ / \mathrm{m}^{3}\right)$

$\mathrm{TETe}_{\mathrm{ab}, \mathrm{t}}$ $(\mathrm{R} \$ / \mathrm{t})$

TETe $_{\mathrm{al}, \mathrm{t}}$ semana $t\left(\mathrm{R} \$ / \mathrm{m}^{3}\right)$

$\operatorname{TCOSI}_{\mathrm{ab}, \mathrm{t}}$
Taxa de estocagem própria de açúcar bruto na semana $t(\mathrm{R} \$ / \mathrm{t})$

Taxa de estocagem própria dos álcoois AEHC e AEAC na

Taxa de estocagem em terceiros de açúcar bruto na semana $t$ pelas corretoras contratadas (\%)

$\operatorname{TCOSI}_{\mathrm{al}, \mathrm{t}}$

Taxa de comercialização de álcoois no mercado spot interno pelas corretoras contratadas $(\%)$

TCOSE $_{a b, t} \quad$ Taxa de comercialização de açúcar VHP no mercado spot externo pelas corretoras contratadas $(\%)$

TCOSE $_{\mathrm{a}, \mathrm{t}} \quad$ Taxa de comercialização de álcoois no mercado spot externo pelas corretoras contratadas $(\%)$

Est $_{a b, t, e} \quad$ Estocagem $(\mathrm{t})$ de açúcar VHP na semana $t$ no tipo de estoque e

Est $\mathrm{al}_{\mathrm{al}, \mathrm{e}} \quad$ Estocagem $\left(\mathrm{m}^{3}\right)$ de álcoois na semana $t$ no tipo de estoque $\mathrm{e}$

$\mathrm{CEP}_{\mathrm{ab}, \mathrm{t}, \mathrm{k}, \mathrm{z}} \quad$ Custo(R $\left.\$\right)$ de estocagem própria de açúcar VHP na semana $t$

$\mathrm{CEP}_{\mathrm{al}, \mathrm{k}, \mathrm{z}, \mathrm{t}} \quad \mathrm{Custo}(\mathrm{R} \$)$ de estocagem própria de álcoois na semana $t$

$\mathrm{CETe}_{a b, t, \mathrm{k}, \mathrm{z}} \quad$ Custo(R\$) de estocagem terceirizada de açúcar VHP na semana $t$

$\mathrm{CETe}_{\mathrm{al}, \mathrm{k}, \mathrm{z}, \mathrm{t}} \quad \mathrm{Custo}(\mathrm{R} \$)$ de estocagem terceirizada de álcoois na semana $t$

$\operatorname{CCOSI}_{a b, k, z, t} \operatorname{Custo}(\mathrm{R} \$)$ de comercialização de açúcar pelo mercado spot interno na semana $t$ pelo processo comercial z

$\operatorname{CCOSI}_{\mathrm{al}, \mathrm{k}, \mathrm{z}, \mathrm{t}} \operatorname{Custo}(\mathrm{R} \$)$ de comercialização dos álcoois pelo mercado spot interno na semana $t$ pelo processo comercial z 
$\operatorname{CCOSI}_{\mathrm{me}, \mathrm{k}, \mathrm{z}, \mathrm{t}}$

Custo(R\$) de comercialização de melaço pelo mercado spot interno na semana $t$ pelo processo comercial z

$\operatorname{CCOSE}_{\mathrm{ab}, \mathrm{k}, \mathrm{z}, \mathrm{t}} \operatorname{Custo(R}$ \$) de comercialização de açúcar pelo mercado spot externo na semana $t$ pelo processo comercial z

$\operatorname{CCOSE}_{\mathrm{al}, \mathrm{k}, \mathrm{z}, \mathrm{t}} \operatorname{Custo}(\mathrm{R} \$)$ de comercialização dos álcoois pelo mercado spot externo na semana $t$ pelo processo comercial z

Cálculos de quantidades comercializadas via mercado spot, quantidades estocadas e custos de comercialização dos produtos em cada processo $\mathrm{z}$

$Q C_{a b, M S I, v, t, k, z}=\left(R S U_{a b, v, k, t} \cdot Q_{v, t}+E s t_{a b, t-1}-Q_{a b, \text { Hedge,t }}\right) \cdot\left(1-S C O S U_{z, t}\right)$

$t=1, . ., 36$

A equação acima calcula a quantidade de açúcar VHP (em $t$ ) comercializada através de corretoras pelo mercado Spot interno em cada semana t.

$\operatorname{CCOSI}_{a b, M S I, t, k, z}=\operatorname{TCOSI}_{a b, t} \cdot Q C_{a b, M S I, v, t, k, z}$ $t=1, . ., 36$

A equação acima calcula os custos de comercialização (em R\$) do açúcar VHP negociado através de corretoras pelo mercado Spot interno em cada semana t.

$Q C_{a b, M S E, v, t, k, z}=\left(R S U_{a b, v, k, t} \cdot Q_{v, t}-Q_{a b, H e d g e, t}+E S t_{a b, t-1}\right) \cdot\left(S C O S U_{z, t}\right)$

$t=1, . ., 36$

A equação acima calcula a quantidade de açúcar VHP (em $t)$ enviada para mercado Spot externo em cada semana t.

$\operatorname{CCOSE}_{a b, M S E, t, k, z}=T C O S E_{a b, t} \cdot Q C_{a b, M S E, v, t, k, z}$ $t=1, . ., 36$

A equação acima calcula os custos de comercialização (em R\$) do açúcar VHP negociado através de corretoras pelo mercado Spot externo em cada semana t.

$Q C_{A E H C, M S I, t, k, z}=\left(R A H_{v, k, t} \cdot Q_{v, t}-Q_{A E H C, H e d g e, t}+E s t_{A E H C, t-1}\right) \cdot\left(1-S C O A H_{z, t}\right)$

$t=1, . ., 36$

A equação acima calcula a quantidade de álcool AEHC $\left(\mathrm{em} \mathrm{m}^{3}\right)$ comercializada através de corretoras pelo mercado Spot interno em cada semana t. 
$C \operatorname{COSI} I_{A E H C, M S I, t, k, z}=T C O S I_{a l, t} \cdot Q C_{A E H C, M S, t, k, z}$

$t=1, . ., 36$

A equação acima calcula os custos de comercialização (em $\mathrm{R} \$$ ) do álcool AEHC negociado através de corretoras pelo mercado Spot interno.

$Q C_{A E H C, M S E, t, k, z}=\left(R A H_{v, k, t} \cdot Q_{v, t}-Q_{A E H C, H e d g e, t}+E S t_{A E H C, t-1}\right) \cdot\left(S C O A H_{z, t}\right)$

$t=1, . ., 36$

A equação acima calcula a quantidade de álcool AEHC $\left(\mathrm{em} \mathrm{m}^{3}\right)$ enviada para mercado Spot externo em cada semana t.

$C \operatorname{COS} E_{A E H C, M S E, t, k, z}=T C O S E_{A E H C, t} \cdot Q C_{A E H C, M S E, v, t, k, z}$

$t=1, . ., 36$

A equação acima calcula os custos de comercialização (em R\$) do álcool AEHC negociado através de corretoras pelo mercado Spot externo.

$Q C_{A E A C, M S I, t, k, z}=\left(R A A_{v, k, t} \cdot Q_{v, t}-Q_{A E A C, \text { Hedge }, t}+E S t_{A E A C, t-1}\right) \cdot\left(1-S C O A A_{z, t}\right)$

$t=1, . ., 36$

A equação acima calcula a quantidade de álcool AEAC $\left(\mathrm{em} \mathrm{m}^{3}\right)$ comercializada através de corretoras pelo mercado Spot interno em cada semana t.

$\operatorname{CCOSI}_{A E A C, M S I, t, k, z}=\operatorname{TCOSI}_{a l, t} \cdot Q C_{A E A C, M S I, t, k, z}$

$t=1, . ., 36$

A equação acima calcula os custos de comercialização (em $\mathrm{R} \$$ ) do álcool AEAC produzido pelo processo industrial $\mathrm{k}$ e comercial $\mathrm{z}$ e negociado através de corretoras pelo mercado Spot interno.

$Q C_{A E A C, M S E, t, k, z}=\left(R A A_{v, k, t} \cdot Q_{v, t}-Q_{A E A C, \text { Hedge,t }}+E S t_{A E A C, t-1}\right) \cdot\left(S C O A A_{z, t}\right)$

$t=1, . ., 36$

A equação acima calcula a quantidade de álcool AEHC $\left(\mathrm{em}^{3}\right)$ enviada para mercado Spot externo em cada semana t.

$C \operatorname{COS} E_{A E A C, M S E, t, k, z}=T C O S E_{a l, t} \cdot Q C_{A E A C, M S E, t, k, z}$

$t=1, . ., 36$ 
A equação acima calcula os custos de comercialização (em R\$) do álcool AEAC produzido pelo processo industrial $\mathrm{k}$ e comercial $\mathrm{z}$ e negociado através de corretoras pelo mercado Spot externo.

$Q C_{m e, t, k, z}=R M_{m e, v, k, t} \cdot Q_{v, t}$

$t=1, . ., 36$

A equação acima calcula a quantidade de melaço (em $t$ ) comercializada através de corretoras pelo mercado Spot interno em cada semana t.

$\mathrm{CCOSI}_{m e, t, k, z}=\operatorname{TCOSI}_{m e, t} \cdot Q C_{m e, t, k, z}$

$t=1, . ., 36$

A equação acima calcula os custos de comercialização (em R \$) do melaço negociado através de contatos comerciais com outras usinas em cada semana t.

\section{Cálculos dos custos de estocagem}

\section{Estoque próprio}

$C E P_{a b, t, k}=T E P_{a b, t} . E s t_{a b, t}$

$t=1, \ldots, 36$

A equação acima calcula os custos de estocagem (em R\$) do açúcar VHP em estoque próprio em cada semana $t$.

$$
\begin{aligned}
& C E P_{A E H C, t, k}=T E P_{a l, t} . E s t_{A E H C, t} \\
& t=1, \ldots, 36
\end{aligned}
$$

A equação acima calcula os custos de estocagem (em R\$) de álcool hidratado em estoque próprio em cada semana $t$.

$$
\begin{aligned}
& C E P_{A E A C, t, k}=T E P_{a l, t} \cdot E s t_{A E A C, t} \\
& t=1, \ldots, 36
\end{aligned}
$$

A equação acima calcula os custos de estocagem (em $\mathrm{R} \$$ ) de álcool anidro em estoque próprio em cada semana $t$. 


\section{Estoque de terceiros}

$C E T e_{a b, t, k}=T E T e_{a b, t} \cdot E s t_{a b, t}$

$t=1, \ldots, 36$

A equação acima calcula os custos de estocagem (em R\$) do açúcar VHP em estoque terceirizado em cada semana $t$.

$$
\begin{aligned}
& \operatorname{CETe}_{A E H C, t, k}=T E T e_{a l, t} . E t_{A E H C, t} \\
& t=1, \ldots, 36
\end{aligned}
$$

A equação acima calcula os custos de estocagem (em $\mathrm{R} \$$ ) de álcool hidratado em estoque terceirizado em cada semana $t$.

$$
\begin{aligned}
& \operatorname{CETe}_{A E A C, t, k}=T E T e_{a l, t} . \text { Est }_{A E A C, t} \\
& t=1, \ldots, 36
\end{aligned}
$$

A equação acima calcula os custos de estocagem (em $\mathrm{R} \$$ ) de álcool anidro em estoque terceirizado em cada semana $t$.

\section{III.2 Receitas obtidas com as vendas dos produtos}

A seguir separam-se inicialmente os preços obtidos com a venda em cada semana $t$ de acordo com o produto comercializado e o canal de comercialização:

1. Açúcar Mercado Spot Interno (SUMSI)

2. Açúcar Mercado Spot Externo (SUMSE)

3. Açúcar Mercado Futuro (SUMF)

4. Álcool hidratado Mercado Spot Interno (AHMSI)

5. Álcool hidratado Mercado Spot Externo (AHMSE)

6. Álcool hidratado Mercado Futuro (AHMF)

7. Álcool anidro Mercado Spot Interno (AAMSI)

8. Álcool anidro Mercado Spot Externo (AAMSE)

9. Álcool anidro Mercado Futuro (AAMF)

10. Melaço Mercado Spot Interno (MEMSI) 
Cálculos das receitas

Receita obtida com açúcar no mercado Spot Interno

$$
R E C_{S U M S I, t}=p_{a b, M S I, t} \cdot Q C_{a b, M S I, v, t, k, z}
$$

Receita obtida com açúcar no mercado Spot Externo

$$
R E C_{S U M S E, t}=p_{a b, M S E, t} \cdot Q C_{a b, M S E, v, t, k, z}
$$

Receita obtida com açúcar no mercado futuro

$$
R E C_{S U M F, t}=p_{a b, \text { Hedge },} \cdot Q_{a b, \text { Hedge }, t}
$$

Receita total obtida com açúcar na semana t

$$
R E C_{a b, t}=R E C_{\text {SUMSI,t }}+R E C_{S U M S E, t}+R E C_{S U M F, t}
$$

Receita obtida com AEHC no mercado Spot Interno

$$
R E C_{A E H C, M S I, t}=p_{A E H C, M S I, t} \cdot Q C_{A E H C, M S I, t, k, z}
$$

Receita obtida com AEHC no mercado Spot Externo

$$
R E C_{A E H C, M S, t}=p_{A E H C, M S E, t} \cdot Q C_{A E H C, M S E, t, k, z}
$$

Receita obtida com AEHC no mercado futuro

$$
R E C_{A E H C, M F, t}=p_{A E H C, H e d g e, t} \cdot Q_{A E H C, \text { Hedge }, t}
$$

Receita total obtida com AEHC na semana $t$

$$
R E C_{A E H C, t}=R E C_{A E H C, M S I, t}+R E C_{A E H C, M S E, t}+R E C_{A E H C, M F, t}
$$

Receita obtida com AEAC no mercado Spot Interno

$$
R E C_{A E A C, M S I, t}=p_{A E A C, M S I, t} \cdot Q C_{A E A C, M S I, t, k, z}
$$

Receita obtida com AEAC no mercado Spot Externo

$$
R E C_{A E A C, M S E, t}=p_{A E A C, M S E, t} \cdot Q C_{A E A C, M S E, t, k, z}
$$

Receita obtida com AEAC no mercado futuro

$$
R E C_{A A M F, t}=p_{A E A C, H e d g e, t} \cdot Q_{A E A C, \text { Hedge }, t} \text { (60) }
$$

Receita total obtida com AEAC na semana $t$

$$
R E C_{A E A C, t}=R E C_{A E A C, M S I, t}+R E C_{A E A C, M S E, t}+R E C_{A E A C, M F, t}
$$

Receita total obtida com melaço na semana t

$$
R E C_{M E, t}=p_{m e, t} \cdot R M_{v, k, t} \cdot Q_{t}
$$




\section{ANEXOS}

\section{ANEXO A - A LINGUAGEM DE MODELAGEM LINGO}

\section{Softwares de otimização}

A utilização de programação linear e não linear é muito útil para problemas de grande porte, em que muitas variáveis e restrições devem ser consideradas. Por isso, o desenvolvimento de algoritmos computacionais eficientes tem sido uma grande preocupação entre os pesquisadores. Dependendo do tamanho do problema, devem-se utilizar sistemas computacionais potentes ou apenas um computador pessoal. Por exemplo, tem-se para resolução de problemas menores de programação linear os softwares X Press-MP, LINDO e MINOS. Para problemas considerados médios, é recomendável a utilização de planilhas eletrônicas com solvers embutidos para resolução de problemas, como a planilha EXCEL da Microsoft (Prado, 1999).

A maioria dos softwares se baseia no algoritmo Simplex, desenvolvido por G. Dantzig em 1947, no qual cada linha relaciona-se com uma restrição e cada coluna com uma variável. Existem centenas de pacotes para PL e, dentre os diversos disponíveis, os listados a seguir são os mais conhecidos e utilizados.

Tabela 59. Alguns softwares utilizados em Programação linear e suas capacidades

\begin{tabular}{|c|c|c|c|}
\hline Software & Fabricante & \multicolumn{2}{|c|}{ Capacidade } \\
\hline \multirow{2}{*}{ LINDO/LINGO } & Lindo Systems & Variáveis & Restrições \\
MPSX & IBM & 2 bilhões & 32.000 \\
& Cplex & & 16 milhões \\
CPLEX & Optimizations & 100.000 & 50.000 \\
OSL & IBM & 2 bilhões & 16 milhões \\
\hline
\end{tabular}

Fonte: Adaptado de Prado, 1999

\section{A linguagem de modelagem LINGO}

O LINGO (Language for INteractive General Optimization) é uma ferramenta computacional para resolução de problemas lineares e não lineares de otimização. $O$ LINGO é versátil e tem boa capacidade quanto ao número de variáveis e restrições, suportando 100.000 variáveis e 32.000 restrições. Por apresentar uma linguagem de modelagem muito parecida com a linguagem de modelagem matemática padrão, facilita a compreensão e a forma de se inserir as equações do modelo, além de permitir 
representar a função objetivo de forma bastante clara e intuitiva. O programa conta ainda com uma extensa biblioteca de funções estatísticas, financeiras, matemáticas e operações em série permitindo expressarmos uma fórmula complexa de modo fácil e claro.

Possui uma função (@OLE) de interface usada para mover dados entre o LINGO e o Excel através de transferências baseadas em OLE (Object Linking and Embedding). Essas transferências são realizadas diretamente pela memória e, portanto, não fazem uso de arquivos intermediários.

Por estar disponível no departamento de Engenharia de Produção da Escola Politécnica da USP, pelas facilidades descritas acima e por suportar o número de variáveis e restrições do modelo desenvolvido, este software foi escolhido para o desenvolvimento da modelagem desta dissertação.

\section{A forma de entrada dos dados e a sintaxe do modelo de programação}

Para a programação do modelo seguimos os seguintes passos:

\section{1) Conjuntos primitivos}

Referentes às variáveis de decisão do problema, como quantidade de cana de variedade $v$ moída por semana, seleção do processo industrial $k$ e seleção do processo comercial $z$.

\section{2) Conjuntos derivados}

Referentes a variáveis que podem ser obtidas a partir dos conjuntos primitivos. 


\section{ANEXO B- Código no LINGO para o exemplo ilustrativo do modelo Semi- Variância com Análise de cenários de Markowitz}

O modelo a seguir faz uso da função de importação de dados do Excel @ole.

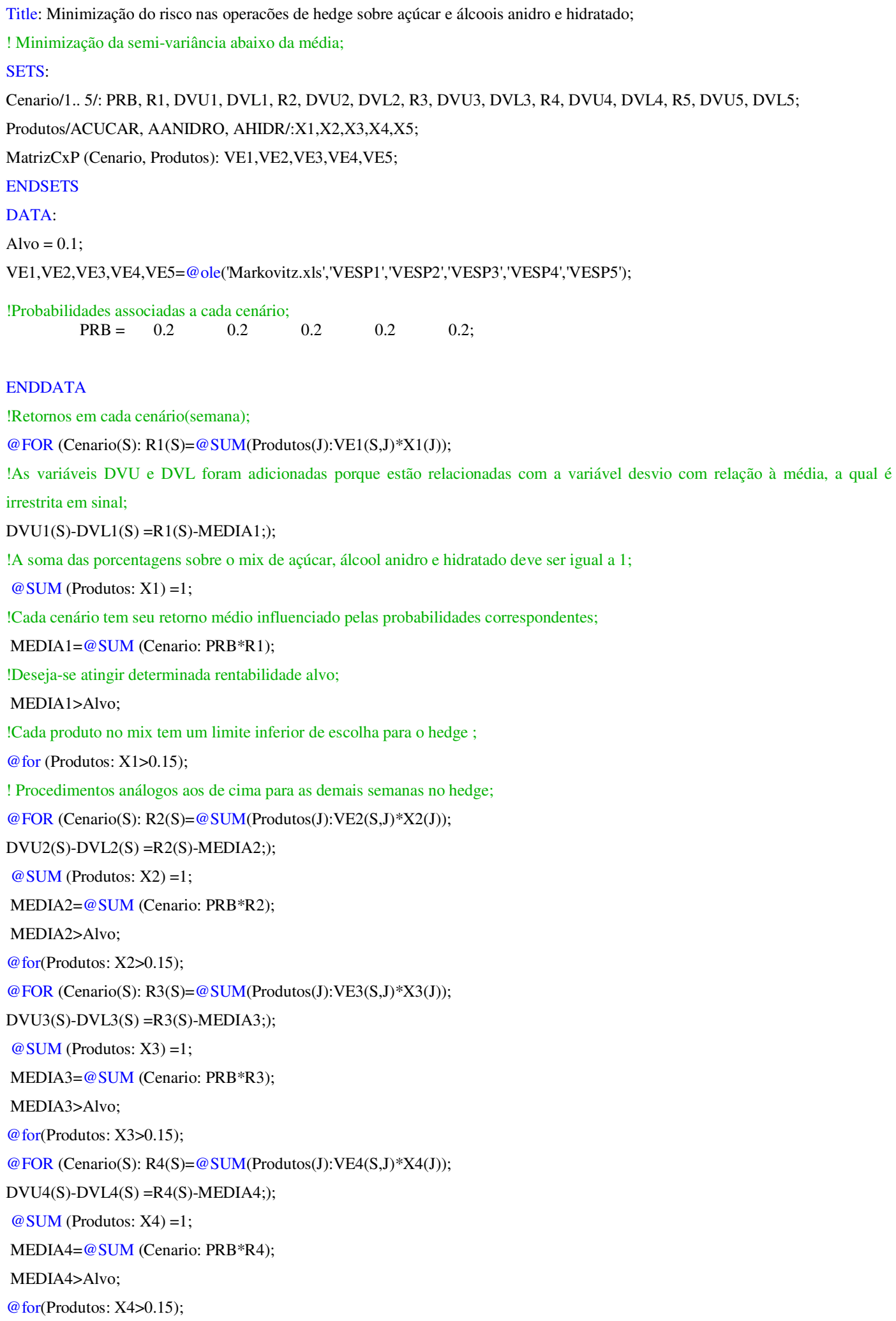


@ FOR $(\operatorname{Cenario}(\mathrm{S}): \mathrm{R} 5(\mathrm{~S})=@ \mathrm{SUM}(\operatorname{Produtos}(\mathrm{J}): \mathrm{VE} 5(\mathrm{~S}, \mathrm{~J}) * \mathrm{X} 5(\mathrm{~J}))$;

DVU5(S)-DVL5(S) =R5(S)-MEDIA5;);

@ SUM (Produtos: X5)=1;

MEDIA5=@SUM (Cenario: PRB*R5);

MEDIA5>Alvo;

@ for(Produtos: X5>0.15);

!Função objetivo;

[OBJ]MIN = @SUM (Cenario: PRB*DVL1^2)+@SUM (Cenario: PRB*DVL2^2)+@SUM (Cenario: PRB*DVL3^2)+@SUM $($ Cenario: PRB*DVL4^2)+@SUM (Cenario: PRB*DVL5^2);

Data:

@ ole('SOVTICE.xls','DemHedge1','DemHedge2','DemHedge3','DemHedge4','DemHedge5')=X1,X2,X3,X4,X5;

Enddata

\section{ANEXO C- Código no LINGO para o Modelo Semi-Variância com Análise de cenários de Markowitz}

Model:

Title: Minimização do risco nas operacoes de hedge sobre acucar e alcoois anidro e hidratado;

! Minimização da semi-variância abaixo da média;

SETS:

!Os cenários se referem a cada uma das cinco semanas estudadas, ou seja, a semana de previsão, duas antes e duas depois, estabelecendo um cenário de preços baseado nas cinco semanas e em suas probabilidades.

Isso confere ao modelo a possibilidade de se trabalhar com cenários mais otimistas ou mais pessimistas, bastando para isso alocar probabilidade maior nos cenários de preços maiores (otimista) ou maior em cenários

de preços menores(pessimista);

Cenario/1.. 5/: PRB, R1, DVU1, DVL1, R2, DVU2, DVL2, R3, DVU3, DVL3, R4, DVU4, DVL4, R5, DVU5, DVL5, R6, DVU6, DVL6, R7, DVU7, DVL7, R8, DVU8, DVL8, R9, DVU9, DVL9, R10, DVU10, DVL10, R11, DVU11, DVL11, R12, DVU12, DVL12, R13, DVU13, DVL13, R14, DVU14, DVL14, R15, DVU15, DVL15, R16, DVU16, DVL16, R17, DVU17, DVL17, R18, DVU18, DVL18, R19, DVU19, DVL19, R20, DVU20, DVL20, R21, DVU21, DVL21, R22, DVU22, DVL22, R23, DVU23, DVL23, R24, DVU24, DVL24, R25, DVU25, DVL25, R26, DVU26, DVL26, R27, DVU27, DVL27, R28, DVU28, DVL28, R29, DVU29, DVL29, R30, DVU30, DVL30, R31, DVU31, DVL31, R32, DVU32, DVL32, R33, DVU33, DVL33, R34, DVU34, DVL34, R35, DVU35, DVL35, R36, DVU36, DVL36;

Produtos/ACUCAR,AANIDRO,AHIDR/:X1,X2,X3,X4,X5,X6,X7,X8,X9,X10,X11,X12,X13,X14,X15,X16,X17,X18,X19,X20,X2 $1, \mathrm{X} 22, \mathrm{X} 23, \mathrm{X} 24, \mathrm{X} 25, \mathrm{X} 26, \mathrm{X} 27, \mathrm{X} 28, \mathrm{X} 29, \mathrm{X} 30, \mathrm{X} 31, \mathrm{X} 32, \mathrm{X} 33, \mathrm{X} 34, \mathrm{X} 35, \mathrm{X} 36$;

MatrizCENARIOxPRODUTO (Cenario, Produtos): VE1,VE2,VE3,VE4,VE5,VE6,VE7,VE8,VE9,VE10,VE11,VE12, VE13,VE14,VE15,VE16,VE17,VE18,VE19,VE20,VE21,VE22,VE23,VE24,VE25,VE26,VE27,VE28,VE29,VE30,VE31,VE32,VE 33,VE34,VE35,VE36;

ENDSETS

DATA:

Alvo $=0.1 ;$

VE1,VE2,VE3,VE4,VE5,VE6,VE7,VE8,VE9,VE10,VE11,VE12,VE13,VE14,VE15,VE16,VE17,VE18,VE19,VE20,VE21,VE22,V E23,VE24,VE25,VE26,VE27,VE28,VE29,VE30,VE31,VE32,VE33,VE34,VE35,VE36=@ ole('Markovitz.xls','VESP1','VESP2','VE SP3','VESP4,',VESP5','VESP6','VESP7','VESP8,',VESP9','VESP10','VESP11','VESP12,',VESP13','VESP14','VESP15','VESP16','V ESP17','VESP18','VESP19','VESP20','VESP21','VESP22','VESP23','VESP24','VESP25','VESP26','VESP27','VESP28','VESP29','V ESP30','VESP31','VESP32','VESP33','VESP34','VESP35','VESP36');

!Probabilidades associadas a cada cenário;

\begin{tabular}{|c|c|c|c|}
\hline $\mathrm{PRB}=$ & 0.2 & 0.2 & 0.2 \\
\hline
\end{tabular}

ENDDATA

!Retornos em cada cenário(semana);

@ FOR $(\operatorname{Cenario}(\mathrm{S}): \mathrm{R} 1(\mathrm{~S})=@ \operatorname{SUM}(\operatorname{Produtos}(\mathrm{J}): \mathrm{VE} 1(\mathrm{~S}, \mathrm{~J}) * \mathrm{X} 1(\mathrm{~J}))$; 


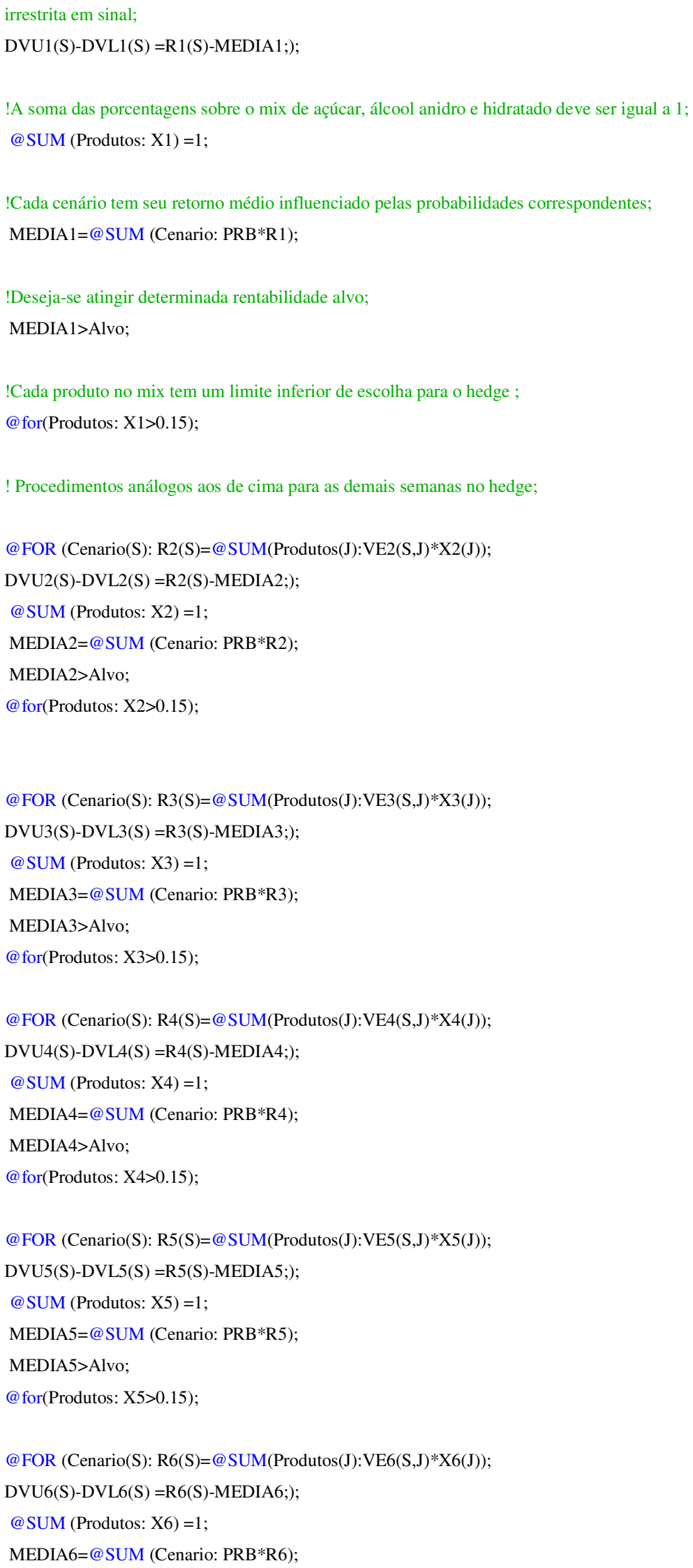




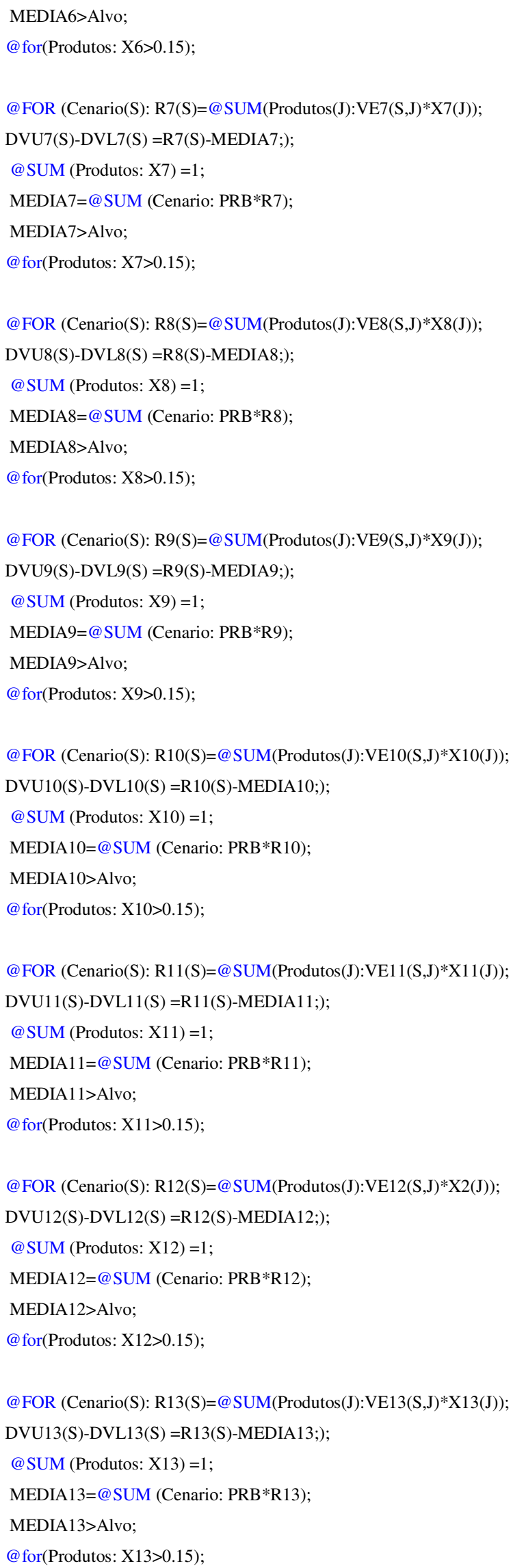




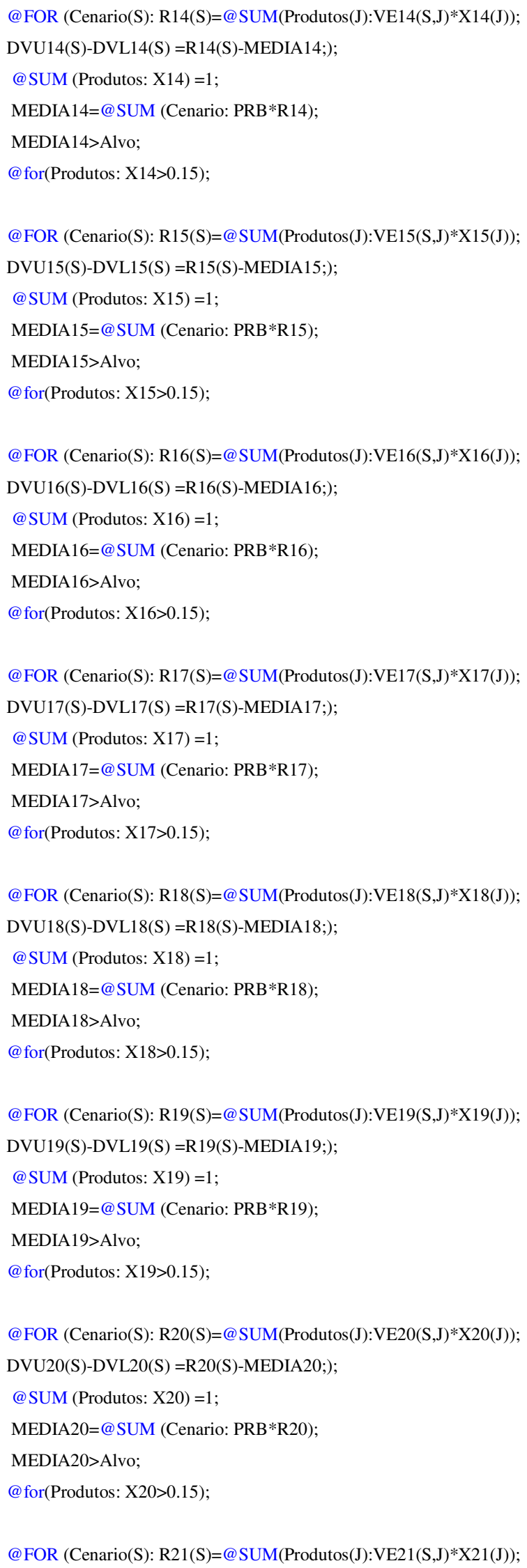




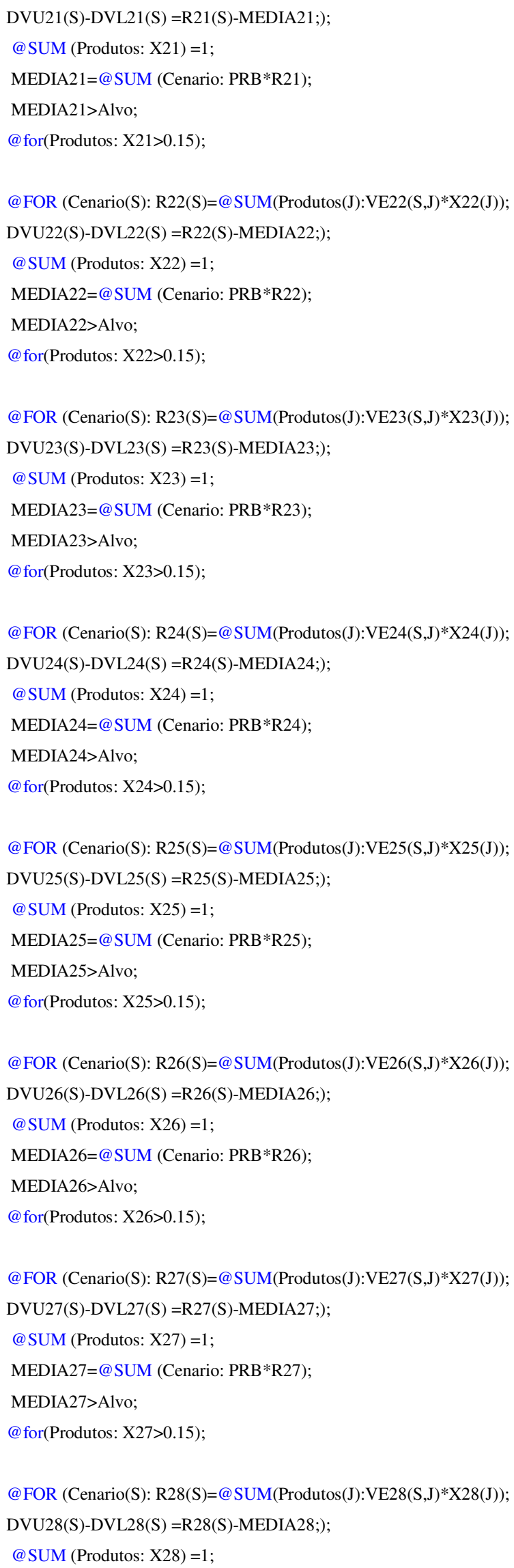




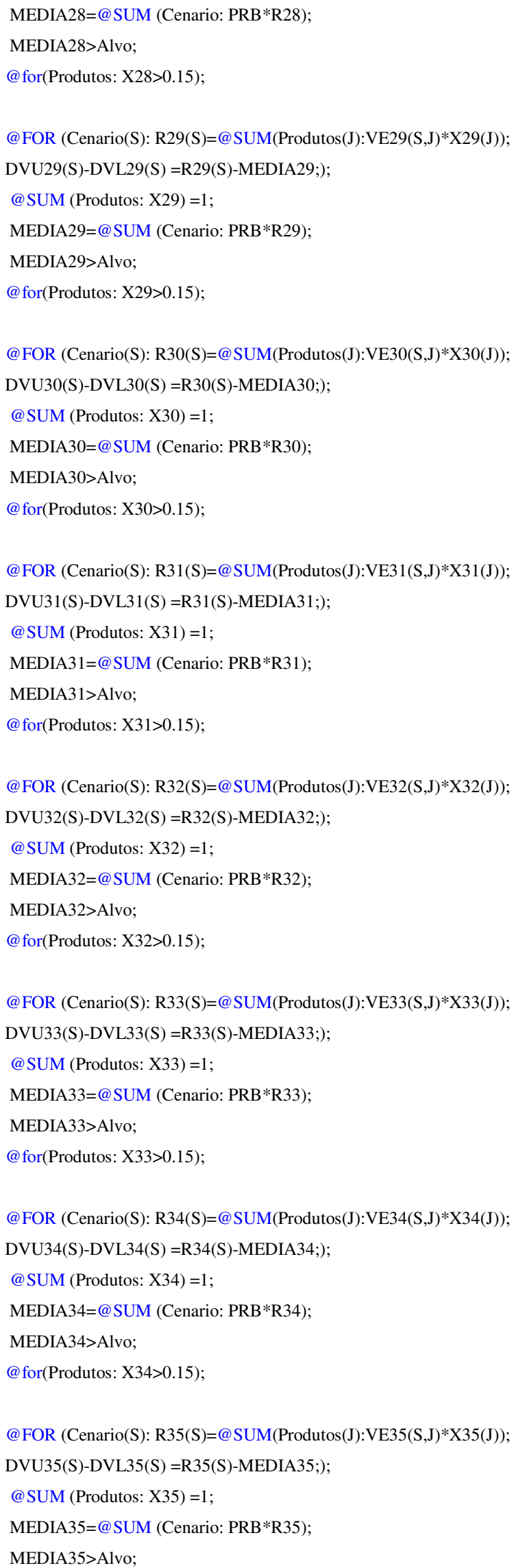


@ for(Produtos: X35>0.15);

@ FOR (Cenario(S): R36(S)=@SUM(Produtos(J):VE36(S,J)*X36(J));

DVU36(S)-DVL36(S) =R36(S)-MEDIA36;);

@SUM (Produtos: X36)=1;

MEDIA36=@SUM (Cenario: PRB*R36);

MEDIA36>Alvo;

@ for(Produtos: X36>0.15);

!Função objetivo;

[OBJ]MIN = @SUM (Cenario: PRB*DVL1^2)+@SUM (Cenario: PRB*DVL2^2)+@SUM (Cenario: PRB*DVL3^2)+@SUM (Cenario: PRB*DVL4^2)+

@SUM (Cenario: PRB*DVL5^2)+@SUM (Cenario: PRB*DVL6^2)+@SUM (Cenario: PRB*DVL6^2)+@SUM (Cenario: PRB*DVL7^2)+

@SUM (Cenario: PRB*DVL8^2)+@SUM (Cenario: PRB*DVL9^2)+@SUM (Cenario: PRB*DVL10^2)+@SUM (Cenario: PRB*DVL11^2)+@SUM (Cenario: PRB*DVL12^2)+

@SUM (Cenario: PRB*DVL13^2)+@SUM (Cenario: PRB*DVL14^2)+@SUM (Cenario: PRB*DVL15^2)+@SUM (Cenario: PRB*DVL16^2)+@SUM (Cenario: PRB*DVL17^2)+

@SUM (Cenario: PRB*DVL18^2)+@SUM (Cenario: PRB*DVL19^2)+@SUM (Cenario: PRB*DVL20^2)+@SUM (Cenario: PRB*DVL21^2)+@SUM (Cenario: PRB*DVL22^2)+

@SUM (Cenario: PRB*DVL23^2)+@SUM (Cenario: PRB*DVL24^2)+@SUM (Cenario: PRB*DVL25^2)+@SUM (Cenario: PRB*DVL26^2)+@SUM (Cenario: PRB*DVL27^2)+@SUM (Cenario: PRB*DVL28^2)

+@SUM (Cenario: PRB*DVL29^2)+@SUM (Cenario: PRB*DVL30^2)+@SUM (Cenario: PRB*DVL31^2)+@SUM (Cenario: PRB*DVL32^2)+@SUM (Cenario: PRB*DVL33^2)+

@SUM (Cenario: PRB*DVL34^2)+@SUM (Cenario: PRB*DVL35^2)+@SUM (Cenario: PRB*DVL36^2);

Data:

@ ole('SOVTICE.xls','DemHedge1','DemHedge2','DemHedge3','DemHedge4','DemHedge5','DemHedge6','DemHedge7','DemHedge 8','DemHedge9','DemHedge10','DemHedge 11','DemHedge12','DemHedge13','DemHedge14','DemHedge 15','DemHedge16','DemHe dge 17','DemHedge 18,',DemHedge19','DemHedge20','DemHedge21','DemHedge22','DemHedge23','DemHedge24','DemHedge25','D emHedge26','DemHedge27','DemHedge28','DemHedge29','DemHedge30','DemHedge31','DemHedge32','DemHedge33','DemHedge 34','DemHedge35','DemHedge36')=X1,X2,X3,X4,X5,X6,X7,X8,X9,X10,X11,X12,X13,X14,X15,X16,X17,X18,X19,X20,X21,X22 ,X23,X24,X25,X26,X27,X28,X29,X30,X31,X32,X33,X34,X35,X36;

Enddata

END 


\section{ANEXO D -Código no LINGO para o exemplo ilustrativo do modelo SOVTICE (Seleção de origem, variedade, transporte, processo industrial/comercial)}

Model:

Title: SOVTICE.lg4;

Sets:

!Definição de vetores usados no modelo;

v1/@ole(SOVITCE,'OrigemVar')/: Cana,PlanSafra;

v2/@ole(SOVITCE,'ProcIC')/: ProcIndCom;

v3/@ole(SOVITCE,'TipoFrota')/: TipoFrota;

v4/@ole(SOVITCE,'TipoEst')/: TipoEstoque;

v5/@ole(SOVITCE,'p')/: Produtos,TcosSpotI,TcosSpotE,TcosHedge;

v6/@ole(SOVITCE,'t')/: t,alfa,PTU,y,CapTranspP,MoagemMin,MoagemMax,MC;

!Definição de matrizes usadas no modelo;

m1(v5,v4): CapEst,EInic,Prev0;

m2(v3,v6): CustoFrota,QCT;

m3(v2,v6):CustoProcIC,QCP,QCPHedge,QCPSpotI,X,rcomerciaisHedge,rcomerciaisSpotI,rcomerciaisSpotE,QCPSpotE

QCPHedgeVHP,QCPHedgeAEAC,QCPHedgeAEHC;

$\mathrm{m} 4(\mathrm{v} 1, \mathrm{v} 6)$ : CustoOrigVar,DispCana,QCF;

m5(v2,v5,v6): RendIndComSpotI,RendIndComSpotE,ProdMExt,ProdMInt,ProdHedge;

m6(v5,v4,v6): CEst,PosEst;

m7(v5,v6): DemHedge,ValorPSpotI,ValorPHedge,Estoque,DemSpotI,DemSpotE,valorPSpotE,vendasI,vendasE;

Endsets

Data:

!Importação de dados da planilha Excel;

alfa,PTU,CapTranspP,MoagemMin,MoagemMax,CapEst,CustoFrota,CustoProcIC,CustoOrigVar,RendIndComSpotI,CEst,DemHed ge,DemSpotI,ValorPSpotI,Einic,PlanSafra,rcomerciaisHedge,rcomerciaisSpotI,CG

valorPHedge,TcosHedge,TcosSpotI,TcosSpotE,RendIndComSpotE,rcomerciaisSpotE,DemSpotE, valorPSpotE=

@ ole(SOVITCE,'alfa','PTU','CapTranspP','MoagemMin','MoagemMax','CapEst','CustoFrota','CustoProcIC','CustoOrigVar','RendIn dComSpotI','CEst','DemHedge','DemSpotI','ValorPSpotI','Einic','PlanSafra',

'rcomerciaisHedge','rcomerciaisSpotI','CG','valorPHedge','TcosHedge','TcosSpotI','TcosSpotE','RendIndComSpotE','rcomerciaisSpo tE','DemSpotE','ValorPSpotE');

Enddata

!Para a escolha dos caminhos k de industrialização/comercialização a variável X deve ser binária em cada semana t; @ for(m3(k,t): @bin(X(k,t)));

!A variável y é binária para ser usada na restrição de moagem mínima do tipo se...então...;

@ for(v6(t):@bin(y(t)));

!A quantidade de cana processada(QCP) é a soma da quantidade processada para o Hedge travado com a quantidade de cana

processada para os mercados Spot interno e externo;

@ for $(\mathrm{m} 3(\mathrm{k}, \mathrm{t}): \mathrm{QCP}(\mathrm{k}, \mathrm{t})=\mathrm{QCPHedge}(\mathrm{k}, \mathrm{t})+\mathrm{QCPSpot} \mathrm{I}(\mathrm{k}, \mathrm{t})+\mathrm{QCPSp} p t \mathrm{E}(\mathrm{k}, \mathrm{t}))$;

!Função objetivo: Maximização da Margem de Contribuição ;

[fo] $\max =$

@ $\operatorname{sum}(\mathrm{m} 3(\mathrm{k}, \mathrm{t}): \operatorname{rcomerciaisHedge}(\mathrm{k}, \mathrm{t}) * \mathrm{QCPHedge}(\mathrm{k}, \mathrm{t}))+@ \operatorname{sum}(\mathrm{m} 7(\mathrm{p}, \mathrm{t}): \operatorname{valorPSpotI}(\mathrm{p}, \mathrm{t}) * \operatorname{vendasI}(\mathrm{p}, \mathrm{t}))+@ \operatorname{sum}(\mathrm{m} 7(\mathrm{p}, \mathrm{t}): \operatorname{valorPSpotE}$ $(\mathrm{p}, \mathrm{t}) * \operatorname{vendasE}(\mathrm{p}, \mathrm{t}))$

-@ $\operatorname{sum}(\mathrm{m} 4(\mathrm{~m}, \mathrm{t}):$ CustoOrigVar(m,t)*QCF $(\mathrm{m}, \mathrm{t}))$

-@ $\operatorname{sum}(\mathrm{m} 2(\mathrm{f}, \mathrm{t}): \operatorname{CustoFrota}(\mathrm{f}, \mathrm{t}) * \mathrm{QCT}(\mathrm{f}, \mathrm{t}))$

-@ $\operatorname{sum}(\mathrm{m} 3(\mathrm{k}, \mathrm{t}): \mathrm{CustoProcIC}(\mathrm{k}, \mathrm{t}) * \mathrm{QCP}(\mathrm{k}, \mathrm{t}))$

- @ $\operatorname{sum}(m 6(\mathrm{p}, \mathrm{e}, \mathrm{t}): \operatorname{CEst}(\mathrm{p}, \mathrm{e}, \mathrm{t}) * \operatorname{PosEst}(\mathrm{p}, \mathrm{e}, \mathrm{t}))$

-@ $\operatorname{sum}(m 7(\mathrm{p}, \mathrm{t}):$ DemHedge $(\mathrm{p}, \mathrm{t}) *$ TcosHedge(p)*valorPHedge $(\mathrm{p}, \mathrm{t}))$

- @ sum $\left(\mathrm{m} 7(\mathrm{p}, \mathrm{t}): \operatorname{vendasI}(\mathrm{p}, \mathrm{t}) * \operatorname{Tcos} \operatorname{SpotI}(\mathrm{p})^{*} \operatorname{valor} P \operatorname{SpotI}(\mathrm{p}, \mathrm{t})\right)$

-@ $\operatorname{sum}(\mathrm{m} 7(\mathrm{p}, \mathrm{t}): \operatorname{vendasE}(\mathrm{p}, \mathrm{t}) * \operatorname{TcosSpotE}(\mathrm{p}) *$ valorPSpotE(p,t));

!Restricao de fluxo de caixa: Com o que a usina vende em cada semana mais o capital de giro ela deve honrar com os compromissos financeiros assumidos;

@ $\operatorname{sum}(\mathrm{m} 3(\mathrm{k}, \mathrm{t}): \operatorname{rcomerciaisHedge}(\mathrm{k}, \mathrm{t}) * \mathrm{QCPHedge}(\mathrm{k}, \mathrm{t}))+@ \operatorname{sum}(\mathrm{m} 7(\mathrm{p}, \mathrm{t}): \operatorname{valorPSpotI}(\mathrm{p}, \mathrm{t}) * \operatorname{vendasI}(\mathrm{p}, \mathrm{t}))+@ \operatorname{sum}(\mathrm{m} 7(\mathrm{p}, \mathrm{t}): \operatorname{valorPSpotE}$ $(\mathrm{p}, \mathrm{t}) * \operatorname{vendas} \mathrm{E}(\mathrm{p}, \mathrm{t}))+\mathrm{CG}>=$

@ $\operatorname{sum}(\mathrm{m} 4(\mathrm{~m}, \mathrm{t}):$ CustoOrigVar $(\mathrm{m}, \mathrm{t}) * \mathrm{QCF}(\mathrm{m}, \mathrm{t}))$

$+@ \operatorname{sum}(\mathrm{m} 2(\mathrm{f}, \mathrm{t}): \operatorname{CustoFrota}(\mathrm{f}, \mathrm{t}) * \mathrm{QCT}(\mathrm{f}, \mathrm{t}))$

$+@ \operatorname{sum}(\mathrm{m} 3(\mathrm{k}, \mathrm{t}): \operatorname{CustoProcIC}(\mathrm{k}, \mathrm{t}) * \mathrm{QCP}(\mathrm{k}, \mathrm{t}))$

+@ $\operatorname{sum}(\mathrm{m} 6(\mathrm{p}, \mathrm{e}, \mathrm{t}): \operatorname{CEst}(\mathrm{p}, \mathrm{e}, \mathrm{t}) * \operatorname{Pos} \mathrm{Est}(\mathrm{p}, \mathrm{e}, \mathrm{t}))$

$+@ \operatorname{sum}(m 7(\mathrm{p}, \mathrm{t}):$ DemHedge $(\mathrm{p}, \mathrm{t}) *$ TcosHedge( $(\mathrm{p}) *$ valorPHedge $(\mathrm{p}, \mathrm{t}))$

$+@ \operatorname{sum}(\mathrm{m} 7(\mathrm{p}, \mathrm{t}): \operatorname{vendasI}(\mathrm{p}, \mathrm{t}) * \operatorname{Tcos} \operatorname{SpotI}(\mathrm{p}) * \operatorname{valor} P \operatorname{SpotI}(\mathrm{p}, \mathrm{t}))$

+@ $\operatorname{sum}(m 7(\mathrm{p}, \mathrm{t}): \operatorname{vendas} E(\mathrm{p}, \mathrm{t}) * \mathrm{~T} \cos \operatorname{SpotE}(\mathrm{p}) * \operatorname{valor} P S p o t E(\mathrm{p}, \mathrm{t}))$; 
!Restrições de balanceamento de estoque dos produtos no final de cada semana;

!Estoque inicial;

@ for(v4(e): @ for(m7(p,t)|t\#eq\#1:PosEst(p,e,t)=EInic(p,e)));

!Balanceamento de estoque;

@ for(m7(p,t)|t\#gt\#1:@sum(v4(e):PosEst(p,e,t))=

@ sum(v4(e):PosEst(p,e,t-1))+@sum(v2(k):(RendIndComSpotI(k,p,t))*QCPSpotI(k,t))

+@ $\operatorname{sum}(\mathrm{v} 2(\mathrm{k}):(\operatorname{RendIndComSpotE}(\mathrm{k}, \mathrm{p}, \mathrm{t})) * \mathrm{QCPSpotE}(\mathrm{k}, \mathrm{t}))-\operatorname{VendasI}(\mathrm{p}, \mathrm{t})-\operatorname{VendasE}(\mathrm{p}, \mathrm{t})-\operatorname{DemHedge}(\mathrm{p}, \mathrm{t}))$;

!Atendimento da demanda hedge;

@ for(v5(p)|p\#eq\#1:@for(v6(t)|t\#gt\#1:@sum(v2(k):(RendIndComSpotI(k,p,t)+RendIndComSpotE(k,p,t))*QCPhedgeVHP(k,t))=De mHedge(p,t)));

@ for(v5(p)|p\#eq\#3:@ for(v6(t)|t\#gt\#1:@ sum(v2(k):(RendIndComSpotI(k,p,t)+RendIndComSpotE(k,p,t))*QCPhedgeAEHC(k,t))=D emHedge $(\mathrm{p}, \mathrm{t})))$;

@ for(v5(p)|p\#eq\#4:@ for(v6(t)|t\#gt\#1:@ sum(v2(k):(RendIndComSpotI(k,p,t)+RendIndComSpotE(k,p,t))*QCPhedgeAEAC(k,t))=D emHedge $(\mathrm{p}, \mathrm{t})))$;

!Formação do QCPHedge;

@ for $(\mathrm{m} 3(\mathrm{k}, \mathrm{t}): \mathrm{QCPHedge}(\mathrm{k}, \mathrm{t})=\mathrm{QCPHedgeVHP}(\mathrm{k}, \mathrm{t})+\mathrm{QCPHedgeAEHC}(\mathrm{k}, \mathrm{t})+\mathrm{QCPHedgeAEAC}(\mathrm{k}, \mathrm{t}))$;

!Vendas para mercado interno e externo devem ser maiores que as demandas respectivas para mercado interno e externo;

@ for $(m 7(\mathrm{p}, \mathrm{t}): \operatorname{DemSpotI}(\mathrm{p}, \mathrm{t})<=\operatorname{VendasI}(\mathrm{p}, \mathrm{t}))$;

$@$ for $(\mathrm{m} 7(\mathrm{p}, \mathrm{t}): \operatorname{DemSpotE}(\mathrm{p}, \mathrm{t})<=\operatorname{VendasE}(\mathrm{p}, \mathrm{t}))$;

!Restricao de vendas: As vendas efetuadas para mercado interno não podem superar a capacidade de produção mais valor presente em estoque;

@ for(m7(p,t)|t\#gt\#1:@sum(v2(k):(RendIndComSpotI(k,p,t))*QCPSpotI(k,t))+@sum(v4(e):PosEst(p,e,t-1))-DemHedge(p,t) $>=\operatorname{VendasI}(\mathrm{p}, \mathrm{t}))$

!Restricao de vendas: As vendas efetuadas para mercado externo não podem superar a capacidade de produção mais valor presente em estoque;

@ for(m7(p,t)|t\#gt\#1:@sum(v2(k):(RendIndComSpotE(k,p,t))*QCPSpotE(k,t))+@sum(v4(e):PosEst(p,e,t-1))-DemHedge(p,t)

$>=\operatorname{VendasE}(\mathrm{p}, \mathrm{t}))$;

!Restriç̃es de balanceamento de estoque de cana no campo;

@ for $(\mathrm{m} 4(\mathrm{~m}, \mathrm{t}) \mid \mathrm{t} \#$ eq\#1:DispCana $(\mathrm{m}, \mathrm{t})=\operatorname{PlanSafra}(\mathrm{m}))$;

$@$ for $(\mathrm{m} 4(\mathrm{~m}, \mathrm{t}) \mid \mathrm{t} \# \mathrm{gt} \# 1: \operatorname{DispCana}(\mathrm{m}, \mathrm{t})=\operatorname{DispCana}(\mathrm{m}, \mathrm{t}-1)-\mathrm{QCF}(\mathrm{m}, \mathrm{t}-1))$

!Estoque de cana no campo: A quantidade de cana fornecida deve ser menor ou igual à disponibilidade de cana no campo;

@ for $(\mathrm{m} 4(\mathrm{~m}, \mathrm{t}): \mathrm{QCF}(\mathrm{m}, \mathrm{t})<=\operatorname{DispCana}(\mathrm{m}, \mathrm{t}))$;

!Compatibilidade entre quantidade de cana colhida e quantidade de cana transportada ;

@ for(v6(t): @ sum(v1(m):QCF(m,t))=@sum(v3(f):QCT(f,t)));

!Compatibilidade entre quantidade de cana transportada e quantidade de cana processada;

@ for(v6(t):@sum(v3(f):qct(f,t))=@sum(v2(k):QCP(k,t)));

!Limitante para Moagem mínima. A idéia agora é fazer com que se ocorrer produção a QCP seja maior ou igual à moagem mínima; @ for(v6(t): @sum(v2(k):-QCP(k,t))+MoagemMin(t)<=100000*y);

$@$ for(v6(t):PTU(t)<=100000*(1-y));

!Limitante para Moagem máxima com o fator PTU, o qual se refere à porcentagem de tempo útil de funcionamento da moagem em cada semana;

@ for(v6(t):@sum(v2(k):QCP(k,t))<=MoagemMax(t)*PTU(t));

!Regulador de quantidade de cana comprada de Terceiros;

@ for $\left(\mathrm{m} 4(\mathrm{~m}, \mathrm{t}) \operatorname{m\# }\right.$ eq\#2:QCF $\left.(\mathrm{m}, \mathrm{t})<=(\mathrm{alfa}(\mathrm{t}) / 100)^{*} @ \operatorname{sum}(\mathrm{v} 2(\mathrm{k}): \mathrm{QCP}(\mathrm{k}, \mathrm{t}))\right)$

!Restrição relativa à capacidade de transporte por frota própria da usina;

@ for(m2(f,t)|f\#eq\#1:QCT(f,t)<=CapTranspP(t));

!Restrição para associar a moagem de cana a cada processo industrial/comercial escolhido;

@ for $(\mathrm{m} 3(\mathrm{k}, \mathrm{t}): \mathrm{QCP}(\mathrm{k}, \mathrm{t})<=\operatorname{MoagemMax}(\mathrm{t}) * \mathrm{PTU}(\mathrm{t}) * \mathrm{X}(\mathrm{k}, \mathrm{t}))$;

!Restrição para alocação do processo industrial/comercial em cada semana;

@ for(v6(t)|t\#eq\#1:@ sum(v2(k):X(k,t))=0)

@ for(v6(t)|t\#gt\#1:@sum(v2(k):X(k,t))=1);

!Capacidade de estocagem de cada produto em cada tipo de estoque, próprio ou terceirizado;

@ for(v2(k): @ for(m6(p,e,t):PosEst(p,e,t)<=capEst(p,e))); 
!Toda a cana processada na safra deve ser igual à toda a cana disponível na safra;

$@ \operatorname{sum}(\mathrm{m} 4(\mathrm{~m}, \mathrm{t}) \mid \mathrm{t} \# \mathrm{eq} \# 1: \operatorname{DispCana}(\mathrm{m}, \mathrm{t}))=@ \operatorname{sum}(\mathrm{m} 3(\mathrm{k}, \mathrm{t}): \mathrm{QCP}(\mathrm{k}, \mathrm{t}))$;

@ for $\left(\mathrm{m} 5(\mathrm{k}, \mathrm{p}, \mathrm{t}): \operatorname{ProdMExt}(\mathrm{k}, \mathrm{p}, \mathrm{t})=(\operatorname{RendIndComSpotE}(\mathrm{k}, \mathrm{p}, \mathrm{t}))^{*} \mathrm{QCPSpotE}(\mathrm{k}, \mathrm{t})\right)$;

@ for $(\mathrm{m} 5(\mathrm{k}, \mathrm{p}, \mathrm{t}): \operatorname{ProdMInt}(\mathrm{k}, \mathrm{p}, \mathrm{t})=(\operatorname{RendIndComSpotI}(\mathrm{k}, \mathrm{p}, \mathrm{t})) * \mathrm{QCPSpotI}(\mathrm{k}, \mathrm{t}))$;

!Produção no hedge por produto;

@ for $\left(\mathrm{m} 5(\mathrm{k}, \mathrm{p}, \mathrm{t}) \mid \mathrm{p} \#\right.$ eq\#1:ProdHedge $\left.(\mathrm{k}, \mathrm{p}, \mathrm{t})=(\operatorname{RendIndComSpotI}(\mathrm{k}, \mathrm{p}, \mathrm{t})+\operatorname{RendIndComSpotE}(\mathrm{k}, \mathrm{p}, \mathrm{t}))^{*} \mathrm{QCPHedgeVHP}(\mathrm{k}, \mathrm{t})\right)$;

@ for $(m 5(k, p, t) \mid p \#$ eq\#3:ProdHedge $(k, p, t)=(\operatorname{RendIndComSpotI}(k, p, t)+\operatorname{RendIndComSpotE}(k, p, t)) * Q C P H e d g e A E H C(k, t))$;

$@$ for $\left(\mathrm{m} 5(\mathrm{k}, \mathrm{p}, \mathrm{t}) \mid \mathrm{p} \#\right.$ eq\#4:ProdHedge $\left.(\mathrm{k}, \mathrm{p}, \mathrm{t})=(\operatorname{RendIndComSpotI}(\mathrm{k}, \mathrm{p}, \mathrm{t})+\operatorname{RendIndComSpotE}(\mathrm{k}, \mathrm{p}, \mathrm{t}))^{*} \mathrm{QCPHedgeAEAC}(\mathrm{k}, \mathrm{t})\right)$;

!Exportação de valores para a planilha Excel;

Data:

@ ole(SOVITCE,'qcf','qct','qcp','X','DispCana','PosEst','MC','QCPhedge','QCPSpotE','QCPSpotI','ProdMExt','ProdMInt','ProdHedge' ,'vendasI','vendasE')=qcf,qct,qcp,x,DispCana,PosEst,fo,QCPhedge,QCPSpotE,QCPSpotI,ProdMExt,ProdMInt,ProdHedge,vendasI,v endasE;

enddata

\section{ANEXO E- Dados de entrada para o modelo SOVTICE}

A seguir são apresentados os dados de entrada para rodar o modelo referentes à safra 2008/2009 na Usina Alta Paulista.

Tabela 60. Dados de entrada sem variação em cada semana

\begin{tabular}{|c|c|}
\hline Parâmetros & Valores \\
\hline CArrTe(R\$/ha) & 684,00 \\
\hline CarrCa(t/ha) & 17,00 \\
\hline ARme(\%) & 18,00 \\
\hline Cproc(R\$/Kg de ART) & 0,124 \\
\hline BMF (\%) & 85,00 \\
\hline PzaMCP(\%) & 43,00 \\
\hline PzaMCS(\%) & 42,00 \\
\hline Polz (\%) & 99,30 \\
\hline Umid (\%) & 0,10 \\
\hline PzaSU(ab)(\%) & 99,40 \\
\hline SMFCP $(\%)$ & 36,55 \\
\hline SMFCS (\%) & 35,70 \\
\hline $\operatorname{Ral}(\mathrm{AEHC})(\mathrm{L} / \mathrm{Kg})$ & 67,87 \\
\hline $\operatorname{Ral}(\mathrm{AEAC})(\mathrm{L} / \mathrm{Kg})$ & 65,03 \\
\hline FatorCSSU & 0,26 \\
\hline FatorCSA & 0,28 \\
\hline FatorConv(al AEHC) & 0,954 \\
\hline FatorConv(al AEAC) & 0,996 \\
\hline Cgiro(R $\$ / \mathrm{sem})$ & 500000,00 \\
\hline Moagem mínima(Mmin, em t/sem) & 44000,00 \\
\hline Moagem máxima(Mmax, em t/sem) & 54000,00 \\
\hline CapEstP(açúcar VHP,em t/sem) & 15000,00 \\
\hline CapEstP(AEHC,em m3/sem) & 14000,00 \\
\hline CapEstP(AEAC,em m3/sem) & 14000,00 \\
\hline TEstP(açúcar VHP,em R\$/t/sem) & 6,20 \\
\hline $\mathrm{TEstP}(\mathrm{AEHC}, \mathrm{em} \mathrm{R} \$ / \mathrm{m} 3 / \mathrm{sem})$ & 8,10 \\
\hline TEstP(AEAC,em R $\$ / \mathrm{m} 3 / \mathrm{sem})$ & 9,30 \\
\hline $\operatorname{TCOS}(\mathrm{al})(\%)$ & 0,030 \\
\hline TCOS(SU) $(\%)$ & 0,032 \\
\hline $\operatorname{TCOS}(\mathrm{me})(\%)$ & 0,050 \\
\hline Estl(SU) $(e m t)$ & 0,000 \\
\hline Estl(AEHC) (em m3) & 0,000 \\
\hline Estl(AEAC) (em m3) & 0,000 \\
\hline CprocMédioCana(R\$/t de cana) & 23,00 \\
\hline
\end{tabular}


Tabela 61. Dados de entrada com variação em cada semana

Dados de entrada com variação em $t$

Semanas pATR (R\$/Kg) $\quad$ Efd(\%) Elbti(\%) $\quad \operatorname{RTD(AEHC)~(\% )~RTD(AEAC)~(\% )~} \quad \delta_{t}$

\begin{tabular}{|c|c|c|c|c|c|c|}
\hline Sem1 & 0,2628 & 87,6 & 87,21 & 59,45 & 56,97 & 1 \\
\hline Sem2 & 0,2745 & 87,7 & 87,31 & 59,52 & 57,03 & 1 \\
\hline Sem3 & 0,2767 & 87,7 & 87,31 & 59,52 & 57,03 & 1 \\
\hline Sem4 & 0,2654 & 87,9 & 87,51 & 59,66 & 57,16 & 1 \\
\hline Sem5 & 0,2538 & 88 & 87,61 & 59,73 & 57,23 & 1 \\
\hline Sem6 & 0,2543 & 88,1 & 87,71 & 59,79 & 57,29 & 1 \\
\hline Sem7 & 0,2568 & 88,4 & 88,00 & 60,00 & 57,49 & 1 \\
\hline Sem8 & 0,2503 & 88,7 & 88,30 & 60,20 & 57,68 & 1 \\
\hline Sem 9 & 0,2506 & 88,7 & 88,30 & 60,20 & 57,68 & 1 \\
\hline Sem10 & 0,2436 & 88,6 & 88,20 & 60,13 & 57,62 & 1 \\
\hline Sem11 & 0,2423 & 88,6 & 88,20 & 60,13 & 57,62 & 1 \\
\hline Sem12 & 0,2367 & 88,9 & 88,50 & 60,34 & 57,81 & 1 \\
\hline Sem13 & 0,2385 & 90,1 & 89,70 & 61,15 & 58,59 & 1 \\
\hline Sem14 & 0,2397 & 90,2 & 89,79 & 61,22 & 58,66 & 1 \\
\hline Sem15 & 0,2402 & 90,2 & 89,79 & 61,22 & 58,66 & 1 \\
\hline Sem16 & 0,2401 & 90,4 & 89,99 & 61,35 & 58,79 & 1 \\
\hline Sem17 & 0,2493 & 90,4 & 89,99 & 61,35 & 58,79 & 1 \\
\hline Sem18 & 0,2438 & 90,5 & 90,09 & 61,42 & 58,85 & 1 \\
\hline Sem19 & 0,2476 & 90,6 & 90,19 & 61,49 & 58,92 & 1 \\
\hline Sem20 & 0,2486 & 91 & 90,59 & 61,76 & 59,18 & 1 \\
\hline Sem21 & 0,2498 & 89,9 & 89,50 & 61,02 & 58,46 & 1 \\
\hline Sem22 & 0,2534 & 89,8 & 89,40 & 60,95 & 58,40 & 1 \\
\hline Sem23 & 0,2564 & 90,1 & 89,70 & 61,15 & 58,59 & 1 \\
\hline Sem24 & 0,2648 & 90,2 & 89,79 & 61,22 & 58,66 & 1 \\
\hline Sem25 & 0,2685 & 90,2 & 89,79 & 61,22 & 58,66 & 1 \\
\hline Sem26 & 0,2756 & 89,9 & 89,50 & 61,02 & 58,46 & 1 \\
\hline Sem27 & 0,2798 & 90 & 89,60 & 61,08 & 58,53 & 1 \\
\hline Sem28 & 0,2865 & 89,8 & 89,40 & 60,95 & 58,40 & 1 \\
\hline Sem29 & 0,2921 & 90,3 & 89,89 & 61,29 & 58,72 & 1 \\
\hline Sem30 & 0,3015 & 90,3 & 89,89 & 61,29 & 58,72 & 1 \\
\hline Sem31 & 0,3035 & 89,7 & 89,30 & 60,88 & 58,33 & 1 \\
\hline Sem32 & 0,3054 & 89,8 & 89,40 & 60,95 & 58,40 & 1 \\
\hline Sem33 & 0,3065 & 90,1 & 89,70 & 61,15 & 58,59 & 1 \\
\hline Sem34 & 0,3076 & 90,2 & 89,79 & 61,22 & 58,66 & 1 \\
\hline Sem35 & 0,3087 & 90,1 & 89,70 & 61,15 & 58,59 & 1 \\
\hline Sem36 & 0,3116 & 89,8 & 89,40 & 60,95 & 58,40 & 1 \\
\hline
\end{tabular}

Tabela 62. Disponibilidade de cada variedade de cana por fonte de fornecimento

\begin{tabular}{|c|c|c|c|}
\hline Variedade de cana & VTCAforn(v) (R\$/t) & DispCanaPrópria (em t) & DispCanaFornec. $(\mathbf{e m}$ t) \\
\hline RB72454 & 41,00 & 84718,09 & 10207,34 \\
SP813250 & 41,50 & 95978,44 & 30550,69 \\
SP791011 & 39,40 & 63407,25 & 17653,04 \\
RB835486 & 41,30 & 61355,26 & 1035,47 \\
SP832847 & 41,20 & 68765,79 & 64578,89 \\
SP801842 & 41,00 & 63190,19 & 25589,66 \\
RB855536 & 41,10 & 194656,73 & 7049,11 \\
RB867515 & 41,60 & 112681,56 & 60987,89 \\
RB855113 & 39,40 & 29264,75 & 13701,28 \\
RB825336 & 38,30 & 12052,66 & 120765,56 \\
RB928064 & 39,50 & 45606,28 & 89897,64 \\
RB855035 & 39,60 & 57456,79 & 61234,89 \\
RB765418 & 38,90 & 43234,56 & 49678,98 \\
RB739735 & 41,40 & 26876,78 & 119675,91 \\
RB855453 & 41,70 & 75155,25 & 125346,76 \\
\hline
\end{tabular}


Tabela 63. Características técnicas de cada processo industrial

\begin{tabular}{|c|c|c|c|c|}
\cline { 2 - 5 } \multicolumn{1}{c|}{} & \multicolumn{3}{c|}{ Caminhos de produção } \\
\hline Processo & SCP & SCS & SM & SA \\
\hline Proc1 & 0,3 & 0,2 & 0,8 & 0,4 \\
Proc2 & 0,3 & 0,2 & 0,8 & 0,8 \\
Proc3 & 0,3 & 0,2 & 1 & 0,4 \\
Proc4 & 0,3 & 0,2 & 1 & 0,8 \\
Proc5 & 0,3 & 0,8 & 0,8 & 0,4 \\
Proc6 & 0,3 & 0,8 & 0,8 & 0,8 \\
Proc7 & 0,3 & 0,8 & 1 & 0,4 \\
Proc8 & 0,3 & 0,8 & 1 & 0,8 \\
Proc9 & 0,6 & 0,2 & 0,8 & 0,4 \\
Proc10 & 0,6 & 0,2 & 0,8 & 0,8 \\
Proc11 & 0,6 & 0,2 & 1 & 0,4 \\
Proc12 & 0,6 & 0,2 & 1 & 0,8 \\
Proc13 & 0,6 & 0,8 & 0,8 & 0,4 \\
Proc14 & 0,6 & 0,8 & 0,8 & 0,8 \\
Proc15 & 0,6 & 0,8 & 1 & 0,4 \\
Proc16 & 0,6 & 0,8 & 1 & 0,8 \\
Proc17 & 0,9 & 0,2 & 0,8 & 0,4 \\
Proc18 & 0,9 & 0,2 & 0,8 & 0,8 \\
Proc19 & 0,9 & 0,2 & 1 & 0,4 \\
Proc20 & 0,9 & 0,2 & 1 & 0,8 \\
Proc21 & 0,9 & 0,8 & 0,8 & 0,4 \\
Proc22 & 0,9 & 0,8 & 0,8 & 0,8 \\
Proc23 & 0,9 & 0,8 & 1 & 0,4 \\
Proc24 & 0,9 & 0,8 & 1 & 0,8 \\
\hline
\end{tabular}

Tabela 64. Características técnicas de cada processo comercial

\begin{tabular}{|c|c|c|c|c|}
\hline Processo & SCOSU & SCOAH & SCOAA & SCOME \\
\hline Proc1 & 0,60 & 0,80 & 0,80 & 1,00 \\
\hline Proc2 & 0,40 & 0,80 & 0,80 & 1,00 \\
\hline Proc3 & 0,60 & 0,60 & 0,80 & 1,00 \\
\hline Proc4 & 0,40 & 0,60 & 0,80 & 1,00 \\
\hline Proc5 & 0,60 & 0,80 & 0,60 & 1,00 \\
\hline Proc6 & 0,40 & 0,80 & 0,60 & 1,00 \\
\hline Proc7 & 0,60 & 0,60 & 0,60 & 1,00 \\
\hline Proc8 & 0,40 & 0,60 & 0,60 & 1,00 \\
\hline
\end{tabular}


Tabela 65. Custo agrícola $(\mathbf{R} \$ / \mathrm{t})$ de cada variedade de cana própria por semana

\begin{tabular}{|c|c|c|c|c|c|c|c|c|c|c|c|c|c|c|c|}
\hline \multicolumn{16}{|c|}{ na própria (R\$ $/ t)$} \\
\hline & RB72454 & SP813250 & SP791011 & RB835486 & SP832847 & SP801842 & SP855536 & RB867515 & RB8551 13 & RB825336 & RB928064 & RB855453 & RB739735 & RB765418 & RB855035 \\
\hline sem 1 & 40,09 & 39,63 & 39,33 & 39,63 & 39,00 & 39,28 & 40,62 & 40,63 & 40,91 & 41,59 & 40,76 & 40,84 & 42,10 & 39,61 & 38,89 \\
\hline sem2 & 39,73 & 39,74 & 39,43 & 39,74 & 39,11 & 39,39 & 40,73 & 40,74 & 41,02 & 41,70 & 40,88 & 40,97 & 42,23 & 39,73 & 39,00 \\
\hline sem 3 & 40,49 & 39,84 & 39,54 & 39,85 & 39,22 & 39,50 & 40,84 & 40,85 & 41,33 & 41,82 & 41,00 & 41,09 & 42,35 & 39,84 & 39,11 \\
\hline sem 4 & 40,10 & 39,74 & 39,62 & 39,92 & 39,28 & 39,56 & 40,93 & 40,93 & 41,22 & 41,91 & 41,03 & 41,12 & 42,39 & 39,87 & 39,16 \\
\hline sem 5 & 41,89 & 41,53 & 41,23 & 41,56 & 40,91 & 41,19 & 42,57 & 42,58 & 42,87 & 43,57 & 42,79 & 42,88 & 44,18 & 41,58 & 40,79 \\
\hline sem 6 & 40,62 & 40,25 & 39,94 & 40,25 & 39,61 & 39,89 & 41,25 & 41,26 & 41,55 & 42,24 & 41,38 & 41,47 & 42,75 & 40,22 & 39,49 \\
\hline sem 7 & 42,30 & 40,88 & 40,57 & 40,90 & 40,25 & 40,54 & 41,90 & 41,91 & 42,06 & 42,90 & 42,09 & 42,18 & 43,47 & 40,90 & 40,13 \\
\hline sem 8 & 42,63 & 41,21 & 40,77 & 41,11 & 40,46 & 40,75 & 42,10 & 42,11 & 42,40 & 43,10 & 42,34 & 42,44 & 43,72 & 41,14 & 40,35 \\
\hline sem 9 & 42,83 & 41,41 & 41,11 & 41,45 & 40,80 & 41,09 & 42,44 & 42,45 & 42,74 & 43,45 & 42,70 & 42,80 & 44,10 & 41,50 & 40,69 \\
\hline sem 10 & 42,66 & 41,24 & 40,94 & 41,28 & 40,63 & 40,92 & 42,27 & 42,28 & 42,57 & 43,27 & 42,52 & 42,62 & 43,91 & 41,32 & 40,52 \\
\hline sem11 & 43,00 & 41,58 & 41,27 & 41,62 & 40,98 & 41,26 & 42,61 & 42,63 & 42,47 & 43,62 & 42,89 & 42,99 & 44,29 & 41,68 & 40,86 \\
\hline sem12 & 42,83 & 41,41 & 40,69 & 41,05 & 40,43 & 40,70 & 42,00 & 42,01 & 42,30 & 42,99 & 42,35 & 42,47 & 43,73 & 41,17 & 40,32 \\
\hline sem13 & 42,72 & 41,32 & 41,03 & 41,39 & 40,77 & 41,04 & 42,34 & 42,36 & 42,65 & 43,34 & 42,72 & 42,84 & 44,10 & 41,53 & 40,66 \\
\hline sem14 & 42,54 & 41,15 & 40,86 & 41,22 & 40,60 & 40,87 & 42,17 & 42,19 & 42,47 & 43,16 & 42,54 & 42,66 & 43,91 & 41,35 & 40,49 \\
\hline sem15 & 42,89 & 41,49 & 41,20 & 41,57 & 40,94 & 41,21 & 42,52 & 42,53 & 42,30 & 43,52 & 42,91 & 43,03 & 44,29 & 41,71 & 40,83 \\
\hline sem16 & 44,78 & 43,34 & 42,58 & 42,99 & 42,39 & 42,65 & 43,89 & 43,92 & 44,21 & 44,91 & 44,53 & 44,68 & 45,94 & 43,30 & 42,28 \\
\hline sem17 & 44,07 & 42,67 & 42,40 & 42,81 & 42,20 & 42,46 & 43,71 & 43,73 & 44,03 & 44,73 & 44,33 & 44,49 & 45,74 & 43,11 & 42,10 \\
\hline sem18 & 44,43 & 43,03 & 42,76 & 43,18 & 42,57 & 42,83 & 44,08 & 44,10 & 44,40 & 45,10 & 44,73 & 44,88 & 46,14 & 43,49 & 42,46 \\
\hline sem19 & 44,25 & 42,85 & 42,58 & 43,00 & 42,39 & 42,65 & 43,89 & 43,92 & 43,93 & 44,91 & 44,53 & 44,68 & 45,94 & 43,30 & 42,28 \\
\hline sem20 & 44,62 & 43,21 & 42,67 & 43,11 & 42,51 & 42,77 & 43,98 & 44,01 & 44,30 & 45,00 & 44,70 & 44,87 & 46,11 & 43,48 & 42,41 \\
\hline sem21 & 45,07 & 43,66 & 42,71 & 43,37 & 43,25 & 43,51 & 44,72 & 44,75 & 44,56 & 45,26 & 44,98 & 45,15 & 46,39 & 43,75 & 42,67 \\
\hline sem22 & 43,88 & 42,50 & 42,24 & 42,67 & 42,07 & 42,33 & 43,54 & 43,56 & 43,85 & 44,55 & 44,23 & 44,39 & 45,62 & 43,01 & 41,97 \\
\hline sem23 & 44,25 & 42,86 & 42,60 & 43,04 & 42,44 & 42,69 & 43,90 & 43,93 & 43,79 & 44,92 & 44,62 & 44,79 & 46,02 & 43,40 & 42,34 \\
\hline sem24 & 44,07 & 42,68 & 42,02 & 42,46 & 41,89 & 42,13 & 43,28 & 43,31 & 43,60 & 44,28 & 44,09 & 44,26 & 45,46 & 42,88 & 41,79 \\
\hline sem25 & 43,99 & 42,62 & 42,38 & 42,83 & 42,26 & 42,49 & 43,65 & 43,68 & 43,97 & 44,66 & 44,48 & 44,66 & 45,87 & 43,27 & 42,16 \\
\hline sem26 & 44,73 & 43,35 & 42,41 & 43,09 & 43,00 & 43,24 & 44,40 & 44,43 & 44,24 & 44,92 & 44,76 & 44,95 & 46,15 & 43,54 & 42,42 \\
\hline sem27 & 43,54 & 42,19 & 41,94 & 42,39 & 41,81 & 42,05 & 43,21 & 43,24 & 43,21 & 44,21 & 44,01 & 44,19 & 45,38 & 42,81 & 41,72 \\
\hline sem28 & 41,33 & 40,03 & 39,48 & 39,90 & 39,35 & 40,16 & 40,68 & 40,71 & 41,00 & 41,64 & 41,42 & 41,58 & 42,72 & 40,29 & 39,27 \\
\hline sem29 & 40,83 & 39,55 & 39,32 & 39,72 & 39,18 & 39,41 & 40,51 & 40,54 & 40,81 & 41,45 & 41,22 & 41,38 & 42,51 & 40,09 & 39,09 \\
\hline sem30 & 41,18 & 39,89 & 39,65 & 40,07 & 39,52 & 39,75 & 40,86 & 40,89 & 41,16 & 41,80 & 41,59 & 41,75 & 42,89 & 40,45 & 39,43 \\
\hline sem31 & 41,00 & 39,72 & 39,48 & 39,90 & 39,35 & 39,58 & 40,69 & 40,71 & 41,47 & 41,63 & 41,41 & 41,57 & 42,70 & 40,27 & 39,26 \\
\hline sem32 & 40,41 & 39,14 & 39,35 & 39,74 & 39,17 & 39,41 & 40,58 & 40,60 & 40,87 & 41,53 & 41,15 & 41,29 & 42,45 & 40,01 & 39,07 \\
\hline sem33 & 41,39 & 40,07 & 39,82 & 40,21 & 39,64 & 40,00 & 41,05 & 41,08 & 41,35 & 42,01 & 41,66 & 41,80 & 42,98 & 40,51 & 39,55 \\
\hline sem34 & 41,36 & 40,05 & 39,80 & 40,19 & 39,62 & 39,88 & 41,03 & 41,05 & 41,33 & 41,99 & 41,63 & 41,77 & 42,95 & 40,48 & 39,52 \\
\hline sem35 & 41,37 & 40,05 & 39,80 & 40,19 & 39,62 & 39,89 & 41,03 & 41,06 & 41,51 & 41,99 & 41,64 & 41,78 & 42,95 & 40,49 & 39,53 \\
\hline sem36 & 41,22 & 39,91 & 39,82 & 40,20 & 39,62 & 39,92 & 41,06 & 41,08 & 41,36 & 42,02 & 41,61 & 41,75 & 42,94 & 40,46 & 39,52 \\
\hline
\end{tabular}


Tabela 66. Custo agrícola $(\mathrm{R} \$ / \mathrm{t})$ de cada variedade de cana de terceiros por semana

\begin{tabular}{|c|c|c|c|c|c|c|c|c|c|c|c|c|c|c|c|}
\hline & RB72454 & SP813250 & SP791011 & RB835486 & SP832847 & SP801842 & SP855536 & RB8675 15 & RB855113 & RB825336 & RB928064 & RB855453 & RB739735 & RB765418 & RB855035 \\
\hline sem 1 & 41,45 & 41,69 & 39,85 & 40,81 & 39,06 & 39,18 & 40,88 & 40,77 & 41,54 & 41,82 & 40,90 & 40,94 & 41,81 & 39,63 & 39,07 \\
\hline sem2 & 41,08 & 41,80 & 39,95 & 40,92 & 39,17 & 39,29 & 40,99 & 40,88 & 41,66 & 41,94 & 41,02 & 41,06 & 41,93 & 39,75 & 39,18 \\
\hline sem 3 & 41,85 & 41,91 & 40,06 & 41,04 & 39,28 & 39,40 & 41,10 & 40,99 & 41,98 & 42,05 & 41,14 & 41,18 & 42,05 & 39,87 & 39,29 \\
\hline sem 4 & 41,46 & 41,80 & 40,15 & 41,13 & 39,34 & 39,47 & 41,19 & 41,08 & 41,87 & 42,14 & 41,18 & 41,21 & 42,09 & 39,90 & 39,35 \\
\hline sem 5 & 43,28 & 43,64 & 41,76 & 42,76 & 40,97 & 41,10 & 42,83 & 42,72 & 43,52 & 43,81 & 42,93 & 42,98 & 43,88 & 41,61 & 40,98 \\
\hline sem 6 & 42,01 & 42,35 & 40,47 & 41,45 & 39,67 & 39,80 & 41,52 & 41,41 & 42,20 & 42,48 & 41,53 & 41,57 & 42,45 & 40,24 & 39,68 \\
\hline sem 7 & 43,68 & 42,98 & 41,10 & 42,10 & 40,31 & 40,44 & 42,17 & 42,05 & 42,70 & 43,14 & 42,23 & 42,28 & 43,17 & 40,92 & 40,32 \\
\hline sem 8 & 44,02 & 43,31 & 41,29 & 42,29 & 40,53 & 40,66 & 42,36 & 42,25 & 43,04 & 43,33 & 42,48 & 42,53 & 43,43 & 41,17 & 40,53 \\
\hline sem 9 & 44,19 & 43,48 & 41,63 & 42,64 & 40,87 & 41,00 & 42,70 & 42,59 & 43,38 & 43,68 & 42,84 & 42,90 & 43,80 & 41,52 & 40,87 \\
\hline sem10 & 44,02 & 43,32 & 41,46 & 42,47 & 40,70 & 40,83 & 42,53 & 42,42 & 43,21 & 43,51 & 42,66 & 42,72 & 43,61 & 41,35 & 40,70 \\
\hline sem11 & 44,37 & 43,65 & 41,80 & 42,81 & 41,04 & 41,17 & 42,87 & 42,77 & 43,08 & 43,86 & 43,03 & 43,09 & 43,99 & 41,70 & 41,05 \\
\hline sem12 & 44,20 & 43,49 & 41,19 & 42,18 & 40,48 & 40,61 & 42,25 & 42,15 & 42,91 & 43,21 & 42,49 & 42,56 & 43,44 & 41,19 & 40,49 \\
\hline sem13 & 44,02 & 43,30 & 41,53 & 42,53 & 40,83 & 40,95 & 42,59 & 42,49 & 43,26 & 43,56 & 42,85 & 42,93 & 43,82 & 41,55 & 40,83 \\
\hline sem14 & 43,85 & 43,14 & 41,36 & 42,35 & 40,66 & 40,78 & 42,42 & 42,32 & 43,08 & 43,39 & 42,67 & 42,75 & 43,63 & 41,37 & 40,66 \\
\hline sem15 & 44,20 & 43,47 & 41,70 & 42,70 & 41,00 & 41,13 & 42,76 & 42,66 & 42,88 & 43,74 & 43,04 & 43,12 & 44,01 & 41,73 & 41,01 \\
\hline sem16 & 46,09 & 45,33 & 43,04 & 44,07 & 42,44 & 42,56 & 44,13 & 44,04 & 44,79 & 45,12 & 44,65 & 44,77 & 45,67 & 43,32 & 42,44 \\
\hline sem17 & 45,30 & 44,55 & 42,87 & 43,88 & 42,26 & 42,38 & 43,94 & 43,86 & 44,60 & 44,93 & 44,46 & 44,57 & 45,47 & 43,13 & 42,26 \\
\hline sem18 & 45,67 & 44,91 & 43,23 & 44,25 & 42,62 & 42,74 & 44,31 & 44,22 & 44,97 & 45,31 & 44,85 & 44,96 & 45,87 & 43,51 & 42,63 \\
\hline sem19 & 45,49 & 44,73 & 43,05 & 44,07 & 42,44 & 42,56 & 44,13 & 44,04 & 44,49 & 45,12 & 44,65 & 44,77 & 45,67 & 43,32 & 42,44 \\
\hline sem20 & 45,86 & 45,09 & 43,13 & 44,14 & 42,56 & 42,68 & 44,20 & 44,12 & 44,86 & 45,20 & 44,82 & 44,95 & 45,84 & 43,49 & 42,57 \\
\hline sem21 & 46,27 & 45,48 & 43,16 & 44,41 & 43,31 & 43,42 & 44,95 & 44,87 & 45,12 & 45,46 & 45,10 & 45,23 & 46,13 & 43,76 & 42,83 \\
\hline sem22 & 45,08 & 44,32 & 42,69 & 43,70 & 42,13 & 42,24 & 43,76 & 43,68 & 44,41 & 44,75 & 44,35 & 44,47 & 45,36 & 43,03 & 42,13 \\
\hline sem23 & 45,45 & 44,68 & 43,05 & 44,07 & 42,49 & 42,61 & 44,13 & 44,05 & 44,31 & 45,12 & 44,74 & 44,87 & 45,76 & 43,42 & 42,49 \\
\hline sem24 & 45,27 & 44,50 & 42,44 & 43,44 & 41,93 & 42,05 & 43,50 & 43,42 & 44,13 & 44,47 & 44,20 & 44,34 & 45,21 & 42,90 & 41,94 \\
\hline sem25 & 45,12 & 44,35 & 42,81 & 43,81 & 42,30 & 42,41 & 43,86 & 43,79 & 44,50 & 44,85 & 44,59 & 44,74 & 45,62 & 43,28 & 42,30 \\
\hline sem26 & 45,87 & 45,08 & 42,84 & 44,07 & 43,04 & 43,16 & 44,61 & 44,54 & 44,76 & 45,11 & 44,87 & 45,02 & 45,90 & 43,56 & 42,56 \\
\hline sem27 & 44,68 & 43,92 & 42,37 & 43,37 & 41,86 & 41,97 & 43,42 & 43,35 & 43,71 & 44,39 & 44,12 & 44,26 & 45,13 & 42,82 & 41,86 \\
\hline sem28 & 42,47 & 41,75 & 39,89 & 40,83 & 39,39 & 40,08 & 40,89 & 40,82 & 41,51 & 41,82 & 41,53 & 41,65 & 42,48 & 40,30 & 39,41 \\
\hline sem29 & 41,92 & 41,21 & 39,72 & 40,66 & 39,22 & 39,33 & 40,72 & 40,65 & 41,32 & 41,63 & 41,33 & 41,45 & 42,27 & 40,10 & 39,23 \\
\hline sem30 & 42,27 & 41,55 & 40,06 & 41,01 & 39,57 & 39,67 & 41,06 & 40,99 & 41,66 & 41,98 & 41,70 & 41,82 & 42,65 & 40,46 & 39,57 \\
\hline sem31 & 42,09 & 41,38 & 39,89 & 40,83 & 39,39 & 39,50 & 40,89 & 40,82 & 42,01 & 41,81 & 41,51 & 41,64 & 42,46 & 40,28 & 39,40 \\
\hline sem32 & 41,50 & 40,80 & 39,79 & 40,74 & 39,22 & 39,33 & 40,80 & 40,71 & 41,41 & 41,72 & 41,26 & 41,36 & 42,20 & 40,02 & 39,22 \\
\hline sem33 & 42,55 & 41,83 & 40,26 & 41,21 & 39,69 & 39,92 & 41,27 & 41,19 & 41,89 & 42,21 & 41,77 & 41,88 & 42,72 & 40,52 & 39,70 \\
\hline sem34 & 42,52 & 41,81 & 40,23 & 41,19 & 39,67 & 39,80 & 41,25 & 41,17 & 41,87 & 42,18 & 41,74 & 41,85 & 42,69 & 40,50 & 39,67 \\
\hline sem35 & 42,53 & 41,82 & 40,24 & 41,19 & 39,67 & 39,81 & 41,25 & 41,17 & 42,06 & 42,19 & 41,75 & 41,86 & 42,70 & 40,50 & 39,68 \\
\hline semso & & & & & & & &,$<0$ & $|, 9|$ & 22 & 1,73 & 83 & & & \\
\hline
\end{tabular}


Tabela 67. Custos dos processos industriais/comerciais para as primeiras 12 semanas

\begin{tabular}{|c|c|c|c|c|c|c|c|c|c|c|c|c|c|}
\hline Processos & Sem0 & Sem1 & Sem2 & Sem3 & Sem4 & Sem5 & Sem6 & Sem7 & Sem8 & Sem9 & Sem10 & Sem11 & Sem12 \\
\hline Procl1C11 & 0,0 & 33,1 & 31,7 & 33,9 & 33,0 & 36,4 & 33,8 & 41,1 & 42,1 & 42,9 & 42,4 & 43,3 & 43,0 \\
\hline Procl1C2I & 0,0 & 26,5 & 25,3 & 27,2 & 26,4 & 29,2 & 27,0 & 32,9 & 33,7 & 34,3 & 34,0 & 34,6 & 34,4 \\
\hline Procl1C3I & 0,0 & 33,1 & 31,7 & 33,9 & 33,0 & 36,4 & 33,8 & 41,1 & 42,1 & 42,9 & 42,4 & 43,3 & 43,0 \\
\hline Procl1C4I & 0,0 & 26,5 & 25,3 & 27,2 & 26,4 & 29,2 & 27,0 & 32,9 & 33,7 & 34,3 & 34,0 & 34,6 & 34,4 \\
\hline Procl1C5I & 0,0 & 33,1 & 31,7 & 33,9 & 33,0 & 36,4 & 33,8 & 41,1 & 42,1 & 42,9 & 42,4 & 43,3 & 43,0 \\
\hline Procl1c6I & 0,0 & 26,5 & 25,3 & 27,2 & 26,4 & 29,2 & 27,0 & 32,9 & 33,7 & 34,3 & 34,0 & 34,6 & 34,4 \\
\hline Procl1C7I & 0,0 & 33,1 & 31,7 & 33,9 & 33,0 & 36,4 & 33,8 & 41,1 & 42,1 & 42,9 & 42,4 & 43,3 & 43,0 \\
\hline Procl1C8I & 0,0 & 26,5 & 25,3 & 27,2 & 26,4 & 29,2 & 27,0 & 32,9 & 33,7 & 34,3 & 34,0 & 34,6 & 34,4 \\
\hline Procl2C1I & 0,0 & 33,1 & 31,7 & 33,9 & 33,0 & 36,4 & 33,8 & 41,1 & 42,1 & 42,9 & 42,4 & 43,3 & 43,0 \\
\hline Procl2C2I & 0,0 & 26,5 & 25,3 & 27,2 & 26,4 & 29,2 & 27,0 & 32,9 & 33,7 & 34,3 & 34,0 & 34,6 & 34,4 \\
\hline Procl2C3I & 0,0 & 33,1 & 31,7 & 33,9 & 33,0 & 36,4 & 33,8 & 41,1 & 42,1 & 42,9 & 42,4 & 43,3 & 43,0 \\
\hline Procl2C4I & 0,0 & 26,5 & 25,3 & 27,2 & 26,4 & 29,2 & 27,0 & 32,9 & 33,7 & 34,3 & 34,0 & 34,6 & 34,4 \\
\hline Procl2C5I & 0,0 & 33,1 & 31,7 & 33,9 & 33,0 & 36,4 & 33,8 & 41,1 & 42,1 & 42,9 & 42,4 & 43,3 & 43,0 \\
\hline Procl2C6I & 0,0 & 26,5 & 25,3 & 27,2 & 26,4 & 29,2 & 27,0 & 32,9 & 33,7 & 34,3 & 34,0 & 34,6 & 34,4 \\
\hline Procl2C7I & 0,0 & 33,1 & 31,7 & 33,9 & 33,0 & 36,4 & 33,8 & 41,1 & 42,1 & 42,9 & 42,4 & 43,3 & 43,0 \\
\hline Procl2C8I & 0,0 & 26,5 & 25,3 & 27,2 & 26,4 & 29,2 & 27,0 & 32,9 & 33,7 & 34,3 & 34,0 & 34,6 & 34,4 \\
\hline Procl3C1I & 0,0 & 33,1 & 31,7 & 33,9 & 33,0 & 36,4 & 33,8 & 41,1 & 42,1 & 42,9 & 42,4 & 43,3 & 43,0 \\
\hline Procl3C2I & 0,0 & 26,5 & 25,3 & 27,2 & 26,4 & 29,2 & 27,0 & 32,9 & 33,7 & 34,3 & 34,0 & 34,6 & 34,4 \\
\hline Procl3C3I & 0,0 & 33,1 & 31,7 & 33,9 & 33,0 & 36,4 & 33,8 & 41,1 & 42,1 & 42,9 & 42,4 & 43,3 & 43,0 \\
\hline Procl3C4I & 0,0 & 26,5 & 25,3 & 27,2 & 26,4 & 29,2 & 27,0 & 32,9 & 33,7 & 34,3 & 34,0 & 34,6 & 34,4 \\
\hline Procl3C5I & 0,0 & 33,1 & 31,7 & 33,9 & 33,0 & 36,4 & 33,8 & 41,1 & 42,1 & 42,9 & 42,4 & 43,3 & 43,0 \\
\hline Procl3C6I & 0,0 & 26,5 & 25,3 & 27,2 & 26,4 & 29,2 & 27,0 & 32,9 & 33,7 & 34,3 & 34,0 & 34,6 & 34,4 \\
\hline Procl3C7I & 0,0 & 33,1 & 31,7 & 33,9 & 33,0 & 36,4 & 33,8 & 41,1 & 42,1 & 42,9 & 42,4 & 43,3 & 43,0 \\
\hline Procl3C8I & 0,0 & 26,5 & 25,3 & 27,2 & 26,4 & 29,2 & 27,0 & 32,9 & 33,7 & 34,3 & 34,0 & 34,6 & 34,4 \\
\hline Procl4C1I & 0,0 & 33,1 & 31,7 & 33,9 & 33,0 & 36,4 & 33,8 & 41,1 & 42,1 & 42,9 & 42,4 & 43,3 & 43,0 \\
\hline Procl4C2I & 0,0 & 26,5 & 25,3 & 27,2 & 26,4 & 29,2 & 27,0 & 32,9 & 33,7 & 34,3 & 34,0 & 34,6 & 34,4 \\
\hline Procl4C3I & 0,0 & 33,1 & 31,7 & 33,9 & 33,0 & 36,4 & 33,8 & 41,1 & 42,1 & 42,9 & 42,4 & 43,3 & 43,0 \\
\hline Procl4C4I & 0,0 & 26,5 & 25,3 & 27,2 & 26,4 & 29,2 & 27,0 & 32,9 & 33,7 & 34,3 & 34,0 & 34,6 & 34,4 \\
\hline Procl4C5I & 0,0 & 33,1 & 31,7 & 33,9 & 33,0 & 36,4 & 33,8 & 41,1 & 42,1 & 42,9 & 42,4 & 43,3 & 43,0 \\
\hline Procl4C6I & 0,0 & 26,5 & 25,3 & 27,2 & 26,4 & 29,2 & 27,0 & 32,9 & 33,7 & 34,3 & 34,0 & 34,6 & 34,4 \\
\hline Procl4C7I & 0,0 & 33,1 & 31,7 & 33,9 & 33,0 & 36,4 & 33,8 & 41,1 & 42,1 & 42,9 & 42,4 & 43,3 & 43,0 \\
\hline Procl4C8I & 0,0 & 26,5 & 25,3 & 27,2 & 26,4 & 29,2 & 27,0 & 32,9 & 33,7 & 34,3 & 34,0 & 34,6 & 34,4 \\
\hline Procl5C1I & 0,0 & 47,7 & 45,7 & 48,9 & 47,5 & 52,5 & 48,6 & 59,2 & 60,6 & 61,8 & 61,2 & 62,4 & 62,0 \\
\hline Procl5C2I & 0,0 & 38,1 & 36,5 & 39,1 & 38,0 & 42,0 & 38,9 & 47,4 & 48,5 & 49,5 & 48,9 & 49,9 & 49,6 \\
\hline Procl5C3I & 0,0 & 47,7 & 45,7 & 48,9 & 47,5 & 52,5 & 48,6 & 59,2 & 60,6 & 61,8 & 61,2 & 62,4 & 62,0 \\
\hline Procl5C4I & 0,0 & 38,1 & 36,5 & 39,1 & 38,0 & 42,0 & 38,9 & 47,4 & 48,5 & 49,5 & 48,9 & 49,9 & 49,6 \\
\hline Procl5C5I & 0,0 & 47,7 & 45,7 & 48,9 & 47,5 & 52,5 & 48,6 & 59,2 & 60,6 & 61,8 & 61,2 & 62,4 & 62,0 \\
\hline Procl5C6I & 0,0 & 38,1 & 36,5 & 39,1 & 38,0 & 42,0 & 38,9 & 47,4 & 48,5 & 49,5 & 48,9 & 49,9 & 49,6 \\
\hline Procl5C7I & 0,0 & 47,7 & 45,7 & 48,9 & 47,5 & 52,5 & 48,6 & 59,2 & 60,6 & 61,8 & 61,2 & 62,4 & 62,0 \\
\hline Procl5C8I & 0,0 & 38,1 & 36,5 & 39,1 & 38,0 & 42,0 & 38,9 & 47,4 & 48,5 & 49,5 & 48,9 & 49,9 & 49,6 \\
\hline Procl6C1I & 0,0 & 47,7 & 45,7 & 48,9 & 47,5 & 52,5 & 48,6 & 59,2 & 60,6 & 61,8 & 61,2 & 62,4 & 62,0 \\
\hline Procl6C2I & 0,0 & 38,1 & 36,5 & 39,1 & 38,0 & 42,0 & 38,9 & 47,4 & 48,5 & 49,5 & 48,9 & 49,9 & 49,6 \\
\hline Procl6C3I & 0,0 & 47,7 & 45,7 & 48,9 & 47,5 & 52,5 & 48,6 & 59,2 & 60,6 & 61,8 & 61,2 & 62,4 & 62,0 \\
\hline Procl6C4I & 0,0 & 38,1 & 36,5 & 39,1 & 38,0 & 42,0 & 38,9 & 47,4 & 48,5 & 49,5 & 48,9 & 49,9 & 49,6 \\
\hline Procl6C5I & 0,0 & 47,7 & 45,7 & 48,9 & 47,5 & 52,5 & 48,6 & 59,2 & 60,6 & 61,8 & 61,2 & 62,4 & 62,0 \\
\hline Procl6C6I & 0,0 & 38,1 & 36,5 & 39,1 & 38,0 & 42,0 & 38,9 & 47,4 & 48,5 & 49,5 & 48,9 & 49,9 & 49,6 \\
\hline Procl6C7I & 0,0 & 47,7 & 45,7 & 48,9 & 47,5 & 52,5 & 48,6 & 59,2 & 60,6 & 61,8 & 61,2 & 62,4 & 62,0 \\
\hline Procl6C8I & 0,0 & 38,1 & 36,5 & 39,1 & 38,0 & 42,0 & 38,9 & 47,4 & 48,5 & 49,5 & 48,9 & 49,9 & 49,6 \\
\hline Procl7C1I & 0,0 & 47,7 & 45,7 & 48,9 & 47,5 & 52,5 & 48,6 & 59,2 & 60,6 & 61,8 & 61,2 & 62,4 & 62,0 \\
\hline Procl7C2I & 0,0 & 38,1 & 36,5 & 39,1 & 38,0 & 42,0 & 38,9 & 47,4 & 48,5 & 49,5 & 48,9 & 49,9 & 49,6 \\
\hline Procl7C3I & 0,0 & 47,7 & 45,7 & 48,9 & 47,5 & 52,5 & 48,6 & 59,2 & 60,6 & 61,8 & 61,2 & 62,4 & 62,0 \\
\hline Procl7C4I & 0,0 & 38,1 & 36,5 & 39,1 & 38,0 & 42,0 & 38,9 & 47,4 & 48,5 & 49,5 & 48,9 & 49,9 & 49,6 \\
\hline Procl7C5I & 0,0 & 47,7 & 45,7 & 48,9 & 47,5 & 52,5 & 48,6 & 59,2 & 60,6 & 61,8 & 61,2 & 62,4 & 62,0 \\
\hline Procl7C6I & 0,0 & 38,1 & 36,5 & 39,1 & 38,0 & 42,0 & 38,9 & 47,4 & 48,5 & 49,5 & 48,9 & 49,9 & 49,6 \\
\hline Procl7C7I & 0,0 & 47,7 & 45,7 & 48,9 & 47,5 & 52,5 & 48,6 & 59,2 & 60,6 & 61,8 & 61,2 & 62,4 & 62,0 \\
\hline Procl7C8I & 0,0 & 38,1 & 36,5 & 39,1 & 38,0 & 42,0 & 38,9 & 47,4 & 48,5 & 49,5 & 48,9 & 49,9 & 49,6 \\
\hline Procl8C1I & 0,0 & 47,7 & 45,7 & 48,9 & 47,5 & 52,5 & 48,6 & 59,2 & 60,6 & 61,8 & 61,2 & 62,4 & 62,0 \\
\hline Procl8C2I & 0,0 & 38,1 & 36,5 & 39,1 & 38,0 & 42,0 & 38,9 & 47,4 & 48,5 & 49,5 & 48,9 & 49,9 & 49,6 \\
\hline Procl8C3I & 0,0 & 47,7 & 45,7 & 48,9 & 47,5 & 52,5 & 48,6 & 59,2 & 60,6 & 61,8 & 61,2 & 62,4 & 62,0 \\
\hline Procl8C4I & 0,0 & 38,1 & 36,5 & 39,1 & 38,0 & 42,0 & 38,9 & 47,4 & 48,5 & 49,5 & 48,9 & 49,9 & 49,6 \\
\hline Procl8C5I & 0,0 & 47,7 & 45,7 & 48,9 & 47,5 & 52,5 & 48,6 & 59,2 & 60,6 & 61,8 & 61,2 & 62,4 & 62,0 \\
\hline
\end{tabular}




\begin{tabular}{|c|c|c|c|c|c|c|c|c|c|c|c|c|c|}
\hline Procl8C6I & 0,0 & 38,1 & 36,5 & 39,1 & 38,0 & 42,0 & 38,9 & 47,4 & 48,5 & 49,5 & 48,9 & 49,9 & 49,6 \\
\hline Procl8C7I & 0,0 & 47,7 & 45,7 & 48,9 & 47,5 & 52,5 & 48,6 & 59,2 & 60,6 & 61,8 & 61,2 & 62,4 & 62,0 \\
\hline Procl8c8I & 0,0 & 38,1 & 36,5 & 39,1 & 38,0 & 42,0 & 38,9 & 47,4 & 48,5 & 49,5 & 48,9 & 49,9 & 49,6 \\
\hline Procl9C1I & 0,0 & 61,3 & 58,7 & 62,9 & 61,1 & 67,5 & 62,5 & 76,2 & 78,0 & 79,5 & 78,6 & 80,2 & 79,7 \\
\hline Procl9C2I & 0,0 & 49,0 & 47,0 & 50,3 & 48,9 & 54,0 & 50,0 & 60,9 & 62,4 & 63,6 & 62,9 & 64,2 & 63,8 \\
\hline Procl9c3I & 0,0 & 61,3 & 58,7 & 62,9 & 61,1 & 67,5 & 62,5 & 76,2 & 78,0 & 79,5 & 78,6 & 80,2 & 79,7 \\
\hline Procl9C4I & 0,0 & 49,0 & 47,0 & 50,3 & 48,9 & 54,0 & 50,0 & 60,9 & 62,4 & 63,6 & 62,9 & 64,2 & 63,8 \\
\hline Procl9C5I & 0,0 & 61,3 & 58,7 & 62,9 & 61,1 & 67,5 & 62,5 & 76,2 & 78,0 & 79,5 & 78,6 & 80,2 & 79,7 \\
\hline Procl9C6I & 0,0 & 49,0 & 47,0 & 50,3 & 48,9 & 54,0 & 50,0 & 60,9 & 62,4 & 63,6 & 62,9 & 64,2 & 63,8 \\
\hline Procl9C7I & 0,0 & 61,3 & 58,7 & 62,9 & 61,1 & 67,5 & 62,5 & 76,2 & 78,0 & 79,5 & 78,6 & 80,2 & 79,7 \\
\hline Procl9C8I & 0,0 & 49,0 & 47,0 & 50,3 & 48,9 & 54,0 & 50,0 & 60,9 & 62,4 & 63,6 & 62,9 & 64,2 & 63,8 \\
\hline Procl10c1l & 0,0 & 61,3 & 58,7 & 62,9 & 61,1 & 67,5 & 62,5 & 76,2 & 78,0 & 79,5 & 78,6 & 80,2 & 79,7 \\
\hline Procl10C2I & 0,0 & 49,0 & 47,0 & 50,3 & 48,9 & 54,0 & 50,0 & 60,9 & 62,4 & 63,6 & 62,9 & 64,2 & 63,8 \\
\hline Procl10C3I & 0,0 & 61,3 & 58,7 & 62,9 & 61,1 & 67,5 & 62,5 & 76,2 & 78,0 & 79,5 & 78,6 & 80,2 & 79,7 \\
\hline Procl10c4I & 0,0 & 49,0 & 47,0 & 50,3 & 48,9 & 54,0 & 50,0 & 60,9 & 62,4 & 63,6 & 62,9 & 64,2 & 63,8 \\
\hline Procl10C5I & 0,0 & 61,3 & 58,7 & 62,9 & 61,1 & 67,5 & 62,5 & 76,2 & 78,0 & 79,5 & 78,6 & 80,2 & 79,7 \\
\hline Procl10C6I & 0,0 & 49,0 & 47,0 & 50,3 & 48,9 & 54,0 & 50,0 & 60,9 & 62,4 & 63,6 & 62,9 & 64,2 & 63,8 \\
\hline Procl10C7I & 0,0 & 61,3 & 58,7 & 62,9 & 61,1 & 67,5 & 62,5 & 76,2 & 78,0 & 79,5 & 78,6 & 80,2 & 79,7 \\
\hline Procl10C8I & 0,0 & 49,0 & 47,0 & 50,3 & 48,9 & 54,0 & 50,0 & 60,9 & 62,4 & 63,6 & 62,9 & 64,2 & 63,8 \\
\hline Procl11C1I & 0,0 & 61,3 & 58,7 & 62,9 & 61,1 & 67,5 & 62,5 & 76,2 & 78,0 & 79,5 & 78,6 & 80,2 & 79,7 \\
\hline Procl11C2I & 0,0 & 49,0 & 47,0 & 50,3 & 48,9 & 54,0 & 50,0 & 60,9 & 62,4 & 63,6 & 62,9 & 64,2 & 63,8 \\
\hline Procl11C3I & 0,0 & 61,3 & 58,7 & 62,9 & 61,1 & 67,5 & 62,5 & 76,2 & 78,0 & 79,5 & 78,6 & 80,2 & 79,7 \\
\hline Procl11C4I & 0,0 & 49,0 & 47,0 & 50,3 & 48,9 & 54,0 & 50,0 & 60,9 & 62,4 & 63,6 & 62,9 & 64,2 & 63,8 \\
\hline Procl11C5I & 0,0 & 61,3 & 58,7 & 62,9 & 61,1 & 67,5 & 62,5 & 76,2 & 78,0 & 79,5 & 78,6 & 80,2 & 79,7 \\
\hline Procl11C6I & 0,0 & 49,0 & 47,0 & 50,3 & 48,9 & 54,0 & 50,0 & 60,9 & 62,4 & 63,6 & 62,9 & 64,2 & 63,8 \\
\hline Procl11C7I & 0,0 & 61,3 & 58,7 & 62,9 & 61,1 & 67,5 & 62,5 & 76,2 & 78,0 & 79,5 & 78,6 & 80,2 & 79,7 \\
\hline Procl11C8I & 0,0 & 49,0 & 47,0 & 50,3 & 48,9 & 54,0 & 50,0 & 60,9 & 62,4 & 63,6 & 62,9 & 64,2 & 63,8 \\
\hline Procl12C1I & 0,0 & 61,3 & 58,7 & 62,9 & 61,1 & 67,5 & 62,5 & 76,2 & 78,0 & 79,5 & 78,6 & 80,2 & 79,7 \\
\hline Procl12C2I & 0,0 & 49,0 & 47,0 & 50,3 & 48,9 & 54,0 & 50,0 & 60,9 & 62,4 & 63,6 & 62,9 & 64,2 & 63,8 \\
\hline Procl12C3I & 0,0 & 61,3 & 58,7 & 62,9 & 61,1 & 67,5 & 62,5 & 76,2 & 78,0 & 79,5 & 78,6 & 80,2 & 79,7 \\
\hline Procl12C4I & 0,0 & 49,0 & 47,0 & 50,3 & 48,9 & 54,0 & 50,0 & 60,9 & 62,4 & 63,6 & 62,9 & 64,2 & 63,8 \\
\hline Procl12C5I & 0,0 & 61,3 & 58,7 & 62,9 & 61,1 & 67,5 & 62,5 & 76,2 & 78,0 & 79,5 & 78,6 & 80,2 & 79,7 \\
\hline Procl12C6I & 0,0 & 49,0 & 47,0 & 50,3 & 48,9 & 54,0 & 50,0 & 60,9 & 62,4 & 63,6 & 62,9 & 64,2 & 63,8 \\
\hline Procl12C7I & 0,0 & 61,3 & 58,7 & 62,9 & 61,1 & 67,5 & 62,5 & 76,2 & 78,0 & 79,5 & 78,6 & 80,2 & 79,7 \\
\hline Procl12C8I & 0,0 & 49,0 & 47,0 & 50,3 & 48,9 & 54,0 & 50,0 & 60,9 & 62,4 & 63,6 & 62,9 & 64,2 & 63,8 \\
\hline Procl13C1I & 0,0 & 75,9 & 72,7 & 77,9 & 75,7 & 83,6 & 77,4 & 94,3 & 96,5 & 98,4 & 97,4 & 99,3 & 98,7 \\
\hline Procl13C2I & 0,0 & 60,7 & 58,1 & 62,3 & 60,6 & 66,9 & 61,9 & 75,4 & 77,2 & 78,7 & 77,9 & 79,4 & 78,9 \\
\hline Procl13C3I & 0,0 & 75,9 & 72,7 & 77,9 & 75,7 & 83,6 & 77,4 & 94,3 & 96,5 & 98,4 & 97,4 & 99,3 & 98,7 \\
\hline Procl13C4I & 0,0 & 60,7 & 58,1 & 62,3 & 60,6 & 66,9 & 61,9 & 75,4 & 77,2 & 78,7 & 77,9 & 79,4 & 78,9 \\
\hline Procl13C5I & 0,0 & 75,9 & 72,7 & 77,9 & 75,7 & 83,6 & 77,4 & 94,3 & 96,5 & 98,4 & 97,4 & 99,3 & 98,7 \\
\hline Procl13C6I & 0,0 & 60,7 & 58,1 & 62,3 & 60,6 & 66,9 & 61,9 & 75,4 & 77,2 & 78,7 & 77,9 & 79,4 & 78,9 \\
\hline Procl13C7I & 0,0 & 75,9 & 72,7 & 77,9 & 75,7 & 83,6 & 77,4 & 94,3 & 96,5 & 98,4 & 97,4 & 99,3 & 98,7 \\
\hline Procl13C8I & 0,0 & 60,7 & 58,1 & 62,3 & 60,6 & 66,9 & 61,9 & 75,4 & 77,2 & 78,7 & 77,9 & 79,4 & 78,9 \\
\hline Procl14C1I & 0,0 & 75,9 & 72,7 & 77,9 & 75,7 & 83,6 & 77,4 & 94,3 & 96,5 & 98,4 & 97,4 & 99,3 & 98,7 \\
\hline Procl14C2I & 0,0 & 60,7 & 58,1 & 62,3 & 60,6 & 66,9 & 61,9 & 75,4 & 77,2 & 78,7 & 77,9 & 79,4 & 78,9 \\
\hline Procl14C3I & 0,0 & 75,9 & 72,7 & 77,9 & 75,7 & 83,6 & 77,4 & 94,3 & 96,5 & 98,4 & 97,4 & 99,3 & 98,7 \\
\hline Procl14C4I & 0,0 & 60,7 & 58,1 & 62,3 & 60,6 & 66,9 & 61,9 & 75,4 & 77,2 & 78,7 & 77,9 & 79,4 & 78,9 \\
\hline Procl14C5I & 0,0 & 75,9 & 72,7 & 77,9 & 75,7 & 83,6 & 77,4 & 94,3 & 96,5 & 98,4 & 97,4 & 99,3 & 98,7 \\
\hline Procl14C6I & 0,0 & 60,7 & 58,1 & 62,3 & 60,6 & 66,9 & 61,9 & 75,4 & 77,2 & 78,7 & 77,9 & 79,4 & 78,9 \\
\hline Procl14C7I & 0,0 & 75,9 & 72,7 & 77,9 & 75,7 & 83,6 & 77,4 & 94,3 & 96,5 & 98,4 & 97,4 & 99,3 & 98,7 \\
\hline Procl14C8I & 0,0 & 60,7 & 58,1 & 62,3 & 60,6 & 66,9 & 61,9 & 75,4 & 77,2 & 78,7 & 77,9 & 79,4 & 78,9 \\
\hline Procl15C1I & 0,0 & 75,9 & 72,7 & 77,9 & 75,7 & 83,6 & 77,4 & 94,3 & 96,5 & 98,4 & 97,4 & 99,3 & 98,7 \\
\hline Procl15C2I & 0,0 & 60,7 & 58,1 & 62,3 & 60,6 & 66,9 & 61,9 & 75,4 & 77,2 & 78,7 & 77,9 & 79,4 & 78,9 \\
\hline Procl15C3I & 0,0 & 75,9 & 72,7 & 77,9 & 75,7 & 83,6 & 77,4 & 94,3 & 96,5 & 98,4 & 97,4 & 99,3 & 98,7 \\
\hline Procl15C4I & 0,0 & 60,7 & 58,1 & 62,3 & 60,6 & 66,9 & 61,9 & 75,4 & 77,2 & 78,7 & 77,9 & 79,4 & 78,9 \\
\hline Procl15C5I & 0,0 & 75,9 & 72,7 & 77,9 & 75,7 & 83,6 & 77,4 & 94,3 & 96,5 & 98,4 & 97,4 & 99,3 & 98,7 \\
\hline Procl15C6I & 0,0 & 60,7 & 58,1 & 62,3 & 60,6 & 66,9 & 61,9 & 75,4 & 77,2 & 78,7 & 77,9 & 79,4 & 78,9 \\
\hline Procl15C7I & 0,0 & 75,9 & 72,7 & 77,9 & 75,7 & 83,6 & 77,4 & 94,3 & 96,5 & 98,4 & 97,4 & 99,3 & 98,7 \\
\hline Procl15C8I & 0,0 & 60,7 & 58,1 & 62,3 & 60,6 & 66,9 & 61,9 & 75,4 & 77,2 & 78,7 & 77,9 & 79,4 & 78,9 \\
\hline Procl16C1I & 0,0 & 75,9 & 72,7 & 77,9 & 75,7 & 83,6 & 77,4 & 94,3 & 96,5 & 98,4 & 97,4 & 99,3 & 98,7 \\
\hline Procl16C2I & 0,0 & 60,7 & 58,1 & 62,3 & 60,6 & 66,9 & 61,9 & 75,4 & 77,2 & 78,7 & 77,9 & 79,4 & 78,9 \\
\hline Procl16C3I & 0,0 & 75,9 & 72,7 & 77,9 & 75,7 & 83,6 & 77,4 & 94,3 & 96,5 & 98,4 & 97,4 & 99,3 & 98,7 \\
\hline Procl16C4I & 0,0 & 60,7 & 58,1 & 62,3 & 60,6 & 66,9 & 61,9 & 75,4 & 77,2 & 78,7 & 77,9 & 79,4 & 78,9 \\
\hline
\end{tabular}




\begin{tabular}{|c|c|c|c|c|c|c|c|c|c|c|c|c|c|}
\hline Procl16C5I & 0,0 & 75,9 & 72,7 & 77,9 & 75,7 & 83,6 & 77,4 & 94,3 & 96,5 & 98,4 & 97,4 & 99,3 & 98,7 \\
\hline Procl16C6I & 0,0 & 60,7 & 58,1 & 62,3 & 60,6 & 66,9 & 61,9 & 75,4 & 77,2 & 78,7 & 77,9 & 79,4 & 78,9 \\
\hline Procl16C7I & 0,0 & 75,9 & 72,7 & 77,9 & 75,7 & 83,6 & 77,4 & 94,3 & 96,5 & 98,4 & 97,4 & 99,3 & 98,7 \\
\hline Procl16C8I & 0,0 & 60,7 & 58,1 & 62,3 & 60,6 & 66,9 & 61,9 & 75,4 & 77,2 & 78,7 & 77,9 & 79,4 & 78,9 \\
\hline Procl17C1I & 0,0 & 89,5 & 85,7 & 91,8 & 89,3 & 98,6 & 91,3 & 111,2 & 113,8 & 116,1 & 114,8 & 117,1 & 116,4 \\
\hline Procl17C2| & 0,0 & 71,6 & 68,6 & 73,5 & 71,4 & 78,9 & 73,1 & 89,0 & 91,1 & 92,9 & 91,9 & 93,7 & 93,1 \\
\hline Procl17C3! & 0,0 & 89,5 & 85,7 & 91,8 & 89,3 & 98,6 & 91,3 & 111,2 & 113,8 & 116,1 & 114,8 & 117,1 & 116,4 \\
\hline Procl17C4| & 0,0 & 71,6 & 68,6 & 73,5 & 71,4 & 78,9 & 73,1 & 89,0 & 91,1 & 92,9 & 91,9 & 93,7 & 93,1 \\
\hline Procl17C5I & 0,0 & 89,5 & 85,7 & 91,8 & 89,3 & 98,6 & 91,3 & 111,2 & 113,8 & 116,1 & 114,8 & 117,1 & 116,4 \\
\hline Procl17C6I & 0,0 & 71,6 & 68,6 & 73,5 & 71,4 & 78,9 & 73,1 & 89,0 & 91,1 & 92,9 & 91,9 & 93,7 & 93,1 \\
\hline Procl17C7| & 0,0 & 89,5 & 85,7 & 91,8 & 89,3 & 98,6 & 91,3 & 111,2 & 113,8 & 116,1 & 114,8 & 117,1 & 116,4 \\
\hline Procl17C8I & 0,0 & 71,6 & 68,6 & 73,5 & 71,4 & 78,9 & 73,1 & 89,0 & 91,1 & 92,9 & 91,9 & 93,7 & 93,1 \\
\hline Procl18C1I & 0,0 & 89,5 & 85,7 & 91,8 & 89,3 & 98,6 & 91,3 & 111,2 & 113,8 & 116,1 & 114,8 & 117,1 & 116,4 \\
\hline Procl18C2I & 0,0 & 71,6 & 68,6 & 73,5 & 71,4 & 78,9 & 73,1 & 89,0 & 91,1 & 92,9 & 91,9 & 93,7 & 93,1 \\
\hline Procl18C3I & 0,0 & 89,5 & 85,7 & 91,8 & 89,3 & 98,6 & 91,3 & 111,2 & 113,8 & 116,1 & 114,8 & 117,1 & 116,4 \\
\hline Procl18C4| & 0,0 & 71,6 & 68,6 & 73,5 & 71,4 & 78,9 & 73,1 & 89,0 & 91,1 & 92,9 & 91,9 & 93,7 & 93,1 \\
\hline Procl18C5I & 0,0 & 89,5 & 85,7 & 91,8 & 89,3 & 98,6 & 91,3 & 111,2 & 113,8 & 116,1 & 114,8 & 117,1 & 116,4 \\
\hline Procl18C6I & 0,0 & 71,6 & 68,6 & 73,5 & 71,4 & 78,9 & 73,1 & 89,0 & 91,1 & 92,9 & 91,9 & 93,7 & 93,1 \\
\hline Procl18C7I & 0,0 & 89,5 & 85,7 & 91,8 & 89,3 & 98,6 & 91,3 & 111,2 & 113,8 & 116,1 & 114,8 & 117,1 & 116,4 \\
\hline Procl18C8I & 0,0 & 71,6 & 68,6 & 73,5 & 71,4 & 78,9 & 73,1 & 89,0 & 91,1 & 92,9 & 91,9 & 93,7 & 93,1 \\
\hline Procl19C1I & 0,0 & 89,5 & 85,7 & 91,8 & 89,3 & 98,6 & 91,3 & 111,2 & 113,8 & 116,1 & 114,8 & 117,1 & 116,4 \\
\hline Procl19C2l & 0,0 & 71,6 & 68,6 & 73,5 & 71,4 & 78,9 & 73,1 & 89,0 & 91,1 & 92,9 & 91,9 & 93,7 & 93,1 \\
\hline Procl19C3I & 0,0 & 89,5 & 85,7 & 91,8 & 89,3 & 98,6 & 91,3 & 111,2 & 113,8 & 116,1 & 114,8 & 117,1 & 116,4 \\
\hline Procl19C4I & 0,0 & 71,6 & 68,6 & 73,5 & 71,4 & 78,9 & 73,1 & 89,0 & 91,1 & 92,9 & 91,9 & 93,7 & 93,1 \\
\hline Procl19C5I & 0,0 & 89,5 & 85,7 & 91,8 & 89,3 & 98,6 & 91,3 & 111,2 & 113,8 & 116,1 & 114,8 & 117,1 & 116,4 \\
\hline Procl19C6I & 0,0 & 71,6 & 68,6 & 73,5 & 71,4 & 78,9 & 73,1 & 89,0 & 91,1 & 92,9 & 91,9 & 93,7 & 93,1 \\
\hline Procl19C7I & 0,0 & 89,5 & 85,7 & 91,8 & 89,3 & 98,6 & 91,3 & 111,2 & 113,8 & 116,1 & 114,8 & 117,1 & 116,4 \\
\hline Procl19C8I & 0,0 & 71,6 & 68,6 & 73,5 & 71,4 & 78,9 & 73,1 & 89,0 & 91,1 & 92,9 & 91,9 & 93,7 & 93,1 \\
\hline Procl20C1I & 0,0 & 89,5 & 85,7 & 91,8 & 89,3 & 98,6 & 91,3 & 111,2 & 113,8 & 116,1 & 114,8 & 117,1 & 116,4 \\
\hline Procl20C2l & 0,0 & 71,6 & 68,6 & 73,5 & 71,4 & 78,9 & 73,1 & 89,0 & 91,1 & 92,9 & 91,9 & 93,7 & 93,1 \\
\hline Procl20C3I & 0,0 & 89,5 & 85,7 & 91,8 & 89,3 & 98,6 & 91,3 & 111,2 & 113,8 & 116,1 & 114,8 & 117,1 & 116,4 \\
\hline Procl20C4I & 0,0 & 71,6 & 68,6 & 73,5 & 71,4 & 78,9 & 73,1 & 89,0 & 91,1 & 92,9 & 91,9 & 93,7 & 93,1 \\
\hline Procl20C5I & 0,0 & 89,5 & 85,7 & 91,8 & 89,3 & 98,6 & 91,3 & 111,2 & 113,8 & 116,1 & 114,8 & 117,1 & 116,4 \\
\hline Procl20C6I & 0,0 & 71,6 & 68,6 & 73,5 & 71,4 & 78,9 & 73,1 & 89,0 & 91,1 & 92,9 & 91,9 & 93,7 & 93,1 \\
\hline Procl20C7I & 0,0 & 89,5 & 85,7 & 91,8 & 89,3 & 98,6 & 91,3 & 111,2 & 113,8 & 116,1 & 114,8 & 117,1 & 116,4 \\
\hline Procl20C8I & 0,0 & 71,6 & 68,6 & 73,5 & 71,4 & 78,9 & 73,1 & 89,0 & 91,1 & 92,9 & 91,9 & 93,7 & 93,1 \\
\hline Procl21C1I & 0,0 & 104,1 & 99,7 & 106,8 & 103,8 & 114,7 & 106,2 & 129,4 & 132,4 & 135,0 & 133,6 & 136,2 & 135,3 \\
\hline Procl21C2l & 0,0 & 83,3 & 79,8 & 85,5 & 83,1 & 91,8 & 85,0 & 103,5 & 105,9 & 108,0 & 106,8 & 109,0 & 108,3 \\
\hline Procl21C3I & 0,0 & 104,1 & 99,7 & 106,8 & 103,8 & 114,7 & 106,2 & 129,4 & 132,4 & 135,0 & 133,6 & 136,2 & 135,3 \\
\hline Procl21C4I & 0,0 & 83,3 & 79,8 & 85,5 & 83,1 & 91,8 & 85,0 & 103,5 & 105,9 & 108,0 & 106,8 & 109,0 & 108,3 \\
\hline Procl21C5I & 0,0 & 104,1 & 99,7 & 106,8 & 103,8 & 114,7 & 106,2 & 129,4 & 132,4 & 135,0 & 133,6 & 136,2 & 135,3 \\
\hline Procl21C6I & 0,0 & 83,3 & 79,8 & 85,5 & 83,1 & 91,8 & 85,0 & 103,5 & 105,9 & 108,0 & 106,8 & 109,0 & 108,3 \\
\hline Procl21C7I & 0,0 & 104,1 & 99,7 & 106,8 & 103,8 & 114,7 & 106,2 & 129,4 & 132,4 & 135,0 & 133,6 & 136,2 & 135,3 \\
\hline Procl21C8I & 0,0 & 83,3 & 79,8 & 85,5 & 83,1 & 91,8 & 85,0 & 103,5 & 105,9 & 108,0 & 106,8 & 109,0 & 108,3 \\
\hline Procl22C1I & 0,0 & 104,1 & 99,7 & 106,8 & 103,8 & 114,7 & 106,2 & 129,4 & 132,4 & 135,0 & 133,6 & 136,2 & 135,3 \\
\hline Procl22C2I & 0,0 & 83,3 & 79,8 & 85,5 & 83,1 & 91,8 & 85,0 & 103,5 & 105,9 & 108,0 & 106,8 & 109,0 & 108,3 \\
\hline Procl22C3I & 0,0 & 104,1 & 99,7 & 106,8 & 103,8 & 114,7 & 106,2 & 129,4 & 132,4 & 135,0 & 133,6 & 136,2 & 135,3 \\
\hline Procl22C4I & 0,0 & 83,3 & 79,8 & 85,5 & 83,1 & 91,8 & 85,0 & 103,5 & 105,9 & 108,0 & 106,8 & 109,0 & 108,3 \\
\hline Procl22C5I & 0,0 & 104,1 & 99,7 & 106,8 & 103,8 & 114,7 & 106,2 & 129,4 & 132,4 & 135,0 & 133,6 & 136,2 & 135,3 \\
\hline Procl22C6I & 0,0 & 83,3 & 79,8 & 85,5 & 83,1 & 91,8 & 85,0 & 103,5 & 105,9 & 108,0 & 106,8 & 109,0 & 108,3 \\
\hline Procl22C7I & 0,0 & 104,1 & 99,7 & 106,8 & 103,8 & 114,7 & 106,2 & 129,4 & 132,4 & 135,0 & 133,6 & 136,2 & 135,3 \\
\hline Procl22C8I & 0,0 & 83,3 & 79,8 & 85,5 & 83,1 & 91,8 & 85,0 & 103,5 & 105,9 & 108,0 & 106,8 & 109,0 & 108,3 \\
\hline Procl23C1I & 0,0 & 104,1 & 99,7 & 106,8 & 103,8 & 114,7 & 106,2 & 129,4 & 132,4 & 135,0 & 133,6 & 136,2 & 135,3 \\
\hline Procl23C2l & 0,0 & 83,3 & 79,8 & 85,5 & 83,1 & 91,8 & 85,0 & 103,5 & 105,9 & 108,0 & 106,8 & 109,0 & 108,3 \\
\hline Procl23C3I & 0,0 & 104,1 & 99,7 & 106,8 & 103,8 & 114,7 & 106,2 & 129,4 & 132,4 & 135,0 & 133,6 & 136,2 & 135,3 \\
\hline Procl23C4I & 0,0 & 83,3 & 79,8 & 85,5 & 83,1 & 91,8 & 85,0 & 103,5 & 105,9 & 108,0 & 106,8 & 109,0 & 108,3 \\
\hline Procl23C5I & 0,0 & 104,1 & 99,7 & 106,8 & 103,8 & 114,7 & 106,2 & 129,4 & 132,4 & 135,0 & 133,6 & 136,2 & 135,3 \\
\hline Procl23C6I & 0,0 & 83,3 & 79,8 & 85,5 & 83,1 & 91,8 & 85,0 & 103,5 & 105,9 & 108,0 & 106,8 & 109,0 & 108,3 \\
\hline Procl23C7I & 0,0 & 104,1 & 99,7 & 106,8 & 103,8 & 114,7 & 106,2 & 129,4 & 132,4 & 135,0 & 133,6 & 136,2 & 135,3 \\
\hline Procl23C8I & 0,0 & 83,3 & 79,8 & 85,5 & 83,1 & 91,8 & 85,0 & 103,5 & 105,9 & 108,0 & 106,8 & 109,0 & 108,3 \\
\hline Procl24C1I & 0,0 & 104,1 & 99,7 & 106,8 & 103,8 & 114,7 & 106,2 & 129,4 & 132,4 & 135,0 & 133,6 & 136,2 & 135,3 \\
\hline Procl24C2I & 0,0 & 83,3 & 79,8 & 85,5 & 83,1 & 91,8 & 85,0 & 103,5 & 105,9 & 108,0 & 106,8 & 109,0 & 108,3 \\
\hline Procl24C3I & 0,0 & 104,1 & 99,7 & 106,8 & 103,8 & 114,7 & 106,2 & 129,4 & 132,4 & 135,0 & 133,6 & 136,2 & 135,3 \\
\hline
\end{tabular}




\begin{tabular}{|c|c|c|c|c|c|c|c|c|c|c|c|c|c|}
\hline Procl24C4I & 0,0 & 83,3 & 79,8 & 85,5 & 83,1 & 91,8 & 85,0 & 103,5 & 105,9 & 108,0 & 106,8 & 109,0 & 108,3 \\
\hline Procl24C5I & 0,0 & 104,1 & 99,7 & 106,8 & 103,8 & 114,7 & 106,2 & 129,4 & 132,4 & 135,0 & 133,6 & 136,2 & 135,3 \\
\hline Procl24C6I & 0,0 & 83,3 & 79,8 & 85,5 & 83,1 & 91,8 & 85,0 & 103,5 & 105,9 & 108,0 & 106,8 & 109,0 & 108,3 \\
\hline Procl24C7I & 0,0 & 104,1 & 99,7 & 106,8 & 103,8 & 114,7 & 106,2 & 129,4 & 132,4 & 135,0 & 133,6 & 136,2 & 135,3 \\
\hline Procl24C8I & 0,0 & 83,3 & 79,8 & 85,5 & 83,1 & 91,8 & 85,0 & 103,5 & 105,9 & 108,0 & 106,8 & 109,0 & 108,3 \\
\hline Procl1C1E & 0,0 & 3,9 & 3,8 & 3,9 & 3,9 & 4,0 & 3,9 & 4,6 & 4,6 & 4,7 & 4,6 & 4,7 & 4,7 \\
\hline Procl1C2E & 0,0 & 4,5 & 4,4 & 4,6 & 4,5 & 4,7 & 4,5 & 5,4 & 5,4 & 5,5 & 5,4 & 5,5 & 5,5 \\
\hline Procl1C3E & 0,0 & 5,3 & 5,2 & 5,4 & 5,3 & 5,5 & 5,4 & 6,3 & 6,4 & 6,4 & 6,4 & 6,4 & 6,4 \\
\hline Procl1C4E & 0,0 & 5,9 & 5,8 & 6,0 & 5,9 & 6,2 & 6,0 & 7,1 & 7,2 & 7,2 & 7,2 & 7,2 & 7,2 \\
\hline Procl1C5E & 0,0 & 6,1 & 6,0 & 6,2 & 6,1 & 6,4 & 6,2 & 7,3 & 7,4 & 7,4 & 7,4 & 7,4 & 7,4 \\
\hline Procl1C6E & 0,0 & 6,8 & 6,6 & 6,9 & 6,8 & 7,0 & 6,8 & 8,1 & 8,1 & 8,2 & 8,2 & 8,2 & 8,2 \\
\hline Procl1C7E & 0,0 & 7,6 & 7,5 & 7,7 & 7,6 & 7,9 & 7,6 & 9,0 & 9,1 & 9,2 & 9,1 & 9,2 & 9,2 \\
\hline Procl1C8E & 0,0 & 8,2 & 8,1 & 8,3 & 8,2 & 8,5 & 8,3 & 9,8 & 9,9 & 10,0 & 9,9 & 10,0 & 10,0 \\
\hline Procl2C1E & 0,0 & 3,8 & 3,8 & 3,9 & 3,8 & 3,9 & 3,8 & 4,5 & 4,6 & 4,6 & 4,6 & 4,6 & 4,6 \\
\hline Procl2C2E & 0,0 & 4,4 & 4,4 & 4,5 & 4,4 & 4,6 & 4,5 & 5,3 & 5,3 & 5,4 & 5,4 & 5,4 & 5,4 \\
\hline Procl2C3E & 0,0 & 6,7 & 6,6 & 6,8 & 6,7 & 7,0 & 6,8 & 8,0 & 8,0 & 8,1 & 8,1 & 8,1 & 8,1 \\
\hline Procl2C4E & 0,0 & 7,3 & 7,2 & 7,4 & 7,3 & 7,6 & 7,4 & 8,7 & 8,8 & 8,9 & 8,9 & 8,9 & 8,9 \\
\hline Procl2C5E & 0,0 & 4,6 & 4,5 & 4,6 & 4,6 & 4,7 & 4,6 & 5,4 & 5,5 & 5,5 & 5,5 & 5,5 & 5,5 \\
\hline Procl2C6E & 0,0 & 5,2 & 5,1 & 5,3 & 5,2 & 5,4 & 5,2 & 6,2 & 6,2 & 6,3 & 6,3 & 6,3 & 6,3 \\
\hline Procl2C7E & 0,0 & 7,5 & 7,3 & 7,6 & 7,5 & 7,7 & 7,5 & 8,9 & 9,0 & 9,0 & 9,0 & 9,1 & 9,0 \\
\hline Procl2C8E & 0,0 & 8,1 & 7,9 & 8,2 & 8,1 & 8,4 & 8,1 & 9,6 & 9,7 & 9,8 & 9,8 & 9,9 & 9,8 \\
\hline Procl3C1E & 0,0 & 3,7 & 3,7 & 3,8 & 3,7 & 3,9 & 3,8 & 4,5 & 4,5 & 4,5 & 4,5 & 4,6 & 4,5 \\
\hline Procl3C2E & 0,0 & 4,4 & 4,3 & 4,4 & 4,4 & 4,6 & 4,4 & 5,2 & 5,3 & 5,3 & 5,3 & 5,4 & 5,3 \\
\hline Procl3C3E & 0,0 & 5,2 & 5,1 & 5,3 & 5,2 & 5,4 & 5,2 & 6,2 & 6,3 & 6,3 & 6,3 & 6,3 & 6,3 \\
\hline Procl3C4E & 0,0 & 5,8 & 5,7 & 5,9 & 5,8 & 6,1 & 5,9 & 7,0 & 7,0 & 7,1 & 7,1 & 7,2 & 7,1 \\
\hline Procl3C5E & 0,0 & 6,0 & 5,9 & 6,1 & 6,0 & 6,3 & 6,1 & 7,2 & 7,3 & 7,3 & 7,3 & 7,3 & 7,3 \\
\hline Procl3C6E & 0,0 & 6,6 & 6,5 & 6,8 & 6,6 & 7,0 & 6,7 & 8,0 & 8,0 & 8,1 & 8,1 & 8,2 & 8,1 \\
\hline Procl3C7E & 0,0 & 7,5 & 7,3 & 7,6 & 7,5 & 7,8 & 7,6 & 8,9 & 9,0 & 9,1 & 9,1 & 9,1 & 9,1 \\
\hline Procl3C8E & 0,0 & 8,1 & 7,9 & 8,2 & 8,1 & 8,5 & 8,2 & 9,7 & 9,8 & 9,9 & 9,8 & 9,9 & 9,9 \\
\hline Procl4C1E & 0,0 & 3,7 & 3,6 & 3,7 & 3,7 & 3,8 & 3,7 & 4,4 & 4,4 & 4,5 & 4,5 & 4,5 & 4,5 \\
\hline Procl4C2E & 0,0 & 4,3 & 4,2 & 4,4 & 4,3 & 4,5 & 4,3 & 5,2 & 5,2 & 5,3 & 5,2 & 5,3 & 5,3 \\
\hline Procl4C3E & 0,0 & 6,6 & 6,5 & 6,7 & 6,6 & 6,9 & 6,7 & 7,9 & 8,0 & 8,0 & 8,0 & 8,1 & 8,0 \\
\hline Procl4C4E & 0,0 & 7,2 & 7,1 & 7,3 & 7,2 & 7,6 & 7,3 & 8,6 & 8,7 & 8,8 & 8,8 & 8,9 & 8,8 \\
\hline Procl4C5E & 0,0 & 4,4 & 4,4 & 4,5 & 4,4 & 4,6 & 4,5 & 5,3 & 5,3 & 5,4 & 5,4 & 5,4 & 5,4 \\
\hline Procl4C6E & 0,0 & 5,1 & 5,0 & 5,1 & 5,1 & 5,3 & 5,1 & 6,1 & 6,1 & 6,2 & 6,2 & 6,2 & 6,2 \\
\hline Procl4C7E & 0,0 & 7,4 & 7,2 & 7,5 & 7,4 & 7,7 & 7,4 & 8,8 & 8,9 & 8,9 & 8,9 & 9,0 & 8,9 \\
\hline Procl4C8E & 0,0 & 8,0 & 7,8 & 8,1 & 8,0 & 8,4 & 8,1 & 9,6 & 9,6 & 9,7 & 9,7 & 9,8 & 9,7 \\
\hline Procl5C1E & 0,0 & 3,3 & 3,3 & 3,4 & 3,4 & 3,4 & 3,4 & 4,0 & 4,0 & 4,0 & 4,0 & 4,0 & 4,0 \\
\hline Procl5C2E & 0,0 & 4,2 & 4,2 & 4,3 & 4,2 & 4,4 & 4,3 & 5,1 & 5,1 & 5,1 & 5,1 & 5,1 & 5,1 \\
\hline Procl5C3E & 0,0 & 4,6 & 4,5 & 4,6 & 4,6 & 4,7 & 4,6 & 5,4 & 5,4 & 5,5 & 5,4 & 5,5 & 5,5 \\
\hline Procl5C4E & 0,0 & 5,5 & 5,4 & 5,5 & 5,5 & 5,7 & 5,5 & 6,5 & 6,6 & 6,6 & 6,6 & 6,6 & 6,6 \\
\hline Procl5C5E & 0,0 & 5,3 & 5,2 & 5,3 & 5,3 & 5,4 & 5,3 & 6,2 & 6,3 & 6,3 & 6,3 & 6,3 & 6,3 \\
\hline Procl5C6E & 0,0 & 6,1 & 6,0 & 6,2 & 6,1 & 6,4 & 6,2 & 7,3 & 7,4 & 7,4 & 7,4 & 7,5 & 7,4 \\
\hline Procl5C7E & 0,0 & 6,5 & 6,4 & 6,6 & 6,5 & 6,7 & 6,5 & 7,7 & 7,7 & 7,8 & 7,7 & 7,8 & 7,8 \\
\hline Procl5C8E & 0,0 & 7,4 & 7,2 & 7,5 & 7,4 & 7,6 & 7,4 & 8,8 & 8,8 & 8,9 & 8,9 & 8,9 & 8,9 \\
\hline Procl6C1E & 0,0 & 3,3 & 3,3 & 3,3 & 3,3 & 3,4 & 3,3 & 3,9 & 3,9 & 3,9 & 3,9 & 3,9 & 3,9 \\
\hline Procl6C2E & 0,0 & 4,2 & 4,1 & 4,2 & 4,2 & 4,3 & 4,2 & 5,0 & 5,0 & 5,1 & 5,1 & 5,1 & 5,1 \\
\hline Procl6C3E & 0,0 & 5,7 & 5,7 & 5,8 & 5,7 & 5,9 & 5,8 & 6,8 & 6,8 & 6,9 & 6,8 & 6,9 & 6,9 \\
\hline Procl6C4E & 0,0 & 6,6 & 6,5 & 6,7 & 6,6 & 6,9 & 6,7 & 7,9 & 8,0 & 8,0 & 8,0 & 8,0 & 8,0 \\
\hline Procl6C5E & 0,0 & 3,9 & 3,9 & 4,0 & 3,9 & 4,0 & 4,0 & 4,6 & 4,7 & 4,7 & 4,7 & 4,7 & 4,7 \\
\hline Procl6C6E & 0,0 & 4,8 & 4,7 & 4,9 & 4,8 & 5,0 & 4,9 & 5,7 & 5,8 & 5,8 & 5,8 & 5,9 & 5,8 \\
\hline Procl6C7E & 0,0 & 6,4 & 6,3 & 6,4 & 6,4 & 6,6 & 6,4 & 7,5 & 7,6 & 7,6 & 7,6 & 7,7 & 7,6 \\
\hline Procl6C8E & 0,0 & 7,3 & 7,1 & 7,4 & 7,3 & 7,5 & 7,3 & 8,6 & 8,7 & 8,8 & 8,8 & 8,8 & 8,8 \\
\hline Procl7C1E & 0,0 & 3,2 & 3,1 & 3,2 & 3,2 & 3,3 & 3,2 & 3,8 & 3,8 & 3,8 & 3,8 & 3,8 & 3,8 \\
\hline Procl7C2E & 0,0 & 4,1 & 4,0 & 4,1 & 4,0 & 4,3 & 4,1 & 4,9 & 4,9 & 5,0 & 4,9 & 5,0 & 5,0 \\
\hline Procl7C3E & 0,0 & 4,4 & 4,3 & 4,5 & 4,4 & 4,6 & 4,4 & 5,2 & 5,3 & 5,3 & 5,3 & 5,3 & 5,3 \\
\hline Procl7C4E & 0,0 & 5,3 & 5,2 & 5,4 & 5,3 & 5,5 & 5,3 & 6,3 & 6,4 & 6,5 & 6,4 & 6,5 & 6,5 \\
\hline Procl7C5E & 0,0 & 5,1 & 5,0 & 5,2 & 5,1 & 5,3 & 5,1 & 6,1 & 6,1 & 6,2 & 6,1 & 6,2 & 6,2 \\
\hline Procl7C6E & 0,0 & 6,0 & 5,9 & 6,1 & 6,0 & 6,3 & 6,0 & 7,2 & 7,2 & 7,3 & 7,3 & 7,3 & 7,3 \\
\hline Procl7C7E & 0,0 & 6,3 & 6,2 & 6,4 & 6,3 & 6,6 & 6,4 & 7,5 & 7,6 & 7,6 & 7,6 & 7,7 & 7,6 \\
\hline Procl7C8E & 0,0 & 7,2 & 7,1 & 7,3 & 7,2 & 7,5 & 7,3 & 8,6 & 8,7 & 8,8 & 8,8 & 8,8 & 8,8 \\
\hline Procl8C1E & 0,0 & 3,1 & 3,1 & 3,2 & 3,1 & 3,2 & 3,1 & 3,7 & 3,7 & 3,8 & 3,7 & 3,8 & 3,8 \\
\hline Procl8C2E & 0,0 & 4,0 & 3,9 & 4,1 & 4,0 & 4,2 & 4,0 & 4,8 & 4,9 & 4,9 & 4,9 & 4,9 & 4,9 \\
\hline
\end{tabular}




\begin{tabular}{|c|c|c|c|c|c|c|c|c|c|c|c|c|c|}
\hline Procl8C3E & 0,0 & 5,6 & 5,5 & 5,7 & 5,6 & 5,8 & 5,6 & 6,6 & 6,7 & 6,7 & 6,7 & 6,8 & 6,7 \\
\hline Procl8C4E & 0,0 & 6,5 & 6,3 & 6,6 & 6,5 & 6,8 & 6,5 & 7,7 & 7,8 & 7,9 & 7,9 & 7,9 & 7,9 \\
\hline Procl8C5E & 0,0 & 3,8 & 3,7 & 3,8 & 3,8 & 3,9 & 3,8 & 4,5 & 4,5 & 4,5 & 4,5 & 4,6 & 4,5 \\
\hline Procl8C6E & 0,0 & 4,6 & 4,5 & 4,7 & 4,6 & 4,9 & 4,7 & 5,6 & 5,6 & 5,7 & 5,7 & 5,7 & 5,7 \\
\hline Procl8C7E & 0,0 & 6,2 & 6,1 & 6,3 & 6,2 & 6,5 & 6,3 & 7,4 & 7,5 & 7,5 & 7,5 & 7,5 & 7,5 \\
\hline Procl8C8E & 0,0 & 7,1 & 7,0 & 7,2 & 7,1 & 7,4 & 7,2 & 8,5 & 8,6 & 8,7 & 8,6 & 8,7 & 8,7 \\
\hline Procl9C1E & 0,0 & 2,9 & 2,9 & 3,0 & 2,9 & 3,0 & 3,0 & 3,4 & 3,4 & 3,5 & 3,4 & 3,5 & 3,5 \\
\hline Procl9C2E & 0,0 & 4,1 & 4,0 & 4,1 & 4,1 & 4,2 & 4,1 & 4,9 & 4,9 & 4,9 & 4,9 & 4,9 & 4,9 \\
\hline Procl9C3E & 0,0 & 4,0 & 4,0 & 4,0 & 4,0 & 4,0 & 4,0 & 4,7 & 4,7 & 4,7 & 4,7 & 4,7 & 4,7 \\
\hline Procl9C4E & 0,0 & 5,1 & 5,1 & 5,2 & 5,1 & 5,3 & 5,2 & 6,1 & 6,1 & 6,2 & 6,2 & 6,2 & 6,2 \\
\hline Procl9C5E & 0,0 & 4,6 & 4,5 & 4,6 & 4,6 & 4,6 & 4,6 & 5,4 & 5,4 & 5,4 & 5,4 & 5,4 & 5,4 \\
\hline Procl9C6E & 0,0 & 5,7 & 5,6 & 5,8 & 5,7 & 5,9 & 5,7 & 6,8 & 6,8 & 6,9 & 6,9 & 6,9 & 6,9 \\
\hline Procl9C7E & 0,0 & 5,6 & 5,5 & 5,6 & 5,6 & 5,7 & 5,6 & 6,6 & 6,6 & 6,6 & 6,6 & 6,7 & 6,6 \\
\hline Procl9C8E & 0,0 & 6,7 & 6,6 & 6,8 & 6,7 & 7,0 & 6,8 & 8,0 & 8,1 & 8,1 & 8,1 & 8,1 & 8,1 \\
\hline Procl10C1E & 0,0 & 2,9 & 2,9 & 2,9 & 2,9 & 2,9 & 2,9 & 3,4 & 3,4 & 3,4 & 3,4 & 3,4 & 3,4 \\
\hline Procl10C2E & 0,0 & 4,0 & 4,0 & 4,1 & 4,0 & 4,2 & 4,1 & 4,8 & 4,8 & 4,9 & 4,9 & 4,9 & 4,9 \\
\hline Procl10C3E & 0,0 & 5,0 & 4,9 & 5,0 & 5,0 & 5,1 & 5,0 & 5,9 & 5,9 & 5,9 & 5,9 & 5,9 & 5,9 \\
\hline Procl10C4E & 0,0 & 6,1 & 6,0 & 6,2 & 6,1 & 6,3 & 6,2 & 7,3 & 7,3 & 7,4 & 7,3 & 7,4 & 7,4 \\
\hline Procl10C5E & 0,0 & 3,4 & 3,4 & 3,5 & 3,4 & 3,5 & 3,5 & 4,0 & 4,0 & 4,1 & 4,0 & 4,1 & 4,1 \\
\hline Procl10C6E & 0,0 & 4,6 & 4,5 & 4,6 & 4,6 & 4,7 & 4,6 & 5,5 & 5,5 & 5,5 & 5,5 & 5,5 & 5,5 \\
\hline Procl10C7E & 0,0 & 5,5 & 5,5 & 5,6 & 5,5 & 5,6 & 5,5 & 6,5 & 6,5 & 6,5 & 6,5 & 6,6 & 6,5 \\
\hline Procl10C8E & 0,0 & 6,6 & 6,6 & 6,7 & 6,7 & 6,9 & 6,7 & 7,9 & 8,0 & 8,0 & 8,0 & 8,0 & 8,0 \\
\hline Procl11C1E & 0,0 & 2,7 & 2,7 & 2,7 & 2,7 & 2,8 & 2,7 & 3,2 & 3,2 & 3,2 & 3,2 & 3,3 & 3,3 \\
\hline Procl11C2E & 0,0 & 3,8 & 3,8 & 3,9 & 3,8 & 4,0 & 3,9 & 4,6 & 4,7 & 4,7 & 4,7 & 4,8 & 4,7 \\
\hline Procl11C3E & 0,0 & 3,8 & 3,7 & 3,8 & 3,8 & 3,9 & 3,8 & 4,5 & 4,5 & 4,5 & 4,5 & 4,5 & 4,5 \\
\hline Procl11C4E & 0,0 & 4,9 & 4,8 & 5,0 & 4,9 & 5,1 & 5,0 & 5,9 & 5,9 & 6,0 & 6,0 & 6,0 & 6,0 \\
\hline Procl11C5E & 0,0 & 4,4 & 4,3 & 4,4 & 4,4 & 4,5 & 4,4 & 5,2 & 5,2 & 5,2 & 5,2 & 5,2 & 5,2 \\
\hline Procl11C6E & 0,0 & 5,5 & 5,4 & 5,6 & 5,5 & 5,7 & 5,5 & 6,6 & 6,6 & 6,7 & 6,7 & 6,7 & 6,7 \\
\hline Procl11C7E & 0,0 & 5,4 & 5,3 & 5,5 & 5,4 & 5,6 & 5,4 & 6,4 & 6,5 & 6,5 & 6,5 & 6,5 & 6,5 \\
\hline Procl11C8E & 0,0 & 6,6 & 6,4 & 6,7 & 6,6 & 6,8 & 6,6 & 7,8 & 7,9 & 8,0 & 7,9 & 8,0 & 8,0 \\
\hline Procl12C1E & 0,0 & 2,7 & 2,6 & 2,7 & 2,7 & 2,7 & 2,7 & 3,2 & 3,2 & 3,2 & 3,2 & 3,2 & 3,2 \\
\hline Procl12C2E & 0,0 & 3,8 & 3,7 & 3,9 & 3,8 & 4,0 & 3,8 & 4,6 & 4,6 & 4,7 & 4,7 & 4,7 & 4,7 \\
\hline Procl12C3E & 0,0 & 4,8 & 4,7 & 4,8 & 4,8 & 4,9 & 4,8 & 5,7 & 5,7 & 5,7 & 5,7 & 5,8 & 5,7 \\
\hline Procl12C4E & 0,0 & 5,9 & 5,8 & 6,0 & 5,9 & 6,2 & 6,0 & 7,1 & 7,2 & 7,2 & 7,2 & 7,2 & 7,2 \\
\hline Procl12C5E & 0,0 & 3,2 & 3,2 & 3,3 & 3,2 & 3,3 & 3,2 & 3,8 & 3,8 & 3,9 & 3,8 & 3,9 & 3,9 \\
\hline Procl12C6E & 0,0 & 4,4 & 4,3 & 4,4 & 4,4 & 4,6 & 4,4 & 5,2 & 5,3 & 5,3 & 5,3 & 5,4 & 5,3 \\
\hline Procl12C7E & 0,0 & 5,3 & 5,3 & 5,4 & 5,3 & 5,5 & 5,4 & 6,3 & 6,4 & 6,4 & 6,4 & 6,4 & 6,4 \\
\hline Procl12C8E & 0,0 & 6,5 & 6,3 & 6,6 & 6,5 & 6,7 & 6,5 & 7,7 & 7,8 & 7,9 & 7,8 & 7,9 & 7,9 \\
\hline Procl13C1E & 0,0 & 2,4 & 2,4 & 2,4 & 2,4 & 2,4 & 2,4 & 2,8 & 2,8 & 2,8 & 2,8 & 2,8 & 2,8 \\
\hline Procl13C2E & 0,0 & 3,8 & 3,8 & 3,9 & 3,8 & 3,9 & 3,9 & 4,6 & 4,6 & 4,6 & 4,6 & 4,6 & 4,6 \\
\hline Procl13C3E & 0,0 & 3,2 & 3,2 & 3,2 & 3,2 & 3,2 & 3,2 & 3,7 & 3,7 & 3,7 & 3,7 & 3,7 & 3,7 \\
\hline Procl13C4E & 0,0 & 4,6 & 4,6 & 4,7 & 4,6 & 4,8 & 4,7 & 5,5 & 5,5 & 5,6 & 5,6 & 5,6 & 5,6 \\
\hline Procl13C5E & 0,0 & 3,7 & 3,7 & 3,7 & 3,7 & 3,7 & 3,7 & 4,3 & 4,3 & 4,3 & 4,3 & 4,3 & 4,3 \\
\hline Procl13C6E & 0,0 & 5,1 & 5,0 & 5,1 & 5,1 & 5,2 & 5,1 & 6,0 & 6,1 & 6,1 & 6,1 & 6,1 & 6,1 \\
\hline Procl13C7E & 0,0 & 4,5 & 4,5 & 4,5 & 4,5 & 4,5 & 4,5 & 5,2 & 5,2 & 5,2 & 5,2 & 5,2 & 5,2 \\
\hline Procl13C8E & 0,0 & 5,9 & 5,8 & 5,9 & 5,9 & 6,0 & 5,9 & 7,0 & 7,0 & 7,1 & 7,0 & 7,1 & 7,1 \\
\hline Procl14C1E & 0,0 & 2,4 & 2,4 & 2,4 & 2,4 & 2,4 & 2,4 & 2,8 & 2,8 & 2,7 & 2,7 & 2,7 & 2,7 \\
\hline Procl14C2E & 0,0 & 3,8 & 3,8 & 3,8 & 3,8 & 3,9 & 3,8 & 4,5 & 4,5 & 4,6 & 4,6 & 4,6 & 4,6 \\
\hline Procl14C3E & 0,0 & 4,0 & 4,0 & 4,0 & 4,0 & 4,0 & 4,0 & 4,7 & 4,7 & 4,7 & 4,7 & 4,7 & 4,7 \\
\hline Procl14C4E & 0,0 & 5,4 & 5,4 & 5,5 & 5,4 & 5,6 & 5,4 & 6,4 & 6,5 & 6,5 & 6,5 & 6,5 & 6,5 \\
\hline Procl14C5E & 0,0 & 2,8 & 2,8 & 2,8 & 2,8 & 2,8 & 2,8 & 3,3 & 3,2 & 3,2 & 3,2 & 3,2 & 3,2 \\
\hline Procl14C6E & 0,0 & 4,2 & 4,2 & 4,3 & 4,2 & 4,3 & 4,3 & 5,0 & 5,0 & 5,1 & 5,1 & 5,1 & 5,1 \\
\hline Procl14C7E & 0,0 & 4,4 & 4,4 & 4,4 & 4,4 & 4,4 & 4,4 & 5,2 & 5,2 & 5,2 & 5,2 & 5,2 & 5,2 \\
\hline Procl14C8E & 0,0 & 5,8 & 5,8 & 5,9 & 5,8 & 6,0 & 5,9 & 6,9 & 7,0 & 7,0 & 7,0 & 7,0 & 7,0 \\
\hline Procl15C1E & 0,0 & 2,1 & 2,1 & 2,2 & 2,1 & 2,2 & 2,1 & 2,5 & 2,5 & 2,5 & 2,5 & 2,5 & 2,5 \\
\hline Procl15C2E & 0,0 & 3,5 & 3,5 & 3,6 & 3,5 & 3,7 & 3,6 & 4,3 & 4,3 & 4,4 & 4,3 & 4,4 & 4,4 \\
\hline Procl15C3E & 0,0 & 3,0 & 2,9 & 3,0 & 3,0 & 3,0 & 3,0 & 3,5 & 3,5 & 3,5 & 3,5 & 3,5 & 3,5 \\
\hline Procl15C4E & 0,0 & 4,4 & 4,3 & 4,4 & 4,4 & 4,6 & 4,4 & 5,2 & 5,3 & 5,3 & 5,3 & 5,4 & 5,4 \\
\hline Procl15C5E & 0,0 & 3,4 & 3,4 & 3,5 & 3,4 & 3,5 & 3,4 & 4,0 & 4,0 & 4,1 & 4,1 & 4,1 & 4,1 \\
\hline Procl15C6E & 0,0 & 4,8 & 4,7 & 4,9 & 4,8 & 5,0 & 4,9 & 5,8 & 5,8 & 5,9 & 5,9 & 5,9 & 5,9 \\
\hline Procl15C7E & 0,0 & 4,2 & 4,2 & 4,3 & 4,3 & 4,3 & 4,3 & 5,0 & 5,0 & 5,1 & 5,0 & 5,1 & 5,1 \\
\hline Procl15C8E & 0,0 & 5,7 & 5,6 & 5,8 & 5,7 & 5,9 & 5,7 & 6,8 & 6,8 & 6,9 & 6,9 & 6,9 & 6,9 \\
\hline Procl16C1E & 0,0 & 2,1 & 2,1 & 2,1 & 2,1 & 2,1 & 2,1 & 2,5 & 2,5 & 2,5 & 2,5 & 2,5 & 2,5 \\
\hline
\end{tabular}




\begin{tabular}{|c|c|c|c|c|c|c|c|c|c|c|c|c|c|}
\hline Procl16C2E & 0,0 & 3,5 & 3,4 & 3,6 & 3,5 & 3,7 & 3,5 & 4,2 & 4,3 & 4,3 & 4,3 & 4,3 & 4,3 \\
\hline Procl16C3E & 0,0 & 3,8 & 3,7 & 3,8 & 3,8 & 3,8 & 3,8 & 4,4 & 4,5 & 4,5 & 4,5 & 4,5 & 4,5 \\
\hline Procl16C4E & 0,0 & 5,2 & 5,1 & 5,3 & 5,2 & 5,4 & 5,2 & 6,2 & 6,2 & 6,3 & 6,3 & 6,3 & 6,3 \\
\hline Procl16C5E & 0,0 & 2,5 & 2,5 & 2,6 & 2,5 & 2,6 & 2,5 & 3,0 & 3,0 & 3,0 & 3,0 & 3,0 & 3,0 \\
\hline Procl16C6E & 0,0 & 3,9 & 3,9 & 4,0 & 3,9 & 4,1 & 4,0 & 4,7 & 4,8 & 4,8 & 4,8 & 4,9 & 4,8 \\
\hline Procl16C7E & 0,0 & 4,2 & 4,1 & 4,2 & 4,2 & 4,3 & 4,2 & 4,9 & 5,0 & 5,0 & 5,0 & 5,0 & 5,0 \\
\hline Procl16C8E & 0,0 & 5,6 & 5,5 & 5,7 & 5,6 & 5,8 & 5,7 & 6,7 & 6,8 & 6,8 & 6,8 & 6,8 & 6,8 \\
\hline Procl17C1E & 0,0 & 2,0 & 2,1 & 2,0 & 2,0 & 1,9 & 2,0 & 2,3 & 2,3 & 2,2 & 2,3 & 2,2 & 2,3 \\
\hline Procl17C2E & 0,0 & 3,7 & 3,7 & 3,7 & 3,7 & 3,8 & 3,7 & 4,4 & 4,4 & 4,4 & 4,4 & 4,4 & 4,4 \\
\hline Procl17C3E & 0,0 & 2,6 & 2,7 & 2,6 & 2,6 & 2,6 & 2,6 & 3,0 & 3,0 & 3,0 & 3,0 & 3,0 & 3,0 \\
\hline Procl17C4E & 0,0 & 4,3 & 4,3 & 4,3 & 4,3 & 4,4 & 4,3 & 5,1 & 5,1 & 5,1 & 5,1 & 5,1 & 5,1 \\
\hline Procl17C5E & 0,0 & 3,0 & 3,0 & 3,0 & 3,0 & 2,9 & 3,0 & 3,4 & 3,4 & 3,4 & 3,4 & 3,4 & 3,4 \\
\hline Procl17C6E & 0,0 & 4,6 & 4,6 & 4,7 & 4,6 & 4,7 & 4,7 & 5,5 & 5,5 & 5,5 & 5,5 & 5,6 & 5,6 \\
\hline Procl17C7E & 0,0 & 3,6 & 3,6 & 3,6 & 3,6 & 3,5 & 3,6 & 4,2 & 4,1 & 4,1 & 4,1 & 4,1 & 4,1 \\
\hline Procl17C8E & 0,0 & 5,3 & 5,2 & 5,3 & 5,3 & 5,4 & 5,3 & 6,2 & 6,3 & 6,3 & 6,3 & 6,3 & 6,3 \\
\hline Procl18C1E & 0,0 & 2,0 & 2,0 & 2,0 & 2,0 & 1,9 & 2,0 & 2,3 & 2,2 & 2,2 & 2,2 & 2,2 & 2,2 \\
\hline Procl18C2E & 0,0 & 3,7 & 3,6 & 3,7 & 3,7 & 3,7 & 3,7 & 4,3 & 4,4 & 4,4 & 4,4 & 4,4 & 4,4 \\
\hline Procl18C3E & 0,0 & 3,2 & 3,3 & 3,2 & 3,2 & 3,2 & 3,2 & 3,7 & 3,7 & 3,7 & 3,7 & 3,7 & 3,7 \\
\hline Procl18C4E & 0,0 & 4,9 & 4,9 & 4,9 & 4,9 & 5,0 & 4,9 & 5,8 & 5,8 & 5,8 & 5,8 & 5,9 & 5,9 \\
\hline Procl18C5E & 0,0 & 2,3 & 2,4 & 2,3 & 2,3 & 2,2 & 2,3 & 2,6 & 2,6 & 2,6 & 2,6 & 2,6 & 2,6 \\
\hline Procl18C6E & 0,0 & 4,0 & 3,9 & 4,0 & 4,0 & 4,1 & 4,0 & 4,7 & 4,7 & 4,8 & 4,7 & 4,8 & 4,8 \\
\hline Procl18C7E & 0,0 & 3,5 & 3,6 & 3,6 & 3,6 & 3,5 & 3,6 & 4,1 & 4,1 & 4,1 & 4,1 & 4,1 & 4,1 \\
\hline Procl18C8E & 0,0 & 5,2 & 5,2 & 5,3 & 5,2 & 5,3 & 5,3 & 6,2 & 6,2 & 6,2 & 6,2 & 6,2 & 6,2 \\
\hline Procl19C1E & 0,0 & 1,7 & 1,7 & 1,7 & 1,7 & 1,7 & 1,7 & 1,9 & 2,0 & 2,0 & 2,0 & 2,0 & 2,0 \\
\hline Procl19C2E & 0,0 & 3,3 & 3,3 & 3,4 & 3,3 & 3,5 & 3,4 & 4,0 & 4,1 & 4,1 & 4,1 & 4,1 & 4,1 \\
\hline Procl19C3E & 0,0 & 2,3 & 2,3 & 2,3 & 2,3 & 2,3 & 2,3 & 2,7 & 2,7 & 2,7 & 2,7 & 2,7 & 2,7 \\
\hline Procl19C4E & 0,0 & 4,0 & 3,9 & 4,1 & 4,0 & 4,2 & 4,0 & 4,8 & 4,8 & 4,9 & 4,9 & 4,9 & 4,9 \\
\hline Procl19C5E & 0,0 & 2,7 & 2,7 & 2,7 & 2,7 & 2,7 & 2,7 & 3,1 & 3,1 & 3,1 & 3,1 & 3,1 & 3,1 \\
\hline Procl19C6E & 0,0 & 4,3 & 4,3 & 4,4 & 4,3 & 4,5 & 4,4 & 5,2 & 5,3 & 5,3 & 5,3 & 5,3 & 5,3 \\
\hline Procl19C7E & 0,0 & 3,3 & 3,3 & 3,4 & 3,3 & 3,3 & 3,3 & 3,9 & 3,9 & 3,9 & 3,9 & 3,9 & 3,9 \\
\hline Procl19C8E & 0,0 & 5,0 & 4,9 & 5,1 & 5,0 & 5,2 & 5,0 & 6,0 & 6,0 & 6,1 & 6,0 & 6,1 & 6,1 \\
\hline Procl20C1E & 0,0 & 1,6 & 1,6 & 1,7 & 1,6 & 1,7 & 1,7 & 1,9 & 1,9 & 1,9 & 1,9 & 1,9 & 1,9 \\
\hline Procl20C2E & 0,0 & 3,3 & 3,2 & 3,4 & 3,3 & 3,5 & 3,4 & 4,0 & 4,0 & 4,1 & 4,1 & 4,1 & 4,1 \\
\hline Procl20C3E & 0,0 & 2,9 & 2,9 & 3,0 & 3,0 & 3,0 & 3,0 & 3,5 & 3,5 & 3,5 & 3,5 & 3,5 & 3,5 \\
\hline Procl20C4E & 0,0 & 4,6 & 4,5 & 4,7 & 4,6 & 4,8 & 4,7 & 5,5 & 5,6 & 5,6 & 5,6 & 5,6 & 5,6 \\
\hline Procl20C5E & 0,0 & 2,0 & 2,0 & 2,0 & 2,0 & 2,0 & 2,0 & 2,3 & 2,3 & 2,3 & 2,3 & 2,3 & 2,3 \\
\hline Procl20C6E & 0,0 & 3,6 & 3,6 & 3,7 & 3,6 & 3,8 & 3,7 & 4,4 & 4,4 & 4,5 & 4,5 & 4,5 & 4,5 \\
\hline Procl20C7E & 0,0 & 3,3 & 3,3 & 3,3 & 3,3 & 3,3 & 3,3 & 3,8 & 3,9 & 3,9 & 3,9 & 3,9 & 3,9 \\
\hline Procl20C8E & 0,0 & 5,0 & 4,9 & 5,0 & 5,0 & 5,1 & 5,0 & 5,9 & 6,0 & 6,0 & 6,0 & 6,0 & 6,0 \\
\hline Procl21C1E & 0,0 & 1,5 & 1,6 & 1,5 & 1,5 & 1,4 & 1,5 & 1,6 & 1,6 & 1,6 & 1,6 & 1,6 & 1,6 \\
\hline Procl21C2E & 0,0 & 3,4 & 3,4 & 3,4 & 3,4 & 3,5 & 3,5 & 4,1 & 4,1 & 4,1 & 4,1 & 4,1 & 4,1 \\
\hline Procl21C3E & 0,0 & 1,9 & 2,0 & 1,8 & 1,9 & 1,7 & 1,9 & 2,1 & 2,1 & 2,0 & 2,0 & 2,0 & 2,0 \\
\hline Procl21C4E & 0,0 & 3,8 & 3,8 & 3,8 & 3,8 & 3,9 & 3,8 & 4,5 & 4,5 & 4,5 & 4,5 & 4,5 & 4,5 \\
\hline Procl21C5E & 0,0 & 2,1 & 2,2 & 2,1 & 2,1 & 1,9 & 2,1 & 2,3 & 2,3 & 2,3 & 2,3 & 2,2 & 2,3 \\
\hline Procl21C6E & 0,0 & 4,0 & 4,0 & 4,0 & 4,0 & 4,1 & 4,1 & 4,7 & 4,8 & 4,8 & 4,8 & 4,8 & 4,8 \\
\hline Procl21C7E & 0,0 & 2,5 & 2,6 & 2,4 & 2,5 & 2,3 & 2,5 & 2,8 & 2,8 & 2,7 & 2,7 & 2,7 & 2,7 \\
\hline Procl21C8E & 0,0 & 4,4 & 4,4 & 4,4 & 4,4 & 4,5 & 4,4 & 5,2 & 5,2 & 5,2 & 5,2 & 5,2 & 5,2 \\
\hline Procl22C1E & 0,0 & 1,5 & 1,6 & 1,4 & 1,5 & 1,3 & 1,5 & 1,6 & 1,6 & 1,6 & 1,6 & 1,5 & 1,6 \\
\hline Procl22C2E & 0,0 & 3,4 & 3,4 & 3,4 & 3,4 & 3,5 & 3,4 & 4,0 & 4,1 & 4,1 & 4,1 & 4,1 & 4,1 \\
\hline Procl22C3E & 0,0 & 2,2 & 2,3 & 2,2 & 2,3 & 2,1 & 2,2 & 2,5 & 2,5 & 2,5 & 2,5 & 2,4 & 2,5 \\
\hline Procl22C4E & 0,0 & 4,2 & 4,2 & 4,2 & 4,2 & 4,2 & 4,2 & 4,9 & 5,0 & 5,0 & 5,0 & 5,0 & 5,0 \\
\hline Procl22C5E & 0,0 & 1,7 & 1,8 & 1,6 & 1,7 & 1,5 & 1,7 & 1,9 & 1,8 & 1,8 & 1,8 & 1,8 & 1,8 \\
\hline Procl22C6E & 0,0 & 3,6 & 3,6 & 3,6 & 3,6 & 3,7 & 3,6 & 4,3 & 4,3 & 4,3 & 4,3 & 4,3 & 4,3 \\
\hline Procl22C7E & 0,0 & 2,4 & 2,5 & 2,4 & 2,5 & 2,3 & 2,4 & 2,8 & 2,7 & 2,7 & 2,7 & 2,7 & 2,7 \\
\hline Procl22C8E & 0,0 & 4,4 & 4,4 & 4,4 & 4,4 & 4,4 & 4,4 & 5,2 & 5,2 & 5,2 & 5,2 & 5,2 & 5,2 \\
\hline Procl23C1E & 0,0 & 1,1 & 1,1 & 1,1 & 1,1 & 1,1 & 1,1 & 1,2 & 1,2 & 1,2 & 1,2 & 1,2 & 1,2 \\
\hline Procl23C2E & 0,0 & 3,0 & 3,0 & 3,1 & 3,0 & 3,2 & 3,1 & 3,7 & 3,7 & 3,7 & 3,7 & 3,8 & 3,7 \\
\hline Procl23C3E & 0,0 & 1,5 & 1,5 & 1,5 & 1,5 & 1,5 & 1,5 & 1,7 & 1,7 & 1,7 & 1,7 & 1,7 & 1,7 \\
\hline Procl23C4E & 0,0 & 3,4 & 3,4 & 3,5 & 3,5 & 3,6 & 3,5 & 4,1 & 4,2 & 4,2 & 4,2 & 4,2 & 4,2 \\
\hline Procl23C5E & 0,0 & 1,7 & 1,8 & 1,7 & 1,8 & 1,7 & 1,7 & 2,0 & 2,0 & 2,0 & 2,0 & 2,0 & 2,0 \\
\hline Procl23C6E & 0,0 & 3,7 & 3,6 & 3,7 & 3,7 & 3,8 & 3,7 & 4,4 & 4,5 & 4,5 & 4,5 & 4,5 & 4,5 \\
\hline Procl23C7E & 0,0 & 2,2 & 2,2 & 2,2 & 2,2 & 2,1 & 2,2 & 2,5 & 2,5 & 2,5 & 2,5 & 2,4 & 2,5 \\
\hline Procl23C8E & 0,0 & 4,1 & 4,0 & 4,2 & 4,1 & 4,2 & 4,1 & 4,9 & 4,9 & 5,0 & 5,0 & 5,0 & 5,0 \\
\hline Procl24C1E & 0,0 & 1,1 & 1,1 & 1,1 & 1,1 & 1,0 & 1,1 & 1,2 & 1,2 & 1,2 & 1,2 & 1,2 & 1,2 \\
\hline Procl24C2E & 0,0 & 3,0 & 2,9 & 3,1 & 3,0 & 3,2 & 3,1 & 3,6 & 3,7 & 3,7 & 3,7 & 3,7 & 3,7 \\
\hline Procl24C3E & 0,0 & 1,9 & 2,0 & 1,9 & 1,9 & 1,9 & 1,9 & 2,2 & 2,2 & 2,2 & 2,2 & 2,2 & 2,2 \\
\hline Procl24C4E & 0,0 & 3,9 & 3,8 & 3,9 & 3,9 & 4,0 & 3,9 & 4,6 & 4,7 & 4,7 & 4,7 & 4,7 & 4,7 \\
\hline Procl24C5E & 0,0 & 1,3 & 1,3 & 1,3 & 1,3 & 1,3 & 1,3 & 1,5 & 1,5 & 1,5 & 1,5 & 1,5 & 1,5 \\
\hline Procl24C6E & 0,0 & 3,2 & 3,2 & 3,3 & 3,2 & 3,4 & 3,3 & 3,9 & 3,9 & 4,0 & 4,0 & 4,0 & 4,0 \\
\hline Procl24C7E & 0,0 & 2,1 & 2,2 & 2,2 & 2,2 & 2,1 & 2,2 & 2,5 & 2,5 & 2,4 & 2,4 & 2,4 & 2,4 \\
\hline Procl24C8E & 0,0 & 4,1 & 4,0 & 4,1 & 4,1 & 4,2 & 4,1 & 4,9 & 4,9 & 4,9 & 4,9 & 5,0 & 5,0 \\
\hline
\end{tabular}


Tabela 68. Rendimentos ( $\left(\mathrm{ou} \mathrm{m}^{3}\right)$ por tonelada de cana processada/comercializada para os processos industriais 1 e 2 e comerciais de 1 a 8 para as primeiras 12 semanas

\begin{tabular}{|c|c|c|c|c|c|c|c|c|c|c|c|c|c|}
\hline \begin{tabular}{|l|} 
Prod/Processo \\
\end{tabular} & em0 & Sem1 & Sem2 & Sem3 & Sem4 & Sem5 & Sem6 & Sem7 & Sem8 & Sem9 & Sem10 & Sem11 & Sem12 \\
\hline VHPProcl1C1 & 0 & 0,075534 & 074354 & 0,076662 & 0,07555 & 0,078053 & 076077 & 0,089738 & , 090383 & 090986 & , 090669 & 091275 & , 091017 \\
\hline melaç & 0 & 3882 & 87296 & 90272 & 8843 & 192267 & 549 & 05857 & 06715 & 07543 & 117 & 949 & 569 \\
\hline AEHC & 0 & 0,042317 & 041479 & 0,043006 & 0,042275 & 0,044106 & 0,042647 & 0,050508 & 0,050958 & 51403 & 177 & 1624 & 5141 \\
\hline AEAC & 0 & 35337 & 083701 & 0,086708 & 0,085266 & 0,088829 & 0,085993 & 01783 & 102664 & 03528 & 3088 & 3956 & 546 \\
\hline VHPP & 0 & 0,060428 & 0,059483 & 0,061329 & ,06044 & 0,062442 & 0,060862 & 1791 & 072306 & 0,072789 & 335 & 07302 & 814 \\
\hline melaçoP & 0 & 8882 & 0,087296 & 0,090272 & 088843 & 0,092267 & 0,089549 & 0,105857 & 106715 & 07543 & 17 & 49 & 569 \\
\hline AEHC & 0 & 317 & 041479 & 0,043006 & 275 & 0,044106 & 647 & 508 & 050958 & 1403 & & 624 & \\
\hline AEA & 0 & 5337 & 083701 & 0,086708 & 0,085266 & 0,088829 & 0,085993 & 01783 & 102664 & 528 & & & \\
\hline VHPP & 0 & 0,075534 & 074354 & 0,076662 & ,07555 & 0,078053 & 777 & 38 & 383 & 986 & 669 & & \\
\hline melaç & 0 & 0,08 & 0,087296 & 0,090272 & 0,088843 & 0,092267 & 0,08 & 0,10 & 106715 & 0,107543 & 17 & & ( \\
\hline AEH & 0 & 0,03 & 0,031109 & 0,032254 & 0,031706 & 0,03308 & 0,031985 & 0,037881 & 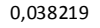 & 552 & 83 & 718 & 558 \\
\hline AEAC & 0 & 337 & 0,083701 & 0,086708 & 0,085266 & 0,088829 & 0,085993 & 783 & , 102664 & 3528 & 88 & & 446 \\
\hline VHP & 0 & 428 & 0,059483 & 0,061329 & 06044 & 0,062442 & 362 & 791 & 306 & 2789 & 335 & 302 & 14 \\
\hline mela & 0 & 882 & 0,087296 & 0,090272 & 843 & 0,092267 & 549 & 857 & 715 & 7543 & 117 & 949 & 569 \\
\hline $\mathrm{AEH}$ & 0 & 0,0 & 109 & 0,0 & 706 & 08 & 885 & 881 & 219 & 552 & 83 & 18 & \\
\hline AEAC & 0 & 337 & 0,083701 & 0,086708 & 0,085266 & 0,088829 & 0,085993 & 783 & 0,102664 & 3528 & 088 & 956 & 546 \\
\hline & 0 & & 4354 & 0,076662 & 555 & 153 & 777 & 738 & 383 & 86 & 669 & & \\
\hline $1 \mathrm{C} 5$ & 0 & 382 & 0,087296 & 0,090272 & 843 & 0,0 & 549 & 857 & 715 & 543 & 17 & 49 & 569 \\
\hline AEH & 0 & 317 & 0,041479 & 0,043006 & 275 & 0,0 & 647 & 508 & 958 & 403 & 77 & 24 & \\
\hline AEA & 0 & 03 & 2776 & 0,0 & 395 & $0, \mathrm{C}$ & 195 & 337 & 998 & 646 & 16 & 67 & \\
\hline C6 & 0 & 0,060428 & 0,059483 & 0,061329 & 0,06044 & 0,0 & 862 & .791 & 306 & 789 & 335 & 302 & 14 \\
\hline mel & 0 & 882 & 0,087296 & 0,090272 & 0,088843 & 0,092267 & 549 & 857 & 715 & 543 & 17 & 949 & 69 \\
\hline AEH & 0 & 317 & 1479 & 0,043006 & 0,042275 & 0,0 & 47 & 508 & 958 & 103 & 77 & 24 & \\
\hline AEA & 0 & 003 & 2776 & 0,0 & 5395 & 0,0 & 495 & 337 & 998 & 546 & 16 & 67 & 766 \\
\hline & 0 & 534 & 074354 & 0,076662 & 07555 & 8053 & 5077 & 9738 & 383 & 986 & 569 & 275 & 017 \\
\hline mel & 0 & 882 & 0,087296 & 0,090272 & 843 & 0,0 & 49 & 57 & 15 & 0 , & 17 & 49 & \\
\hline AEH & 0 & 738 & 0,031109 & 0,032254 & 706 & 08 & & 881 & 19 & 552 & 383 & 718 & 58 \\
\hline AEA & 0 & 03 & 0,062776 & 0,0 & 395 & 0,0 & 95 & 337 & 998 & 0, & 16 & 67 & 66 \\
\hline c8 & 0 & 0,060428 & 0,059483 & 0,061329 & 06044 & 0,062442 & 862 & .791 & 306 & 789 & 535 & 302 & 14 \\
\hline mela & 0 & 882 & 0,087296 & 0,090272 & 0,088843 & 0,092267 & 49 & 857 & 715 & 543 & 17 & 49 & 69 \\
\hline AEr & 0 & 38 & 109 & 0,0 & 706 & 08 & 85 & 381 & 19 & 52 & 383 & 18 & 58 \\
\hline AEA & 0 & 003 & 0,062776 & 0,0 & 6395 & 522 & 95 & 337 & 998 & 546 & 316 & 67 & 66 \\
\hline & 0 & 0,038575 & 0,038031 & 0,039132 & 0386 & 0,0 & 0,0 & 751 & 051 & 23 & 77 & 51 & 42 \\
\hline melc & 0 & 509 & 0,044334 & 4578 & ,045085, & 0,046705 & 422 & 39 & 405 & 0, & 38 & 31 & 57 \\
\hline AEHC & 0 & 635 & 0,082958 & 0,086012 & 084549 & 0,0 & 0,085293 & 16 & & 305 & 35 & 48 & 21 \\
\hline AEAC & 0 & 0,035553 & 0,034918 & 0,036109 & 035537 & 0,036907 & 882 & 0,0 & 86 & 0 , & 347 & & \\
\hline & 0 & 3086 & ,030425 & 0,031305 & 3088 & 0,031788 & 075 & 0,036601 & 0,0 & 058 & 342 & 161 & 074 \\
\hline mela & 0 & 4509 & 0,044334 & 4578 & 085 & 0,046705 & 422 & 539 & 05 & 141 & 238 & 31 & 57 \\
\hline $\mathrm{AEHC}$ & 0 & 0,084635 & 0,082958 & 0,086012 & 084549 & 0,088213 & 085293 & 016 & 317 & 805 & 355 & 248 & 821 \\
\hline AEACP & 0 & 5553 & 0,034918 & 0,036109 & ,035537 & 0,036907 & 82 & 343 & 686 & 017 & 847 & 18 & 028 \\
\hline & 0 & 0 , & 31 & 0, & 386 & 0, & 43 & 51 & 51 & & 77 & & \\
\hline mel & 0 & & 334 & 78 & 085 & 6705 & 122 & 39 & 05 & 141 & 38 & & 57 \\
\hline & 0 & 6 & 19 & 0, & 12 & & & & & & & & \\
\hline AEA & 0 & 5533 & 918 & 0,036109 & 0,035537 & 907 & & 343 & 86 & 0 , & 347 & & \\
\hline & 0 & & 25 & $0, \mathrm{C}$ & 88 & 88 & & 01 & & & & & \\
\hline $\mathrm{mel}$ & 0 & & 334 & & 085 & 05 & & & & & & & \\
\hline$A E$ & 0 & 76 & 219 & 0,0 & 12 & 16 & & 62 & & & 766 & 36 & \\
\hline $\mathrm{AE}$ & 0 & 53 & 918 & 0,0 & 537 & 0, & & & & & & & \\
\hline & 0 & & & & & & & & & & & & \\
\hline $\mathrm{mel}$ & 0 & & & & & & & & & & & & \\
\hline & 0 & & & & & & & & & & & & \\
\hline $\mathrm{AE}$ & 0 & 0,0 & 89 & 0,0 & 53 & & & & & & & & \\
\hline & 0 & & & & & & & & & & & & \\
\hline & 0 & & & & & & & & & & & & \\
\hline & 0 & & & & & & & & & & & & \\
\hline AEA & 0 & 664 & 0,026189 & & 0,026653 & & & & & & & & \\
\hline & $\begin{array}{l}0 \\
0\end{array}$ & 75 & & & & & & & & & & & \\
\hline & 0 & & & & & & & & & & & & \\
\hline & 0 & & & & 553 & & & & & & & & \\
\hline & 0 & & & & & & & & & & & & $0 / 4$ \\
\hline & 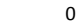 & & & & & & & & & & 0,054238 & & \\
\hline
\end{tabular}


Tabela 69. Preços dos produtos comercializados no mercado spot interno

\begin{tabular}{|c|c|c|c|c|}
\hline & VHP(R\$/t) & AEHC(R\$/m3) & $\operatorname{AEAC}(\mathbf{R} \$ / \mathrm{m} 3)$ & Melaço $(\mathrm{R} \$ / \mathrm{m} 3)$ \\
\hline Sem1 & 540,234843 & 769,755 & 875,772 & 198,288 \\
\hline Sem2 & 545,7647679 & 747,495 & 847,152 & 191,808 \\
\hline Sem3 & 559,9079993 & 729,645 & 831,252 & 188,208 \\
\hline Sem4 & 574,7922003 & 714,21 & 816,094 & 184,776 \\
\hline Sem5 & 579,4346946 & 707,07 & 807,084 & 182,736 \\
\hline Sem6 & 582,3277676 & 707,07 & 806,978 & 182,712 \\
\hline Sem7 & 583,5616315 & 743,19 & 836,764 & 189,456 \\
\hline Sem 8 & 587,0531079 & 770,595 & 871,108 & 197,232 \\
\hline Sem9 & 593,8118365 & 786,975 & 886,902 & 200,808 \\
\hline Sem10 & 602,3010272 & 793,275 & 889,552 & 201,408 \\
\hline Sem11 & 609,7196247 & 796,635 & 889,976 & 201,504 \\
\hline Sem12 & 617,3745211 & 800,31 & 883,934 & 200,136 \\
\hline Sem13 & 625,5793611 & 782,04 & 869,624 & 196,896 \\
\hline Sem14 & 630,2911516 & 757,47 & 856,162 & 193,848 \\
\hline Sem15 & 632,2553663 & 734,16 & 825,846 & 186,984 \\
\hline Sem16 & 634,0436563 & 732,06 & 819,168 & 185,472 \\
\hline Sem17 & 627,3689872 & 761,355 & 843,654 & 191,016 \\
\hline Sem18 & 620,2260299 & 804,195 & 850,332 & 192,528 \\
\hline Sem19 & 610,4190857 & 787,29 & 879,906 & 199,224 \\
\hline Sem20 & 596,9471151 & 730,275 & 882,556 & 199,824 \\
\hline Sem21 & 594,1081637 & 693 & 871,32 & 197,28 \\
\hline Sem22 & 587,5255752 & 671,16 & 849,908 & 192,432 \\
\hline Sem23 & 586,332657 & 664,335 & 834,856 & 189,024 \\
\hline Sem24 & 584,8888553 & 670,95 & 813,232 & 184,128 \\
\hline Sem 25 & 585,3154975 & 711,165 & 816,73 & 184,92 \\
\hline Sem26 & 586,6107546 & 759,255 & 869,942 & 196,968 \\
\hline Sem27 & 588,8611516 & 749,49 & 863,582 & 195,528 \\
\hline Sem28 & 600,8365338 & 759,675 & 935,344 & 211,776 \\
\hline Sem29 & 612,5620551 & 761,355 & 943,082 & 213,528 \\
\hline Sem30 & 622,5441365 & 752,85 & 937,04 & 212,16 \\
\hline Sem31 & 630,130464 & 732,27 & 919,02 & 208,08 \\
\hline Sem32 & 637,6583012 & 728,805 & 910,01 & 206,04 \\
\hline Sem33 & 644,9972623 & 746,655 & 900,364 & 203,856 \\
\hline Sem34 & 654,0042089 & 778,365 & 913,402 & 206,808 \\
\hline Sem 35 & 666,0135862 & 775,53 & 917,96 & 207,84 \\
\hline Sem36 & 681,8481853 & 776,37 & 926,44 & 209,76 \\
\hline Sem37 & 690,865149 & 779,94 & 945,732 & 214,128 \\
\hline Sem38 & 692,4114469 & 796,74 & 962,268 & 217,872 \\
\hline Sem39 & 693,6779732 & 803,775 & 979,334 & 221,736 \\
\hline Sem40 & 696,3543511 & 803,67 & 982,62 & 222,48 \\
\hline Sem41 & 699,2264507 & 801,465 & 988,768 & 223,872 \\
\hline Sem42 & 698,7648472 & 774,48 & 975,518 & 220,872 \\
\hline Sem43 & 696,9319813 & 746,76 & 940,644 & 212,976 \\
\hline Sem44 & 694,2269095 & 717,99 & 930,998 & 210,792 \\
\hline Sem45 & 687,9970817 & 716,415 & 926,44 & 209,76 \\
\hline Sem46 & 687,9427239 & 769,125 & 955,272 & 216,288 \\
\hline Sem47 & 687,6983085 & 803,67 & 972,02 & 220,08 \\
\hline Sem48 & 690,6063115 & 775,635 & 951,032 & 215,328 \\
\hline Sem49 & 690,6089564 & 773,01 & 930,044 & 210,576 \\
\hline Sem50 & 699,0887637 & 772,695 & 934,39 & 211,56 \\
\hline Sem51 & 718,8625809 & 775,53 & 931,74 & 210,96 \\
\hline Sem52 & 731,8418558 & 776,16 & 920,504 & 208,416 \\
\hline
\end{tabular}


Tabela 70. Preços dos produtos comercializados no mercado spot externo

\begin{tabular}{|c|c|c|c|}
\hline & VHP(R\$/t) & AEHC(R\$/m3) & AEAC(R\$/m3) \\
\hline Sem1 & 568,3270549 & 746,66235 & 893,28744 \\
\hline Sem2 & 574,1445358 & 725,07015 & 864,09504 \\
\hline Sem3 & 589,0232153 & 707,75565 & 847,87704 \\
\hline Sem4 & 604,6813948 & 692,7837 & 832,41588 \\
\hline Sem5 & 609,5652987 & 685,8579 & 823,22568 \\
\hline Sem6 & 612,6088115 & 685,8579 & 823,11756 \\
\hline Sem7 & 613,9068363 & 720,8943 & 853,49928 \\
\hline Sem8 & 617,5798695 & 747,47715 & 888,53016 \\
\hline Sem 9 & 624,690052 & 763,36575 & 904,64004 \\
\hline Sem 10 & 633,6206807 & 769,47675 & 907,34304 \\
\hline Sem11 & 641,4250452 & 772,73595 & 907,77552 \\
\hline Sem12 & 649,4779962 & 776,3007 & 901,61268 \\
\hline Sem13 & 658,1094879 & 758,5788 & 887,01648 \\
\hline Sem14 & 663,0662915 & 734,7459 & 873,28524 \\
\hline Sem15 & 665,1326454 & 712,1352 & 842,36292 \\
\hline Sem16 & 667,0139265 & 710,0982 & 835,55136 \\
\hline Sem17 & 659,9921745 & 738,51435 & 860,52708 \\
\hline Sem18 & 652,4777835 & 780,06915 & 867,33864 \\
\hline Sem19 & 642,1608782 & 763,6713 & 897,50412 \\
\hline Sem20 & 627,9883651 & 708,36675 & 900,20712 \\
\hline Sem 21 & 625,0017882 & 672,21 & 888,7464 \\
\hline Sem22 & 618,0769052 & 651,0252 & 866,90616 \\
\hline Sem23 & 616,8219551 & 644,40495 & 851,55312 \\
\hline Sem24 & 615,3030758 & 650,8215 & 829,49664 \\
\hline Sem 25 & 615,7519034 & 689,83005 & 833,0646 \\
\hline Sem 26 & 617,1145139 & 736,47735 & 887,34084 \\
\hline Sem 27 & 619,4819315 & 727,0053 & 880,85364 \\
\hline Sem28 & 632,0800336 & 736,88475 & 954,05088 \\
\hline Sem29 & 644,4152819 & 738,51435 & 961,94364 \\
\hline Sem 30 & 654,9164316 & 730,2645 & 955,7808 \\
\hline Sem31 & 662,8972481 & 710,3019 & 937,4004 \\
\hline Sem 32 & 670,8165328 & 706,94085 & 928,2102 \\
\hline Sem33 & 678,5371199 & 724,25535 & 918,37128 \\
\hline Sem34 & 688,0124277 & 755,01405 & 931,67004 \\
\hline Sem35 & 700,6462926 & 752,2641 & 936,3192 \\
\hline Sem36 & 717,304291 & 753,0789 & 944,9688 \\
\hline Sem 37 & 726,7901367 & 756,5418 & 964,64664 \\
\hline Sem38 & 728,4168422 & 772,8378 & 981,51336 \\
\hline Sem39 & 729,7492278 & 779,66175 & 998,92068 \\
\hline Sem40 & 732,5647774 & 779,5599 & 1002,2724 \\
\hline Sem41 & 735,5862261 & 777,42105 & 1008,54336 \\
\hline Sem42 & 735,1006193 & 751,2456 & 995,02836 \\
\hline Sem43 & 733,1724444 & 724,3572 & 959,45688 \\
\hline Sem44 & 730,3267088 & 696,4503 & 949,61796 \\
\hline Sem45 & 723,77293 & 694,92255 & 944,9688 \\
\hline Sem46 & 723,7157455 & 746,05125 & 974,37744 \\
\hline Sem47 & 723,4586205 & 779,5599 & 991,4604 \\
\hline Sem48 & 726,5178397 & 752,36595 & 970,05264 \\
\hline Sem49 & 726,5206222 & 749,8197 & 948,64488 \\
\hline Sem50 & 735,4413794 & 749,51415 & 953,0778 \\
\hline Sem51 & 756,2434352 & 752,2641 & 950,3748 \\
\hline Sem52 & 769,8976323 & 752,8752 & 938,91408 \\
\hline
\end{tabular}


Tabela 71. Demanda hedge dos produtos comercializados

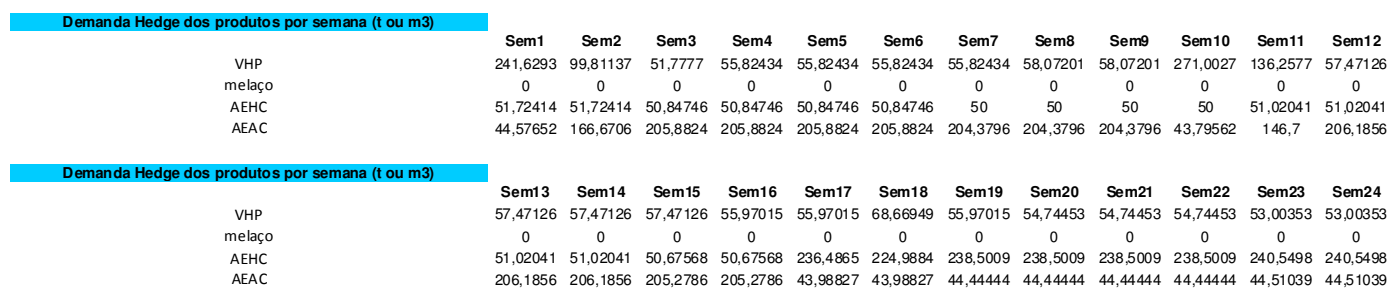

Tabela 72. . Demanda spot para mercado interno dos produtos comercializados

\begin{tabular}{|c|c|c|c|c|c|c|c|c|c|c|c|c|}
\hline \multicolumn{13}{|c|}{ Demanda Spotl dos produtos por semana ( $t$ ou $\mathrm{m} 3$ ) } \\
\hline & Semo & Sem1 & Sem2 & Sem3 & Sem4 & Sem5 & Sem6 & Sem7 & Sem8 & Sem9 & Sem 10 & Sem11 \\
\hline VHP & 0 & 200 & 200 & 200 & 200 & 200 & 200 & 200 & 200 & 200 & 200 & 200 \\
\hline melaço & 0 & 0 & 0 & 0 & 0 & 0 & 0 & 0 & 0 & 0 & 0 & 0 \\
\hline AEHC & 0 & 100 & 100 & 100 & 100 & 100 & 100 & 100 & 100 & 100 & 100 & 100 \\
\hline AEAC & 0 & 100 & 100 & 100 & 100 & 100 & 100 & 100 & 100 & 100 & 100 & 100 \\
\hline \multicolumn{13}{|c|}{ Demanda Spotl dos produtos por semana (t ou $\mathrm{m} 3$ ) } \\
\hline & Sem12 & Sem13 & Sem14 & Sem15 & Sem16 & Sem17 & Sem 18 & Sem19 & Sem20 & Sem21 & Sem22 & Sem23 \\
\hline VHP & 200 & 200 & 200 & 200 & 200 & 200 & 200 & 200 & 200 & 200 & 200 & 200 \\
\hline melaço & 0 & 0 & 0 & 0 & 0 & 0 & 0 & 0 & 0 & 0 & 0 & 0 \\
\hline AEHC & 100 & 100 & 100 & 100 & 100 & 100 & 100 & 100 & 100 & 100 & 100 & 100 \\
\hline AEAC & 100 & 100 & 100 & 100 & 100 & 100 & 100 & 100 & 100 & 100 & 100 & 100 \\
\hline \multicolumn{13}{|c|}{ Demanda Spotl dos produtos por semana (t ou $\mathrm{m} 3$ ) } \\
\hline & Sem24 & Sem25 & Sem26 & Sem27 & Sem28 & Sem29 & Sem30 & Sem31 & Sem32 & Sem33 & Sem34 & Sem35 \\
\hline VHP & 200 & 200 & 200 & 200 & 200 & 200 & 200 & 200 & 200 & 200 & 200 & 200 \\
\hline melaço & 0 & 0 & 0 & 0 & 0 & 0 & 0 & 0 & 0 & 0 & 0 & 0 \\
\hline AEHC & 100 & 100 & 100 & 100 & 100 & 100 & 100 & 100 & 100 & 100 & 100 & 100 \\
\hline AEAC & 100 & 100 & 100 & 100 & 100 & 100 & 100 & 100 & 100 & 100 & 100 & 100 \\
\hline \multicolumn{13}{|c|}{ Demanda Spotl dos produtos por semana ( $t$ ou $\mathrm{m} 3$ ) } \\
\hline & Sem36 & Sem37 & Sem38 & Sem39 & Sem 40 & Sem41 & Sem42 & Sem43 & Sem44 & Sem45 & Sem46 & Sem47 \\
\hline VHP & 200 & 200 & 200 & 200 & 200 & 200 & 200 & 200 & 200 & 200 & 200 & 200 \\
\hline melaço & 0 & 0 & 0 & 0 & 0 & 0 & 0 & 0 & 0 & 0 & 0 & 0 \\
\hline AEHC & 100 & 100 & 100 & 100 & 100 & 100 & 100 & 100 & 100 & 100 & 100 & 100 \\
\hline AEAC & 100 & 100 & 100 & 100 & 100 & 100 & 100 & 100 & 100 & 100 & 100 & 100 \\
\hline \multicolumn{13}{|c|}{ Demanda Spotl dos produtos por semana (t ou $\mathrm{m} 3$ ) } \\
\hline & Sem48 & Sem49 & Sem50 & Sem51 & Sem52 & & & & & & & \\
\hline VHP & 200 & 200 & 200 & 200 & 200 & & & & & & & \\
\hline melaço & 0 & 0 & 0 & 0 & 0 & & & & & & & \\
\hline AEHC & 100 & 100 & 100 & 100 & 100 & & & & & & & \\
\hline AEAC & 100 & 100 & 100 & 100 & 100 & & & & & & & \\
\hline
\end{tabular}

Tabela 73. Demanda spot para mercado externo dos produtos comercializados

\begin{tabular}{|c|c|c|c|c|c|c|c|c|c|c|c|c|}
\hline \multicolumn{13}{|c|}{ Demanda SpotE d os produtos por semana ( $t$ ou $\mathrm{m} 3$ ) } \\
\hline & Sem0 & Sem1 & Sem2 & Sem3 & Sem4 & Sem5 & Sem6 & Sem7 & Sem8 & Sem9 & Sem 10 & Sem11 \\
\hline VHP & 0 & 50 & 50 & 50 & 50 & 50 & 50 & 50 & 50 & 50 & 50 & 50 \\
\hline melaço & 0 & 0 & 0 & 0 & 0 & 0 & 0 & 0 & 0 & 0 & 0 & 0 \\
\hline AEHC & 0 & 80 & 80 & 80 & 80 & 80 & 80 & 80 & 80 & 80 & 80 & 80 \\
\hline AEAC & 0 & 100 & 100 & 100 & 100 & 100 & 100 & 100 & 100 & 100 & 100 & 100 \\
\hline \multicolumn{13}{|c|}{ Demanda SpotE dos produtos por semana (t ou $\mathrm{m} 3$ ) } \\
\hline & Sem12 & Sem13 & Sem14 & Sem15 & Sem16 & Sem17 & Sem 18 & Sem19 & Sem20 & Sem21 & Sem22 & Sem23 \\
\hline VHP & 50 & 50 & 50 & 50 & 50 & 50 & 50 & 50 & 50 & 50 & 50 & 50 \\
\hline melaço & 0 & 0 & 0 & 0 & 0 & 0 & 0 & 0 & 0 & 0 & 0 & 0 \\
\hline AEHC & 80 & 80 & 80 & 80 & 80 & 80 & 80 & 80 & 80 & 80 & 80 & 80 \\
\hline AEAC & 100 & 100 & 100 & 100 & 100 & 100 & 100 & 100 & 100 & 100 & 100 & 100 \\
\hline \multicolumn{13}{|c|}{ Demanda SpotE dos produtos por semana (t ou $\mathrm{m} 3$ ) } \\
\hline & Sem24 & Sem25 & Sem26 & Sem27 & Sem28 & Sem29 & Sem30 & Sem31 & Sem32 & Sem33 & Sem 34 & Sem35 \\
\hline VHP & 50 & 50 & 50 & 50 & 50 & 50 & 50 & 50 & 50 & 50 & 50 & 50 \\
\hline melaço & 0 & 0 & 0 & 0 & 0 & 0 & 0 & 0 & 0 & 0 & 0 & 0 \\
\hline AEHC & 80 & 80 & 80 & 80 & 80 & 80 & 80 & 80 & 80 & 80 & 80 & 80 \\
\hline AEAC & 100 & 100 & 100 & 100 & 100 & 100 & 100 & 100 & 100 & 100 & 100 & 100 \\
\hline \multicolumn{13}{|c|}{ Demanda SpotE dos produtos por semana (t ou $\mathrm{m} 3$ ) } \\
\hline & Sem36 & Sem37 & Sem38 & Sem39 & Sem 40 & Sem41 & Sem42 & Sem43 & Sem44 & Sem45 & Sem 46 & Sem47 \\
\hline VHP & 50 & 50 & 50 & 50 & 50 & 50 & 50 & 50 & 50 & 50 & 50 & 50 \\
\hline melaço & 0 & 0 & 0 & 0 & 0 & 0 & 0 & 0 & 0 & 0 & 0 & 0 \\
\hline AEHC & 80 & 80 & 80 & 80 & 80 & 80 & 80 & 80 & 80 & 80 & 80 & 80 \\
\hline AEAC & 100 & 100 & 100 & 100 & 100 & 100 & 100 & 100 & 100 & 100 & 100 & 100 \\
\hline \multicolumn{13}{|c|}{ Demanda SpotE d os produtos por semana (t ou $\mathrm{m} 3$ ) } \\
\hline & Sem48 & Sem49 & Sem50 & Sem51 & Sem52 & & & & & & & \\
\hline VHP & 50 & 50 & 50 & 50 & 50 & & & & & & & \\
\hline melaço & 0 & 0 & 0 & 0 & 0 & & & & & & & \\
\hline AEHC & 80 & 80 & 80 & 80 & 80 & & & & & & & \\
\hline AEAC & 100 & 100 & 100 & 100 & 100 & & & & & & & \\
\hline
\end{tabular}




\section{ANEXO F- Dados de saída para o modelo SOVTICE}

Tabela 74. Estoque dos produtos acabados $\left(\mathrm{em} \mathrm{t} \mathrm{ou}^{3}\right.$ ) no final de cada semana

\begin{tabular}{|c|c|c|c|c|c|c|c|c|c|c|c|c|c|}
\hline & Sem0 & Sem1 & Sem2 & Sem3 & Sem 4 & Sem5 & Sem6 & Sem7 & Sem8 & Sem9 & Sem10 & Sem11 & Sem12 \\
\hline VHP.Eprop & 3000 & 5534,831 & 8164,165 & 10965,59 & 255,8243 & 255,8243 & 255,8243 & 258,072 & 258,072 & 471,0027 & 336,2577 & 257,4713 & 257,4713 \\
\hline VHP.Eterc & 0 & 0 & 0 & 0 & 0 & 0 & 0 & 0 & 0 & 0 & 0 & 0 & 0 \\
\hline melaço.Eprop & 0 & 0 & 0 & 0 & 0 & 0 & 0 & 0 & 0 & 0 & 0 & 0 & 0 \\
\hline melaço.Eterc & 0 & 0 & 0 & 0 & 0 & 0 & 0 & 0 & 0 & 0 & 0 & 0 & 0 \\
\hline AEHC.Eprop & 2000 & 151,7241 & 150,8475 & 150,8475 & 1506,506 & 2942,335 & 4314,289 & 6034,09 & 1888,273 & 2421,758 & 2353,214 & 2411,529 & 151,0204 \\
\hline AEHC.Eterc & 0 & 0 & 0 & 0 & 0 & 0 & 0 & 0 & 0 & 0 & 0 & 0 & 0 \\
\hline AEAC.Eprop & 2000 & 266,6706 & 305,8824 & 305,8824 & 305,8824 & 3498,328 & 6566,327 & 10332,98 & 304,3796 & 143,7956 & 246,7 & 306,1856 & 306,1856 \\
\hline AEAC.Eterc & $\overline{0}$ & 0 & 0 & $\overline{0}$ & 0 & $\overline{0}$ & $\overline{0}$ & $\overline{0}$ & 0 & $\overline{0}$ & 0 & 0 & 0 \\
\hline
\end{tabular}

\begin{tabular}{|c|c|c|c|c|c|c|c|c|c|c|c|c|}
\hline & Sem13 & Sem14 & Sem15 & Sem16 & Sem17 & Sem18 & Sem19 & Sem20 & Sem21 & Sem22 & Sem23 & Sem24 \\
\hline VHP.Eprop & 257,4713 & 257,4713 & 255,9701 & 255,9701 & 268,6695 & 255,9701 & 254,7445 & 254,7445 & 254,7445 & 253,0035 & 253,0035 & 253,1513 \\
\hline \multirow{6}{*}{$\begin{array}{l}\text { VHP.Eterc } \\
\text { melaço.Eprop } \\
\text { melaço.Eterc } \\
\text { AEHC.Eprop } \\
\text { AEHC.Eterc } \\
\text { AEAC.Eprop }\end{array}$} & 0 & 0 & 0 & 0 & 0 & 0 & 0 & 0 & $\overline{0}$ & 0 & 0 & 0 \\
\hline & 0 & 0 & 0 & 0 & 0 & 0 & 0 & 0 & 0 & 0 & 0 & 0 \\
\hline & 0 & 0 & 0 & 0 & 0 & 0 & 0 & 0 & 0 & 0 & 0 & 0 \\
\hline & 151,0204 & 1918,608 & 3706,85 & 6149,584 & 8309,297 & 338,5009 & 338,5009 & 338,5009 & 2585,096 & 4203,787 & 6390,662 & 8474,706 \\
\hline & 0 & 0 & 0 & 0 & 0 & 0 & 0 & 0 & 0 & 0 & 0 & 0 \\
\hline & 306,1856 & 305,2786 & 305,2786 & \begin{tabular}{|l|}
5515,751 \\
\end{tabular} & 143,9883 & 5375,207 & 144,4444 & 144,4444 & \begin{tabular}{|l|}
144,4444 \\
\end{tabular} & \begin{tabular}{|l|}
144,5104 \\
\end{tabular} & 144,5104 & 5175,773 \\
\hline \multirow[t]{2}{*}{ AEAC.Eterc } & 0 & 0 & 0 & 0 & 0 & 0 & 0 & 0 & 0 & 0 & 0 & 0 \\
\hline & Sem25 & Sem26 & Sem27 & Sem28 & Sem29 & Sem30 & Sem31 & Sem32 & Sem33 & Sem34 & Sem35 & Sem36 \\
\hline \multirow{7}{*}{$\begin{array}{c}\text { VHP.Eprop } \\
\text { VHP.Eterc } \\
\text { melaço.Eprop } \\
\text { melaço.Eterc } \\
\text { AEHC.Eprop } \\
\text { AEHC.Eterc } \\
\text { AEAC.Eprop }\end{array}$} & 253,1513 & 251,8684 & 4835,339 & 9206,437 & 13565,27 & 247,619 & 247,619 & 2344,613 & 6565,878 & 10785,65 & 15000 & 4000 \\
\hline & 0 & 0 & 0 & 0 & 0 & 0 & 0 & 0 & 0 & 0 & 0 & 0 \\
\hline & 0 & 0 & 0 & 0 & 0 & 0 & 0 & 0 & 0 & 0 & 0 & 0 \\
\hline & 0 & 0 & 0 & 0 & 0 & 0 & 0 & 0 & 0 & 0 & 0 & 0 \\
\hline & 10949,9 & 151,8135 & 2595,53 & 2440,891 & 151,8135 & 151,1945 & 2444,357 & 4696,275 & 6708,602 & 2349,767 & 2804,278 & 4800 \\
\hline & 0 & 0 & 0 & 0 & 0 & 0 & 0 & 0 & 0 & 0 & 0 & 0 \\
\hline & 10448,6 & 14000 & 14000 & 308,9552 & 308,9552 & 307,1006 & 307,1006 & 144,3787 & 144,3787 & 144,7761 & 144,7761 & 5010,08 \\
\hline AEAC.Eterc & 0 & 0 & 5210,761 & 0 & 0 & 0 & 0 & 0 & 0 & 0 & 0 & 0 \\
\hline
\end{tabular}

\begin{tabular}{|c|c|c|c|c|c|c|c|c|c|c|c|c|}
\hline & Sem37 & Sem38 & Sem39 & Sem40 & Sem41 & Sem42 & Sem43 & Sem44 & Sem45 & Sem46 & Sem47 & Sem48 \\
\hline VHP.Eprop & 3750 & 3500 & 3250 & 3000 & 2750 & 2500 & 2250 & 2000 & 1750 & 1500 & 1250 & 1000 \\
\hline VHP.Eterc & 0 & 0 & 0 & 0 & 0 & 0 & 0 & 0 & 0 & 0 & 0 & 0 \\
\hline melaço.Eprop & 0 & 0 & 0 & 0 & 0 & 0 & 0 & 0 & 0 & 0 & 0 & 0 \\
\hline melaço.Eterc & 0 & 0 & 0 & 0 & 0 & 0 & 0 & 0 & 0 & 0 & 0 & 0 \\
\hline AEHC.Eprop & 4500 & 4200 & 3900 & 3600 & 3300 & 3000 & 2700 & 2400 & 2100 & 1800 & 1500 & 1200 \\
\hline AEHC.Eterc & 0 & 0 & 0 & 0 & 0 & 0 & 0 & 0 & 0 & 0 & 0 & 0 \\
\hline AEAC.Eprop & 3000 & 2800 & 2600 & 2400 & 2200 & 2000 & 1800 & 1600 & 1400 & 1200 & 1000 & 800 \\
\hline AEAC.Eterc & $\overline{0}$ & $\overline{0}$ & $\overline{0}$ & $\overline{0}$ & 0 & 0 & 0 & 0 & 0 & 0 & 0 & 0 \\
\hline
\end{tabular}

\begin{tabular}{|c|c|c|c|c|}
\hline & Sem49 & Sem50 & Sem51 & Sem52 \\
\hline VHP.Eprop & 750 & 500 & 250 & 0 \\
\hline VHP.Eterc & 0 & 0 & 0 & 0 \\
\hline melaço.Eprop & $\overline{0}$ & $\overline{0}$ & 0 & $\overline{0}$ \\
\hline melaço.Eterc & 0 & 0 & 0 & 0 \\
\hline AEHC.Eprop & 900 & 600 & 300 & 0 \\
\hline AEHC.Eterc & 0 & 0 & 0 & 0 \\
\hline AEAC.Eprop & 600 & 400 & 200 & 0 \\
\hline AEAC.Eterc & 0 & 0 & 0 & 0 \\
\hline
\end{tabular}


Tabela 75. Disponibilidade de cada variedade de cana (t) no campo no início de cada semana

\begin{tabular}{|c|c|c|c|c|c|c|c|c|c|c|c|c|c|}
\hline & Sem0 & Sem1 & Sem2 & Sem3 & Sem4 & Sem5 & Sem6 & em7 & Sem8 & Sem9 & Sem10 & & \\
\hline cprop & 718,09 & 84718,09 & 40718,09 & 40718,09 & 6925,43 & 0 & $\overline{0}$ & 0 & $\overline{0}$ & $\overline{0}$ & $\overline{0}$ & 0 & 0 \\
\hline cforn & 207,34 & 10207,34 & 207,34 & 10207,34 & 0 & 0 & 0 & 0 & 0 & 0 & 0 & 0 & 0 \\
\hline SP2 & 5978,44 & 95978,44 & 95978,44 & 95978,44 & 95978,44 & 978,44 & 95978,44 & 95978,44 & 95978,44 & 95978,44 & 95978,44 & 95978,44 & 9597 \\
\hline SP2 & 0550,69 & 30550,69 & 30550,69 & 30550,69 & 550,69 & 0550,69 & 30550,69 & 0550,69 & 30550,69 & 30550,69 & 30550,69 &, 69 & 3055 \\
\hline B33 & 3407,25 & 63407,25 & 63407,25 & 6340 & 63407,25 & 3407,25 & 63407,25 & 25 & 25 & 25 & 25 & & \\
\hline cforn & 7653,04 & 17653,04 & 17653,04 & 17653,04 & 7653,04 & 17653,04 & 17653,04 & 17653,04 & 17653,04 & 1765 & 1765 & 04 & 1765 \\
\hline P4 & 61355,26 & 61355,26 & 61355,26 & 61355,26 & 61355,26 & 1355,26 & 61355,26 & 1355,26 & 61355,26 & 61355,26 & 6135 & 5,26 & 61355,26 \\
\hline SP4 & 1035,47 & 47 & 47 & 103 & & & & & & & & & \\
\hline B5 & 68765,79 & 68765,79 & 68765,79 & 687 &, 79 & 79 & 68 & & & & & & \\
\hline cforn & 4578,89 & 64578,89 & 64578,89 & 64578,89 & 64578,89 & 39 & 645 & 645 & 645 & 89 & 645 & & 89 \\
\hline P6 & 63190,19 & 63190,19 & 63190,19 & 6319 & 63190,19 & 63190,19 & 631 & 631 & 631 & 63 & & & \\
\hline cfom & 25589,66 & 25589,66 & 25589,66 & 25589,66 & 25589,66 & 25589,66 & 255 & 2558 & 255 & 255 & 255 & 25 & \\
\hline & 194656,7 & 194656,7 & 194656,7 & 19465 & 5,7 & 194656,7 & 19 & 194 & 7 & 19 & & & \\
\hline cforn & 7049,105 & 7049 & 704 & 704 & 704 & 704 & 70 & 704 & 704 & 704 & & & \\
\hline & 112681,6 & 112681,6 & 112681,6 & 112681,6 & 112681,6 & 112681,6 & 112 & 112 & 112 & 112 & 112 & 1,6 & 112 \\
\hline cfom & 60987,89 & 6098 & 609 & 609 & & $60 s$ & & 60 & 39 & & & & \\
\hline & 2926 & 292 & 292 & 292 & & 29 & & & & & & & \\
\hline cforr & 13701,28 & 28 & 137 & 137 & 28 & 13 & 13 & 13 & & 13 & & & \\
\hline cpro & 12052,66 & 120 & 120 & 120 & 66 & 12 & 12 & & & & & & \\
\hline cforn & 120765,6 & 120 & 120 & 120 & 5,6 & 12 & & & & & & & \\
\hline & 45606,28 & 4560 & 4560 & 456 & 28 & 456 & & 45 & & & & & \\
\hline cforne & 89897,64 & 8985 & 898 & 898 & 64 & 898 & 898 & 898 & 89 & 89 & 8989 & 889 & 89 \\
\hline & 57456,79 & 57456,79 & 57456,79 & & 57456,79 & 54000 & 54000 & 54000 & 54000 & 54000 & 0 & 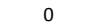 & 0 \\
\hline cfornec & 61234,89 & 61234,89 & 61234,89 & 612 & 61234,89 & 5449 & 440 & 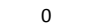 & 0 & 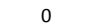 & 0 & & 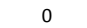 \\
\hline & 43234,56 & 43234,56 & 43234,56 & 15407,43 & 15407,43 & 15407,43 & 15407,43 & 407 & 407 & 407 & 407 & 407 & 407 \\
\hline cfornecidaRB13 & 49678,98 & 49678,98 & 49678,98 & 33506,11 & 33506,11 & 33506,11 & 0 & 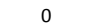 & 0 & 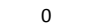 & 0 & 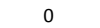 & 0 \\
\hline & 26876,78 & 26876,78 & 26876,78 & 26876,78 & 26876,78 & 0 & 0 & 0 & 0 & 0 & 0 & 0 & 0 \\
\hline cforn & 119675,9 & 119675,9 & 119675,9 & 119675,9 & 119675,9 & 119675,9 & 119675,9 & 119675,9 & 9800 & +0 & & 0 & 0 \\
\hline & 75155,25 & 75155,25 & 75155,25 & 75155,25 & 75155,25 & & & & & & & & 25 \\
\hline RB15 & 125346,8 & 125346,8 & 125346,8 & 125346,8 & 125346,8 & 125346,8 & 125346,8 & 125346,8 & 125346,8 & 125346,8 & 125346,8 & 125346,8 & 125346,8 \\
\hline
\end{tabular}

\begin{tabular}{|c|c|c|c|c|c|c|c|c|c|c|c|c|c|}
\hline & Sem13 & Sem14 & Sem15 & Sem16 & Sem17 & Sem18 & Sem19 & Sem20 & Sem21 & Sem22 & Sem23 & Sem24 & Sem25 \\
\hline cpropriaRB1 & $\overline{0}$ & $\overline{0}$ & $\overline{0}$ & $\overline{0}$ & $\overline{0}$ & $\overline{0}$ & $\overline{0}$ & $\overline{0}$ & $\overline{0}$ & $\overline{0}$ & $\overline{0}$ & $\overline{0}$ & $\overline{0}$ \\
\hline cfornecidaRB1 & 0 & 0 & 0 & 0 & 0 & 0 & 0 & 0 & 0 & 0 & 0 & 0 & 0 \\
\hline cpropriaSP2 & 95978,44 & 95978,44 & 95978,44 & 95978,44 & 95978,44 & 95978,44 & 95978,44 & 95978,44 & 95978,44 & 95978,44 & 95978,44 & 95978,44 & 77449,31 \\
\hline cfomecidaSP2 & 30550,69 & 30550,69 & 30550,69 & 30550,69 & 0550,69 & 30550,69 & 30550,69 & 30550,69 & 30550,69 & 30550,69 & 30550,69 & 30550,69 & 30550,69 \\
\hline cpropriaRB3 & 63407,25 & 63407,25 & 63407,25 & 63407,25 & 63407,25 & 63407,25 & 63407,25 & 63407,25 & 36346,96 & 36346,96 & 36346,96 & 36346,96 & 36346,96 \\
\hline cfornecidaRB3 & 17653,04 & 17653,04 & 17653,04 & 17653,04 & 17653,04 & 17653,04 & 17653,04 & 17653,04 & 17653,04 & 17653,04 & 17653,04 & 17653,04 & 17653,04 \\
\hline SP4 & 61355,26 & 61355,26 & 61355,26 & 61355,26 & 61355,26 & 61355,26 & 61355,26 & 61355,26 & 61355,26 & 61355,26 & 61355,26 & 61355,26 & 61355,26 \\
\hline cfo mecidaSP4 & 1035,47 & 1035,47 & 1035,47 & 1035,47 & 1035,47 & 1035,47 & 1035,47 & 1035,47 & 1035,47 & 1035,47 & 1035,47 & 1035,47 & 1035,47 \\
\hline cpro & 35353,05 & 35353,05 & 35353,05 & 0 & 0 & 0 & 0 & 0 & 0 & 0 & 0 & 0 & 0 \\
\hline cforne & 4578,89 & 64578,89 & 64578,89 & 58676,84 & 12833,06 & 0 & 0 & 0 & 0 & 0 & 0 & 0 & 0 \\
\hline SP6 & 3190,19 & 63190,19 & 63190,19 & 63190,19 & 55033,98 & 55033,98 & 55033,98 & 55033,98 & 55033,98 & 1033,975 & 0 & 0 & 0 \\
\hline JaSP6 & 25589,66 & 25589,66 & 25589,66 & 25589,66 & 25589,66 & 25589,66 & 0 & 0 & 0 & 0 & 0 & 0 & 0 \\
\hline cpro & 194656,7 & 194656,7 & 194656,7 & 194656,7 & 194656,7 & 194656,7 & 194656,7 & 194656,7 & 194656,7 & 194656,7 & 194656,7 & 140656,7 & 106832,4 \\
\hline cfornec & 7049,105 & 7049,105 & 7049,105 & 7049,105 & 7049,105 & 7049,105 & 7049,105 & 7049,105 & 7049,105 & 7049,105 & 7049,105 & 7049,105 & 7049,105 \\
\hline SP8 & 112681,6 & 112681,6 & 112681,6 & 112681,6 & 112681,6 & 112681,6 & 112681,6 & 112681,6 & 112681,6 & 112681,6 & 112681,6 & 112681,6 & 112681,6 \\
\hline daSP8 & 60987,89 & 60987,89 & 60987,89 & 60987,89 & 609 & 60987,89 & 60987,89 & 60987,89 & 60987,89 & 60987,89 & 60987,89 & 60987,89 & 60987,89 \\
\hline BB9 & 29264,75 & 29264,75 & 29264,75 & 29264,75 & 29264,75 & 29264,75 & 29264,75 & 29264,75 & 29264,75 & 29264,75 & 0 & 0 & 0 \\
\hline daRB9 & 13701,28 & 13701,28 & 13701,28 & 13701,28 & 13701,28 & 13701,28 & 13701,28 & 13701,28 & 13701,28 & 13701,28 & 0 & 0 & 0 \\
\hline 10 & 12052,66 & 12052,66 & 12052,66 & 12052,66 & 12052,66 & 12052,66 & 12052,66 & 12052,66 & 12052,66 & 12052,66 & 12052,66 & 12052,66 & 12052,66 \\
\hline cforne & 120765,6 & 120765,6 & 120765,6 & 120765,6 & 120765,6 & 120765,6 & 120765,6 & 120765,6 & 120765,6 & 120765,6 & 120765,6 & 120765,6 & 120765,6 \\
\hline cpro & 23282,19 & 0 & 0 & 0 & 0 & 0 & 0 & 0 & 0 & 0 & 0 & 0 & 0 \\
\hline aRB11 & 15310,38 & 0 & 0 & 0 & 0 & 0 & 0 & 0 & 0 & 0 & 0 & 0 & 0 \\
\hline P12 & 0 & 0 & 0 & 0 & 0 & 0 & 0 & 0 & 0 & 0 & 0 & 0 & 0 \\
\hline cfornec & 0 & 0 & 0 & 0 & 0 & 0 & 0 & 0 & 0 & c & 0 & 0 & 0 \\
\hline B 13 & 15407,43 & 0 & 0 & 0 & 0 & 0 & 0 & 0 & 0 & 0 & 0 & 0 & 0 \\
\hline cfornecidaRB13 & 0 & 0 & 0 & 0 & 0 & 0 & 0 & 0 & 0 & 0 & 0 & 0 & 0 \\
\hline cpropriaSP14 & 0 & 0 & 0 & 0 & 0 & 0 & 0 & 0 & 0 & 0 & 0 & 0 & 0 \\
\hline cfornecidaSP14 & 0 & 0 & 0 & 0 & 0 & 0 & 0 & 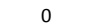 & 0 & 0 & 0 & 0 & 0 \\
\hline cpropriaRB 15 & 75155,25 & 75155,25 & 31155,25 & 28410,35 & 28410,35 & 28410,35 & 0 & 0 & 0 & 0 & 0 & 0 & 0 \\
\hline cfornecidaRB15 & 125346,8 & 125346,8 & 125346,8 & 125346,8 & 125346,8 & 84179,82 & 84179,82 & 30179,82 & 3240,111 & 3240,111 & 3240,111 & 3240,111 & 3240,111 \\
\hline
\end{tabular}




\begin{tabular}{|c|c|c|c|c|c|c|c|c|c|c|c|}
\hline & Sem26 & Sem27 & Sem28 & Sem29 & Sem30 & Sem31 & Sem32 & Sem33 & Sem34 & Sem35 & Sem36 \\
\hline cpropriaRB1 & 0 & 0 & 0 & 0 & 0 & $\overline{0}$ & $\overline{0}$ & $\overline{0}$ & 0 & $\overline{0}$ & 0 \\
\hline cfornecidaRB1 & 0 & 0 & 0 & 0 & 0 & 0 & 0 & 0 & 0 & 0 & 0 \\
\hline cpropriaSP2 & 77449,31 & 77449,31 & 77449,31 & 77449,31 & 77449,31 & 77449,31 & 54000 & 54000 & 54000 & 54000 & 0 \\
\hline cfomecidaSP2 & 30550,69 & 30550,69 & 30550,69 & 30550,69 & 30550,69 & 30550,69 & 0 & 0 & 0 & 0 & 0 \\
\hline cpropriaRB3 & 0 & 0 & 0 & 0 & 0 & 0 & 0 & 0 & 0 & 0 & 0 \\
\hline cfornecidaRB3 & 0 & 0 & 0 & 0 & 0 & 0 & 0 & 0 & 0 & 0 & 0 \\
\hline cpropriaSP4 & 61355,26 & 61355,26 & 61355,26 & 61355,26 & 61355,26 & 61355,26 & 61355,26 & 50759,89 & 50759,89 & 50759,89 & 50759,89 \\
\hline cfomecidaSP4 & 1035,47 & 1035,47 & 1035,47 & 1035,47 & 0 & 0 & 0 & 0 & 0 & 0 & 0 \\
\hline cpropriaRB5 & 0 & 0 & 0 & 0 & 0 & 0 & 0 & 0 & 0 & 0 & 0 \\
\hline cfornecidaRB5 & 0 & 0 & 0 & 0 & 0 & 0 & 0 & 0 & 0 & 0 & 0 \\
\hline cpropriaSP6 & 0 & 0 & 0 & 0 & 0 & 0 & 0 & 0 & 0 & 0 & 0 \\
\hline cfomecidaSP6 & 0 & 0 & 0 & 0 & 0 & 0 & 0 & 0 & 0 & 0 & 0 \\
\hline cpropriaRB7 & 106832,4 & 52832,38 & 38723,07 & 38723,07 & 38723,07 & 38723,07 & 38723,07 & 0 & 0 & 0 & 0 \\
\hline cfornecidaRB7 & 7049,105 & 7049,105 & 0 & 0 & 0 & 0 & 0 & 0 & 0 & 0 & 0 \\
\hline cpropriaSP8 & 112681,6 & 112681,6 & 112681,6 & 112681,6 & 112681,6 & 112681,6 & 112681,6 & 108000 & 54000 & 0 & 0 \\
\hline cfomecidaSP8 & 60987,89 & 60987,89 & 28146,31 & 28146,31 & 28146,31 & 0 & 0 & 0 & 0 & 0 & 0 \\
\hline cpropriaRB9 & 0 & 0 & 0 & 0 & 0 & 0 & 0 & 0 & 0 & 0 & 0 \\
\hline cfornecidaRB9 & 0 & 0 & 0 & 0 & 0 & 0 & 0 & 0 & 0 & 0 & 0 \\
\hline cpropriaSP10 & 12052,66 & 12052,66 & 12052,66 & 12052,66 & 0 & 0 & 0 & 0 & 0 & 0 & 0 \\
\hline cfornecidaSP10 & 120765,6 & 120765,6 & 120765,6 & 66765,56 & 25853,69 & 0 & 0 & 0 & 0 & 0 & 0 \\
\hline cpropriaRB 11 & 0 & 0 & 0 & 0 & 0 & 0 & 0 & 0 & 0 & 0 & 0 \\
\hline cfornecidaRB11 & 0 & 0 & 0 & 0 & 0 & 0 & 0 & 0 & 0 & 0 & 0 \\
\hline cpropriaSP12 & 0 & 0 & 0 & 0 & 0 & 0 & 0 & 0 & 0 & 0 & 0 \\
\hline cfornecidaSP12 & 0 & 0 & 0 & 0 & 0 & 0 & 0 & 0 & 0 & 0 & 0 \\
\hline cpropriaRB 13 & 0 & 0 & 0 & 0 & 0 & 0 & 0 & 0 & 0 & 0 & 0 \\
\hline cfornecidaRB13 & 0 & 0 & 0 & 0 & 0 & 0 & 0 & 0 & 0 & 0 & 0 \\
\hline cpropriaSP14 & 0 & 0 & 0 & 0 & 0 & 0 & 0 & 0 & 0 & 0 & 0 \\
\hline cfornecidaSP14 & 0 & 0 & 0 & 0 & 0 & 0 & 0 & 0 & 0 & 0 & 0 \\
\hline cpropriaRB 15 & 0 & 0 & 0 & 0 & 0 & 0 & 0 & 0 & 0 & 0 & 0 \\
\hline cfornecidaRB15 & 3240,111 & 3240,111 & 3240,111 & 3240,111 & 3240,111 & 3240,111 & 3240,111 & 3240,111 & 3240,111 & 3240,111 & 3240,111 \\
\hline
\end{tabular}

\section{Tabela 76. Quantidade (t) de cada variedade de cana colhida em cada semana}

\begin{tabular}{|c|c|c|c|c|c|c|c|c|c|c|c|c|c|}
\hline & Sem0 & Sem1 & Sem2 & Sem3 & Sem4 & Sem5 & Sem6 & Sem7 & Sem8 & Sem9 & Sem10 & Sem11 & Sem12 \\
\hline cpropriaRB1 & 0 & 44000 & 0 & 33792,66 & 6925,43 & 0 & 0 & 0 & 0 & 0 & 0 & 0 & 0 \\
\hline cfornecidaRB1 & 0 & 0 & 0 & 10207,34 & 0 & 0 & 0 & 0 & 0 & 0 & 0 & 0 & 0 \\
\hline cpropriaSP2 & 0 & 0 & 0 & 0 & 0 & 0 & 0 & 0 & 0 & 0 & 0 & 0 & 0 \\
\hline cfo mecidaSP2 & 0 & 0 & 0 & 0 & 0 & 0 & 0 & 0 & 0 & 0 & 0 & 0 & 0 \\
\hline cpropriaRB3 & 0 & 0 & 0 & 0 & 0 & 0 & 0 & 0 & 0 & 0 & 0 & 0 & 0 \\
\hline cfornecidaRB3 & 0 & 0 & 0 & 0 & 0 & 0 & 0 & 0 & 0 & 0 & 0 & 0 & 0 \\
\hline cpropriaSP4 & 0 & 0 & 0 & 0 & 0 & 0 & 0 & 0 & 0 & 0 & 0 & 0 & 0 \\
\hline cfo mecidaSP4 & 0 & 0 & 0 & 0 & 0 & 0 & 0 & 0 & 0 & 0 & 0 & 0 & 0 \\
\hline cpropriaRB5 & 0 & 0 & 0 & 0 & 0 & 0 & 0 & 0 & 0 & 0 & 0 & 0 & 33412,74 \\
\hline cfornecidaRB5 & 0 & 0 & 0 & 0 & 0 & 0 & 0 & 0 & 0 & 0 & 0 & 0 & 0 \\
\hline cpropriaSP6 & 0 & 0 & 0 & 0 & 0 & 0 & 0 & 0 & 0 & 0 & 0 & 0 & 0 \\
\hline cfo mecidaSP6 & 0 & 0 & 0 & 0 & 0 & 0 & 0 & 0 & 0 & 0 & 0 & 0 & 0 \\
\hline cpropriaRB7 & 0 & 0 & 0 & 0 & 0 & 0 & 0 & 0 & 0 & 0 & 0 & 0 & 0 \\
\hline cfornecidaRB7 & 0 & 0 & 0 & 0 & 0 & 0 & 0 & 0 & 0 & 0 & 0 & 0 & 0 \\
\hline cpropriaSP8 & 0 & 0 & 0 & 0 & 0 & 0 & 0 & 0 & 0 & 0 & 0 & 0 & 0 \\
\hline cfo mecidaSP8 & 0 & 0 & 0 & 0 & 0 & 0 & 0 & 0 & 0 & 0 & 0 & 0 & 0 \\
\hline cpropriaRB9 & 0 & 0 & 0 & 0 & 0 & 0 & 0 & 0 & 0 & 0 & 0 & 0 & 0 \\
\hline cfornecidaRB9 & 0 & 0 & 0 & 0 & 0 & 0 & 0 & 0 & 0 & 0 & 0 & 0 & 0 \\
\hline cpropriaSP10 & 0 & 0 & 0 & 0 & 0 & 0 & 0 & 0 & 0 & 0 & 0 & 0 & 0 \\
\hline cfornecidaSP10 & 0 & 0 & 0 & 0 & 0 & 0 & 0 & 0 & 0 & 0 & 0 & 0 & 0 \\
\hline cpropriaRB 11 & 0 & 0 & 0 & 0 & 0 & 0 & 0 & 22324,09 & 0 & 0 & 0 & 0 & 0 \\
\hline cfornecidaRB11 & 0 & 0 & 0 & 0 & 0 & 0 & 0 & 0 & 0 & 0 & 0 & 54000 & 20587,26 \\
\hline cpropriaSP12 & 0 & 0 & 0 & 0 & 3456,79 & 0 & 0 & 0 & 0 & 54000 & 0 & 0 & 0 \\
\hline cfornecidaSP12 & 0 & 0 & 0 & 0 & 6741 & 10493,89 & 44000 & 0 & 0 & 0 & 0 & 0 & 0 \\
\hline cpropriaRB 13 & 0 & 0 & 27827,13 & 0 & 0 & 0 & 0 & 0 & 0 & 0 & 0 & 0 & 0 \\
\hline cfornecidaRB13 & 0 & 0 & 16172,87 & 0 & 0 & 33506,11 & 0 & 0 & 0 & 0 & 0 & 0 & 0 \\
\hline cpropriaSP14 & 0 & 0 & 0 & 0 & 26876,78 & 0 & 0 & 0 & 0 & 0 & 0 & 0 & 0 \\
\hline cfornecidaSP14 & 0 & 0 & 0 & 0 & 0 & 0 & 0 & 21675,91 & 44000 & 0 & 54000 & 0 & 0 \\
\hline cpropriaRB 15 & 0 & 0 & 0 & 0 & 0 & 0 & 0 & 0 & 0 & 0 & 0 & 0 & 0 \\
\hline cfornecidaRB15 & 0 & 0 & 0 & 0 & 0 & 0 & 0 & 0 & 0 & 0 & 0 & 0 & 0 \\
\hline
\end{tabular}




\begin{tabular}{|c|c|c|c|c|c|c|c|c|c|c|c|c|c|}
\hline & Sem13 & Sem14 & Sem15 & Sem16 & Sem17 & Sem18 & Sem19 & Sem20 & Sem21 & Sem22 & Sem23 & Sem24 & Sem25 \\
\hline cpropriaRB1 & 0 & 0 & 0 & 0 & 0 & 0 & 0 & 0 & 0 & 0 & 0 & 0 & 0 \\
\hline cfornecidaRB1 & 0 & 0 & 0 & 0 & 0 & 0 & 0 & 0 & 0 & 0 & 0 & 0 & 0 \\
\hline cpropriaSP2 & 0 & 0 & 0 & 0 & 0 & 0 & 0 & 0 & 0 & 0 & 0 & 18529,13 & 0 \\
\hline cfomecidaSP2 & 0 & 0 & 0 & 0 & 0 & 0 & 0 & 0 & 0 & 0 & 0 & 0 & 0 \\
\hline cpropriaRB3 & 0 & 0 & 0 & 0 & 0 & 0 & 0 & 27060,29 & 0 & 0 & 0 & 0 & 36346,96 \\
\hline cfornecidaRB3 & 0 & 0 & 0 & 0 & 0 & 0 & 0 & 0 & 0 & 0 & 0 & 0 & 17653,04 \\
\hline cpropriaSP4 & 0 & 0 & 0 & 0 & 0 & 0 & 0 & 0 & 0 & 0 & 0 & 0 & 0 \\
\hline cfomecidaSP4 & 0 & 0 & 0 & 0 & 0 & 0 & 0 & 0 & 0 & 0 & 0 & 0 & 0 \\
\hline cpropriaRB5 & 0 & 0 & 35353,05 & 0 & 0 & 0 & 0 & 0 & 0 & 0 & 0 & 0 & 0 \\
\hline cfornecidaRB5 & 0 & 0 & 5902,047 & 45843,79 & 12833,06 & 0 & 0 & 0 & 0 & 0 & 0 & 0 & 0 \\
\hline cpropriaSP6 & 0 & 0 & 0 & 8156,215 & 0 & 0 & 0 & 0 & 54000 & 1033,975 & 0 & 0 & 0 \\
\hline cfomecidaSP6 & 0 & 0 & 0 & 0 & 0 & 25589,66 & 0 & 0 & 0 & 0 & 0 & 0 & 0 \\
\hline cpropriaRB7 & 0 & 0 & 0 & 0 & 0 & 0 & 0 & 0 & 0 & 0 & 54000 & 33824,34 & 0 \\
\hline cfornecidaRB7 & 0 & 0 & 0 & 0 & 0 & 0 & 0 & 0 & 0 & 0 & 0 & 0 & 0 \\
\hline cpropriaSP8 & 0 & 0 & 0 & 0 & 0 & 0 & 0 & 0 & 0 & 0 & 0 & 0 & 0 \\
\hline cfo mecidaSP8 & 0 & 0 & 0 & 0 & 0 & 0 & 0 & 0 & 0 & 0 & 0 & 0 & 0 \\
\hline cpropriaRB9 & 0 & 0 & 0 & 0 & 0 & 0 & 0 & 0 & 0 & 29264,75 & 0 & 0 & 0 \\
\hline cfornecidaRB9 & 0 & 0 & 0 & 0 & 0 & 0 & 0 & 0 & 0 & 13701,28 & 0 & 0 & 0 \\
\hline cpropriaSP10 & 0 & 0 & 0 & 0 & 0 & 0 & 0 & 0 & 0 & 0 & 0 & 0 & 0 \\
\hline cfornecidaSP10 & 0 & 0 & 0 & 0 & 0 & 0 & 0 & 0 & 0 & 0 & 0 & 0 & 0 \\
\hline cpropriaRB11 & 23282,19 & 0 & 0 & 0 & 0 & 0 & 0 & 0 & 0 & 0 & 0 & 0 & 0 \\
\hline cfornecidaRB11 & 15310,38 & 0 & 0 & 0 & 0 & 0 & 0 & 0 & 0 & 0 & 0 & 0 & 0 \\
\hline cpropriaSP12 & 0 & 0 & 0 & 0 & 0 & 0 & 0 & 0 & 0 & 0 & 0 & 0 & 0 \\
\hline cfornecidaSP12 & 0 & 0 & 0 & 0 & 0 & 0 & 0 & 0 & 0 & 0 & 0 & 0 & 0 \\
\hline cpropriaRB 13 & 15407,43 & 0 & 0 & 0 & 0 & 0 & 0 & 0 & 0 & 0 & 0 & 0 & 0 \\
\hline cfornecidaRB13 & 0 & 0 & 0 & 0 & 0 & 0 & 0 & 0 & 0 & 0 & 0 & 0 & 0 \\
\hline cpropriaSP14 & 0 & 0 & 0 & 0 & 0 & 0 & 0 & 0 & 0 & 0 & 0 & 0 & 0 \\
\hline cfornecidaSP14 & 0 & 0 & 0 & 0 & 0 & 0 & 0 & 0 & 0 & 0 & 0 & 0 & 0 \\
\hline cpropriaRB 15 & 0 & 44000 & 2744,905 & 0 & 0 & 28410,35 & 0 & 0 & 0 & 0 & 0 & 0 & 0 \\
\hline cfornecidaRB15 & 0 & 0 & 0 & 0 & 41166,94 & 0 & 54000 & 26939,71 & 0 & 0 & 0 & 0 & 0 \\
\hline
\end{tabular}

\begin{tabular}{|c|c|c|c|c|c|c|c|c|c|c|c|}
\hline & Sem26 & Sem27 & Sem28 & Sem29 & Sem30 & Sem31 & Sem32 & Sem33 & Sem34 & Sem35 & Sem36 \\
\hline cpropriaRB1 & 0 & 0 & 0 & 0 & 0 & 0 & 0 & 0 & 0 & 0 & 0 \\
\hline cfornecidaRB1 & 0 & 0 & 0 & 0 & 0 & 0 & 0 & 0 & 0 & 0 & 0 \\
\hline cpropriaSP2 & 0 & 0 & 0 & 0 & 0 & 23449,31 & 0 & 0 & 0 & 54000 & 0 \\
\hline cfornecidaSP2 & 0 & 0 & 0 & 0 & 0 & 30550,69 & 0 & 0 & 0 & 0 & 0 \\
\hline cpropriaRB3 & 0 & 0 & 0 & 0 & 0 & 0 & 0 & 0 & 0 & 0 & 0 \\
\hline cfornecidaRB3 & 0 & 0 & 0 & 0 & 0 & 0 & 0 & 0 & 0 & 0 & 0 \\
\hline cpropriaSP4 & 0 & 0 & 0 & 0 & 0 & 0 & 10595,37 & 0 & 0 & 0 & 50759,89 \\
\hline cfornecidaSP4 & 0 & 0 & 0 & 1035,47 & 0 & 0 & 0 & 0 & 0 & 0 & 0 \\
\hline cpropriaRB5 & 0 & 0 & 0 & 0 & 0 & 0 & 0 & 0 & 0 & 0 & 0 \\
\hline cfornecidaRB5 & 0 & 0 & 0 & 0 & 0 & 0 & 0 & 0 & 0 & 0 & 0 \\
\hline cpropriaSP6 & 0 & 0 & 0 & 0 & 0 & 0 & 0 & 0 & 0 & 0 & 0 \\
\hline cfornecidaSP6 & 0 & 0 & 0 & 0 & 0 & 0 & 0 & 0 & 0 & 0 & 0 \\
\hline cpropriaRB7 & 54000 & 14109,32 & 0 & 0 & 0 & 0 & 38723,07 & 0 & 0 & 0 & 0 \\
\hline cfornecidaRB7 & 0 & 7049,105 & 0 & 0 & 0 & 0 & 0 & 0 & 0 & 0 & 0 \\
\hline cpropriaSP8 & 0 & 0 & 0 & 0 & 0 & 0 & 4681,56 & 54000 & 54000 & 0 & 0 \\
\hline cfornecidaSP8 & 0 & 32841,58 & 0 & 0 & 28146,31 & 0 & 0 & 0 & 0 & 0 & 0 \\
\hline cpropriaRB9 & 0 & 0 & 0 & 0 & 0 & 0 & 0 & 0 & 0 & 0 & 0 \\
\hline cfornecidaR B9 & 0 & 0 & 0 & 0 & 0 & 0 & 0 & 0 & 0 & 0 & 0 \\
\hline cpropriaSP10 & 0 & 0 & 0 & 12052,66 & 0 & 0 & 0 & 0 & 0 & 0 & 0 \\
\hline cfornecidaSP10 & 0 & 0 & 54000 & 40911,87 & 25853,69 & 0 & 0 & 0 & 0 & 0 & 0 \\
\hline cpropriaRB11 & 0 & 0 & 0 & 0 & 0 & 0 & 0 & 0 & 0 & 0 & 0 \\
\hline cfornecidaRB11 & 0 & 0 & 0 & 0 & 0 & 0 & 0 & 0 & 0 & 0 & 0 \\
\hline cpropriaSP12 & 0 & 0 & 0 & 0 & 0 & 0 & 0 & 0 & 0 & 0 & 0 \\
\hline cfornecidaSP12 & 0 & 0 & 0 & 0 & 0 & 0 & 0 & 0 & 0 & 0 & 0 \\
\hline cpropriaRB 13 & 0 & 0 & 0 & 0 & 0 & 0 & 0 & 0 & 0 & 0 & 0 \\
\hline cfornecidaRB13 & 0 & 0 & 0 & 0 & 0 & 0 & 0 & 0 & 0 & 0 & 0 \\
\hline cpropriaSP14 & 0 & 0 & 0 & 0 & 0 & 0 & 0 & 0 & 0 & 0 & 0 \\
\hline cfornecidaSP14 & 0 & 0 & 0 & 0 & 0 & 0 & 0 & 0 & 0 & 0 & 0 \\
\hline cpropriaRB 15 & 0 & 0 & 0 & 0 & 0 & 0 & 0 & 0 & 0 & 0 & 0 \\
\hline cfornecidaRB15 & 0 & 0 & 0 & 0 & 0 & 0 & 0 & 0 & 0 & 0 & 3240,111 \\
\hline
\end{tabular}


Tabela 77. Vendas (t ou $\mathrm{m}^{3}$ ) no mercado interno

\begin{tabular}{|c|c|c|c|c|c|c|c|c|c|c|c|c|c|}
\hline & Sem0 & Sem1 & Sem2 & Sem3 & Sem4 & Sem5 & Sem6 & Sem7 & Sem8 & Sem9 & Sem10 & Sem11 & Sem12 \\
\hline VHP & 0 & $\overline{0}$ & 43,20757 & 43,20757 & 11212,18 & 20000 & 2341,941 & 2841,61 & 2863,567 & 3464,436 & 3478,992 & 3622,383 & 3641,312 \\
\hline Melaco & 0 & 0 & 0 & 0 & 0 & 0 & 0 & 0 & 0 & 0 & 0 & 0 & 0 \\
\hline AEHC & 0 & 1515,804 & 1511,101 & 1589,99 & 200 & 1200 & 1200 & 200 & 200 & 200 & 200 & 200 & 2469,964 \\
\hline AEAC & 0 & 4951,482 & 3047,755 & 3203,98 & 3333 & 100 & 100 & 100 & 13931,4 & 5136,556 & 4896,304 & 4952,684 & 4972,766 \\
\hline & Sem13 & Sem14 & Sem15 & Sem16 & Sem17 & Sem18 & Sem19 & Sem20 & Sem21 & Sem22 & Sem23 & Sem24 & Sem25 \\
\hline VHP & 3676,527 & 2903,868 & 2928,437 & 3845,011 & 3697,341 & 3740,38 & 3721,895 & 3754,108 & 8304 & 2923,917 & 3744,454 & 3599,441 & 3884,382 \\
\hline $\begin{array}{c}\text { Melaco } \\
\text { AEHC }\end{array}$ & $\begin{array}{c}0 \\
2496,2\end{array}$ & $\begin{array}{c}0 \\
200\end{array}$ & $\begin{array}{c}0 \\
200\end{array}$ & $\begin{array}{c}0 \\
200\end{array}$ & $\begin{array}{c}0 \\
200\end{array}$ & $\begin{array}{c}0 \\
2385,379\end{array}$ & $\begin{array}{c}0 \\
2368,99\end{array}$ & $\begin{array}{c}0 \\
2395,95\end{array}$ & $\begin{array}{c}0 \\
200\end{array}$ & $\begin{array}{c}0 \\
200\end{array}$ & $\begin{array}{c}0 \\
200\end{array}$ & $\begin{array}{c}0 \\
200\end{array}$ & $\begin{array}{c}0 \\
200\end{array}$ \\
\hline $\begin{array}{l}\text { AEHC } \\
\text { AEAC }\end{array}$ & $\begin{array}{c}2496,2 \\
5024,924\end{array}$ & 3962,013 & 4001,577 & 100 & 10648,91 & $\begin{array}{c}2385,3 / 9 \\
100\end{array}$ & $\begin{array}{c}2368,99 \\
10529,46\end{array}$ & 5351,474 & 5449,348 & 4192,18 & 5337,094 & 7337,094 & 3000 \\
\hline & Sem25 & Sem26 & Sem27 & Sem28 & Sem29 & Sem30 & Sem31 & Sem32 & Sem33 & Sem34 & Sem35 & Sem36 & Sem37 \\
\hline VHP & 3884,382 & 3943,218 & 43,20757 & 43,20757 & 43,20757 & 14744,54 & 3681,37 & 1894,159 & 43,20757 & 43,20757 & 43,20757 & 10251 & 43,20757 \\
\hline Melaco & 0 & 0 & 0 & 0 & 0 & 0 & 0 & 0 & 0 & 0 & 0 & 0 & 0 \\
\hline AEHC & 200 & 2726,744 & 5400 & 200 & 2478,013 & 2502,726 & 200 & 4000 & 2300 & 4500 & 4500 & 200 & 3245 \\
\hline AEAC & 3000 & 1922,007 & 2000 & 2911,599 & 4988,614 & 5037,328 & 5018,42 & 5100,994 & 494,4641 & 4991,3 & 4986,899 & 4300 & 1910,08 \\
\hline & Sem37 & Sem38 & Sem39 & Sem40 & Sem41 & Sem42 & Sem43 & Sem44 & Sem45 & Sem46 & Sem47 & Sem48 & Sem49 \\
\hline VHP & 43,20757 & 43,20757 & 43,20757 & 1235 & 43,20757 & 2345 & 43,20757 & 43,20757 & 43,20757 & 43,20757 & 43,20757 & 199,9184 & 43,20757 \\
\hline Melaco & 0 & 0 & 0 & 0 & 0 & 0 & 0 & 0 & 0 & 0 & 0 & 0 & 0 \\
\hline AEHC & 3245 & 200 & 200 & 200 & 200 & 200 & 200 & 200 & 200 & 200 & 200 & 200 & 200 \\
\hline AEAC & 1910,08 & 100 & 3456 & 2345 & 100 & 100 & 100 & 100 & 100 & 100 & 100 & 100 & 100 \\
\hline & Sem50 & Sem51 & Sem52 & & & & & & & & & & \\
\hline VHP & 43,20757 & 43,20757 & 43,20757 & & & & & & & & & & \\
\hline Melaco & 0 & 0 & 0 & & & & & & & & & & \\
\hline AEHC & 200 & 200 & 200 & & & & & & & & & & \\
\hline AEAC & 100 & 100 & 100 & & & & & & & & & & \\
\hline
\end{tabular}

Tabela 78. Vendas $\left(t\right.$ ou $\mathrm{m}^{3}$ ) no mercado externo

\begin{tabular}{|c|c|c|c|c|c|c|c|c|c|c|c|c|c|c|}
\hline & Sem0 & Sem1 & Sem2 & Sem3 & Sem4 & Sem5 & Sem6 & Sem7 & Sem8 & Sem9 & Sem10 & Sem11 & Sem12 & \\
\hline VHP & 0 & 0 & 50 & 50 & 13503,67 & 2905,967 & 2817,459 & 3419,368 & 3445,819 & 4169,657 & 4187,192 & 4359,932 & 4382,735 & \\
\hline Melaco & 0 & 0 & 0 & 0 & 0 & 0 & 0 & 0 & 0 & 0 & 0 & 0 & 0 & \\
\hline AEHC & 0 & 1515,804 & 1511,101 & 1589,99 & 200 & 200 & 200 & 200 & 200 & 200 & 200 & 200 & 2469,964 & \\
\hline \multirow[t]{2}{*}{ AEAC } & 0 & 4951,482 & 3047,755 & 3203,98 & 3136,083 & 100 & 100 & 100 & 13931,4 & 5136,556 & 4896,304 & 4952,684 & 4972,766 & \\
\hline & Sem13 & Sem14 & Sem15 & Sem16 & Sem17 & Sem18 & Sem19 & Sem20 & Sem21 & Sem22 & Sem23 & Sem24 & Sem25 & \\
\hline VHP & 4425,157 & 3494,367 & 3523,964 & 4628,127 & 4450,232 & 4502,08 & 4479,811 & 4518,618 & 10000 & 3518,519 & 4506,988 & 4332,294 & 4675,557 & \\
\hline Melaco & 0 & 0 & 0 & 0 & 0 & 0 & 0 & 0 & 0 & 0 & 0 & 0 & 0 & \\
\hline AEHC & 2496,2 & 200 & 200 & 200 & 200 & 2385,379 & 2368,99 & 2395,95 & 200 & 200 & 200 & 200 & 200 & \\
\hline \multirow[t]{2}{*}{ AEAC } & 5024,924 & 3962,013 & 4001,577 & 100 & 10648,91 & 100 & 10529,46 & 5351,474 & 5449,348 & 4192,18 & 5337,094 & 100 & 100 & \\
\hline & Sem26 & Sem27 & Sem28 & Sem29 & Sem30 & Sem31 & Sem32 & Sem33 & Sem34 & Sem35 & Sem36 & Sem37 & Sem38 & \\
\hline VHP & 4746,435 & 50 & 50 & 50 & 17759,38 & 4430,993 & 2278,074 & 50 & 50 & 50 & 12345,67 & 50 & 50 & \\
\hline Melaco & 0 & 0 & 0 & 0 & 0 & 0 & 0 & 0 & 0 & 0 & 0 & 0 & 0 & \\
\hline AEHC & 2726,744 & 200 & 200 & 2478,013 & 2502,726 & 200 & 200 & 200 & 200 & 200 & 200 & 200 & 200 & \\
\hline \multirow[t]{2}{*}{ AEAC } & 1922,007 & 100 & 23911,6 & 4988,614 & 5037,328 & 5018,42 & 5100,994 & 4994,464 & 4991,3 & 4986,899 & 100 & 1910,08 & 100 & \\
\hline & Sem39 & Sem40 & Sem41 & Sem42 & Sem43 & Sem44 & Sem45 & Sem46 & Sem47 & Sem48 & Sem49 & Sem50 & Sem51 & Sem52 \\
\hline VHP & 50 & 50 & 50 & 50 & 50 & 50 & 50 & 50 & 50 & 238 & 50 & 50 & 50 & 50 \\
\hline Melaco & 0 & 0 & 0 & 0 & 0 & 0 & 0 & 0 & 0 & 0 & 0 & 0 & 0 & 0 \\
\hline AEHC & 200 & 200 & 200 & 200 & 200 & 200 & 200 & 200 & 200 & 200 & 3450 & 200 & 200 & 200 \\
\hline AEAC & 100 & 100 & 100 & 100 & 100 & 100 & 100 & 100 & 100 & 100 & 100 & 100 & 100 & 100 \\
\hline
\end{tabular}


Tabela 79. Processos utilizados em cada semana

\begin{tabular}{|c|c|c|c|c|c|c|c|c|c|c|c|c|c|c|}
\hline & Sem 0 & Sem1 & Sem2 & Sem3 & Sem4 & Sem5 & Sem6 & Sem7 & Sem8 & Sem9 & Sem10 & Sem11 & Sem12 & \\
\hline Procl1C1E & 0 & 1 & 1 & 1 & 0 & 1 & 0 & $\overline{0}$ & $\overline{0}$ & 0 & $\overline{0}$ & 0 & 0 & \\
\hline Procl24C5I & 0 & 0 & 0 & 0 & 1 & 0 & 0 & 0 & 0 & 1 & 0 & 0 & 0 & \\
\hline Procl1C4E & 0 & 0 & 0 & 0 & 0 & 0 & 1 & 0 & 0 & 0 & 0 & 0 & 0 & \\
\hline Procl20C6I & 0 & 0 & 0 & 0 & 0 & 0 & 0 & 1 & 0 & 0 & 0 & 0 & 0 & \\
\hline Procl24C6I & 0 & 0 & 0 & 0 & 0 & 0 & 0 & 0 & 1 & 0 & 0 & 0 & 0 & \\
\hline \multirow[t]{2}{*}{ Procl10C4E } & 0 & 0 & 0 & 0 & 0 & 0 & 0 & 0 & 0 & 0 & 1 & 1 & 1 & \\
\hline & Sem13 & $\overline{S e m 14}$ & Sem15 & Sem16 & Sem17 & Sem18 & Sem19 & Sem20 & Sem21 & Sem22 & Sem23 & Sem24 & Sem25 & \\
\hline Procl1C1E & 1 & 0 & 0 & 0 & 0 & 0 & 0 & 0 & 0 & 0 & 0 & 1 & 1 & \\
\hline Procl24C3I & 0 & 1 & 0 & 0 & 0 & 0 & 0 & 0 & 0 & 1 & 0 & 0 & 0 & \\
\hline Procl24C1I & 0 & 0 & 1 & 0 & 0 & 0 & 0 & 0 & 0 & 0 & 0 & 0 & 0 & \\
\hline Procl23C6I & 0 & 0 & 0 & 1 & 0 & 1 & 0 & 0 & 0 & 0 & 0 & 0 & 0 & \\
\hline Procl23C4I & 0 & 0 & 0 & 0 & 1 & 0 & 0 & 0 & 1 & 0 & 1 & 0 & 0 & \\
\hline \multirow[t]{2}{*}{ Procl23C7I } & 0 & 0 & 0 & 0 & 0 & 0 & 1 & 1 & 0 & 0 & 0 & 0 & 0 & \\
\hline & Sem26 & Sem27 & Sem28 & Sem29 & Sem30 & Sem31 & Sem32 & Sem33 & Sem34 & Sem35 & Sem36 & Sem37 & Sem38 & \\
\hline \multirow{7}{*}{$\begin{array}{l}\text { Procl1C8E } \\
\text { Procl1C1E } \\
\text { Procl24C4I } \\
\text { Procl1C5E } \\
\text { Procl1C3I } \\
\text { Procl1C6I }\end{array}$} & 1 & 1 & 1 & 0 & 0 & 0 & 0 & 0 & 0 & 1 & 1 & 0 & 0 & \\
\hline & 0 & 0 & 0 & 1 & 1 & 1 & 1 & 0 & 0 & 0 & 0 & 0 & 0 & \\
\hline & 0 & 0 & 0 & 0 & 0 & 0 & 0 & 1 & 0 & 0 & & 0 & 0 & \\
\hline & 0 & 0 & 0 & 0 & 0 & 0 & 0 & 0 & 1 & 0 & 0 & 0 & 0 & \\
\hline & 0 & 0 & 0 & 0 & 0 & 0 & 0 & 0 & 0 & 0 & 0 & 1 & 0 & \\
\hline & 0 & 0 & 0 & 0 & 0 & 0 & 0 & 0 & 0 & 0 & 0 & 0 & 1 & \\
\hline & Sem39 & Sem40 & Sem41 & Sem42 & Sem43 & Sem44 & Sem45 & Sem46 & Sem47 & Sem48 & Sem49 & Sem50 & Sem51 & Sem52 \\
\hline \multirow{3}{*}{$\begin{array}{l}\text { Procl1C3I } \\
\text { Procl1C1E } \\
\text { Procl6C3E }\end{array}$} & 1 & 1 & 1 & 1 & 1 & 1 & 0 & 0 & 0 & 0 & $\overline{0}$ & 0 & 0 & 1 \\
\hline & 0 & 0 & 0 & 0 & 0 & 0 & 1 & 1 & 1 & 1 & 0 & 0 & 0 & 0 \\
\hline & 0 & 0 & 0 & 0 & 0 & 0 & 0 & 0 & 0 & 0 & 1 & 1 & 1 & 0 \\
\hline
\end{tabular}




\section{GLOSSÁRIO}

Com base em Rodrigues (2005), Fernandes (2003), Paiva (2006) e colaboradores da usina USALPA foi elaborada a terminologia a seguir utilizada nesta dissertação.

\section{Glossário utilizado para avaliação da qualidade da cana-de-açúcar}

BRIX: Porcentagem, em peso, de sólidos solúveis no caldo de cana. Representa o peso de sólidos dissolvidos em $100 \mathrm{~g}$ de solução. Assim, quando uma solução tem $20^{\circ}$ Brix, quer dizer que em $100 \mathrm{~g}$ desta solução tem $20 \mathrm{~g}$ de sólidos dissolvidos, sendo os $80 \mathrm{~g}$ restantes de água. Determinado pelo aerômetro de Brix.

POLARIZAÇÃO OU POL: Porcentagem, em peso, de sacarose aparente ou a soma algébrica dos desvios provocados no plano de polarização pelas substâncias opticamente ativas (açúcares), contidos nos produtos da usina (caldo), por leitura direta. Na prática, quantidade de sacarose encontrada em $100 \mathrm{~g}$ da solução. Assim, quando uma solução tem Pol de 14, quer dizer que em $100 \mathrm{~g}$ desta solução temos $14 \mathrm{~g}$ de sacarose. Determinada em sacarímetro.

PUREZA: Porcentagem de sacarose nos sólidos solúveis totais (Brix).

AÇÚCARES REDUTORES (AR): Todos os açúcares (monossacarídeos) que tem a propriedade de reduzir o cobre das soluções cupro-alcalinas (licor de Fehling).

No caldo da cana, são a glicose e a levulose. Além da quantidade normalmente existente na cana, se formam na fabricação do açúcar, pelo desdobramento da molécula de sacarose, sob a ação de ácidos diluídos e calor.

FIBRA: Parte lenhosa da cana, insolúvel na água.

BAGAÇO: Resíduo fibroso, resultante da extração do caldo das canas.

MELAÇO: Mel esgotado, do qual não mais se extrai açúcar, por razões econômicas. 


\section{Glossário referente às operações industriais}

CALDO ABSOLUTO: Caldo em cuja composição entram todos os sólidos solúveis na cana e toda a água da cana.

CALDO PRIMÁRIO: Caldo extraído na primeira unidade de esmagamento do conjunto de moendas. Esse caldo não contém água de embebição.

CALDO SECUNDÁRIO: Mistura dos caldos extraídos em todas as unidades de esmagamento do conjunto de moendas. Compreende a fração extraída do caldo absoluto encontrado nas canas mais a água de embebição, adicionada durante a operação de moagem.

CALDO SULFITADO: Caldo misto após passagem pela coluna de sulfitação onde absorveu certa quantidade de anidrido sulfuroso.

CALDO CLARIFICADO: Caldo límpido e transparente obtido após as operações de tratamento químico, aquecimento e decantação.

CALDO FILTRADO: Resultante da operação de filtração do lodo produzido no processo de decantação.

TORTA: Resíduo sólido retido nos filtros após a operação de filtração do lodo dos decantadores.

XAROPE: Produto resultante da concentração parcial do caldo clarificado.

MASSA COZIDA: Produto resultante da concentração do xarope e méis, constituído de cristais de açúcar em suspensão no mel-mãe.

MÉIS: Produtos resultantes da separação dos cristais das massas cozidas. 